\title{
Chemical and Biological Stability of Solvent Refined Coal Liquids
}

C. W. Wright

W. C. Weimer

January 1984

Prepared for the U.S. Department of Energy under Contract DE-AC06-76RLO 1830

Pacific Northwest Laboratory Operated for the U.S. Department of Energy by Battelle Memorial Institute 


\title{
DISCLAIMER
}

This report was prepared as an account of work sponsored by an agency of the United States Government. Neither the United States Government nor any agency thereof, nor any of their employees, makes any warranty, express or implied, or assumes any legal liability or responsibility for the accuracy, completeness, or usefulness of any information, apparatus, product, or process disclosed, or represents that its use would not infringe privately owned rights. Reference herein to any specific commercial product, process, or service by trade name, trademark, manufacturer, or otherwise, does not necessarily constitute or imply its endorsement, recommendation, or favoring by the United States Government or any agency thereof. The views and opinions of authors expressed herein do not necessarily state or reflect those of the United States Government or any agency thereof.

\author{
PACIFIC NORTHWEST LABORATORY \\ operated by \\ BATTELLE \\ for the \\ UNITED STATES DEPARTMENT OF ENERGY \\ under Contract DE-AC06-76RLO 1830
}

\begin{tabular}{|c|c|}
\hline \multicolumn{2}{|c|}{$\begin{array}{l}\text { Printed in the United States of America } \\
\text { Available from } \\
\text { National Technical Information Service } \\
\text { United States Department of Commerce } \\
5285 \text { Port Royal Road } \\
\text { Springfield, Virginia } 22161\end{array}$} \\
\hline \multicolumn{2}{|c|}{$\begin{array}{l}\text { NTIS Price Codes } \\
\text { Microfiche A01 }\end{array}$} \\
\hline \multicolumn{2}{|c|}{ Printed Copy } \\
\hline Pages & $\begin{array}{l}\text { Price } \\
\text { Codes }\end{array}$ \\
\hline $001-025$ & $\mathrm{~A} 02$ \\
\hline $026-050$ & $\mathrm{~A} 03$ \\
\hline $051-075$ & $\mathrm{~A} 04$ \\
\hline $076-100$ & A05 \\
\hline $101-125$ & A06 \\
\hline $126-150$ & $A 07$ \\
\hline 151.175 & $\mathrm{~A} 08$ \\
\hline $176-200$ & A09 \\
\hline $201-225$ & $A 010$ \\
\hline $226-250$ & A011 \\
\hline $251-275$ & A 012 \\
\hline $276-300$ & $\mathrm{~A} 013$ \\
\hline
\end{tabular}


CHEMICAL AND BIOLOGICAL STABILITY OF SOLVENT REFINED COAL LIQUIDS

C. W. Wright

W. C. Weimer

January 1984

Prepared for the U.S. Department of Energy under Contract DE-AC06-76RL0 1830

Pacific Northwest Laboratory Richland, Washington 99352 


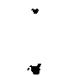




\section{CONTR IBUTORS}

Gas Chromatography $\quad$ Bioassay

B. K. Hayden

D. L. Stewart

R. B. Lucke

Direct Probe

Statistical Analysis Mass Spectrometry

D. S. Daly E. K. Chess

\section{ACKNOWLEDGMENTS}

This work was funded by the Department of Energy under Contract DE-AC06-76RLO 1830. 
-

,

. 


\section{FOREWORD}

This report presents results of both long-term and short-term stability studies of the chemical composition and biological activity of solvent refined coal (SRC) I and I I liquids which were provided by the Pittsburg and Midway Coal Mining Co. Sample constituency was monitored as a function of storage temperature, dilution, cover atmosphere, and ambient light. Biological activity was measured using the histidine reversion microbial mutagenicity assay with $\underline{S}$. typhimurium TA98. Chemical composition was monitored using high resolution gas chromatography (GC) and high resolution gas chromatography/mass spectrometry (GC/MS). The relative amounts of major components were computed in relation to an internal standard which had been added. Data were analyzed by computerbased analysis of variance techniques. 


\section{EXECUTIVE SUMMARY}

Both long-term and short-term stability studies of the chemical composition and biological activity of solvent refined coal (SRC) I and II liquids have been performed. Concentrations of major sample components were monitored as a function of storage time, temperature, dilution, cover atmosphere, and ambient lighting conditions. Biological activity was measured with a histidine reversion assay for mutagenicity against S. typhimurium TA98 with S-9 rat-1iver homogenate metabolic activation. Chemical composition was monitored using high resolution gas chromatography $(\mathrm{GC})$ and gas chromatography/mass spectrometry (GC/MS). The data were analyzed by computer-based analysis of variance techniques (ANOVA). A brief synopsis of parameters of the experiments performed at $4^{\circ} \mathrm{C}, 20^{\circ} \mathrm{C}, 60^{\circ} \mathrm{C}$, and $100^{\circ} \mathrm{C}$ and the results obtained are given below.

A total of seventeen samples consisting of SRC-I light oil, wash solvent, and process solvents, and SRC-II naphthas, middle distillates, heavy distillates, and fuel oil blends (FOB) were monitored during storage in a repository. Conditions of repository storage were $4{ }^{\circ} \mathrm{C}$, in the dark, under a nitrogen atmosphere, in inert (glass or Teflon-lined stainless steel) containers. After storaye for four years under these conditions, there was no significant change in the chemical composition or biological activity of the SRC materials. Certain of the heavy end samples, however, tended to form layers upon standing. Herre, without adequate mixing prior to sampling or use, the chemical characterisics of these samples would deviate from the bulk composition due to inhomogeneity in the bulk oil.

SRC-II FOB was chosen as a sample to undergo storage at harsher conditions than those of the repository, since many of the components found in this sample are representative of the components found in the other SRC materials. Changes that occurred in the $F O B$ under harsher conditions are probably analogous to changes that may occur over longer periods of time in the repository. Samples of FOB were stored in duplicate under storage parameters of cover atmosphere (air vs. nitrogen), ambient lighting (light vs. darkness), and dilution (undiluted vs. dilution in methylene chloride) at $-20^{\circ} \mathrm{C}$ and at room temperature $\left(\sim 20^{\circ} \mathrm{C}\right)$ for one year. There was no significant change in the major chemical 
constituency for any of the samples stored under these conditions, except the samples stored diluted in methylene chloride, under an air atmosphere, in the light. For this sample the cresols and more highly alkylated phenols, indan and alkylated indans, indanol, and tetralin peaks showed a significant decrease in concentration. Similar decomposition occurred with SRC-II FOB diluted in methylene chloride and stored at $-20^{\circ} \mathrm{C}$ for three years. The only significant. changes in biological activity as measured by the microbial mutagenicity test occurred in the samples stored either diluted or undiluted at room temperature, in the light, under an air atmosphere. When diluted, the activity was completely eliminated, while undiluted it decreased by about a factor of two after storage for one year. When diluted and stored at $-20^{\circ} \mathrm{C}$ for three years the mutagenicity was also significantly decreased.

Eighteen and three $\mathrm{FOB}$ samples were stored at $60^{\circ} \mathrm{C}$ and $100^{\circ} \mathrm{C}$, respectively, in the dark under an air atmosphere. The samples were monitored seven times over a 32-week period under these severe conditions. Of the major chemical constituents, the cresols, alkylated indans, and indanol decreased in concentration most significantly. In addition, after storage at $100^{\circ} \mathrm{C}$ for 16 weeks, the indole and amino-polycyclic aromatic hydrocarbons (amino-PAH) degraded. This was determined when the nitrogen-containing polycyclic aromatic fraction was studied more closely. Biological activity was completely eliminated after storage at these increased temperatures.

Overal1, when degradation occurred, biological activity decreased and concentrations of hydroxylated PAH, partially hydrogenated PAH, indoles, and amino-PAH decreased. Thus far (four years), degradation of materials stored neat in the repository has not been detected. 


\section{CONTENTS}

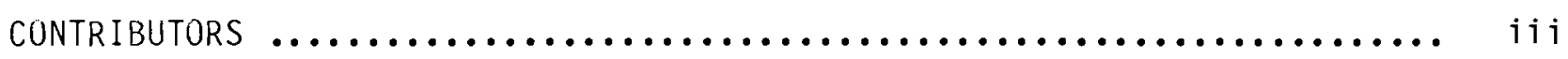

ACKNOWLEDGMENTS $\ldots \ldots \ldots \ldots \ldots \ldots \ldots \ldots \ldots \ldots \ldots \ldots \ldots \ldots \ldots \ldots \ldots \ldots \ldots \ldots \ldots$

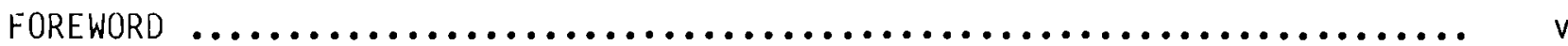

EXECUTIVE SUMMARY $\ldots \ldots \ldots \ldots \ldots \ldots \ldots \ldots \ldots \ldots \ldots \ldots \ldots \ldots \ldots \ldots \ldots \ldots \ldots \ldots \ldots \ldots \ldots$

1.0 INTRODUCTION $\ldots \ldots \ldots \ldots \ldots \ldots \ldots \ldots \ldots \ldots \ldots \ldots \ldots \ldots \ldots \ldots \ldots \ldots \ldots \ldots \ldots \ldots$

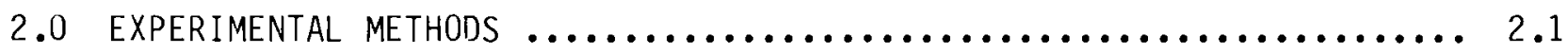

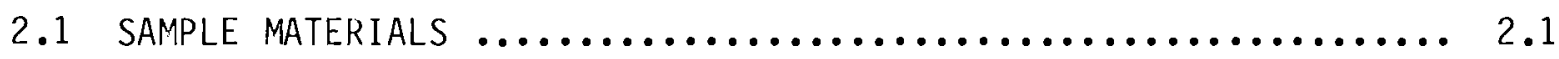

2.2 STABILITY STUdies PARAMETERS $\ldots \ldots \ldots \ldots \ldots \ldots \ldots \ldots \ldots \ldots \ldots \ldots \ldots$

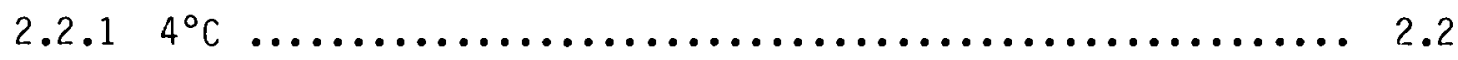

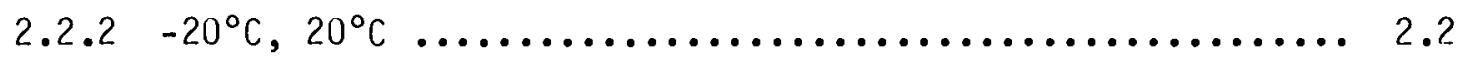

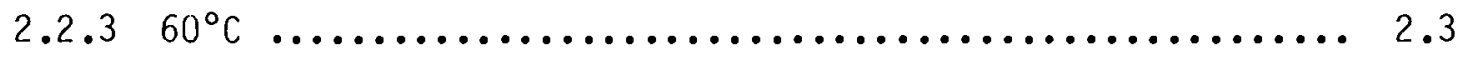

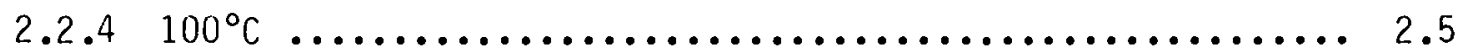

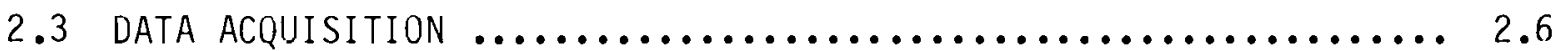

2.3.1 High Resolution Gas Chromatography ............... 2.6

2.3.2 Chemical Fractionation $\ldots \ldots \ldots \ldots \ldots \ldots \ldots \ldots \ldots \ldots \ldots \ldots . . . . . . \ldots$

2.3.3 Direct Probe Mass Suectrometry................... 2.12

2.3 .4 Microbial Mutagenicity $\ldots \ldots \ldots \ldots \ldots \ldots \ldots \ldots \ldots \ldots \ldots \ldots \ldots \ldots \ldots$

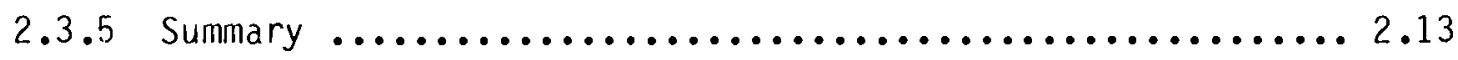

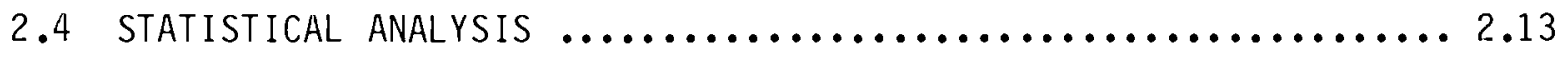

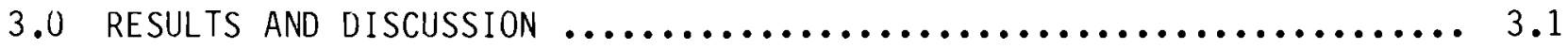

3.1 HIGH RESOLUTION GAS CHROMATOGRAPHY $\ldots \ldots \ldots \ldots \ldots \ldots \ldots \ldots \ldots \ldots \ldots \ldots$

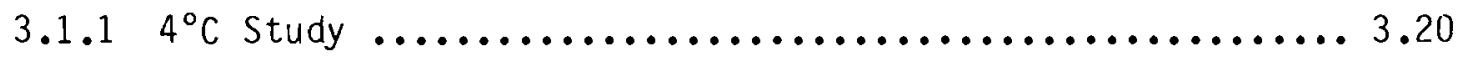

$3.1 .2-20^{\circ} \mathrm{C}, 20^{\circ} \mathrm{C}$ Study $\ldots \ldots \ldots \ldots \ldots \ldots \ldots \ldots \ldots \ldots \ldots \ldots \ldots .20$

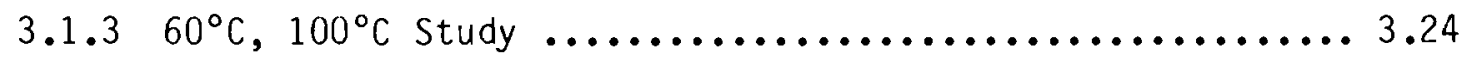


3.1 .4 Summary $\ldots \ldots \ldots \ldots \ldots \ldots \ldots \ldots \ldots \ldots \ldots \ldots \ldots \ldots \ldots \ldots, 3.28$

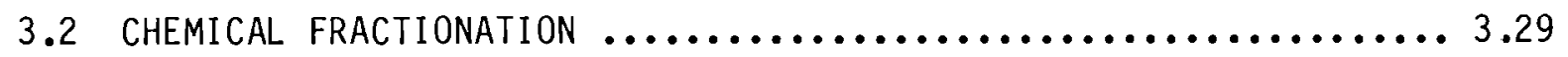

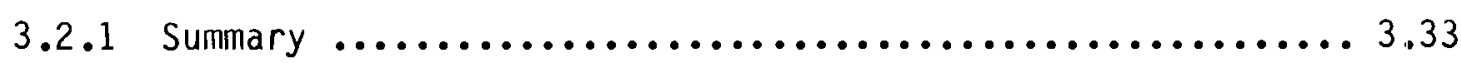

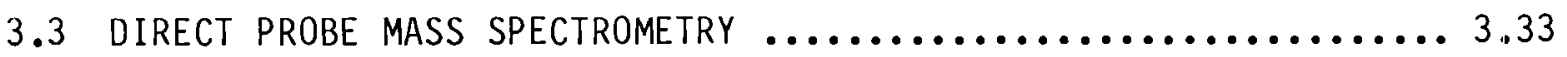

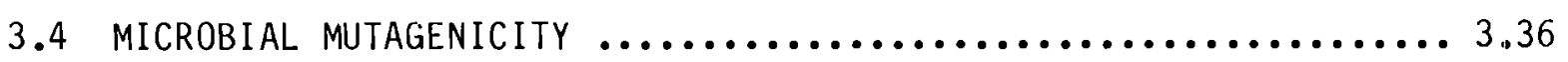

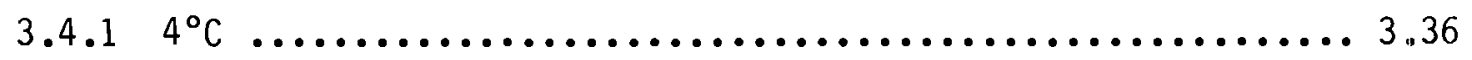

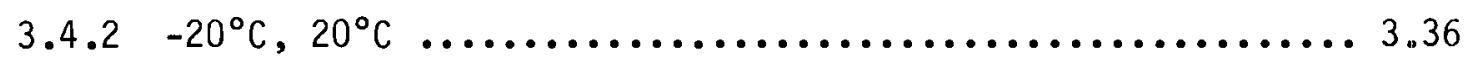

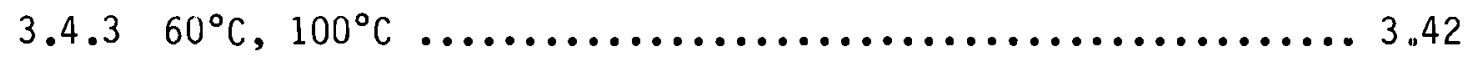

3.4 .4 Summary $\ldots \ldots \ldots \ldots \ldots \ldots \ldots \ldots \ldots \ldots \ldots \ldots \ldots \ldots \ldots \ldots, 3.42$

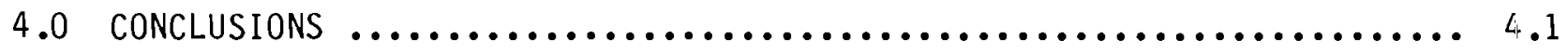

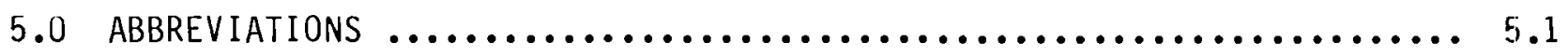

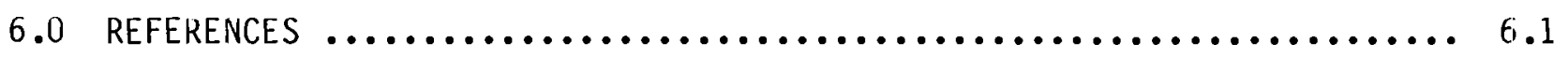

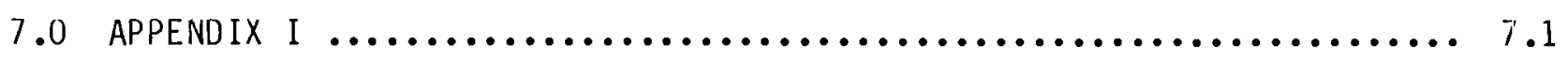

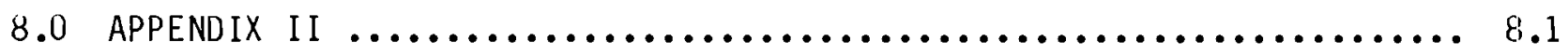


FIGURES

2.1. Schematic Diagram of $-20^{\circ} \mathrm{C}$ and $20^{\circ} \mathrm{C}$ Stability Study

Parameters of Temperature, Light, Cover Atmosphere,

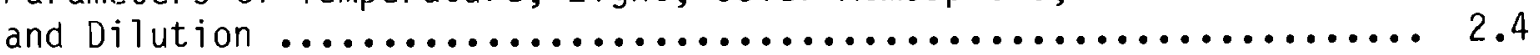

2.2. Chemical Class Fractionation Using Alumina and Silicic

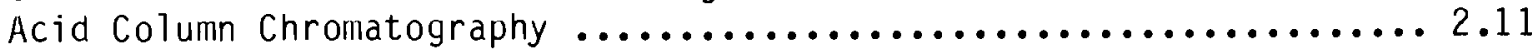

3.1. High Resolution Gas Chromatogram of an SRC-I I Naphtha.

Conditions: $90 \mathrm{M} \times 0.28 \mathrm{mrn}$ i.d. Glass Capillary Colurnn

Coated with SF-96; 1:71 Split Ratio Injection; Helium

Carrier Gas; 12 min Isothermal at $35^{\circ} \mathrm{C}$ then Temperature

Programmed to $175^{\circ} \mathrm{C}$ at $8^{\circ} \mathrm{C} / \mathrm{min}$. Numbers Refer to

Identifications Given in Table $3.1 . \ldots \ldots \ldots \ldots \ldots \ldots \ldots \ldots \ldots \ldots . \ldots . \ldots$

3.2. High Resolution Gas Chromatogram of an SRC-I Light $0 i 1$.

Conditions: Same as in Figure 3.1. Numbers Refer to

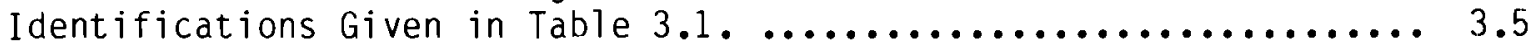

3.3. High Resolution Gas Chromatogram of an SRC-II Middle

Distillate. Conditions: $30 \mathrm{M} \times 0.25 \mathrm{~mm}$ i.d. Fused

Silica Capillary Column Coated with SE-52; Splitless

Injection; Helium Carrier Gas at $50 \mathrm{~cm} / \mathrm{s}$ Linear

Velocity; 2 min Isothermal at $40^{\circ} \mathrm{C}$ then Temperature

Programmed to $170^{\circ} \mathrm{C}$ at $2^{\circ} \mathrm{C} / \mathrm{min}$ and to $250^{\circ} \mathrm{C}$ at $15^{\circ} \mathrm{C} / \mathrm{min}$.

Numbers Refer to Identifications Given in Table $3.1 \ldots . . \ldots \ldots . . . .3 .6$

3.4. High Resolution Gas Chromatogram of an SRC-II Fuel $0 i 1$

Blend. Conditions: Same as in Figure 3.3, Except

Temperature Proyrammed to $200^{\circ} \mathrm{C}$ at $2^{\circ} \mathrm{C} / \mathrm{min}$. Numbers

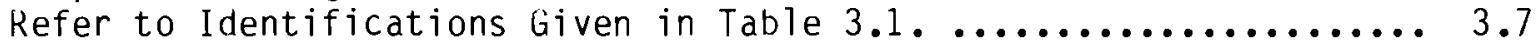

3.5. High Resolution Gas Chromatoyram of an SRC-I Wash Solvent.

Conditions: Same as in Figure 3.3, Except Temperature

Proyrammed to $120^{\circ} \mathrm{C}$ at $2^{\circ} \mathrm{C} / \mathrm{min}$. Numbers Refer to

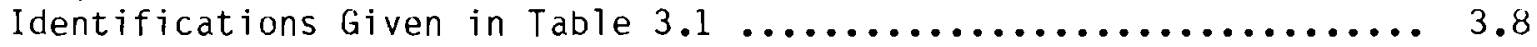

3.6. High Resolution Gas Chromatogram of an SRC-II Heavy

Distillate. Conditions: $15 \mathrm{M} \times 0.25 \mathrm{~mm}$ i.d. Fused

Silica Capillary Columin Coated with SE-52; Splitless

Injection; Hydrogen Carrier Gas at $100 \mathrm{~cm} / \mathrm{s}$ Linear

Velocity; 2 min Isothermal at $50^{\circ} \mathrm{C}$ then Temperature

Programined to $100^{\circ} \mathrm{C}$ at $10^{\circ} \mathrm{C} / \mathrm{min}$, to $225^{\circ} \mathrm{C}$ at $2{ }^{\circ} \mathrm{C} / \mathrm{min}$,

and to $300^{\circ} \mathrm{C}$ at $15^{\circ} \mathrm{C} / \mathrm{min}$. Numbers Refer to

Ident ifications Given in Table 3.1 . 
3.7. High Resolution Gas Chromatogram of an SRC-I Process Solvent. Conditions: Same as in Figure 3.6, Except Temperature Programmed from $50^{\circ} \mathrm{C}$ to $200^{\circ} \mathrm{C}$ at $2^{\circ} \mathrm{C} / \mathrm{min}$ Only. Numbers refer to Identification Given in Table 3.1 . .............. 3.10

3.8 High Resolution Gas Chromatogram of the Control Sample from the $-20^{\circ} \mathrm{C}$ and $20^{\circ} \mathrm{C}$ Studies of an SRC-II Fuel $0 i 1$ Blend. Conditions: $30 \mathrm{M} \times 0.25 \mathrm{~mm}$ i.d. Fused Silica Capillary Column, Splitless Injection, Helium Carrier Gas at $50 \mathrm{~cm} / \mathrm{s}$ Linear Velocity, $2 \mathrm{~min}$ Isothermal at $70^{\circ} \mathrm{C}$ then Temperature Programmed to $200^{\circ} \mathrm{C}$ at $2^{\circ} \mathrm{C} / \mathrm{min}$. Numbers Refer to Identifications Given in Table $3.1 . \ldots . . . \ldots . . . . . . . . . . . . . . .3 .11$

3.9 High Resolution Gas Chromatogram of the Time=0 Sample from the $60^{\circ} \mathrm{C}$ Study of an SRC-II Fuel $0 i 1$ Blend. Conditions: Same as in Figure 3.8. Numbers Refer to

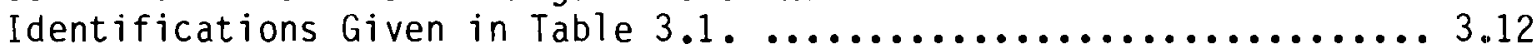

3.10 High Resolution Gas Chromatogram of the Time=0 Sample from the $100^{\circ} \mathrm{C}$ Study of an SRC-II Fuel $0 i 1$ Blend. Conditions: $30 \mathrm{M} \times 0.25 \mathrm{~mm}$ i.d. Fused Silica Capillary Column Coated with SE-52, Splitless Injection, Helium Carrier Gas at $50 \mathrm{~cm} / \mathrm{s}$ Linear Velocity, $2 \mathrm{~min}$ Isothermal at $40^{\circ} \mathrm{C}$ then Temperature Programmed to $200^{\circ} \mathrm{C}$ at $2^{\circ} \mathrm{C} / \mathrm{min}$ and to $250^{\circ} \mathrm{C}$ at $15^{\circ} \mathrm{C} / \mathrm{min}$. Numbers Refer to

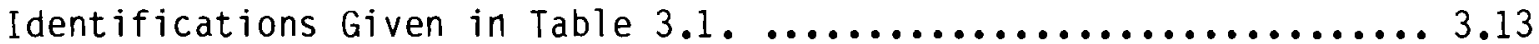

3.11 Relative Amounts of Components in SRC-II Naphtha Sample 3317-055-04 Using Three Different Split Ratios for Injection. Amounts for Specific Peaks Were Connected

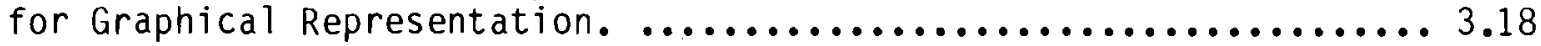

3.12 Log Transformed Data from Chromatographic Results for SRC-II Fuel 0il Blend Samples Stored in the Repository. Data Points After Two Years are Offset by 0.3 Peak Units. ......... 3.21

3.13 Log Transformed Data from Chromatographic Results for SRC-II Fuel $0 \mathrm{il}$ Blend Samples Stored at $-20^{\circ} \mathrm{C}$ and $20^{\circ} \mathrm{C}$ Under Various Parameters of Cover Atmosphere, Ambient Light, and Dilution (See Figure 2.1). Top: All Samples Stored Undiluted Offset By 0.1 Peak Units. Bottom: Condition 4 Versus $1: 20$ and $1: 200$ Dilutions with Methylene Chloride 0 ffset by 0.25 and 0.5 Peak Units, Respectively. 
3.14 Log Transformed Data from Chromatographic Results for SRC-II Fuel 0 il Blend Stored at $60^{\circ} \mathrm{C}$, Under an Air Atmosphere, in the Dark. Data Points for Time $=0$ are Offset by 0.0 Peak Units, 16 Weeks by 0.25 Peak Units,

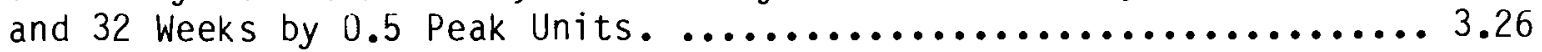

3.15 ECD Chromatograms of Derivatized Amino-PAH Fractions from an SRC-II Fuel 0 il Blend Before (Top) and After (Bottom) Storage at $100^{\circ} \mathrm{C}$ for 16 Weeks. Conditions: $50^{\circ} \mathrm{C}$ to $300^{\circ} \mathrm{C}$ at $3^{\circ} \mathrm{C} / \mathrm{min}, 15 \mathrm{M} \times 0.25 \mathrm{~mm}$ i.d. DB-5 Column, Helium Carrier at $50 \mathrm{~cm} / \mathrm{s}$ Linear Velocity. .................32

3.16 Direct Probe Results for SRC-II Heavy Distillate Sampled from a Mixed Container (top), Two $\mathrm{cm}$ from the Top of an Undisturbed Container (middle), and Five $\mathrm{cm}$ from the Botton of an Undisturbed Container (bottom). 3.34

3.17 Direct Probe Results for SRC-II Heavy Distillate Sampled from the Bottom of an Undisturbed Container (top) and from the Subsequently Partitioned Light (middle) and Heavy (bottom) Sludges.

3.18 Comparison of Microbial Mutagenicity for SRC Materials

in 1979 Versus Those Stored in the Repository at $4{ }^{\circ} \mathrm{C}$

in the Dark, Under a Nitroyen Atmosphere in 1983.

Replicates Refer to Those Identified in Table $3.11 . \ldots \ldots \ldots \ldots \ldots . . . .38$

3.19 Comparison of Microbial Mutagenicity for an SRC-II

Fuel 0 il Blend Stored Under Various Conditions at

$-20^{\circ} \mathrm{C}$ and $20^{\circ} \mathrm{C}$. Conditions Refer to Those in

Figure 2.1 of the Experimental Methods Section $2.0 \ldots \ldots \ldots \ldots . . . .3 .40$

3.20 Comparison of Microbial Mutagenicity Data for SRC-II

Fuel $0 i 1 \mathrm{Blend}$ Under Accelerated Conditions of Elevated

Temperatures of $60^{\circ} \mathrm{C}$ and $100^{\circ} \mathrm{C}$

8.1 Log Transformed Data from Chromatographic Results for

SRC-II Naphtha Samples Stored in the Respository.

Data Points After Two Years are Offset by 0.3 Peak Units ........ 8.2

8.2 Log Transformed Data from Chromatographic Results for

SRC-I Light 0il Sample Stored in the Repository.

Data Points After Two Years are offset by 0.3 Peak Units ......... 8.4

8.3 Log Transformed Data from Chromatographic Results for

SRC-II Middle Distillate Samples Stored in the Repository. Data Points After Two Years are Offset by 0.3 Peak Units 
8.4 Log Transformed Data from Chromatographic Results for SRC-II Heavy Distillate Samples Stored in the

Repository. Data Points After Two Years are Offset

by 0.3 Peak Units $\ldots \ldots \ldots \ldots \ldots \ldots \ldots \ldots \ldots \ldots \ldots \ldots \ldots \ldots \ldots \ldots \ldots \ldots . \ldots . \ldots . \ldots$

8.b Log Transformed Data from Chromatographic Results for

SRC-I Wash Solvent Sample Stored in the Repository.

Data Points After Two Years are Offset by 0.3 Peak Units .........8.10

8.6 Log Transformed Data from Chromatographic Results for SRC-I Process Solvent Samples Stored in the Repository.

Data Points After Two Years are Offset by 0.3 Peak Units .........8.12

8.7 Log Transformed Data from Chromatographic Results for

SRC-II Fuel 0 il Blend Stored at $100^{\circ} \mathrm{C}$, Under an $\mathrm{Air}$

Atmosphere, in the Dark. Data Points for Time $=0$ are

0 ffset by 0.0 Peak Units, 16 Weeks by 0.3 Peak Units ............ 8.14 


\section{$\underline{\text { TABLES }}$}

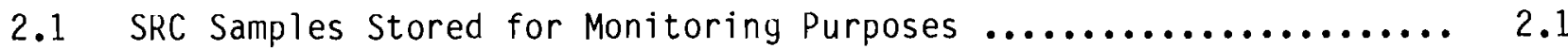

2.2 Intercomparison from $-20^{\circ} \mathrm{C}$ and $20^{\circ} \mathrm{C}$ Studies to Monitor

the Effects of Storage Under Various Conditions ................ 2.5

2.3 Subsampling Schedule for the $60^{\circ} \mathrm{C}$ Stability Study of

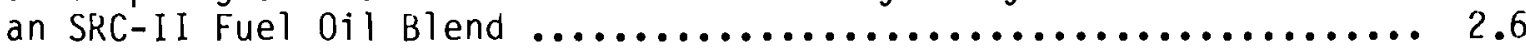

2.4 Internal Standards Added for High Resolution Gas

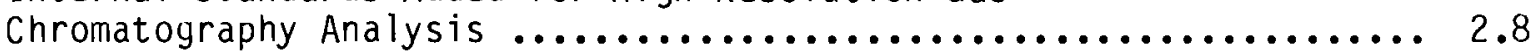

2.5 Conditions for Gas Chromatography Analysis $\ldots \ldots \ldots \ldots \ldots \ldots \ldots . . .2 .9$

2.6 Sample Data Table from an SRC-II Fuel Oil Blend Sample

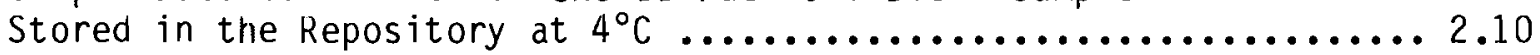

2.7 Summary of Analyses of Stability Study Samples $\ldots \ldots \ldots \ldots \ldots \ldots \ldots \ldots 2.14$

3.1 Compounds Monitored in the Stability Studies $\ldots \ldots \ldots \ldots \ldots \ldots \ldots . . .2$

3.2 Comparison of Peak Area versus Height for Computing

Relative Amounts of Components in SRC-II Middle

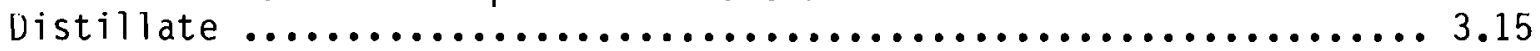

3.3 Comparison of Chromatographic Variability After One

Day Using the Same Experimental Set-Up $\ldots \ldots \ldots \ldots \ldots \ldots \ldots \ldots \ldots \ldots . . .17$

3.4 Comparison of Chromatographic Variability After

Modification of Experimental Set-Up .......................... 3.19

3.5 F Values from the ANOVA Techniques Applied to the

SRC-II Fuel 0il Blend Chromatographic Data After

Storage in the Repository for Two Years $\ldots \ldots \ldots \ldots \ldots \ldots \ldots \ldots \ldots . . .22$

3.6 F Values from the ANOVA Techniques Applied to the

SRC-II Fuel 0il Blend Chromatographic Data After

Storaye at $-20^{\circ} \mathrm{C}$ and Room Temperature Under

Various Parameters of Light, Atmosphere, and

vilution for One Year

3.7 F Values from the ANOVA Techniques Applied to the

SRC-II Fuel 0il Blend Chromatographic vata After

Storage at $60^{\circ} \mathrm{C}$, in the Dark, Under an Air

Atmosphere for 16 and 32 Weeks 
3.8 Total Area Counts Chromatographed Per mg Crude SRC-II Fuel 011 Blend Before and After Storage at $100^{\circ} \mathrm{C}$ for 16 Weeks

3.9 Mean of PAH Compound Concentration in the PAH Fraction of an SRC-II Fuel $0 i 1$ Blend Before and After Storage at $100^{\circ} \mathrm{C}$, in the Dark, Under an Air Atmosphere for 16 Weeks

3.10 Mean of Nitrogen Heterocyclu Concentration in the N-PAC Fraction of an SRC-II Fuel $0 i l$ Blend Before and After Storage at $100^{\circ} \mathrm{C}$, in the Dark, Under an Air Atmosphere for 16 weeks

3.11 Results of Microbial Mutagenicity After Storage at $4^{\circ} \mathrm{C}$, in the Dark, Under a Nitrogen Atmosphere for Four Years

3.12 Results of Microbial Mutagenicity for Samples from Varying Depths of an Undisturbed Container of SRC-II Heavy Distillate Stored at $4^{\circ} \mathrm{C}$, in the Dark, Under a Nitrogen Atmosphere ...

3.13 Results of Microbial Mutagenicity Tests Against S. typhimurium TA98, $-20^{\circ} \mathrm{C}$ and $20^{\circ} \mathrm{C}$ Stability Study

3.14 Mutagenic Effects of Storage Under Various Conditions at $-20^{\circ} \mathrm{C}$ and $20^{\circ} \mathrm{C}$ for One Year

7.1 Chromatographic Results for SRC-II Naphtha Sample 3317-125-01B Stored at $4^{\circ} \mathrm{C}$, in the Dark, Under a Nitrogen Atmosphere

7.2 Chromatographic Results for SRC-II Naphtha Sample 3317-055-04 Stored at $4^{\circ} \mathrm{C}$, in the Dark, Under a Nitrogen Atmosphere

7.3 Chromatographic Results for SRC-I Light 0il Sample 3317-073-16 Stored at $4{ }^{\circ} \mathrm{C}$, in the Dark, Under a Nitrogen Atmosphere

7.4 Chromatographic Results for SRC-II Middle Distillate Sample 3317-129-02 Stored at $4^{\circ} \mathrm{C}$, in the Dark, Under a Nitrogen Atmosphere

7.5 Chromatographic Results for SRC-II Middle Distillate Sample 3317-130-02 Stored at $4^{\circ} \mathrm{C}$, in the Dark, Under a Nitrogen Atmosphere 
7.6 Chromatoyraphic Results for SRC-II Middle Distillate Sample 3317-131-02 Stored at $4^{\circ} \mathrm{C}$, in the Dark, Under

a Nitroyen Atmosphere

7.7 Chromatographic Results for SRC-II Middle Distillate Saniple 3317-058-01 Stored at $4^{\circ} \mathrm{C}$, in the Dark, Under a Nitroyen Atmosphere

7.8 Chromatographic Results for SRC-I I Fuel 0il

$B l$ end Sample 3317-079-24 Stored at $4^{\circ} \mathrm{C}$, in the

Dark, Under a Nitrogen Atmosphere

7.9 Chromatographic Results for SRC-II Fuel 0 il

Blend Sample 3317-079-23 Stored at $4{ }^{\circ} \mathrm{C}$, in the

Dark, Under a Nitrogen Atmosphere

7.10 Chromatoyraphic Results for SRC-II Fuel 0 il $\mathrm{Bl}$ end

Sample 3317-079-25 Stored at $4{ }^{\circ} \mathrm{C}$, in the Dark, Under

a Nitrogen Atmosphere

7.11 Chronatographic Results for SRC-II Fuel 0 il Blend

Sample 3317-079-26 Stored at $4^{\circ} \mathrm{C}$, in the Dark, Under

a Nitrogen Atmosphere

7.12 Chromatographic Results for SRC-I Wash Solvent

3317-075-19 Stored at $4^{\circ} \mathrm{C}$, in the Dark, Under

a Nitrogen Atmosphere

7.13 Chromatographic Results for SRC-II Heavy Distillate

Sariple 3317-132-02 Stored at $4^{\circ} \mathrm{C}$, in the Dark, Under

a Nitrogen Atmosphere

7.14 Chromatographic Results for SRC-I I Heavy Distillate Sample 3317-134-02 Stored at $4^{\circ} \mathrm{C}$, in the Dark, Under a Nitroyen Atmosphere

7.15 Chromatoyraphic Results for SRC-II Heavy Distillate Sample 3317-015-11 Stored at $4^{\circ} \mathrm{C}$, in the Dark, Under a Nitrogen Atmosphere 7.16

7.16 Chronatoyraphic Results for SRC-I Process Solvent Sample 3317-066-26 Stored at $4^{\circ} \mathrm{C}$, in the Dark, Under a Nitrogen Atmosphere 7.17

7.17 Chromatographic Results for SRC-I Process Solvent Sample 3317-066-27 Stored at $4^{\circ} \mathrm{C}$, in the Dark, Under a Nitrogen Atmosphere 
7.18 Chromatographic Results for SRC-II Fuel 0 il Blend Sample $3317-079-25$ Stored at $-20^{\circ} \mathrm{C}$ and $20^{\circ} \mathrm{C}$ Under

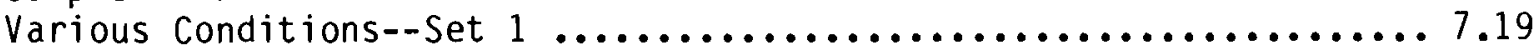

7.19 Chromatographic Results for SRC-II Fuel 0il Blend Sample $3317-079-25$ Stored at $-20^{\circ} \mathrm{C}$ and $20^{\circ} \mathrm{C}$ Under

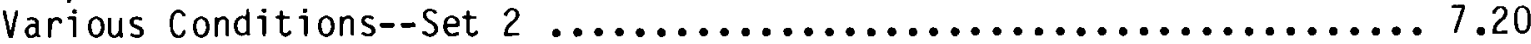

7.20 Chronatographic Results for SRC-II Fuel 0il Blend Sample 3317-079-25 Stored at $60^{\circ} \mathrm{C}$, in the Dark, Under an Air Atmosphere

7.21 Chromatographic Results for SRC-II Fuel $0 i 1$ Blend Sample 3317-079-25 Stored at $100^{\circ} \mathrm{C}$, in the Dark, Under an Air Atmosphere

7.22 Chromatographic Results for SRC-II Fuel 0il Blend Samples Stored at $-20^{\circ} \mathrm{C}$, in the Dark, Under a Nitrogen Atmosphere for Three Years Diluted with Methylene Chloride

8.1 F Values from the ANOVA Techniques Applied to the SRC-II Naphtha Chromatographic Data After Storage in the Repository for Two Years ........................ 8.3

8.2 F Values from the ANOVA Techniques Applied to the SRC-I Light 0il Chromatographic Data After Storage in the Repository for Two Years ......................... \&.5

8.3 F Values from the ANOVA Techniques Applied to the SRC-II Middle Distillate Chromatographic Data After Storage in the Repository for Two Years

8.4 F Values from the ANOVA Techniques Applied to the SRC-II Heavy Distillate Chromatographic Data After Storage in the Repository for Two Years

8.5 F Values from the ANOVA Techniques Applied to the SRC-I Wash Solvent Chromatograhic Data After Storage in the Repository for Two Years

8.6 F Values from the ANOVA Techniques Applied to the SRC-I Process Solvent Chromatograhic Data After Storage in the Repository for Two Years

8.7 F Values from the ANOVA Techniques Applied to the SRC-II Fuel 0il Blend Chromatographic Data After Storage at $100^{\circ} \mathrm{C}$ for 16 Weeks 


\section{$1.0 \quad$ INTROUUCTION}

The Pacific Northwest Laboratory (PNL) maintains a repository of synfuel materials. The materials in this repository are utilized for comparative purposes between synfuels technologies, for evaluation of sample characteristics from various process streams within a single technology, and for biological testing. These research materials are stored in a refriyerated repository maintained at approximately $4^{\circ} \mathrm{C}$. A computerized materials accounting system is used to track the quantity of each material remaining in the repository and to identify the investigators to whom subsamples of these materials have been released.

Several solvent refined coal (SRC) I and II liquids have been obtained in large quantities $(>25 \mathrm{~L})$ and have been stored and subsampled throughout longrunning biological or ecological testing regimes. Since the coal liquids are used over long periods of time, it is necessary to determine if the integrity of the chemical composition and bioloyical activity is maintained during storaye. The chemical compositions of these materials were determined initially and have been monitored during their storage in the repository at $4^{\circ} \mathrm{C} . \mathrm{Along}$ with this monitoring, several experiments designed to monitor the chemical composition of the SRC materials under other storage conditions chosen to accelerate the kinetics of the reactions causing chemical change have been performed. The effects of storage at $-20^{\circ} \mathrm{C}, 20^{\circ} \mathrm{C}, 60^{\circ} \mathrm{C}$, and $100^{\circ} \mathrm{C}$ as well as cover atmosphere, dilution, and ambient lighting conditions were investigated. Results of these experiments serve as benchmarks for changes in chemical composition which may occur over a longer period of time in the repository. Results also give insight into the enviromental degradation of the coal liquids. The same SRC coal liquid samples stored in the repository and under the harsher experimental conditions were monitored for changes in mutagenicity by a microbial bioassay against . typhimurium TA98.

Several other studies have been conducted on the aging characteristics of synthetic fuels. Kershaw and Gray (1) found that there was no significant change in the IR, 'H NMR spectra, or average molecular weight of coal hydroyenation liquids stored at room temperature while bubbling oxygen or nitrogen 
through the liquids. The viscosity did increase over a period of time, with the greatest increase found in the samples stored under oxygen. Studies by Karn et. al. (2-4) gave similar results. SYNTHOIL products were stored under a variety of conditions which included ambient temperatures as well as $30^{\circ} \mathrm{C}$ and $61^{\circ} \mathrm{C}$, atmospheres of nitrogen, air, and oxygen, stirred and unstirred samples, and ambient liyht versus darkness. They found that the greatest effect of exposure to oxygen was increased viscosity. Accelerated carbonyl formation giving rise to an increased average molecular weight under storage conditions with oxygen and elevated temperatures was noted from IR spectral analysis. Frankenfeld et al. (5-7) found that the addition of nitrogen compounds, particularly alkylated heterocyclic nitrogen compounds, promoted sediment formation upon storage of petroleum-derived jet fuels and shale liquids. Oxygen promoted sediment formation to a significant degree. Results of these experiments also showed an increase in viscosity of the products upon storage over time and at elevated temperature.

Studies involving SRC products have implicated oxidative coupling of phenolic compounds as a major aging mechanisin $(8,9)$. A 3:7 blend of solid SRC-I product and SRC-II middle distillate were aged in the presence of $\mathrm{Cu}$ and $\mathrm{O}_{2}$ by Hara et al. (10). Viscosity increased significantly with time and was attributed to the formation of higher molecular weight components. White et al. (11) quantified individual phenolic compounds in an SRC-II middle distillate before and after accelerated aging in the presence of $\mathrm{Cu}$ and $\mathrm{O}_{2}$. The concentration of phenolic constitutents decreased during aging. Dimers, trimers, tetramers, and larger oligomers formed by the condensation of phenols were characterized in the aging product by high resolution mass spectrometry (HRMS).

The stability studies of synthetic fuels described in the present report differ from those previously presented in the literature in several ways. Most notably, the aging investigations have been carried out over a long period of time, four years. Secondly, the aging characteristics were related to the biological activities of the aged products. Finally, the data analysis methods in the present study were more rigorous than those utilized by other investigators. The samples were analyzed on a peak-to-peak basis by high resolution gas chromatography (GC). Individual components were identified by gas 
chromatography/mass spectrometry (GC/MS) and were monitored over a period of time under the various storage conditions previously mentioned. Changes in composition were represented by changes in the amounts of individual components. Results were analyzed by computer-based analysis of variance to deterinine when a sample's composition had changed. The experiments allowed the acquisition of data to determine under what conditions the composition of SRC materials changed, which specific components were being rlodified, and whether storage under the conditions of the repository is a viable means of maintenance for coal liquids over long periods of time without experiencing chemical changes. 
. 


\subsection{EXPERIMENTAL METHODS}

\subsection{SAMPLE MATERIALS}

The following SRC-I materials (with number of replicates) were subsampled in small volumes $(<1 L)$ and stored for monitoring purposes: one light oil (LO); one wash solvent (WS); and two process solvents (PS). In addition to these SRC-I materials, the following SRC-II materials (with number of replicates) were stored for monitoring purposes: two naphthas $(N)$; four middle distillates (MD); three heavy distillates (HD); and four fuel oil blends (FOB), a mixture of 2.9 parts middle distillate to 1 part heavy distillate. Table 2.1 summarizes the samples stored for monitoring purposes and their approximate boiling point ranges. All samples were supplied by the Pittsburg and Midway

TABLE 2.1. SRC Samples Stored for Monitoring Purposes

\begin{tabular}{|c|c|c|}
\hline Sample & $\begin{array}{c}\text { Identification } \\
\text { Number } \\
\end{array}$ & $\begin{array}{l}\text { Approximate Boiling } \\
\text { Point Range } \\
\end{array}$ \\
\hline SRC-I Light Uil & $3317-073-16$ & ambient $-380^{\circ} \mathrm{F}$ \\
\hline SRC-I Wash Solvent & $3317-075-19$ & $380-480^{\circ} \mathrm{F}$ \\
\hline $\begin{array}{l}\text { SRC-I Process Solvent } \\
\text { SRC-I Process Solvent }\end{array}$ & $\begin{array}{l}3317-066-26 \\
3317-066-27\end{array}$ & $480-.850^{\circ} \mathrm{F}$ \\
\hline $\begin{array}{ll}\text { SRC-I I Naphtha } \\
\text { SRC-I I Naphtha }\end{array}$ & $\begin{array}{l}3317-125-01 B \\
3317-055-04\end{array}$ & ambient $-350^{\circ} \mathrm{F}$ \\
\hline $\begin{array}{l}\text { SRC-II Middle Distillate } \\
\text { SRC-II Middle Distillate } \\
\text { SRC-II Middle Distillate } \\
\text { SRC-II Middle Distillate }\end{array}$ & $\begin{array}{l}3317-129-02 \\
3317-130-02 \\
3317-131-02 \\
3317-058-02\end{array}$ & $350-550^{\circ} \mathrm{F}$ \\
\hline $\begin{array}{llll}\text { SRC-II } & \text { Fuel } & 0 i l & \text { Blend } \\
\text { SRC-I I } & \text { Fuel } & 0 i 1 & \text { Blend } \\
\text { SRC-II } & \text { Fuel } & 0 i l & \text { Blend } \\
\text { SRC-II } & \text { Fuel } & 0 i l & \text { Blend }\end{array}$ & $\begin{array}{l}3317-079-23 \\
3317-079-24 \\
3317-079-25 \\
3317-079-26\end{array}$ & $350-850^{\circ} \mathrm{F}$ \\
\hline $\begin{array}{l}\text { SRC-II Heavy Distillate } \\
\text { SRC-II Heavy Distillate } \\
\text { SRC-II Heavy Distillate }\end{array}$ & $\begin{array}{l}3317-132-02 \\
3317-134-02 \\
3317-015-11\end{array}$ & $550-850^{\circ} \mathrm{F}$ \\
\hline
\end{tabular}


Coal Mining Co. Each replicate represents a discrete sample collected from the Ft. Lewis, WA, pilot plant during a period of stable, lined-out operating conditions. While these operating conditions have been defined for each sample, the samples may not be representative of materials that will be produced at commercial coal liquefaction facilities.

\subsection{STABILITY STUDIES PARAMETERS}

\section{$2.2 .1 \quad 4^{\circ} \mathrm{C}$}

The 17 subsamples of distillates from the SRC-I and II processes, described in the preceding section, were stored under the same identical conditions as have all of the larger-volume coal liquefaction research materials in the repository. They were stored in the dark in inert containers at a temperature of $4^{\circ} \mathrm{C}$ under a blanket of nitrogen atmosphere. (Teflon-lined stainless steel drums are used for storing large-volume samples. The smaller samples were stored in glass jars with aluminum-lined caps or in Teflon bottles.) The chemical composition and biological activity of each of the 17 subsamples were monitored every two to four years. (The methods used for this monitoring are presented in the Data Acquisition Section 2.3, page 2.6.) Monitoring of the 17 samples stored under these conditions over time has shown the long-term chemical and biological effects of storage of coal liquefaction materials.

In addition to the biennial monitoring of samples stored under repository conditions, studies at $-20^{\circ} \mathrm{C}, 20^{\circ} \mathrm{C}, 60^{\circ} \mathrm{C}$ and $100^{\circ} \mathrm{C}$ were performed with an SRCII fuel oil blend sample. Chanyes in the FOB components under the accelerated aging conditions of these studies are assumed to be analogous to changes that. may occur over longer periods of time in the repository. The FOB was chosen for these additional stability studies because, due to its wide boiling range. $\left(350^{\circ}\right.$ to $\left.850^{\circ} \mathrm{F}\right)$, many of the components found in this sample are also found in the other SRC distillate materials stored in the repository.

\section{$2.2 .2-20^{\circ} \mathrm{C}, 20^{\circ} \mathrm{C}$}

Ten-mL samples of the SRC-II FOB were stored in glass vials in duplicate in a freezer at $-20^{\circ} \mathrm{C}$. The effect of cover atmosphere was monitored by 
blanketiny one sample set with nitrogen (the control) and the other sample set with air (condition 1 ). This control also served as the control for the studies at $20^{\circ} \mathrm{C}$.

Ten-mL samples of the SRC-II FOB were stored in glass vials in duplicate at room temperature (approximately $20^{\circ} \mathrm{C}$ ). The effects of ambient light, cover atmosphere, and dilution were studied by storing these sample sets under the following conditions: (A) undiluted in the light and covered with an inert nitrogen atmosphere (condition 2); (B) diluted 1:200 or 1:20 FOB:methylene chloride, stored in the light, and covered with an air atmosphere (condition 3); (C) undiluted in the light and covered with an air atmosphere (condition 4); (D) undiluted in the dark and covered with a nitrogen atmosphere (condition 5); and (E) undiluted in the dark and covered with an air atmosphere (condition 6). A schematic diagram of the stability study parameters of the $-20^{\circ} \mathrm{C}$ and $20^{\circ} \mathrm{C}$ studies is shown in Figure 2.1 . The labeled conditions correspond with those given in the text.

The effects of dilution, cover atmosphere, temperature, and ambient light were monitored by the comparison of both chemical composition and biological activity data for the samples shown in Table 2.2. The effects of singular and multiple parameters were monitored for the samples as shown in the table. $2.2 .3 \quad 60^{\circ} \mathrm{C}$

One-nL samples of an SRC-II FOB were placed in each of 18 inert glass vials which served as replicates for this study. They were sealed with screwon caps under an air atmosphere and were stored in an oven at $60^{\circ} \mathrm{C}$ in the dark. The vials were subsampled in duplicate according to the schedule shown in Table 2.3. At each subsampling occasion, three of the replicate vials were opened and subsampled for the first time. These same vials were opened and subsampled a second time at the next subsampling occasion along with the three others being subsampled for the first time. The subsampling proceeded in this manner with each vial opened and subsampled on no more than three subsequent subsarnpling occasions. 
SRC II

FUEL OIL BLEND
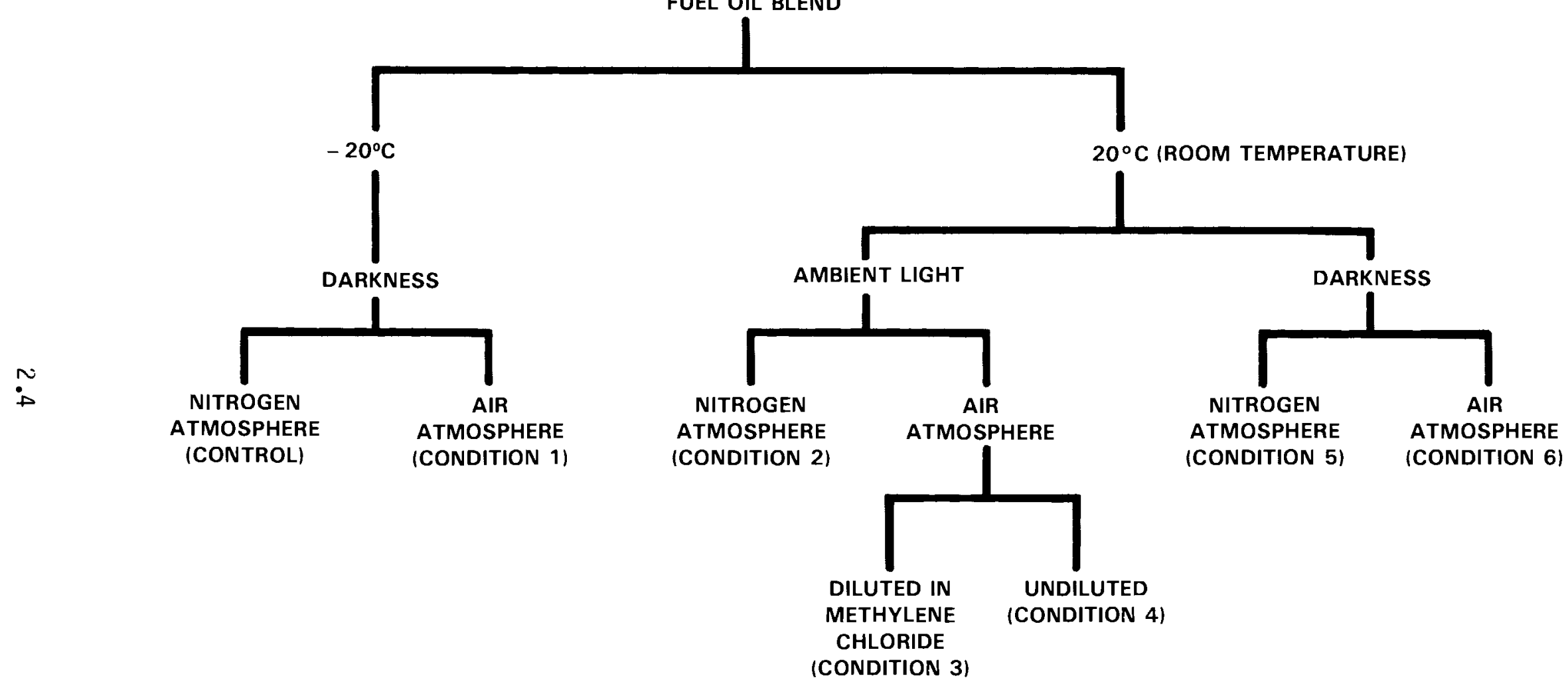

FIGURE 2.1. Schematic Diagram of $-20^{\circ} \mathrm{C}$ and $20^{\circ} \mathrm{C}$ Stability Study Parameters of Temperature, Light, Cover Atmosphere, and Dilution 
TABLE 2.2. Intercomparison from $-20^{\circ} \mathrm{C}$ and $20^{\circ} \mathrm{C}$ Studies to Monitor the Effects of Storage Under Various Conditions

\begin{tabular}{|c|c|}
\hline Sample Comparison(a) & Parameter(s) Monitored \\
\hline Condition 3 versus Condition 4 & Dilution \\
\hline $\begin{array}{l}\text { Control versus Condition } 1 \\
\text { Condition } 2 \text { versus Condition } 4 \\
\text { Condition } 5 \text { versus Condition } 6\end{array}$ & Air Atmosphere \\
\hline $\begin{array}{l}\text { Control versus Condition } 5 \\
\text { Condition } 1 \text { versus Condition } 6\end{array}$ & Room Temperature \\
\hline $\begin{array}{l}\text { Condition } 2 \text { versus Condition } 5 \\
\text { Condition } 4 \text { versus Condition } 6\end{array}$ & Ambient Light \\
\hline $\begin{array}{l}\text { Control versus Condition } 2 \\
\text { Condition } 1 \text { versus Condition } 4\end{array}$ & Ambient Light plus room temperature \\
\hline Control versus Condition 6 & Air atmosphere plus room temperature \\
\hline Control versus Condition 4 & $\begin{array}{l}\text { Ambient Light plus air atmosphere and } \\
\text { room temperature }\end{array}$ \\
\hline Control versus Condition 3 & $\begin{array}{l}\text { Ambient Light plus air atmosphere, } \\
\text { room temperature, and dilution }\end{array}$ \\
\hline
\end{tabular}

(a) Conditions correspond to those shown in Figure 2.1

Following this subsampling procedure allowed the effects, if any, of numerous samplings from a particular vial to be monitored. It also provided a large number of replicate analyses for statistical purposes. For example, at the 32 week subsampling, 18 subsamples were taken from 9 vials stored under the same conditions. Each of the 18 subsamples were analyzed four times by high resolution gas chromatography (explained in the Data Acquisition Section 2.3, page 2.6) to give a total of 72 sets of data for analysis of one subsampling of the $60^{\circ} \mathrm{C}$ stability study.

$2.2 .4 \quad 100^{\circ} \mathrm{C}$

One-mL samples of an SRC-II FOB were placed in each of three inert glass vials for the stability study at $100^{\circ} \mathrm{C}$. The vials were sealed with screw-on 
TABLE 2.3. Subsampling Schedule for the $60^{\circ} \mathrm{C}$ Stability Study of an SRC-II Fuel 0il Blend

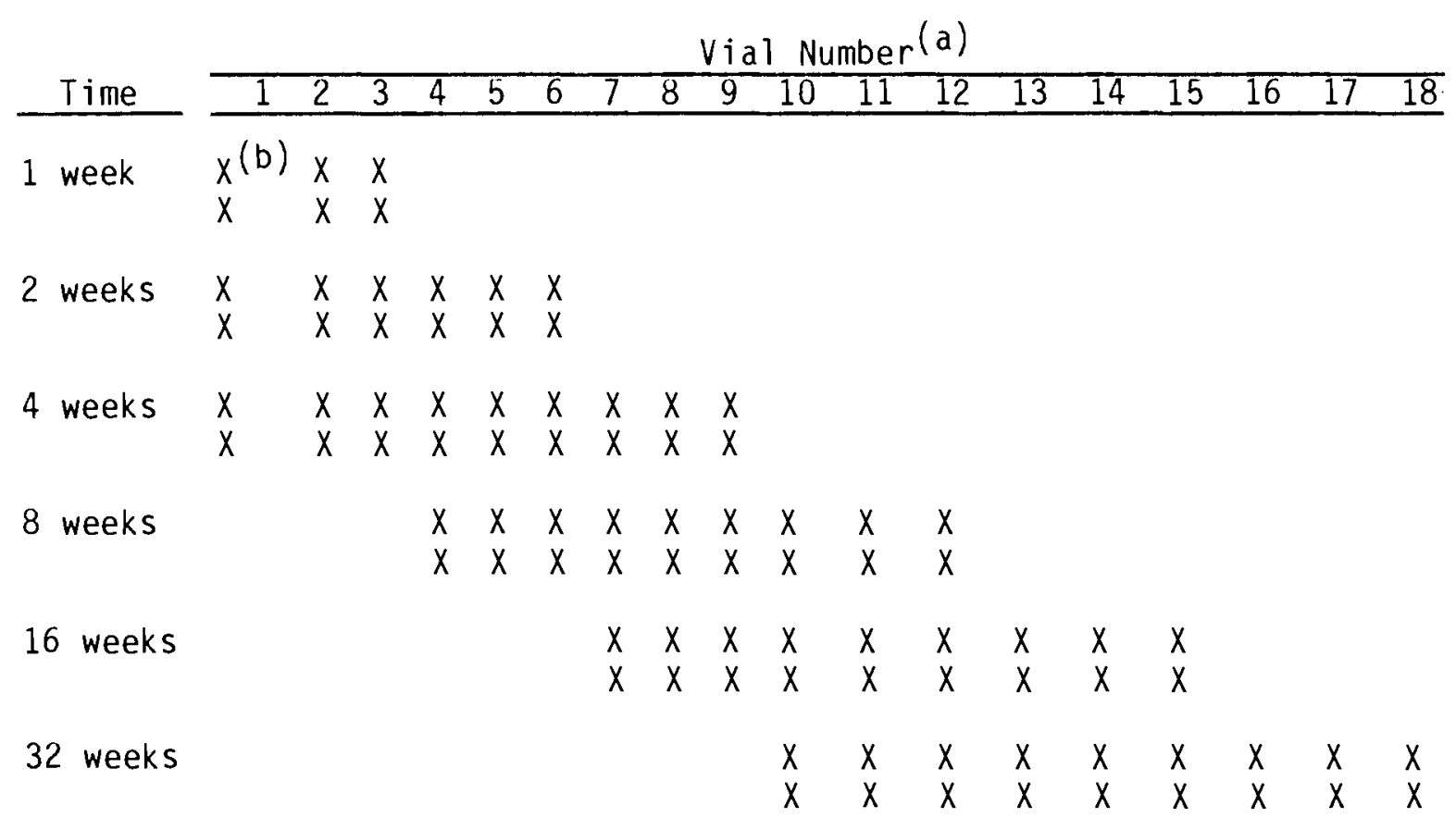

(a) Represents replicate samples stored in the oven.

(b) Each $X$ represents a subsampling of the vial for analysis.

caps under an air atmosphere and were stored in an oven at $100^{\circ} \mathrm{C}$ in the dark. Each vial was subsampled in duplicate at 1 week, 2 weeks, 4 weeks, 8 weeks, 16 weeks, and 32 weeks from the first day they were placed in the oven. The changes which occur under these harsh conditions, chosen to accelerate the kinetics of reactions which cause chemical change, serve as benchmarks for changes that may occur under mild conditions of storage over longer periods of time.

\subsection{DATA ACQUISITION}

\subsubsection{High Resolution Gas Chromatography}

Samples stored under the conditions described in the Stability Studies Parameters Section 2.2 were analyzed for chemical composition by high resolution yas chromatography using 15-30 M fused silica columns coated with SE-52. Samples were diluted approximately $25 \mu \mathrm{L}$ in $5 \mathrm{~mL}$ of methylene chloride containing a known quantity of an internal standard for the $4^{\circ} \mathrm{C}$ study. Samples 
were diluted approximately $50 \mu \mathrm{L}$ in $5 \mathrm{~mL}$ of methylene chloride containing a known quantity of an internal standard for the $-20^{\circ} \mathrm{C}, 20^{\circ} \mathrm{C}$ and $60^{\circ} \mathrm{C}$ studies. Samples were diluted approximately $40 \mu \mathrm{L}$ in $5 \mathrm{~mL}$ of methylene chloride containing a known quantity of an internal standard for the $100^{\circ} \mathrm{C}$ study. (Volumes were approxinate since small volumes of viscous liquids were ineasured.) Samples of SRC-II naphthas and SRC-I light oil were analyzed neat, with the addition of an internal standard, usiny a 90 M ylass capillary column coated with SF-96. The $5 \mathrm{~mL}$ of diluted sample were placed equally in three separate vials for analysis.

Internal standards were chosen that would not cause any interference in the gas chromatographic analysis. Straight-chain aliphatic hydrocarbons were used because a large selection of compounds with different elution times was available and their presence would not be expected to chemically modify any of the constituents already present in the complex synfuel mixtures. Since the samples analyzed were rough distillate cuts of SRC products, each different sample type needed a different internal standard (ISTD) to ensure there was no co-elution of internal standard with a component already present at a significant level in the material. This was particularly important since some aliphatic hydrocarbons are expected to be found in the SRC materials studied. Table 2.4 contains the list of SRC materials studied and the internal standards which were added for gas chromatography analysis.

After dilution and the addition of an internal standard, the diluted samples in two of the three vials prepared were analyzed by high resolution gas chromatography using the conditions summarized in Table 2.5. The third vial was stored for other analyses. The amounts of the major peaks in the chromatograms were calculated by normalizing the peak area or height of the individual peaks of interest to the internal standard peak. The following equation was used:

$\frac{\text { Area or height of peak of interest }}{\text { Area or height of internal standard }} \cdot 100=$ Amount of peak of interest 
TABLE 2.4. Internal Standards Added for High Resolution Gas Chromatography Analysis

SRC Material

Naphtha(a)
Middle Distillate(a)
Fuel Oil Blend (a)
Heavy Distillate(a)

Light $0 i^{(b)}$ Wash Solvent $(b)$ Process Solvent $(b)$
Internal Standard

$$
\begin{aligned}
& \mathrm{C}_{11} \mathrm{H}_{24} \text { n-Undecane } \\
& \mathrm{C}_{19} \mathrm{H}_{40} \text { n-Nonadecane } \\
& \mathrm{C}_{19} \mathrm{H}_{40} \text { n-Nonadecane } \\
& \mathrm{C}_{15} \mathrm{H}_{32} \text { n-Pentadecane } \\
& \mathrm{C}_{11} \mathrm{H}_{24} \text { n-Undecane } \\
& \mathrm{C}_{15} \mathrm{H}_{32} \text { n-Pentadecane } \\
& \mathrm{C}_{12} \mathrm{H}_{26} \text { \& } \mathrm{C}_{19} \mathrm{H}_{40} \text { n-Dodecane \& n-Nonadecane }
\end{aligned}
$$

(a) SRC-II material.

(b) SRC-I material.

The amount of the peak of interest was calculated as a percent of the internal standard peak response. At the end of every gas chromatographic run, a table of data similar to that shown in Table 2.6 was acquired. The retention time of each peak was reported with the amount present. Multiple injections of each sample vial were performed for statistical purposes. Each diluted sample was analyzed a minimum of four times.

The individual peaks that were monitored were identified through gas chromatography/mass spectrometry (GC/MS) using the third vial of diluted samples which had been previously set aside. An Hewlett-Packard 5992 benchtop GC/MS system equipped with a 30 M SE-52 fused silica column was used for the SRC-I WS and PS and the SRC-II MD, HD, and FOB. An Hewlett Packard 5982A GC/MS system equipped with a 90M SF-96 glass capillary column and split injection was used for the analysis of the SRC-I LO and the SRC-II N.

\subsubsection{Chemical Fractionation}

One-hundred-my samples of the FUB stored under the control condition $\left(-20^{\circ} \mathrm{C}\right.$, nitrogen atmosphere, in the dark) and the conditions of $100^{\circ} \mathrm{C}$, air atmosphere, in the dark for 16 weeks were chemically fractionated in triplicate to identify any measurable changes in chemical class composition. The fractionation scheme used is depicted in Figure 2.2 (12). Briefly, the sarmples were eluted through a column packed with $9 \mathrm{~g}$ of neutral alumina. Aliphatic 
TABLE 2.5. Conditions for Gas Chromatography Analysis

\begin{tabular}{|c|c|c|c|c|c|c|}
\hline $\begin{array}{c}\text { Stability } \\
\text { Study Temperature } \\
\end{array}$ & Sample & & $\begin{array}{l}\text { illary } \\
\text { olumn }\end{array}$ & $\begin{array}{c}\text { Carrier } \\
\text { Gas-Velocity } \\
\end{array}$ & $\begin{array}{l}\text { Injection } \\
\text { Technique }\end{array}$ & Oven Temperature Program \\
\hline $4^{\circ} \mathrm{C}$ & $S R C-I I N(a)$ & 90 & M SF-96 & $\mathrm{He}-30 \mathrm{~cm} / \mathrm{s}$ & split $1: 71$ & $\begin{array}{l}12 \text { min } 035^{\circ} \mathrm{C} \text {, then } \\
8^{\circ} \mathrm{C} / \mathrm{min} \text { to } 175^{\circ} \mathrm{C}\end{array}$ \\
\hline $4^{\circ} \mathrm{C}$ & SRC-I I MD (a) & 30 & $M S E-52$ & $\mathrm{He}-50 \mathrm{~cm} / \mathrm{s}$ & splitless $(c)$ & $\begin{array}{l}2 \min { }^{\circ} 40^{\circ} \mathrm{C} \text {, then } 2^{\circ} \mathrm{C} / \mathrm{min} \\
\text { to } 170^{\circ} \mathrm{C} \text {; and } 15^{\circ} \mathrm{C} / \mathrm{min} \text { to } \\
250^{\circ} \mathrm{C}\end{array}$ \\
\hline $4^{\circ} \mathrm{C}$ & SRC-II HD (a) & 15 & M SE-52 & $\mathrm{H}_{2}-100 \mathrm{~cm} / \mathrm{s}$ & splitless $(c)$ & $\begin{array}{l}2 \mathrm{~min} 050^{\circ} \mathrm{C} \text {, then } \\
10^{\circ} \mathrm{C} / \mathrm{min} \text { to } 100^{\circ} \mathrm{C} ; 2^{\circ} \mathrm{C} / \mathrm{min} \\
\text { to } 225^{\circ} \mathrm{C} \text {; and } 15^{\circ} \mathrm{C} / \mathrm{min} \text { to } \\
225^{\circ} \mathrm{C}\end{array}$ \\
\hline $4^{\circ} \mathrm{C}, 100^{\circ} \mathrm{C}$ & SRC-II FOB (a) & 30 & $M S E-52$ & $\mathrm{He}-50 \mathrm{~cm} / \mathrm{s}$ & splitless $(c)$ & $\begin{array}{l}2 \min { }^{\circ} 40^{\circ} \mathrm{C} \text {, then } 2^{\circ} \mathrm{C} / \mathrm{min} \\
\text { to } 200^{\circ} \mathrm{C} \text {; and } 15^{\circ} \mathrm{C} / \mathrm{min} \text { to } \\
250^{\circ} \mathrm{C}\end{array}$ \\
\hline $4^{\circ} \mathrm{C}$ & $S R C-I \quad L O(a)$ & 90 & M SF-96 & $\mathrm{He}-30 \mathrm{~cm} / \mathrm{s}$ & split $1: 71$ & $\begin{array}{l}12 \mathrm{~min} \text { a } 35^{\circ} \mathrm{C} \text {, then } \\
8^{\circ} \mathrm{C} / \mathrm{min} \text { to } 175^{\circ} \mathrm{C}\end{array}$ \\
\hline $4^{\circ} \mathrm{C}$ & SRC-I WS $(a)$ & 30 & $M S E-52$ & $\mathrm{He}-50 \mathrm{~cm} / \mathrm{s}$ & splitless $(c)$ & $\begin{array}{l}2 \min 040^{\circ} \mathrm{C} \text {, then } 2^{\circ} \mathrm{C} / \mathrm{min} \\
\text { to } 120^{\circ} \mathrm{C} \text {; and } 15^{\circ} \mathrm{C} / \mathrm{min} \text { to } \\
250^{\circ} \mathrm{C}\end{array}$ \\
\hline $4^{\circ} \mathrm{C}$ & SRC-I PS $(a)$ & 15 & $M S E-52$ & $\mathrm{H}_{2}-100 \mathrm{~cm} / \mathrm{s}$ & splitless $(c)$ & $\begin{array}{l}2 \min { }^{\circ} 50^{\circ} \mathrm{C} \text {, then } 2^{\circ} \mathrm{C} / \mathrm{min} \\
\text { to } 200^{\circ} \mathrm{C}\end{array}$ \\
\hline$-20^{\circ} \mathrm{C}, \quad 20^{\circ} \mathrm{C}, 60^{\circ} \mathrm{C}$ & SRC-II FOB (b) & 30 & M SE-52 & $\mathrm{He}-50 \mathrm{~cm} / \mathrm{s}$ & splitless $(c)$ & $\begin{array}{l}2 \min d 70^{\circ} \mathrm{C} \text {, then } 2^{\circ} \mathrm{C} / \mathrm{min} \\
\text { to } 200^{\circ} \mathrm{C}\end{array}$ \\
\hline
\end{tabular}

(a) Chromatographed on an Hewlett-Packard 5880A gas chromatoyraph.

(b) Chromatographed on an Hewlett-Packard 5710 gas chromatograph.

(c) An autosampler was used for injection at time $=2$ years, manual injection was used in all other cases. 
TABLE 2.6. Sample Data Table From an SRC-II Fuel $0 i 1$ Blend Samp.le Stored in the Repository at $4^{\circ} \mathrm{C}$

\begin{tabular}{|c|c|c|}
\hline Retention Time & Amount (a) & $\begin{array}{c}\text { Standard Deviation } \\
\text { of Amount } \\
\text { (6 Runs) }\end{array}$ \\
\hline 11.35 & 77.1 & 6.1 \\
\hline 11.49 & 13.0 & 1.1 \\
\hline 13.85 & 20.9 & 2.0 \\
\hline 15.70 & 46.4 & 3.5 \\
\hline 17.21 & 78.2 & 8.1 \\
\hline 20.57 & 17.0 & 1.3 \\
\hline 21.28 & 30.2 & 2.1 \\
\hline 21.87 & 23.4 & 1.4 \\
\hline 22.04 & 58.0 & 4.6 \\
\hline 23.23 & 21.5 & 0.73 \\
\hline 23.43 & 132.8 & 8.5 \\
\hline 25.72 & 16.4 & 1.0 \\
\hline 29.11 & 42.6 & 2.2 \\
\hline 29.60 & 35.4 & 1.4 \\
\hline 30.95 & 117.0 & 4.9 \\
\hline 31.95 & 27.9 & 1.0 \\
\hline 33.07 & 20.7 & 0.81 \\
\hline 34.62 & 19.7 & 1.6 \\
\hline 35.40 & 31.0 & 1.1 \\
\hline 36.30 & 14.9 & 1.5 \\
\hline 36.68 & 37.5 & 1.2 \\
\hline 37.47 & 40.3 & 1.1 \\
\hline 38.14 & 34.0 & 1.2 \\
\hline 38.38 & 64.7 & 1.0 \\
\hline 42.46 & 18.3 & 0.78 \\
\hline 42.92 & 18.9 & 0.43 \\
\hline 44.41 & 15.5 & 0.50 \\
\hline 48.79 & 14.0 & 1.0 \\
\hline 49.49 & 10.8 & 0.97 \\
\hline 50.01 & 11.6 & 0.57 \\
\hline 59.54 & 36.7 & 1.5 \\
\hline 75.60 & 11.8 & 0.88 \\
\hline
\end{tabular}

(a) Percent of internal standard based on $2.50 \mathrm{mg} / \mathrm{mL} C_{19}$ ISTD. 


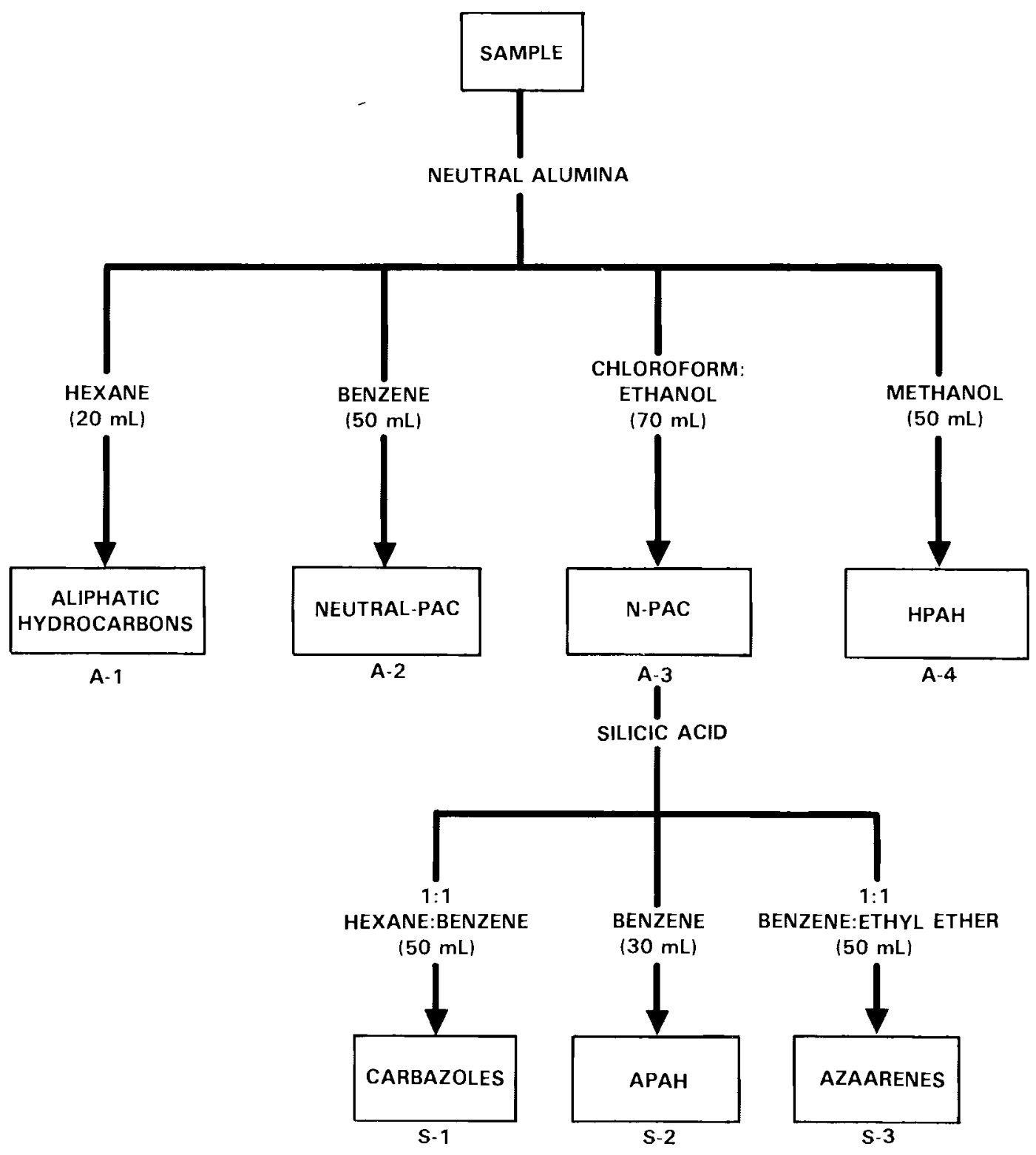

FIGURE 2.2. Chemical Class Fractionation Using Alumina and Silicic Acid Column Chromatoyraphy

hydrocarbons were eluted with hexane (fraction A-1), polycyclic aromatic hydrocarbons (PAH) were eluted with benzene (fraction $A-2)$, nitrogen-containing polycyclic aromatic compounds (N-PAC) were eluted with 99:1 chloroform: ethanol (fraction A-3), and hydroxylated PAH (HPAH) were eluted with methanol. To further fractionate the nitrogen-containing PAC for the analysis of mutagenically 
active aromatic amines, the A-3 fraction was eluted through a silicic acid column. The carbazoles were eluted with 1:1 hexane:benzene (fraction S-1), an amino-PAH rich fraction was eluted with benzene (fraction S-2), and the azaarenes were eluted with 1:1 benzene:ethyl ether. The weight percent of the sample eluting in each of the seven fractions monitored the chemical composition of classes of organic compounds found in the FOB under the harshest storage conditions versus the mildest storage conditions $\left(-20^{\circ} \mathrm{C}\right)$.

Individual components in the $A-2, A-3$, and $S-2$ fractions were quantitated through high resolution GC using SE-54 bonded phase fused silica columns to monitor the more trace level constituents of the FOB under the harshest versus mildest storage conditions. These fractions were chosen since they contain the greatest quantities of mutagenic or carcinogenic constituents (13-16). Response factors were calculated for standards at seven different concentrations ranging over two orders of magnitude. If a standard was not available, a response factor for a standard of similar retention time and chemical class was used. Samples were analyzed at three different concentration levels, i.e., $10 \mathrm{mg} / \mathrm{mL}, 5.0 \mathrm{mg} / \mathrm{mL}$, and $2.5 \mathrm{mg} / \mathrm{mL}$ with 2-chloroanthracene added as an internal standard at a final concentration of $50 \mathrm{ng} / \mu \mathrm{L}$. The amino-PAH were quantitated through the use of an electron capture detector after dervatization with pentafluoropropionic anhydride (PFP) to the corresponding fluoroamides (17).

\subsubsection{Direct Probe Mass Spectrometry}

Several samples of SRC-II heavy distillate were taken from varying depths of the Teflon-lined stainless steel container (60 L capacity) used to store the sample in the repository. The container was pressurized with nitrogen and material was forced out from specific depths with the use of a Teflon sampling hose. Six samples were obtained from the $29 \mathrm{~cm}$ depth of HD sample in the repository. The first sampling depth was two $\mathrm{cm}$ from the top of the undisturbed container, the second was five $\mathrm{cm}$ from the bottom of the undisturbed container, and the third was from the bottom of the undisturbed container. The sample from the bottom of the container was noted to contain both light and heavy sludges, which formed the fourth and fifth samples when separated. The sixth sample of SRC-II HD was taken after the container was mixed continuously for $18 \mathrm{~h}$ at room temperature. 
Five $\mu \mathrm{L}$ of each of these six samples were analyzed by low-voltage probe mass spectrometry on a VG-ZAB-1F mass spectrometer at $10 \mathrm{eV}$ with a $6 \mathrm{kV}$ accelerating voltage. The probe was brought from ambient to $250^{\circ} \mathrm{C}$ while scanning a inass range of 60-500 amu. The dynamic mass resolution was 1:2000. The source temperature was $250^{\circ} \mathrm{C}$. Data were acquired and processed by a VG 2035 data system.

\subsubsection{Microbial Mutagenicity}

Microbial mutagenicity was measured against $\underline{S}$. typhimurium TA98 after metabolic activation with S-9 rat liver homogenate (18). The two SRC-II naphthas, four middle distillates, three heavy distillates, and four fuel oil blends, along with the SRC-I light oil, wash solvent, and two process solvents which were stored in the repository, under a nitrogen atmosphere, in the dark, were monitored for changes in biological activity after four years. A sample of the control and those under conditions 1 through 6 from Figure $2.1\left(-20^{\circ} \mathrm{C}\right.$ and $20^{\circ} \mathrm{C}$ studies with additional parameters of cover atmosphere, dilution, light, and dark) were monitored for microbial mutagenicity after one year and after three years for a sample of FOB diluted in methylene chloride and stored at $-20^{\circ} \mathrm{C}$. Samples of SRC-II FOB exposed to 32 weeks at $60^{\circ} \mathrm{C}$ and 6 and 26 weeks at $100^{\circ} \mathrm{C}$ under an air atmosphere in the dark were also monitored for changes in microbial mutagenicity. In addition, the microbial mutagenicity of the samples of SRC-II HD from varying depths in the storaye container were compared with the homogenized sample.

\section{3 .5 Summary}

Table 2.7 contains a summary of the types of analyses that were performed on the samples stored under the various conditions of the stability studies. Results of these analyses are given in the Results and Discussion Section, page 3.1 .

\subsection{STATISTICAL ANALYSIS}

Each peak concentration relative to the internal standard was identified with a descriptive vector of values. Variables defined by these values included the SRC material studied ( $N$, LO, MD, FOB, etc.), the storage 
TABLE 2.7. Summary of Analyses of Stability Study Samples

\begin{tabular}{|c|c|c|c|c|c|}
\hline Samples & $\underline{\mathrm{GC}}$ & $\mathrm{GC} / \mathrm{MS}$ & Bioassay & $\begin{array}{c}\text { Chemical } \\
\text { Fractionation/ } \\
\text { Quantitation } \\
\end{array}$ & $\begin{array}{l}\text { Direct } \\
\text { Probe }\end{array}$ \\
\hline SRC-I I N, $4^{\circ} \mathrm{C}$ & $x$ & $x$ & $x$ & & \\
\hline SRC-I I MD, $4^{\circ} \mathrm{C}$ & $x$ & $x$ & $x$ & & \\
\hline SRC-I I HD, $4^{\circ} \mathrm{C}$ & $x$ & $x$ & $x$ & & $x$ \\
\hline SRC-II FOB, $4^{\circ} \mathrm{C}$ & $x$ & $x$ & $x$ & & \\
\hline SRC-I LO, $4^{\circ} \mathrm{C}$ & $x$ & $x$ & $x$ & & \\
\hline SRC-I WS, $4^{\circ} \mathrm{C}$ & $x$ & $x$ & $x$ & & \\
\hline SRC-I PS, $4^{\circ} \mathrm{C}$ & $x$ & $x$ & $x$ & & \\
\hline $\begin{array}{l}\text { SRC-II FOB, }-20^{\circ} \mathrm{C} \\
\text { (control) }\end{array}$ & $x$ & $x$ & $x$ & $x$ & \\
\hline $\begin{array}{l}\text { SRC-I I FOB, }-200^{\circ} \mathrm{C} \\
(\text { condition } 1)(\mathrm{a})\end{array}$ & $x$ & & $x$ & & \\
\hline $\begin{array}{l}\text { SRC-I I FOB, } 22^{\circ} \mathrm{C} \\
(\text { condition } 2)^{(a)}\end{array}$ & $x$ & & $x$ & & \\
\hline $\begin{array}{l}\text { SRC-I I FOB, } 22^{\circ} \mathrm{C} \\
(\text { condition } 3)^{(a)}\end{array}$ & $x$ & $x$ & $x$ & & \\
\hline $\begin{array}{l}\text { SRC-II FOB, } 20^{\circ} \mathrm{C} \\
\text { (condition } 4)^{(a)}\end{array}$ & $x$ & & $x$ & & \\
\hline $\begin{array}{l}\text { SRC-I I FOB, } 20^{\circ} \mathrm{C} \\
\text { (condition } 5)^{(a)}\end{array}$ & $x$ & & $x$ & & \\
\hline $\begin{array}{l}\text { SRC-I I FOB, } 29^{\circ} \mathrm{C} \\
\left.\text { (condition } 6)^{2}\right)\end{array}$ & $x$ & & $x$ & & \\
\hline SRC-II FOB, $60^{\circ} \mathrm{C}$ & $x$ & $x$ & $x$ & & \\
\hline SRC-II FOB, $100^{\circ} \mathrm{C}$ & $x$ & & $x$ & $x$ & \\
\hline
\end{tabular}

(a) Conditions refer to those given in Figure 2.1. 
conditions, the time of analysis, the replicate, the vial after dilution, the chromatographic run, and peak number. With each relative concentration characterized by a unique vector of values, the data in each analysis set were described by summary statistics and further explored using ARTHUR (19), a collection of pattern recognition routines; PNL-enhanced MINITAB (20), a linear algebra/database management tool; and RUMMAGE (21), an analysis of variance statistical packaye.

Through interactive color yraphics, relative concentrations versus peak number were displayed on a high resolution screen. These graphs were enhanced by the use of background indicator variables such as time or replicate to determine the color of each plotted point. Offset plotting where the data at one treatment level was plotted near the data from another level was also utilized. In this manner, a summary chromatogram was created. This use of yraphics allowed for an efficient determination of ylobal characteristics or patterns in an analysis set as well as specific data characteristics such as the identification of outliers and other data anomalies.

Several characteristics comnon to all the data sets were identified. The displays and summary statistics revealed that the variation increased with increase in the mean relative concentration. Under this circumstance, analysis of variance (ANOVA) techniques are not optimal. To increase the power of the analysis, the natural logarithm transform for each relative concentration was calculated; the transformed data set replaced the original in further analysis. The transform reduced the dependent relationship between the mean and variance in the relative concentration data distribution. The log transformed data were then assumed normally distributed and analyzed through ANOVA techniques (22) suitable for unbalanced designs (21).

ANOVA is a statistical technique whereby measures of variation for each factor are calculated and then compared to a measure of variation assigned to the pure experimental error. The comparison statistic is called an F statistic:

$$
F=\frac{M S(\text { factor })}{M S(\text { error })}
$$


Under assumption of no factor effect, the ratio would equal 1 because any variation measured for the factor would be pure experimental error. The further this ratio deviates from 1 , the stronger the effect of the factor on the relative concentrations. For ANOVA, it is assumed that the numerator and denominator of the $F$ statistic are estimated independently. A relative error of $20 \%$ or the estimate of the pure error (which ever was larger) was used for the MS (error) value $(0.04$ for $20 \%$ error). The $20 \%$ error determination is considered a true experimental error determined in experiments presented in the Results and Discussion Section page 3.14. Peak-to-peak statistical analysis was used so that specific compositional changes could be monitored. General compositional trends can be observed from the specific peak changes in the samples. The relative concentrations of the $4^{\circ} \mathrm{C}$ data set were adjusted for variation in the concentration of the internal standard from the initial measurement to the after-storage measurements. A multiplication factor, the ratio of the ISTD concentration in the initial analysis to the ISTD concentration in the analysis after storage, was used to correct for these differences induced by the experimental procedure. For the $60^{\circ} \mathrm{C}$ and $100^{\circ} \mathrm{C}$ data sets, a reference peak was chosen for normalization of dilution over the long-running experiments. 


\subsection{RESULTS AND DISCUSSION}

\subsection{HIGH RESOLUTION GAS CHROMATOGRAPHY}

The complete list of individual compounds monitored in all the stability studies is given in Table 3.1. The numbers refer to peaks designated in the chromatograms shown in Figures 3.1 through 3.10, which are representative gas chromatoyrams of the SRC-II naphthas, SRC-I light oil, SRC-II middle distillates, SRC-II fuel oil blends, SRC-I wash solvent, SRC-II heavy distillates, and SRC-I process solvents. Numbered peaks, identified in Table 3.1, are those inonitored in the sample while being stored in the repository at $4{ }^{\circ} \mathrm{C}$, in the dark, and under a nitrogen atmosphere. The internal standard added to each of the samples is labeled in the chromatograms. The components were identified by GC/MS. It should be noted that the identifications given in Table 3.1 are for major components found in particular peaks and that minor components can co-elute with these peaks.

Representative gas chromatoyrams from the accelerated stability studies using an SRC-II FOB are presented in Figures 3.8 through 3.10 . Figure 3.8 is an example of the sample kept under the control conditions $\left(-20^{\circ} \mathrm{C}\right.$, dark, under nitrogen atmosphere) and shows the peaks monitored in the $-20^{\circ} \mathrm{C}$ and $20^{\circ} \mathrm{C}$ studies. Figures 3.9 and 3.10 show the peaks monitored in the $60^{\circ} \mathrm{C}$ and $100^{\circ} \mathrm{C}$ studies, respectively, through the example of the time=0 samples. Identification of the peaks is also given in Table 3.1. For Figures 3.1 through 3.10, all peaks labeled with the same number represent the same compound. This allows the intercomparison of data for a specific compound between different SRC materials.

Appendix $I$ is a compendium of the data gathered during the accelerated stability studies as well as the data for the repository samples. The mean values of all GC runs calculating the individual peak heights or areas, normalized to an internal standard, for the seventeen materials stored in the repository at $4^{\circ} \mathrm{C}$, in the dark, and under a nitrogen atmosphere are presented in Tables 7.1-7.17 of Appendix I. Tables 7.18 and 7.19 in Appendix I contain two sets of mean values of GC data collected for the $-20^{\circ} \mathrm{C}$ and $20^{\circ} \mathrm{C}$ study. 
TABLE 3.1. Compounds Monitored in the Stability Studies

\begin{tabular}{|c|c|c|c|}
\hline Peak No. (a) & Compound (b) & Peak No. (a) & Compound (b) \\
\hline 1 & $C_{1}$-Butane & 32 & Indan \\
\hline 2 & Pentane & 33 & o-Cresol \\
\hline 3 & Pentene & 34 & $\bar{C}_{4}$-Benzene \\
\hline 4 & $C_{2}$-Butane & 35 & m- \& $\mathrm{p}$-Cresol, $\mathrm{C}_{1}$-Indan \\
\hline 5 & $C_{1}$-Pentane & 36 & $\bar{n}$-Undecane \\
\hline 6 & n-Hexane & 37 & $\mathrm{C}_{2}$-Phenol \\
\hline 7 & Hexene & 38 & $C_{1}$-Indan \\
\hline 8 & Benzene & 39 & $c_{1}$-Indan \\
\hline 9 & Cyclohexane & 40 & $\mathrm{C}_{2}$-Phenol \\
\hline 10 & Cyclohexene & 41 & Tetralin \\
\hline 11 & $\mathrm{C}_{7} \mathrm{H}_{16}$ & 42 & $c_{2}$-Phenol \\
\hline 12 & Heptene & 43 & Naphthalene \\
\hline 13 & n-Heptane & 44 & $\mathrm{C}_{2}$-Phenol \\
\hline 14 & $c_{1}-C_{y c l}$ ohexane & 45 & $\mathrm{C}_{3}$-Phenol \\
\hline 15 & $\mathrm{C}_{2}$-Pentene & 46 & $C_{1}$-Dihydronaphthalene \\
\hline 16 & Toluene & 47 & $\mathrm{C}_{1}$-Tetralin \\
\hline 17 & $\mathrm{C}_{8} \mathrm{H}_{18}$ & 48 & $c_{1}$-Tetralin \\
\hline 18 & $\mathrm{C}_{8} \mathrm{H}_{18}$ & 49 & $\mathrm{C}_{1}$-Tetralin, $\mathrm{C}_{3}$-Phenol \\
\hline 19 & $C_{2}$-Cyclohexane & 50 & $C_{1}$-Dihydronaphthalene \\
\hline 20 & n-Octane & 51 & $\mathrm{C}_{3}$-Phenol \\
\hline 21 & $\mathrm{C}_{3}$-Cyclohexane & 52 & $c_{3}$-Phenol \\
\hline 22 & o-xylene & 53 & $\mathrm{C}_{2}$-Indan \\
\hline 23 & m-Xylene & 54 & $\mathrm{C}_{2}$-Indan \\
\hline 24 & $\mathrm{p}$-Xylene & 55 & $c_{2}$-Indan \\
\hline 25 & n-Nonane & 56 & 2-Methyl naphthalene \\
\hline 26 & $\mathrm{C}_{4}$-Cyclohexane & 57 & 1-Methylnaphthalene \\
\hline 27 & $\mathrm{C}_{3}$-Benzene & 58 & $c_{3}$-Indan \\
\hline 28 & Phenol & 59 & $\mathrm{C}_{3}$-Indan \\
\hline 29 & $C_{3}$-Benzene & 60 & Indanol \\
\hline 30 & $\mathrm{C}_{3}$-Benzene & 61 & $\mathrm{C}_{2}$-Tetralin \\
\hline 31 & n-Decane & & \\
\hline
\end{tabular}


TABLE 3.1. (contd)

\begin{tabular}{|c|c|c|c|}
\hline Peak No. (a) & Compound $(\mathrm{b})$ & Peak No. (a) & Compound (b) \\
\hline 62 & $\mathrm{C}_{4}$-Phenol & 82 & $\mathrm{C}_{1}$-Fluorene \\
\hline 63 & $C_{4}$-Phenol, $C_{3}$-Indan & 83 & Dibenzothiophene \\
\hline 64 & Biphenyl & 84 & Tetrahydrophenanthrene \\
\hline 65 & 2-Ethylnaphthalene & 85 & Phenanthrene \\
\hline 66 & 2,6-Dimethy lnaphthalene & 86 & $C_{2}$-Fluorene \\
\hline 67 & $\mathrm{C}_{2}$-Naphthalene & 87 & $C_{2}-F l u o r e n e$ \\
\hline \multirow[t]{2}{*}{68} & $\mathrm{C}_{2}$-Naphthalene, & 88 & $C_{2}$-Fluorene \\
\hline & Diphenylether & 89 & Carbazole \\
\hline 69 & Acenaphthene & 90 & 3-Methyl phenanthrene \\
\hline 70 & $C_{3}$-Naphthalene & 91 & 2-Methylphenanthrene \\
\hline 71 & $C_{3}$-Naphthalene & 92 & 1-Methylphenanthrene \\
\hline 72 & Dibenzofuran & 93 & $C_{2}-X$ anthene \\
\hline 73 & Isopropylnaphthalene & 94 & Phenylnaphthalene \\
\hline 74 & Fluorene & 95 & $\mathrm{C}_{2}$-Phenanthrene \\
\hline \multirow[t]{2}{*}{75} & $C_{1}$-Acenaphthene, & 96 & Fluoranthene \\
\hline & $C_{2}$-Bipheny 1 & 97 & Pyrene \\
\hline 76 & $\mathrm{C}_{4}$-Naphthalene & 98 & Dihydropyrene \\
\hline 77 & $\mathrm{C}_{4}$-Naphthalene & 99 & Benzo[b]fluorene, \\
\hline 78 & Xanthene & & 2- or 4-Methylpyrene \\
\hline 79 & $C_{1}-$ Fluorene & 100 & $C_{1}$-Benzo $[b]$ fluorene, \\
\hline 80 & $C_{1}-$ Fluorene & & $C_{2}$-Pyrene \\
\hline 81 & $C_{1}-F l$ uorene & 101 & $C_{1}$-Chrysene \\
\hline
\end{tabular}

(a) Numbers refer to peaks in Figures 3.1-3.10.

(b) Compounds tentatively identified by GC/MS.

Tables 7.20 and 7.21 in Appendix I contain the mean values of GC data collected during the $60^{\circ} \mathrm{C}$ and $100^{\circ} \mathrm{C}$ accelerated studies, respectively. Table 7.22 in Appendix I contains the mean values of GC data collected for an FOB sample diluted in methylene chloride and stored at $-20^{\circ} \mathrm{C}$ for three years. 


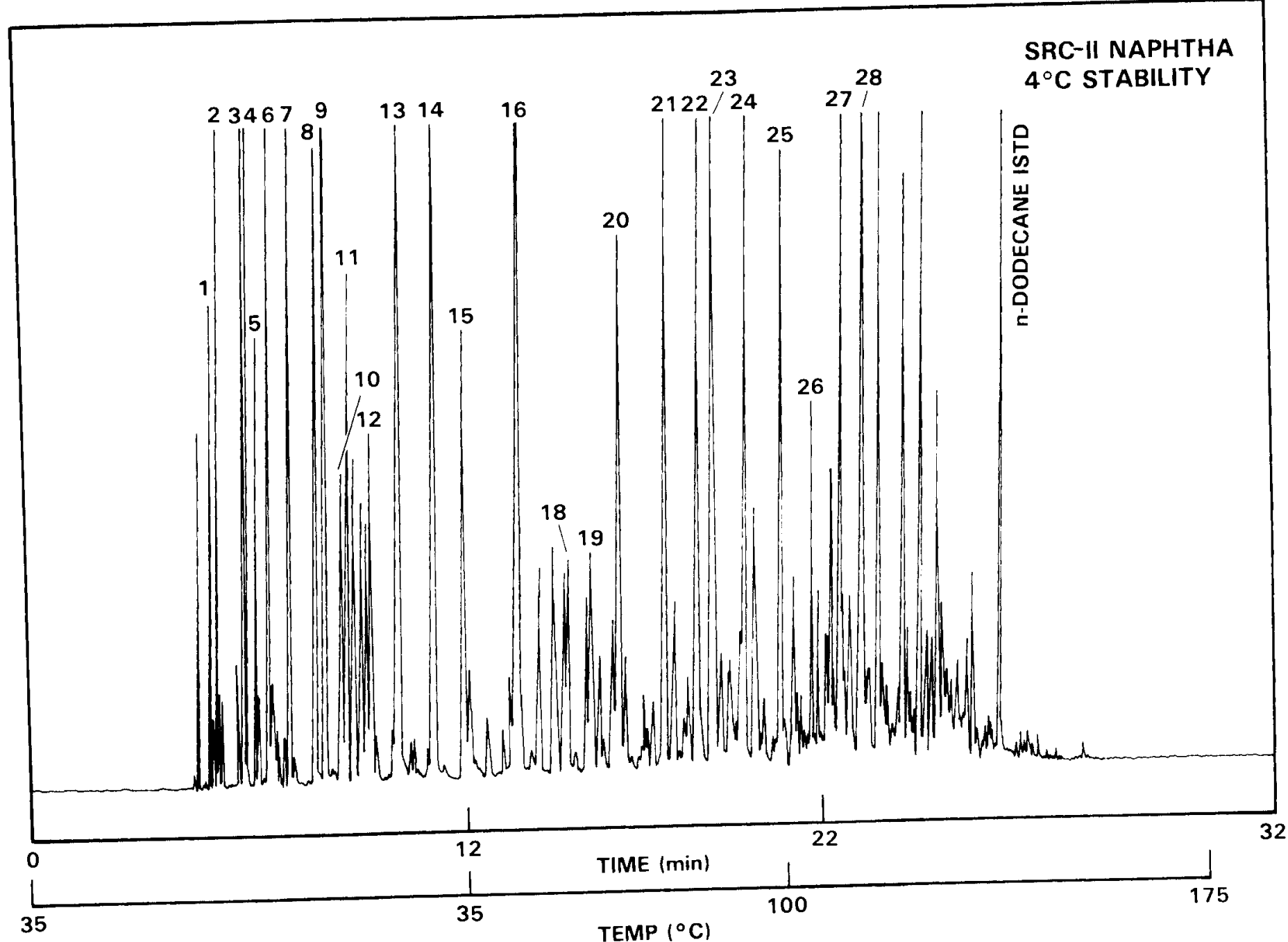

High Resolution Gas Chromatogram of an SRC-II Naphtha. Conditions: $90 \mathrm{M} \times 0.28 \mathrm{~mm}$ i. i.d. Glass Capillary Column Coated $35^{\circ} \mathrm{C}$ then Temperature Programmed to $175^{\circ} \mathrm{C}$ at Carrier Gas; $12 \mathrm{~min}$ Isothermal at $35^{\circ} \mathrm{C}$ then Temperature 


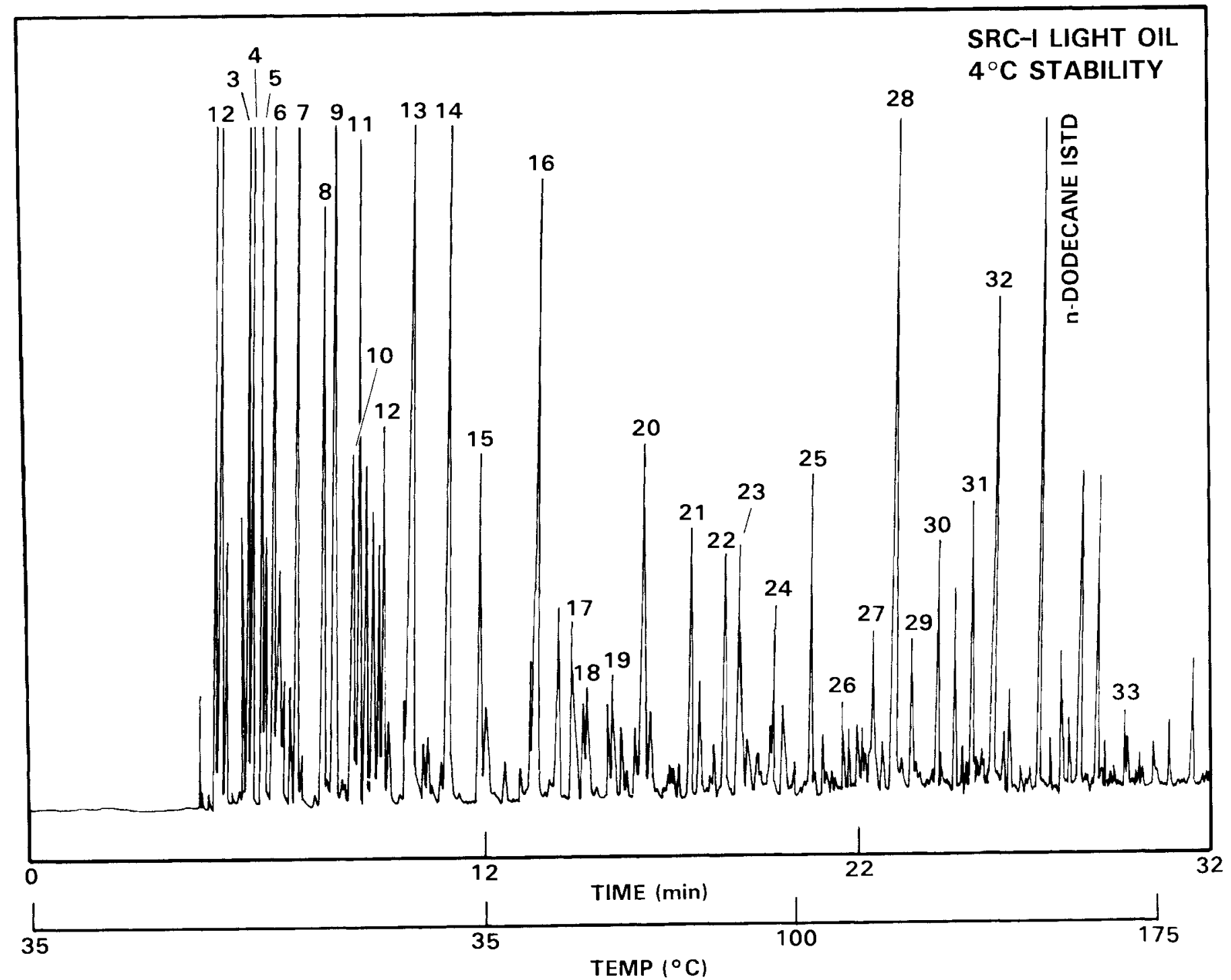

FIGURE 3.2. High Resolution Gas Chromatoyram of an SRC-I Light 0il. Conditions: Same as in Figure 3.1. Numbers Refer to Identifications Given in Table 3.1. 


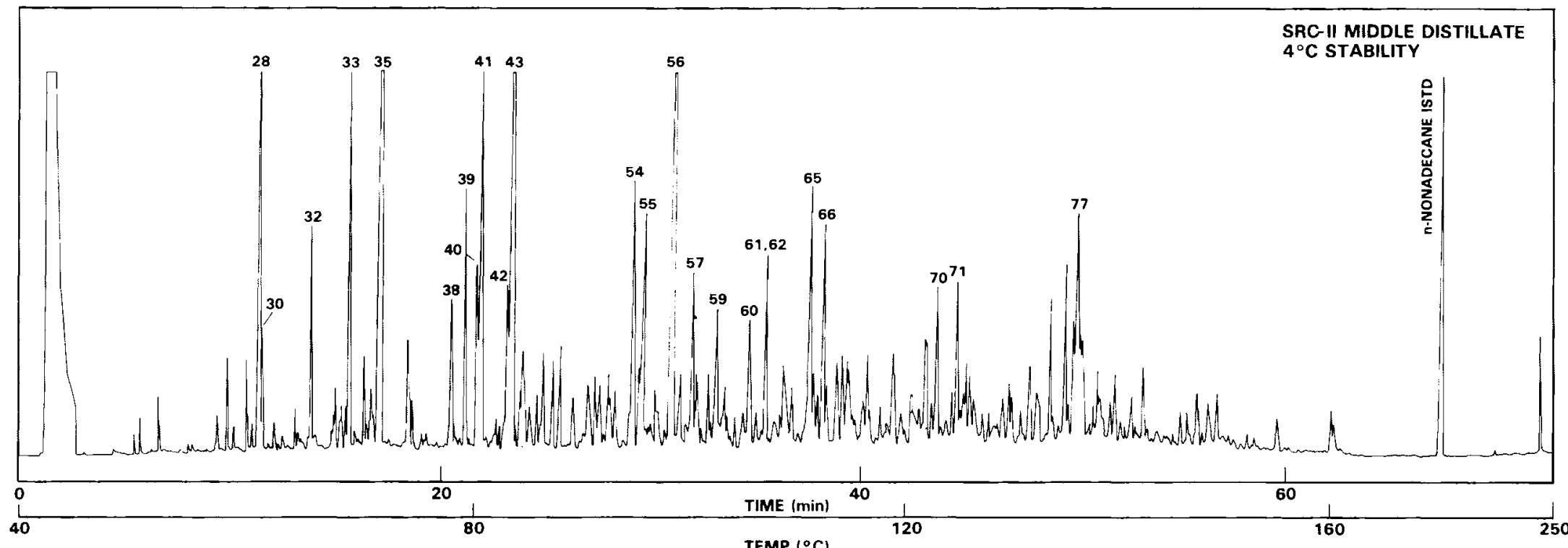

TEMP $\left({ }^{\circ} \mathrm{C}\right)$

FIGURE 3.3. High Resolution Gas Chromatogram of an SRC-II Middle Distillate. Conditions: $30 \mathrm{M} \times 0.25 \mathrm{~mm}$ i.d. Fused Silica Capillary Column Coated with SE-52; Splitless Injection; Helium Carrier Gas at $50 \mathrm{~cm} / \mathrm{s}$ Linear Velocity; $2 \mathrm{~min}$ Isothermal at $40^{\circ} \mathrm{C}$ then Temperature Programmed to $170^{\circ} \mathrm{C}$ at $2^{\circ} \mathrm{C} / \mathrm{min}$ and to $250^{\circ} \mathrm{C}$ at $15^{\circ} \mathrm{C} / \mathrm{min}$. Numbers Refer to Identifications Given in Table 3.1 . 


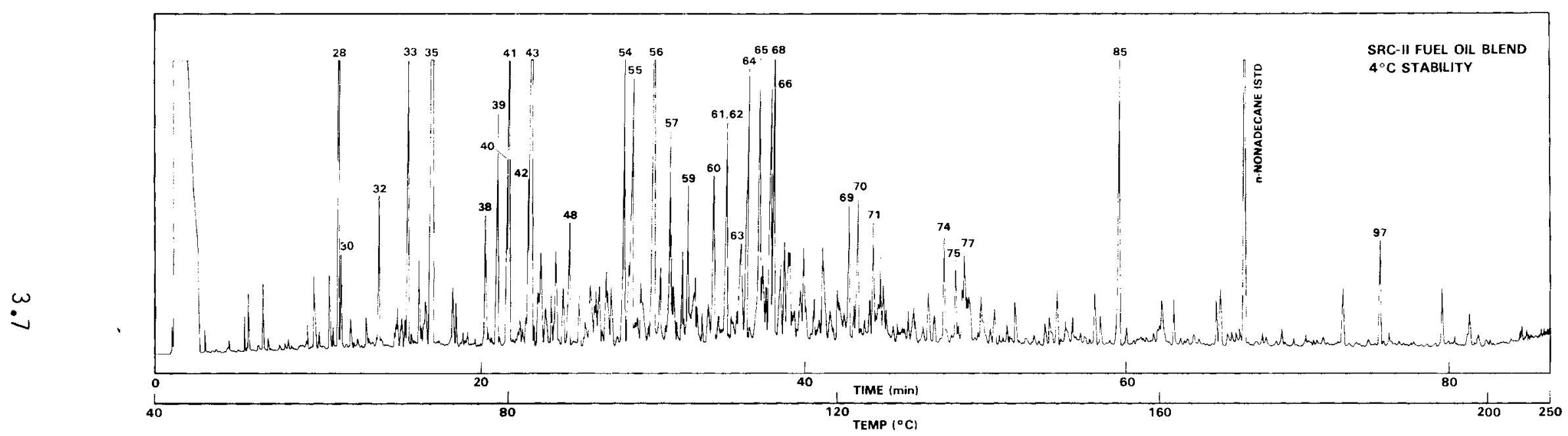

FIGURE 3.4. High Resolution Gas Chromatogram of an SRC-II Fuel 0il Blend. Conditions: Same as in Figure 3.3 , Except Temperature Programmed to $200^{\circ} \mathrm{C}$ at $2^{\circ} \mathrm{C} / \mathrm{min}$. Numbers Refer to Identifications Given in Table 3.1 . 


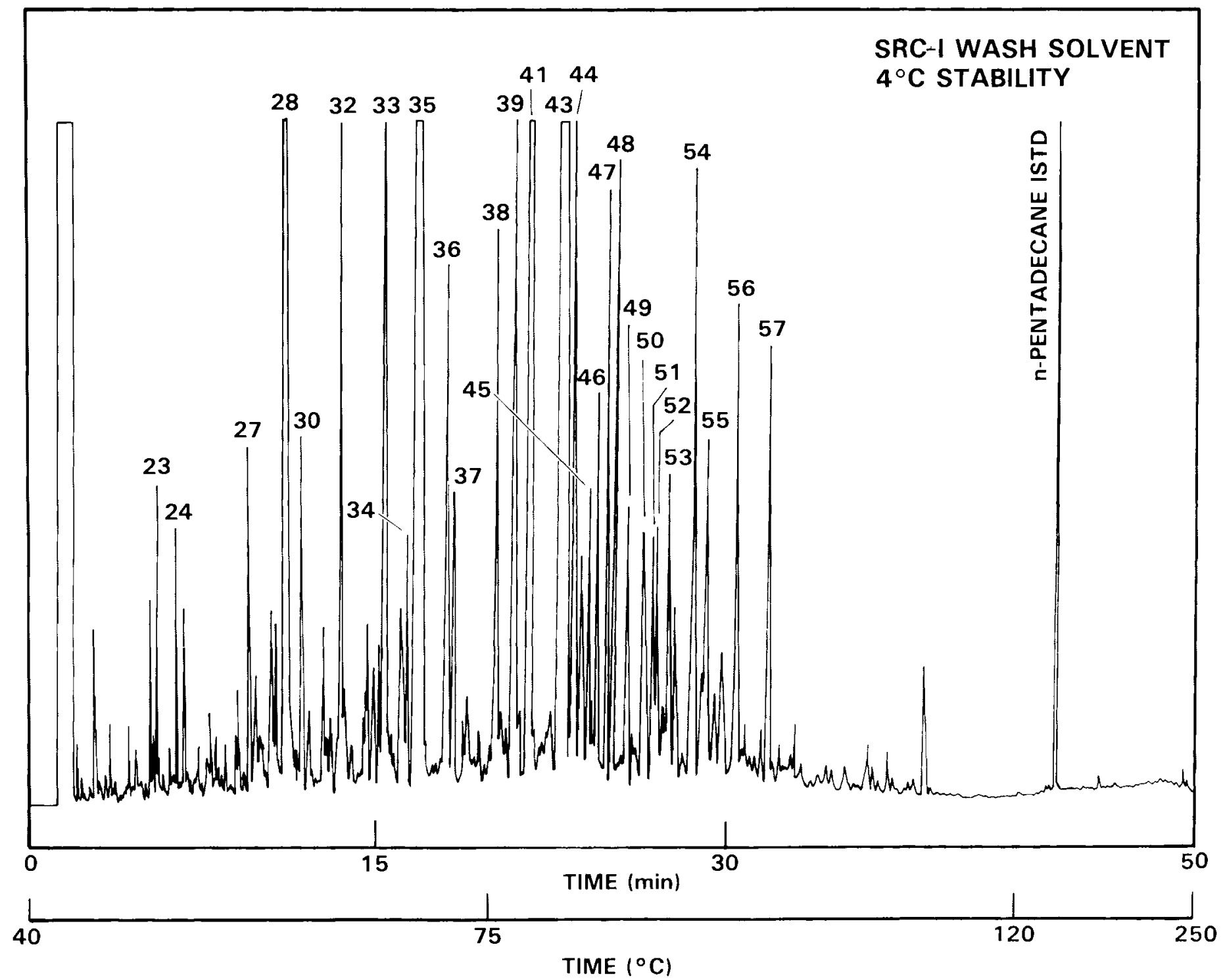

FIGURE 3.5. High Resolution Gas Chromatogram of an SRC-I Wash Solvent. Conditions: Same as in Figure 3.3 , Except Temperature Programmed to $120^{\circ} \mathrm{C}$ at $2^{\circ} \mathrm{C} / \mathrm{min}$. Numbers Refer to Identifications Given in Table 3.1 . 


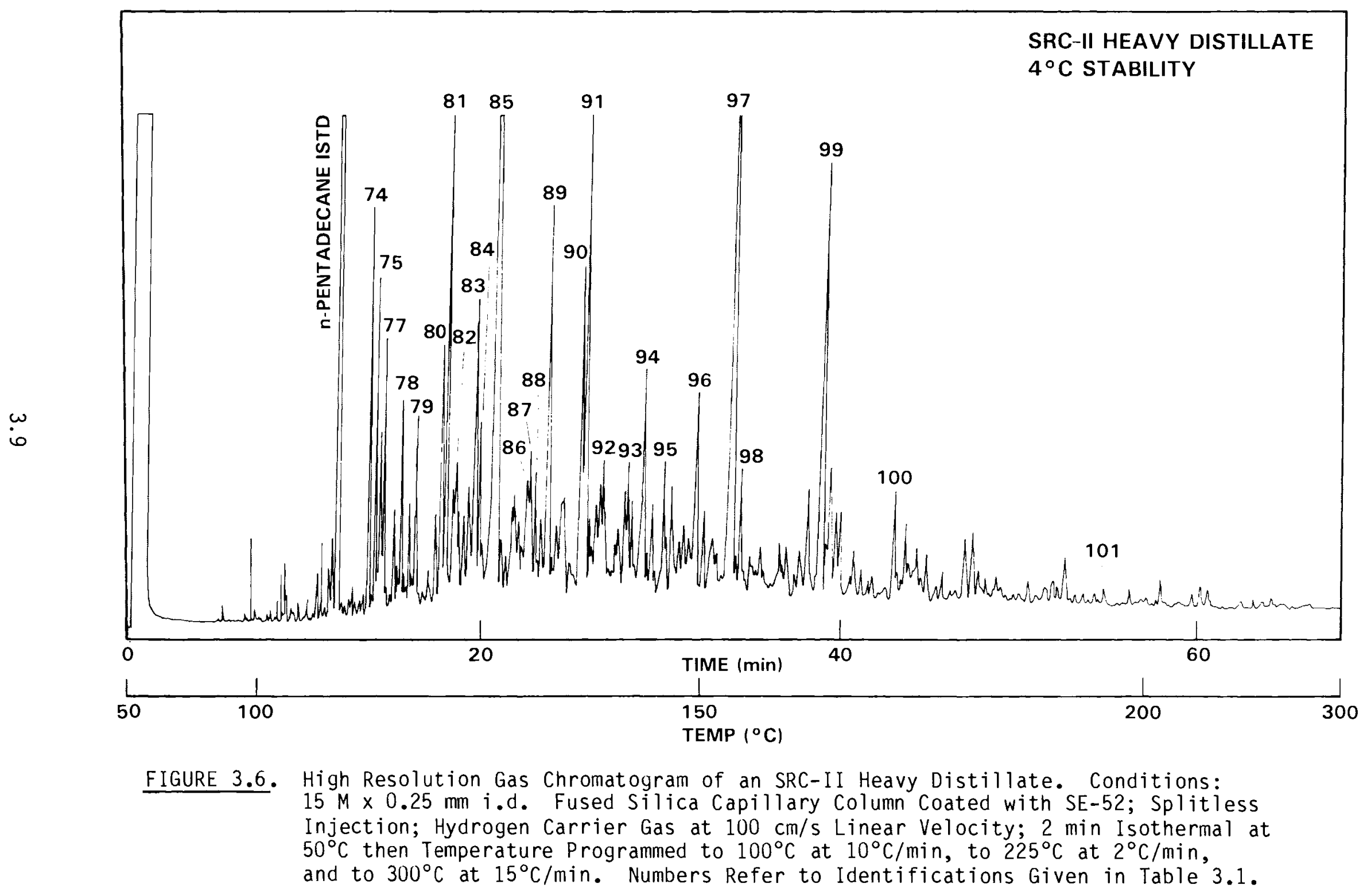




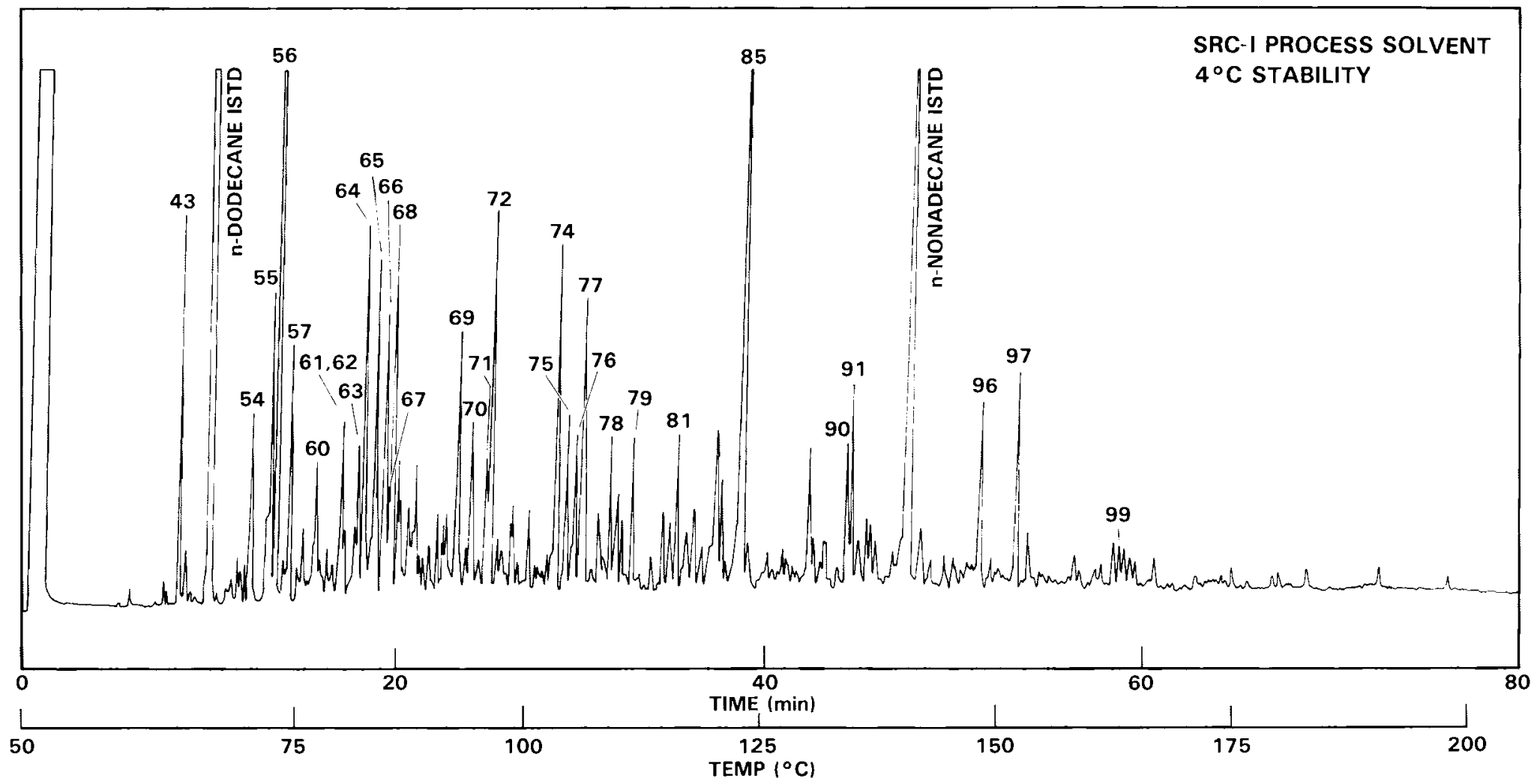

FIGURE 3.7. High Resolution Gas Chromatogram of an SRC-I Process Solvent. Conditions: Same as in Figure 3.6 , Except Temperature Programmed from $50^{\circ} \mathrm{C}$ to $200^{\circ} \mathrm{C}$ at $2^{\circ} \mathrm{C} / \mathrm{min}$ Only. Numbers Refer to Identifications Given in Table 3.1 . 


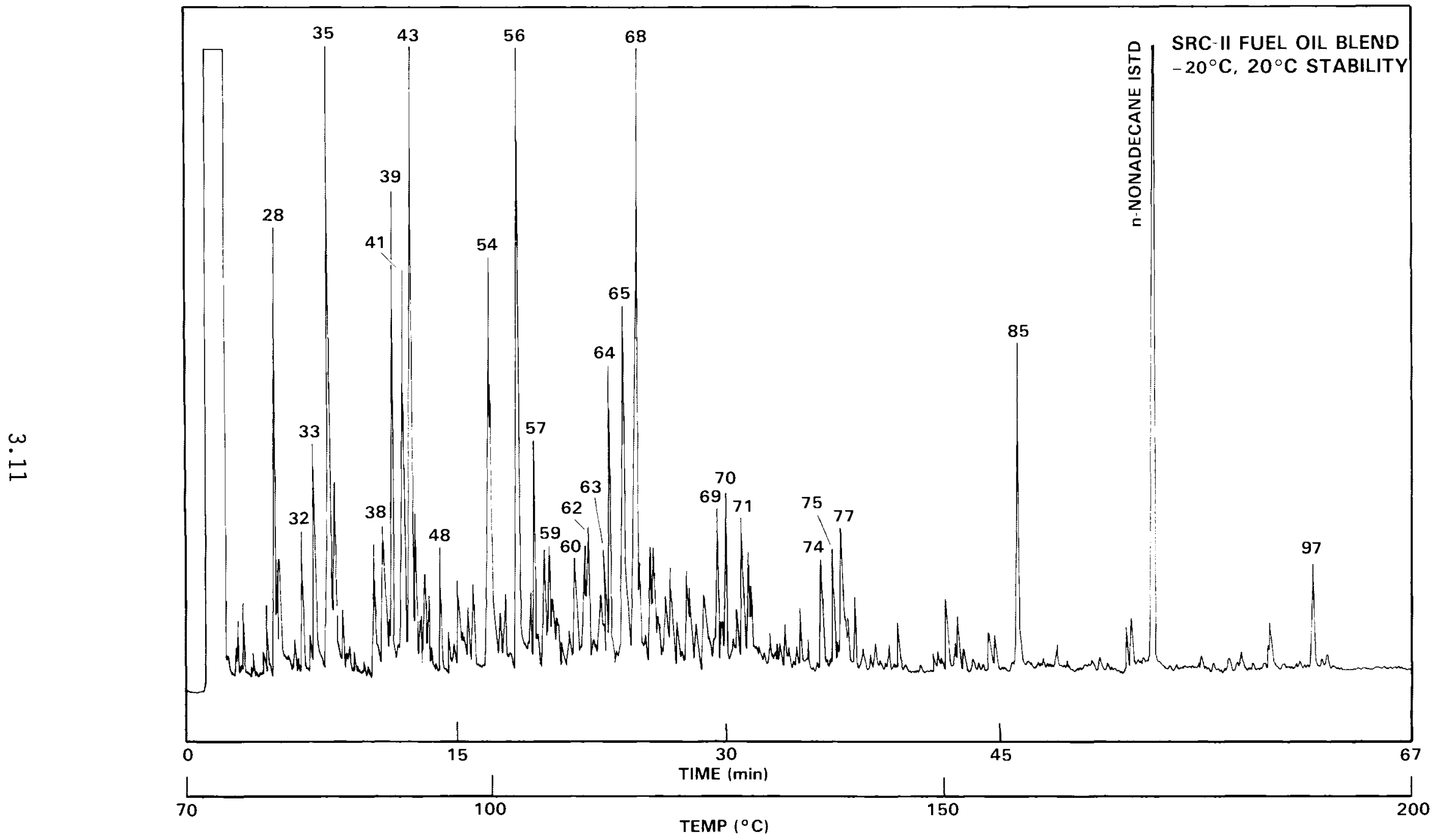

FIGURE 3.8. High Resolution Gas Chronatogram of the Control Sample from the $-20^{\circ} \mathrm{C}$ and $20^{\circ} \mathrm{C}$ Studies of an SRC-II Fuel 0il Blend. Conditions: $30 \mathrm{M} \times 0.25 \mathrm{~mm}$ i.d. Fused Silica Capillary Column, Splitless Injection, Helium Carrier Gas at $50 \mathrm{~cm} / \mathrm{s}$ Linear Velocity, $2 \mathrm{~min}$ I sothermal at $70^{\circ} \mathrm{C}$ then Temperature Programmed to $200^{\circ} \mathrm{C}$ at $2{ }^{\circ} \mathrm{C} / \mathrm{min}$. Numbers Refer to Identifications Given in Table 3.1 . 


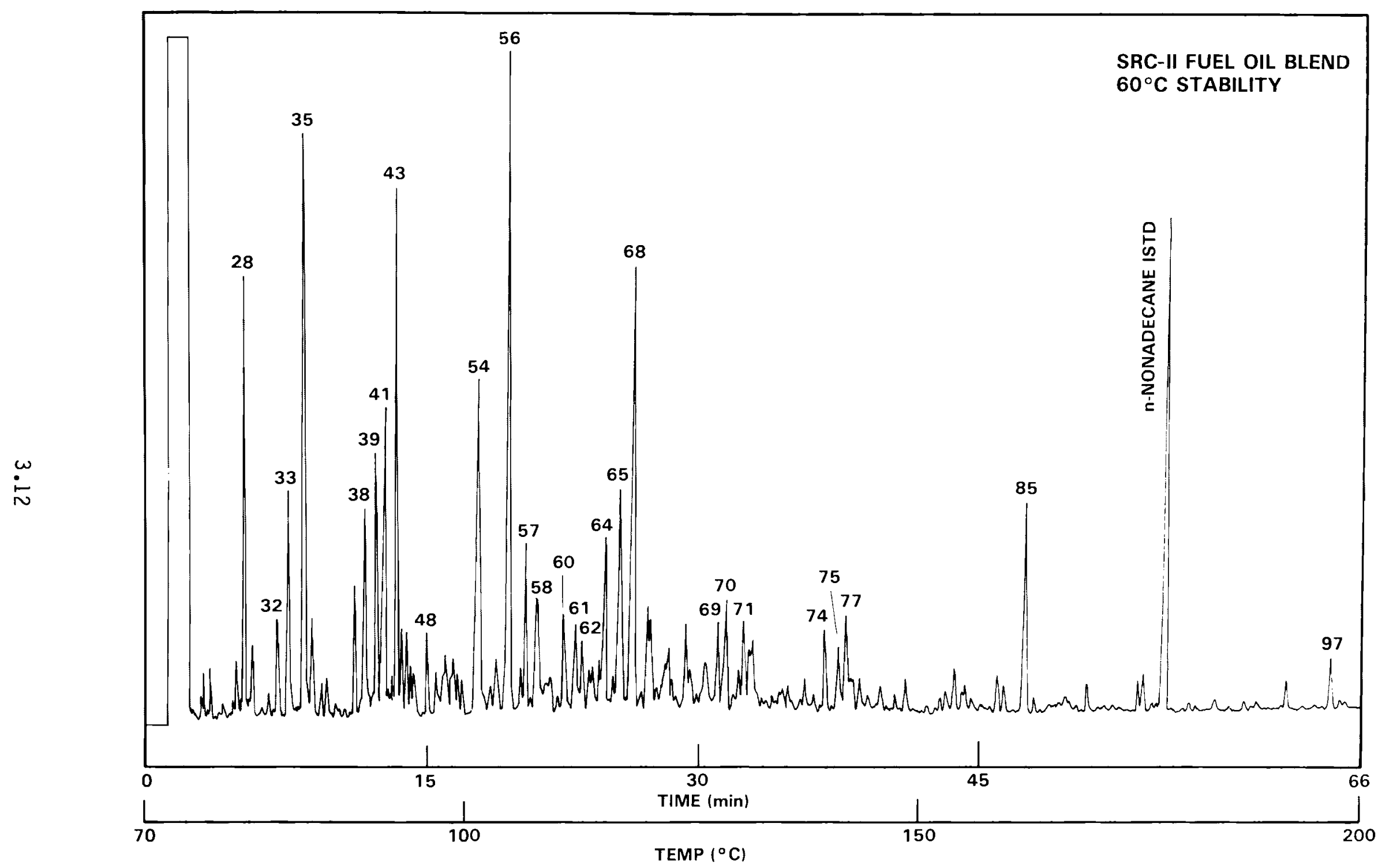

FIGURE 3.9. High Resolution Gas Chromatogram of the Time=0 Sample from the $60^{\circ} \mathrm{C}$ Study of an SRC-II Fuel $0 i 1$ Blend. Conditions: Same as in Figure 3.8. Numbers Refer to Identifications Given in Table 3.1 . 


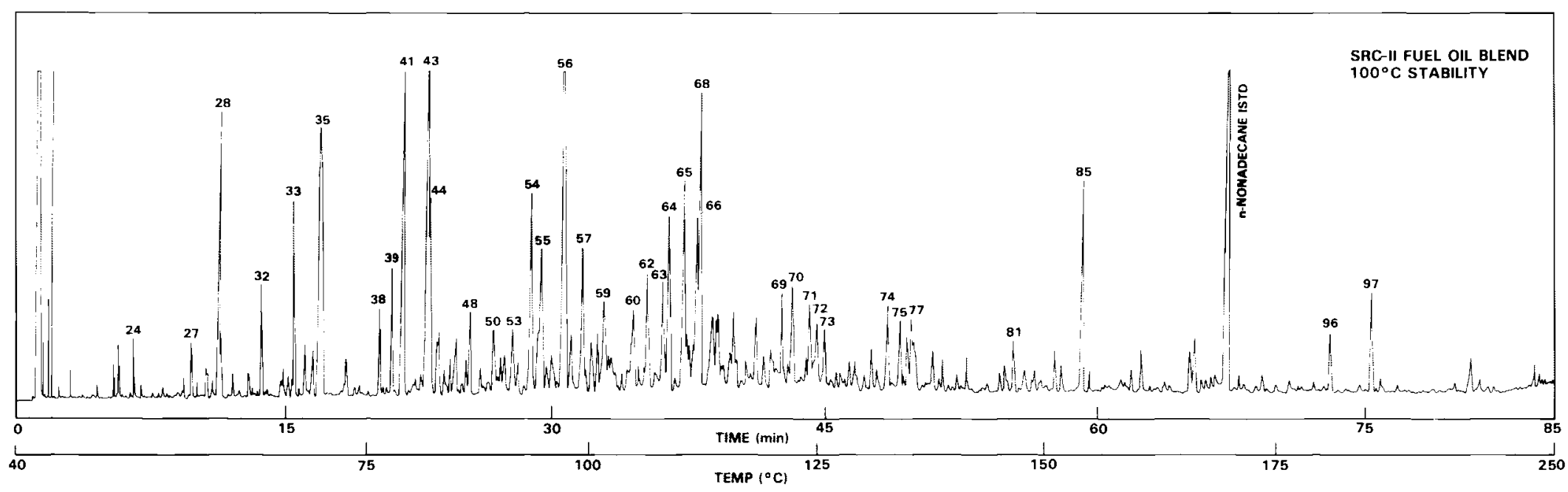

FIGURE 3.10. High Resolution Gas Chromatogram of the Time=0 Sample from the $100^{\circ} \mathrm{C}$ Study of an SRC-II Fuel 0il Blend. Conditions: $30 \mathrm{M} \times 0.25 \mathrm{~mm}$ i.d. Fused Silica Capillary Column Coated with SE-52, Splitless Injection, Helium Carrier Gas at $50 \mathrm{~cm} / \mathrm{s}$ Linear Velocity, 2 min Isothermal at $40^{\circ} \mathrm{C}$ then Temperature Programmed to $200^{\circ} \mathrm{C}$ at $2^{\circ} \mathrm{C} / \mathrm{min}$ and to $250^{\circ} \mathrm{C}$ at $15^{\circ} \mathrm{C} / \mathrm{min}$. Numbers Refer to Identifications Given in Table 3.1 . 
Analysis of the GC data to detect changes in composition over a period of time requires the ability to distinguish between actual changes in the sample and changes in the data which were due to differences in the GC experimental set-up. Data changes which might have been interpreted as changes may have been, in actuality, discrete differences caused by dissimilarities in chromatographic parameters. Flow rates through the column and the detector, injection technique, method of integration, column resolution, and/or differences in dilution all effect the data collected. To establish the level of error introduced by these parameters, four experiments were conducted. The first compared integration of area versus measurement of height in computing the relative amounts of components in the SRC materials compared to the internal standard. The second experiment consisted of chromatographing, under the same conditions, the same sample one day after it was originally analyzed; however, other samples were chromatographed in between the analyses. The third experiment compared results using split injection with split ratios varying by $\pm 10 \%$. Finally, an experiment was performed in which all chromatographic parameters were reset to their initial settings after a complete modification of the instrument.

To compare integration using peak heights versus peak areas, two chromatographic runs were performed on the same SRC-II MD sample. After each run, two report tables were printed. The first used the heights of the peaks to calculate the relative amounts of components in the complex mixture based on the height of the internal standard. The second report used areas of the same peaks to calculate the relative amounts of the same components based on the area of the same internal standard. The results in Table 3.2 varied from a range of a $+30 \%$ change in relative amount to a $-38 \%$ change for particular peaks integrated by height versus area in the same run, with the duplicate runs giving similar results. There were no consistent trends in the same run except a tendency for early eluting peaks to yield smaller relative amounts when integrated using areas versus heights and late eluting peaks to yield greater relative amounts when integrated using areas versus heights. There were some exceptions to this trend. These data lead to the conclusion that one method of integration must be used for an entire series of samples; experiments 
TABLE 3.2. Comparison of Peak Area versus Height for Computing Relative Arnounts of Components in SRC-II Middle Distillate

\begin{tabular}{|c|c|c|c|}
\hline $\begin{array}{l}\text { Retention } \\
\text { Time (min) }\end{array}$ & $\begin{array}{l}\text { Relatije } \\
\text { Area }\end{array}$ & $\begin{array}{l}\text { Relatiye } \\
\text { Height }\end{array}$ & $\begin{array}{l}\text { Percent Changes } \\
\text { Area versus Height }\end{array}$ \\
\hline 11.4 & 62.5 & 76.6 & -18.4 \\
\hline 11.5 & 11.7 & 17.0 & -31.1 \\
\hline 13.9 & 19.0 & 29.5 & -35.6 \\
\hline 15.7 & 36.7 & 51.8 & -29.1 \\
\hline 17.2 & 83.5 & 76.0 & +9.87 \\
\hline 17.3 & 47.5 & 77.1 & -38.4 \\
\hline 20.6 & 14.8 & 18.3 & -19.1 \\
\hline 21.3 & 25.9 & 30.9 & -16.2 \\
\hline 21.9 & 18.7 & 21.6 & -13.4 \\
\hline 22.1 & 55.9 & 54.3 & +2.95 \\
\hline 23.3 & 19.5 & 19.4 & +0.515 \\
\hline 23.5 & 106 & 102 & +3.92 \\
\hline 29.1 & 35.2 & 35.3 & -0.283 \\
\hline 29.6 & 33.1 & 27.4 & +20.8 \\
\hline 31.0 & 91.1 & 88.7 & +2.71 \\
\hline 32.0 & 15.3 & 18.3 & -16.4 \\
\hline 33.1 & 18.8 & 16.5 & +13.9 \\
\hline 34.7 & 17.5 & 16.1 & +8.70 \\
\hline 37.5 & 38.3 & 30.2 & +26.8 \\
\hline 38.2 & 32.0 & 26.1 & +22.6 \\
\hline 43.5 & 21.0 & 18.7 & +12.3 \\
\hline 44.5 & 22.3 & 19.8 & +12.6 \\
\hline 50.1 & 22.8 & 17.5 & +30.3 \\
\hline
\end{tabular}

(a) Based on $3.59 \mathrm{mg} / \mathrm{mL} \mathrm{C} 19$ ISTD, SRC-II MD Sample, $1: 16$ dilution.

conducted using peak height inteyration $\left(4^{\circ} \mathrm{C}, 100^{\circ} \mathrm{C}\right)$ cannot be correlated to experiments using peak area integration $\left(-20^{\circ} \mathrm{C}, 20^{\circ} \mathrm{C}, 60^{\circ} \mathrm{C}\right)$ for the computation of relative amounts of major components under the chromatographic conditions used.

Results of the second experiment to establish a level of error caused solely by experimental variability showed that results varied up to $13 \%$ for individual peaks. After chromatographing a SRC-II MD sample five times and calculating a mean and standard deviation of the mean for the relative amounts of components based on an internal standard, another suite of samples was chromatographed. The next day, using the exact same set-up, the original 
sample was again chromatographed and the results, given in Table 3.3 , were compared to the original means and standard deviation of the means previously calculated. Although the majority of results obtained on the second day were within two standard deviations of the mean, a few were not. Results under these conditions varied by a maximum of $-13 \%$ of the original data.

Since the SRC-II $N$ and SRC-I LO samples were chromatographed using a split injection technique, $\pm 10 \%$ modifications of the split ratio (representing the estimated experimental error of this measurement) were made to check the variability of results. Figure 3.11 shows a plot of the relative amounts of specific peaks in an SRC-II $N$ sample at three different split ratios. The amounts for each peak were connected to form a yraphical representation of each chromatogram. As can be seen in the figure, wide variabilities were computed, with the least variability in the late eluting components closest to the internal standard. Slight variations in the split ratio can easily account for $50 \%$ error in the relative amounts calculated.

The final experiment was designed to analyze the variability of results due to irreproducibility of chromatographic parameters. Initial flow rates of helium carrier gas and hydrogen and air gases for the flame ionization detector (FID) were measured. A sample of an SRC-II FOB was then chromatographed in duplicate. Means and standard deviations of the mean were calculated for the relative amounts of components based on the internal standard for the two chromatographic runs. The chromatographic column was then removed, the FID turned off, and all gas flows modified. One loop of each end of the column was then broken off (to simulate normal attrition), the column was reinstalled in the oven, the injection port liner was changed, and all gas flows were set to the initial conditions. The same sample was then chromatographed and relative amounts of the same components were calculated. These results were compared to the initial results and are given in Table 3.4. The data varied up to a maximum of $26 \%$ for some particular peaks. Variability averaged $10-12 \%$. It was decided from these four experimental studies that a $20 \%$ change in the relative amount of a peak was necessary before it was considered to be a change due to deyradation at a $5 \%$ a level. 
TABLE 3.3. Comparison of Chromatographic Variability After One Day Using the Same Experimental Set-Up

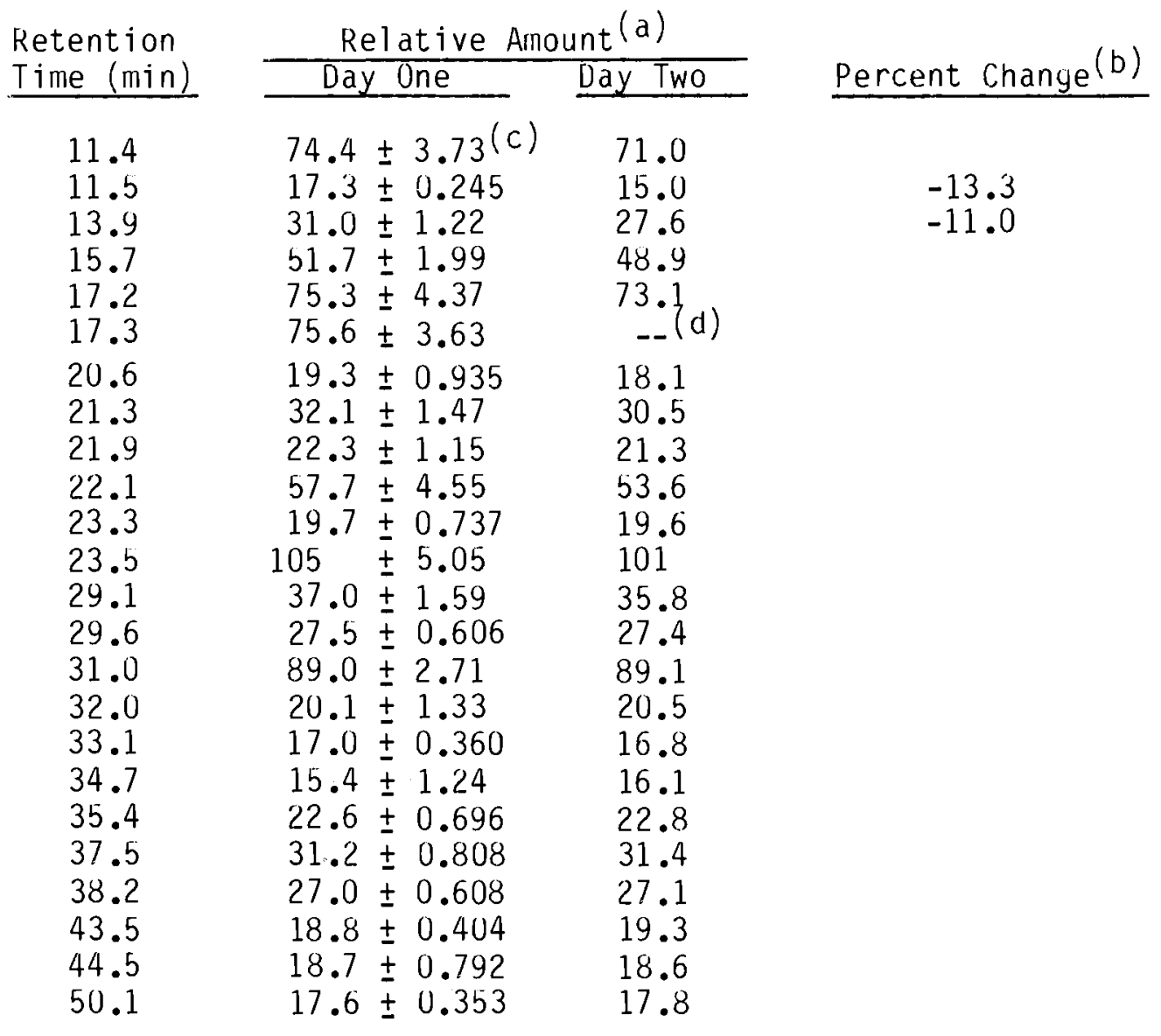
(a) Based on $3.59 \mathrm{mg} / \mathrm{mL} \mathrm{C}_{19}$ ISTD, SRC-II MD Sample, $1: 16^{9}$ dilution.
(b) Only given when change is greater
than $10 \%$, day one versus day two.
(c) Based on five chromatographic determinations.
(d) No data. 


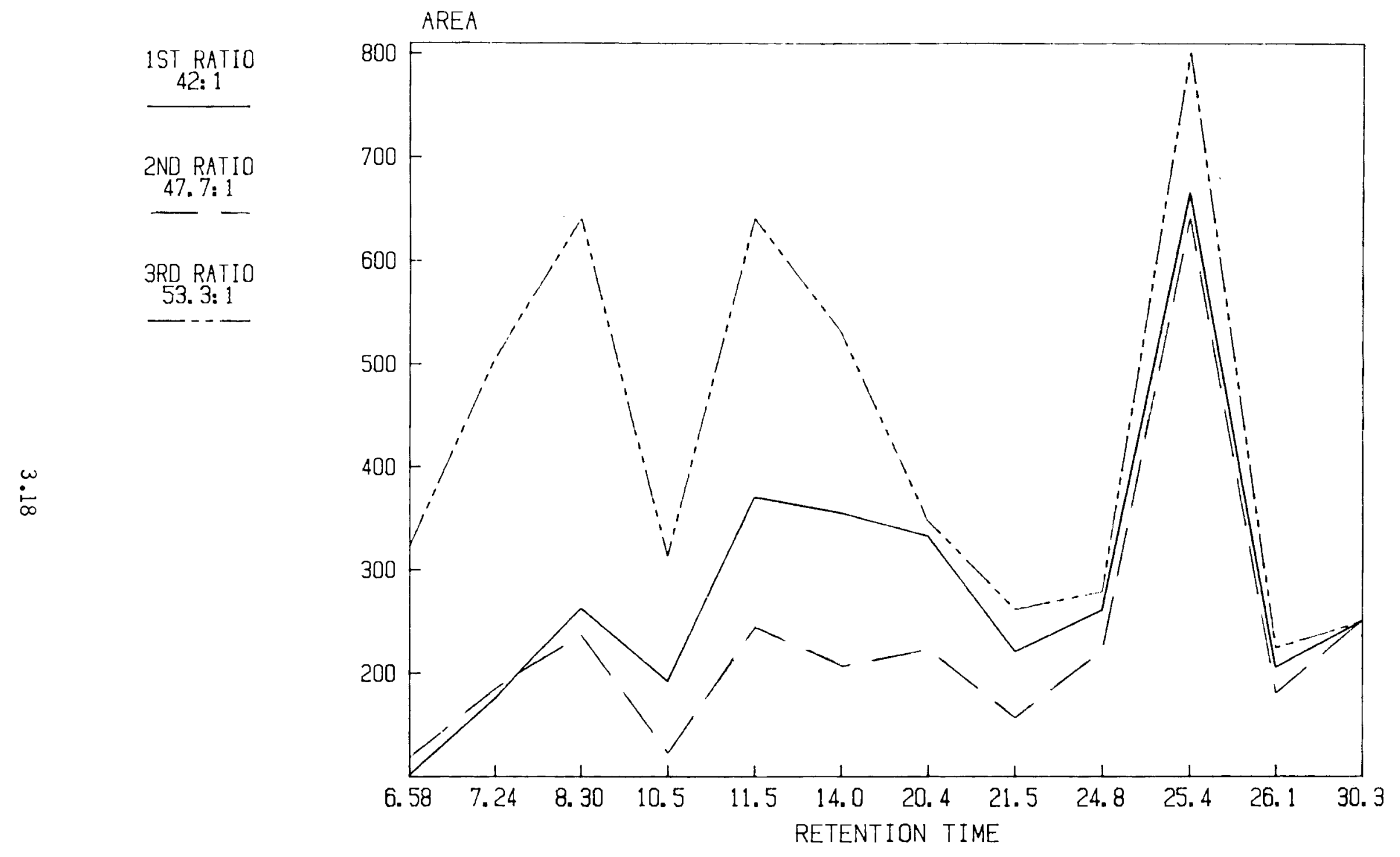

FIGURE 3.11. Relative Amounts of Components in SRC-II Naphtha Sample 3317-055-04 Using Three Different Split Ratios for Injection. Amounts for Specific Peaks Were Connected for Graphical Representation. 
TABLE 3.4. Comparison of Chromatographic Variability After Modification of Experimental Set-Up

\begin{tabular}{|c|c|c|c|c|}
\hline $\begin{array}{l}\text { Retention } \\
\text { Time (min) }\end{array}$ & $\frac{\text { Rel }}{\text { Bef }}$ & $\frac{\text { at ive Am }}{\text { ore }}$ & $\frac{\operatorname{lnt}(a)}{\text { After }}(b)$ & Percent Change (d) \\
\hline 9.93 & 26.7 & \pm 2.79 & 31.0 & +16.1 \\
\hline 12.1 & 4.75 & \pm 0.49 & 5.46 & +14.9 \\
\hline 14.0 & 16.9 & \pm 1.68 & 18.4 & \\
\hline 15.5 & & $N \bar{D}(a)$ & 36.5 & \\
\hline 18.5 & 9.88 & \pm 1.14 & 10.9 & +10.3 \\
\hline 19.2 & 12.0 & \pm 1.31 & 12.6 & \\
\hline 19.9 & 44.2 & \pm 4.82 & 43.9 & \\
\hline 21.3 & 78.7 & $\pm 7.5 b$ & 75.1 & \\
\hline 21.6 & 29.4 & \pm 2.60 & 26.9 & \\
\hline 23.5 & 12.8 & \pm 1.50 & 13.6 & \\
\hline 24.8 & 7.99 & \pm 0.800 & 9.61 & +20.3 \\
\hline 25.9 & 7.59 & \pm 0.544 & 7.23 & \\
\hline 26.9 & 35.7 & \pm 3.98 & 35.4 & \\
\hline 27.7 & 23.1 & \pm 2.10 & 23.7 & \\
\hline 28.7 & 96.0 & \pm 9.00 & 96.5 & \\
\hline 29.6 & 27.7 & \pm 2.61 & 28.6 & \\
\hline 31.0 & $1 \cup .9$ & \pm 1.06 & 11.3 & \\
\hline 32.5 & 7.02 & \pm 0.485 & 8.38 & +19.4 \\
\hline 33.1 & 15.7 & \pm 1.53 & 16.6 & \\
\hline 33.9 & 12.7 & $\pm 1.1 \mathrm{~b}$ & 11.9 & \\
\hline 34.3 & 39.1 & \pm 3.19 & 40.5 & \\
\hline 35.1 & 39.9 & \pm 2.04 & 40.2 & \\
\hline 35.8 & 47.0 & \pm 3.97 & 49.3 & \\
\hline 36.1 & 66.1 & \pm 5.35 & 67.3 & \\
\hline 40.4 & 18.1 & \pm 1.14 & 20.2 & \\
\hline 41.0 & 24.0 & \pm 1.93 & 27.0 & \\
\hline 42.0 & 16.2 & \pm 1.74 & 19.5 & +20.4 \\
\hline 42.3 & 12.6 & \pm 1.56 & 15.9 & +26.2 \\
\hline 42.9 & 11.8 & \pm 1.60 & 12.9 & \\
\hline 46.2 & 13.9 & \pm 1.15 & 15.4 & \\
\hline 46.8 & 15.0 & \pm 0.680 & 16.0 & \\
\hline 47.5 & 17.8 & \pm 0.643 & 20.6 & +13.6 \\
\hline 53.1 & 10.1 & \pm 0.424 & 11.9 & +17.8 \\
\hline 56.9 & 47.6 & \pm 0.448 & 48.5 & \\
\hline 70.4 & 13.8 & \pm 0.610 & 15.6 & +13.0 \\
\hline 72.7 & 22.6 & \pm 0.937 & 24.7 & \\
\hline
\end{tabular}

(a) Based on $0.400 \mathrm{mg} / \mathrm{mL} C_{19}$ ISTD, SRC-I I FOB, $1: 201$ dilution.

(b) After readjustment of carrier yas, yas flows in FID, and breaking a loop off each end of the capillary column.

(c) No data.

(d) Only given when change is greater than $10 \%$, before versus after. 


\section{$3.1 .1 \quad 4^{\circ} \mathrm{C}$ Study}

Log transformed data from the ANOVA statistical analysis are presented for the four SRC-II FOB replicates stored in the repository in Figure 3.12 . The data are shown as paired sets which compare the results of these samples at time zero and after two years of storage. Table 3.5 presents the $F$ values for the peak-to-peak statistical analysis of the FOB. An F value greater than 18.51 shows a significant change in composition for a particular peak. The obvious overlap of data in Figure 3.12 and the lack of statistical significance at a $5 \% \propto$ level in Table 3.2 show that there was no change in the chemical composition of the $F O B$ after two years in the repository, as measured by the components monitored.

Similar results were achieved from the statistical analyses of chromatographic data from the SRC-I LO, WS and PS, and SRC-II N, MD, and HD. No significant degradation changes in the chemical composition (as monitored by the compounds in Table 3.1) greater than chromatographic error occurred in any of the $17 \mathrm{SRC}$ materials stored in the repository at $4^{\circ} \mathrm{C}$, in inert containers, in the dark, under a nitrogen atmosphere over a two year period. Some statistically significant increases in the concentration of some components did occur, nowever, but they cannot be attributed to decomposition. In addition, if inconsistent results were achieved between replicates, no conclusions as to decomposition were drawn. Log transformed plots of all the SRC materials stored in the repository along with tables of calculated $F$ values are presented in Figures and Tables 8.1 through 8.6 of Appendix II.

$3.1 .2-20^{\circ} \mathrm{C}, 20^{\circ} \mathrm{C}$ Study

Loy transformed data from the chromatographic analysis of SRC-II FOB Samples stored at $-20^{\circ} \mathrm{C}$ and room temperature under various parameters of ambient light, cover atmosphere, and dilution are presented in Figure 3.13. The top portion of the figure shows the results of all the FOB samples stored undiluted, each offset from the others. The bottom portion of the figure shows the results of the samples stored diluted $1: 20$ and 1:200 in methylene chloride versus the sample stored under the same conditions except not diluted (in the light, under an air atmosphere, at room temperature). F Values for the data 


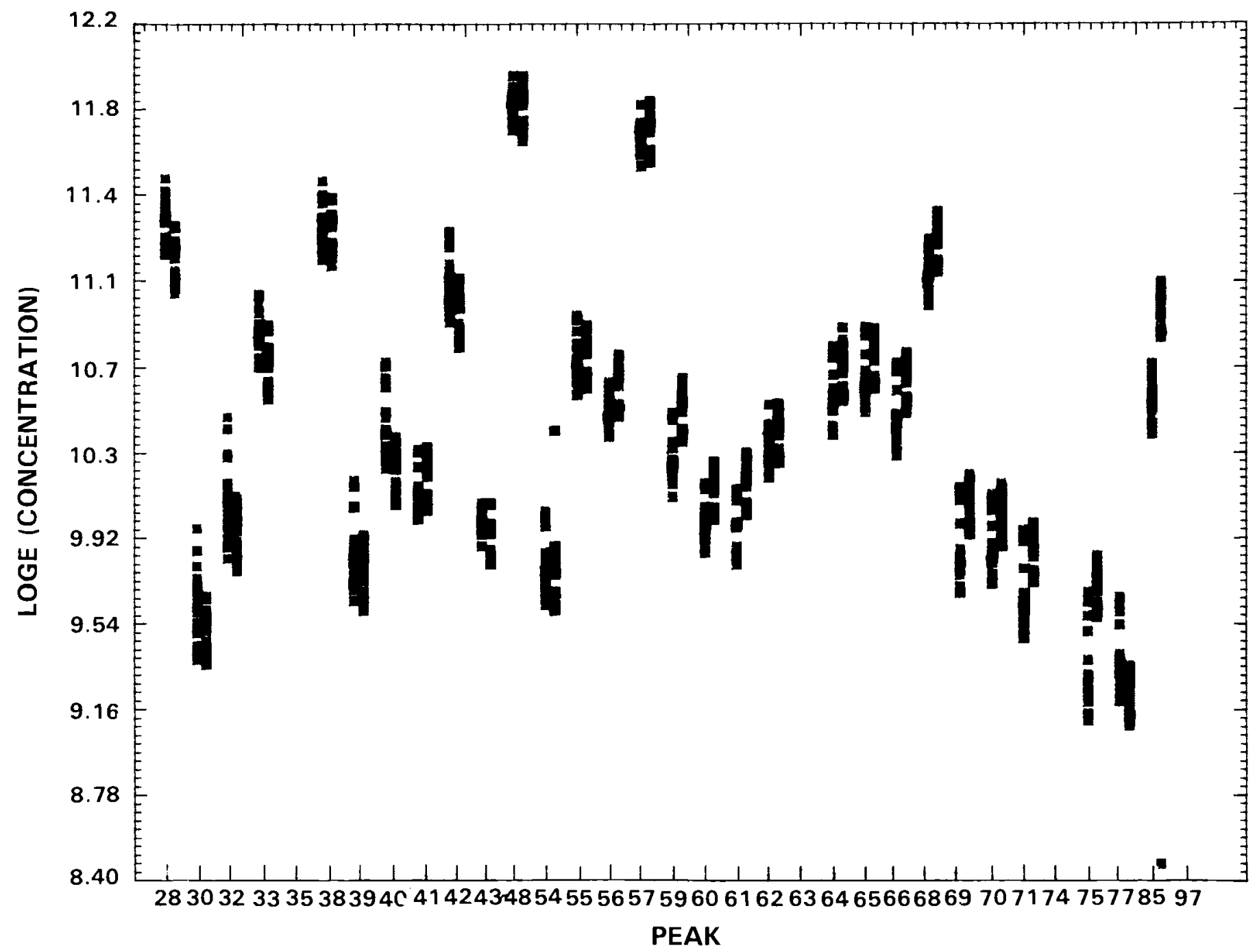

FIGURE 3.12. Loy Transformed Data from Chronatographic Results for SRC-II Fuel 0 il Blend Samples Stored in the Repository. Data Points After Two Years are 0 ffset by 0.3 Peak Units. 
TABLE 3.5. F Values From the ANOVA Techniques Applied to the SRC-II Fuel 0il Blend Chromatographic Data After Storage in the Repository for Two Years

\begin{tabular}{|c|c|c|}
\hline Peak (a) & Calculated $F$ Value & $\begin{array}{c}\text { Critical F Value } \\
(5 \% \propto \alpha \text { Level })\end{array}$ \\
\hline 28 & 5.54 & $18.51^{(d)}$ \\
\hline $\begin{array}{l}30 \\
32\end{array}$ & 2.48 & 18.51 \\
\hline 33 & $\begin{array}{l}.02 \\
3.75\end{array}$ & $\begin{array}{l}10.51 \\
18.51\end{array}$ \\
\hline 35 & 0.02 & 18.51 \\
\hline 38 & 1.80 & 18.51 \\
\hline 39 & 9.52 & 18.51 \\
\hline 40 & 1.12 & 18.51 \\
\hline 41 & 3.95 & 18.51 \\
\hline 42 & 0.39 & 18.51 \\
\hline 43 & 0.0025 & 18.51 \\
\hline 48 & 0.0025 & 18.51 \\
\hline 54 & 0.05 & 18.51 \\
\hline 55 & 2.94 & 18.51 \\
\hline 56 & 0.08 & 18.51 \\
\hline 57 & 10.39 & 18.51 \\
\hline 59 & 6.32 & 18.51 \\
\hline 60 & 9.34 & 18.51 \\
\hline 61,62 & 0.82 & 18.51 \\
\hline $63^{\circ}$ & $N D(b)$ & \\
\hline 64 & 2.84 & 18.51 \\
\hline 65 & 1.29 & 18.51 \\
\hline 66 & 5.10 & 18.51 \\
\hline 68 & 4.36 & 18.51 \\
\hline 69 & 10.62 & 18.51 \\
\hline 70 & 4.42 & 18.51 \\
\hline 71 & 7.56 & 18.51 \\
\hline 74 & & \\
\hline 75 & $29.01(c)$ & 18.51 \\
\hline 77 & 6.48 & 18.51 \\
\hline 85 & 4.31 & $4.30(e)$ \\
\hline 97 & ND & \\
\hline
\end{tabular}

(a) Peaks refer to compounds identified by GC/MS contained in Table 3.1 and shown in Figure 3.4.

(b) No data collected.

(c) Although significant, this change was thought to be attributed to chromatography, not degradation. The amount of the peak increased, not decreased.

(d) Based on $20 \%$ error.

(e) Based on calculated statistical error. 


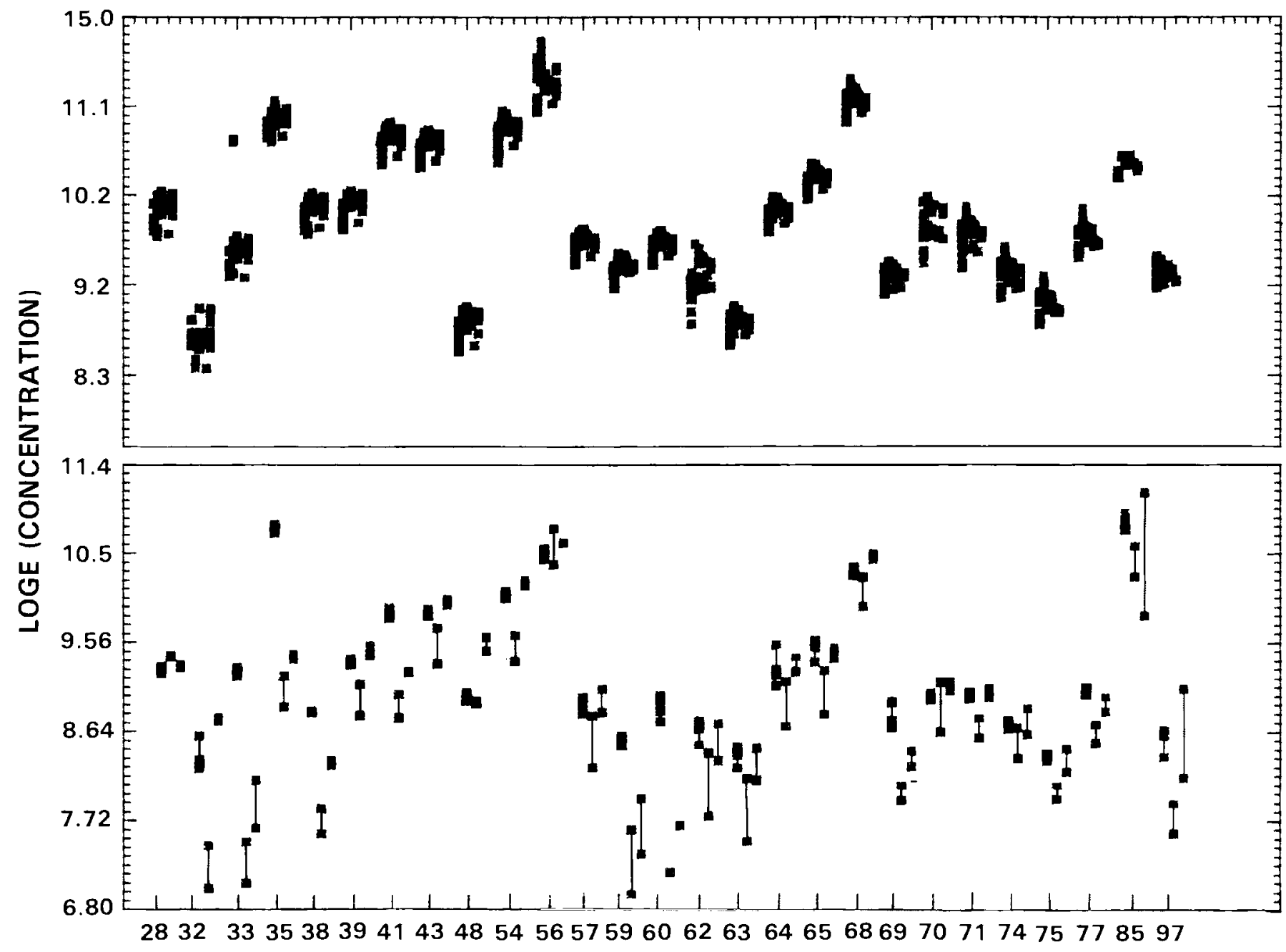

PEAK

FIGURE 3.13. Log Transformed Data from Chrobilatographic Results for SRC-II Fuel $0 i 1$ Blend Samples Stored at $-20^{\circ} \mathrm{C}$ and $20^{\circ} \mathrm{C}$ Under Various Parameters of Cover Atmosphere, Ambient Light, and Dilution (See Figure 2.1) Top: All Samples Stored Undiluted Offset by 0.1 Peak Units. Bottom: Condition 4 Versus $1: 20$ and $1: 200$ Dilutions with Methylene Chloride Uffset by 0.25 and 0.5 Peak Units, Respectively. 
presented in the figure are in Table 3.6. Values greater than 19.3 or 19.0 show significant (greater than $20 \%$ ) changes in composition of particular peaks.

No replicate (samples stored in duplicate) or vial effects were significant. There was no significant chemical composition difference for any of the undiluted FOB samples regardless of increased temperature, ambient light, or air atmosphere during storage for one year. This is shown by the tight cluster of data in the top portion of Figure 3.13 and by the $F$ Values given for the undiluted samples in Table 3.6 all being less than 19.3. There were, however, significant degradation chanyes in the chemical composition of the samples stored diluted in methylene chloride in the light, under an air atmosphere, at room temperature (see Figure 3.13, bottom, and Table 3.6, F Values for diluted samples). Under these conditions the peaks numbered 32 (indan), 33 (o-cresol), 35 ( $\mathrm{m} \& \mathrm{p}$-cresol and $\mathrm{C}_{1}$-indan), 59 ( $\mathrm{C}_{3}$-indan), and 60 (indanol) showed degradation significant at a $5 \%$ a level. (Similar degradation of the phenol, indan, $\underline{0}, \underline{m}$, and $p$-cresol was noted after storage of the FOB diluted in methylene chloride for three years, at $-20^{\circ} \mathrm{C}$, in the dark, under a nitrogen atmosphere. See Table 7.22 in Appendix I for chromatographic data.) Degradation in methylene chloride can likely be attributed to trace hydrochloric acid residues which are commonly found in this solvent.

$3.1 .360^{\circ} \mathrm{C}, 100^{\circ} \mathrm{C}$ Study

Log transformed data from the chromatographic results obtained for the samples of SRC-II FOB stored at $60^{\circ} \mathrm{C}$ are presented in Figure 3.14. Three data sets are presented offset from each other: before accelerated storage (time=0); after 16 weeks of storage at $60^{\circ} \mathrm{C}$; and after 32 weeks of storage at $60^{\circ} \mathrm{C}$. F Values from the ANOVA techniques are shown in Table 3.7. The data variability increased with time. Even though the vials were sealed there tended to be an increase in heavier molecular weight compounds and decrease in lighter materials due to volatility effects which were significant at the $5 \% \alpha$ level. Peaks which were the most significantly effected by storage, giving changes greater than the experimental error, and showing consistent decrease in concentration over time were those labeled 33 (o-cresol), $38\left(C_{1}\right.$-indan), 58 $\left(C_{3}-\right.$ indan), and 60 (indanol). 
TABLE 3.6. F Values From the ANOVA Techniques Applied to the SRC-II Fuel 0 il Blend Chromatographic Data After Storage at $-20^{\circ} \mathrm{C}$ and Room Temperature Under Various Parameters of Light, Atmosphere, and Dilution for One Year

\begin{tabular}{|c|c|c|c|c|}
\hline \multirow[b]{2}{*}{ Peak (a) } & \multicolumn{2}{|c|}{ Undiluted Samples (b) } & \multicolumn{2}{|c|}{ Diluted Samples (c) } \\
\hline & $\begin{array}{l}\text { Calculated } \\
\text { F Value } \\
\end{array}$ & $\begin{array}{l}\text { Critical } \mathrm{F} \text { value } \\
(5 \% \text { a Level }) \\
\end{array}$ & $\begin{array}{l}\text { Calculated } \\
\text { F Value } \\
\end{array}$ & $\begin{array}{c}\text { Critical F Value } \\
(5 \% \alpha \text { Level }) \\
\end{array}$ \\
\hline 28 & 1.59 & 19.3 & 0.339 & $19.0(\mathrm{e})$ \\
\hline 32 & 2.86 & & 32.55 & 19.0 \\
\hline 33 & 3.86 & & 81.83 & 19.0 \\
\hline 35 & 1.38 & & 63.45 & 19.0 \\
\hline 38 & 1.69 & & 19.3 & 19.0 \\
\hline 39 & 2.27 & & 10.675 & 19.0 \\
\hline 41 & 2.71 & & 18.50 & 19.0 \\
\hline 43 & 2.44 & & 2.88 & 19.0 \\
\hline 48 & 2.56 & & 6.246 & 19.0 \\
\hline 54 & 3.12 & & $180.1(\mathrm{~d})$ & 19.0 \\
\hline 56 & 3.38 & & 0.178 & 19.0 \\
\hline 57 & 1.88 & & 3.14 & 19.0 \\
\hline 59 & 1.37 & & 33.36 & 19.0 \\
\hline 60 & 1.83 & & 40.07 & 19.0 \\
\hline 62 & 3.75 & & 5.76 & 19.0 \\
\hline 63 & 2.04 & & 5.82 & 19.0 \\
\hline 64 & 1.99 & & 2.66 & 19.0 \\
\hline 65 & 1.73 & & 3.95 & 19.0 \\
\hline 68 & 2.24 & & 1.66 & 19.0 \\
\hline 69 & 0.88 & & 12.2 & 19.0 \\
\hline 70 & 1.59 & & 0.58 & 19.0 \\
\hline 71 & 2.72 & & 2.42 & 19.0 \\
\hline 74 & 1.59 & & 0.868 & 19.0 \\
\hline 75 & 1.62 & & 2.67 & 19.0 \\
\hline 77 & 1.61 & & 3.46 & 19.0 \\
\hline 85 & 0.88 & & 2.89 & $5.14(f)$ \\
\hline 97 & 0.25 & & 3.96 & 5.14 \\
\hline
\end{tabular}

(a) Peak numbers refer to compounds identified by by GC/MS contained in Table 3.1 and shown in Figure 3.8

(b) Samples stored under control and conditions 1,2,4-6 as outlined in Figure 2.1

(c) Samples stored under conditions 3 and 4 as outlined in Figure 2.1

(d) One dilution showed a significant change, but the other did not, therefore no conclusions regarding this peak were included.

(e) Based on $20 \%$ error.

(f) Based on calculated statistical error. 


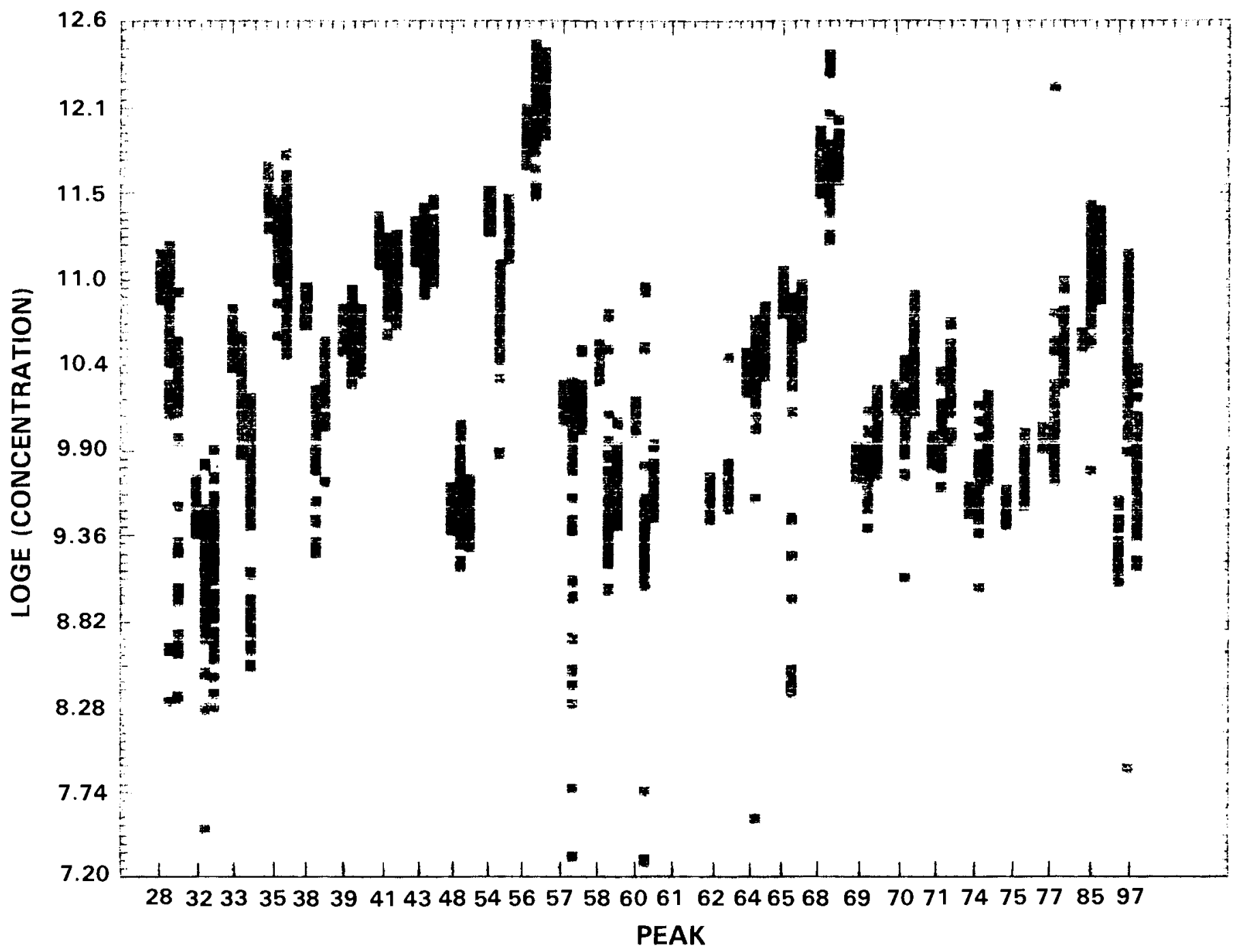

FIGURE 3.14. Log Transformed Data from Chromatographic Results for SRC-II Fuel 0il Blend Samples Stored at $60^{\circ} \mathrm{C}$, Under an Air Atmosphere, in the Dark. Data Points for Time $=0$ are offset by 0.0 Peak Units, 16 Weeks by 0.25 Peak Units, and 32 Weeks by 0.5 Peak Units. 
TABLE 3.7. F Values from the ANOVA Techniques Applied to the SRC-I I Fuel Dil Blend Chromatographic Data After Storage at $60^{\circ} \mathrm{C}$ in the Dark, Under an Air Atmosphere for 16 and 32 weeks.

\begin{tabular}{ccc} 
Peak $(\mathrm{a})$ & Calculated F Value & $\begin{array}{c}\text { Critical F Value } \\
(5 \% \text { a Level })\end{array}$ \\
\cline { 3 - 3 } 28 & 33.48 & $3.91(\mathrm{e})$ \\
32 & 23.63 & 3.91 \\
33 & 139.16 & 3.91 \\
35 & 25.98 & 3.91 \\
38 & 159.8 & 3.91 \\
39 & 2.5 & 19.0 \\
41 & 16.8 & 19.0 \\
43 & 0.02 & 19.0 \\
48 & $18.2(\mathrm{f})$ & 19.0 \\
54 & 132.0 & 19.0 \\
56 & 14.75 & 19.0 \\
57 & 67.50 & 19.0 \\
58 & 178.50 & 19.0 \\
60 & 127.3 & 19.0 \\
61 & ND & \\
62 & 5.75 & 19.0 \\
64 & 10.75 & 19.0 \\
65 & 80.5 & 19.0 \\
68 & 2.25 & 19.0 \\
69 & 22.0 & 19.0 \\
70 & 82.0 & 19.0 \\
71 & 67.5 & 19.0 \\
74 & 45.5 & 19.0 \\
75 & $14.25(\mathrm{~d})$ & 19.0 \\
77 & 116.25 & 19.0 \\
85 & $65.0(\mathrm{~d})$ & 19.0 \\
97 & $384.0(\mathrm{~d})$ & 19.0 \\
& &
\end{tabular}

\footnotetext{
(a) Peak numbers refer the compounds identified by GC/MS contained in Table 3.1 and shown in Figure 3.9

(b) After 16 weeks, it appeared degradation had occurred, however, at 32 weeks the component had not deyraded, therefore, no conclusions about this peak were made.

(c) No data.

(d) Data showed increase in component, therefore not a component which degrades.

(e) Based on calculated statistical error.

(f) Based on 20\% error.
} 
Results of the $100^{\circ} \mathrm{C}$ study were similar to those of the $60^{\circ} \mathrm{C}$ study, although the volatility effects were greater. Log transformed data and $F$ Values are given in Figure and Table 8.7 of Appendix II, respectively.

\section{1 .4 Summary}

After two years, the SRC samples stored in the repository at $4^{\circ} \mathrm{C}$, in inert containers, under a nitrogen atmosphere, in the dark have shown no chemical composition changes as monitored by high resolution gas chromatography. When degradation did occur under harsher storage conditions of $60^{\circ} \mathrm{C}, 100^{\circ} \mathrm{C}$, or room temperature diluted in methylene chloride under air atmospheres, the hydroxylated PAH (phenols, cresols, indanol) and partially hydrogenated PAH (indans, tetralin) showed the greatest amount of degradation. Degradation of more than $20 \%$ of the original amount had to occur before chromatographic differences were interpreted as actual differences in the sample. Dilution with methylene chloride and storage in the freezer at $-20^{\circ} \mathrm{C}$ for three years caused similar degradation of phenolic materials as occurred in the samples stored under harsh conditions.

For all data sets analyzed, the differences in vial subsamples (after dilution) and chromatographic runs were not found to be significant. Therefore, for statistical purposes, the emphasis of replication should be placed on duplicating the storage vials not the subsamples from these vials or the subsequent number of chromatographic runs. Though not significant in a statistical sense, the order in which the chromatographic runs were made showed a definite trend; the later chromatograms had lower relative concentrations than the earlier runs. This shows that samples should be analyzed on a random basis to exhibit errors found in the chromatography. Instead of running a diluted sample four times in a row, as was done in this study, replicate chromatographic runs should be made randomly throughout the analysis of all other diluted samples. 


\subsection{CHEMICAL FRACTIUNATION}

After fractionation into chemical classes, as previously described, each fraction was analyzed by GC after dilution to a consistent volume. The total area counts were computed relative to the internal standard and corrected for differences in initial starting material. Table 3.8 gives the comparison of the approximate total area of the chromatographable peaks for each fraction from the alumina separation. After storage at $100^{\circ} \mathrm{C}$ for 16 weeks, the aliphatic hydrocarbon $(A-1), N-P A C(A-3)$, and hydroxylated PAH $(A-4)$ fractions decreased in total chromatographable materials; the PAH (A-2) fraction increased. Overa 11 , about $20 \%$ less material was chromatographable after storage at $100^{\circ} \mathrm{C}$, in the dark, under an air atmosphere for 16 weeks. (This was based on the fractionation of $100 \mathrm{mg}$ of material before and after harsh storage conditions and dilution of all fractions to a consistent volume before chromatography.)

The components in the PAH fraction $(A-2)$ were chromatographed and norma 1ized to pyrene to see if the peak profile of any components changed after storage at $100^{\circ} \mathrm{C}$. Table 3.9 presents the means of the normalized data for 25 polycyclic aromatic compounds in the A-2 fraction. Means were determined from six chromatoyraphic runs for the "before" sample and three chromatographic runs for the "after" sample. Applying an error margin of $\pm 20 \%$ (determined as previously described), the peak profile of the components monitored did not change in the PAH fraction.

TABLE 3.8. Total Area Counts Chromatographed per mg Crude SRC-II Fuel 0 il Blend Before and After Storage at $100^{\circ} \mathrm{C}$ for 16 weeks

\begin{tabular}{lccr}
\multicolumn{1}{c}{ Alumina Fractions } & & Before & After \\
\cline { 1 - 1 } aliphatics (A-1) & & $3300($ a $)$ & 2400 \\
PAH (A-2) & 1400 & 1800 \\
N-PAC (A-3) & 640 & 240 \\
$\begin{array}{lll}\text { hydroxylated PAH (A-4) } \\
\quad \text { Total }\end{array}$ & $\frac{4600}{9940}$ & $\frac{3700}{8140}$
\end{tabular}

(a) All values were normalized to the addition of 2-Chloroanthracene as an internal standard 
TABLE 3.9. Mean of PAH Compound Concentration in the PAH Fraction of an SRC-II Fuel 0il Blend Before and After Storage at $100^{\circ} \mathrm{C}$, in the Dark, Under an Air Atmosphere for 16 Weeks

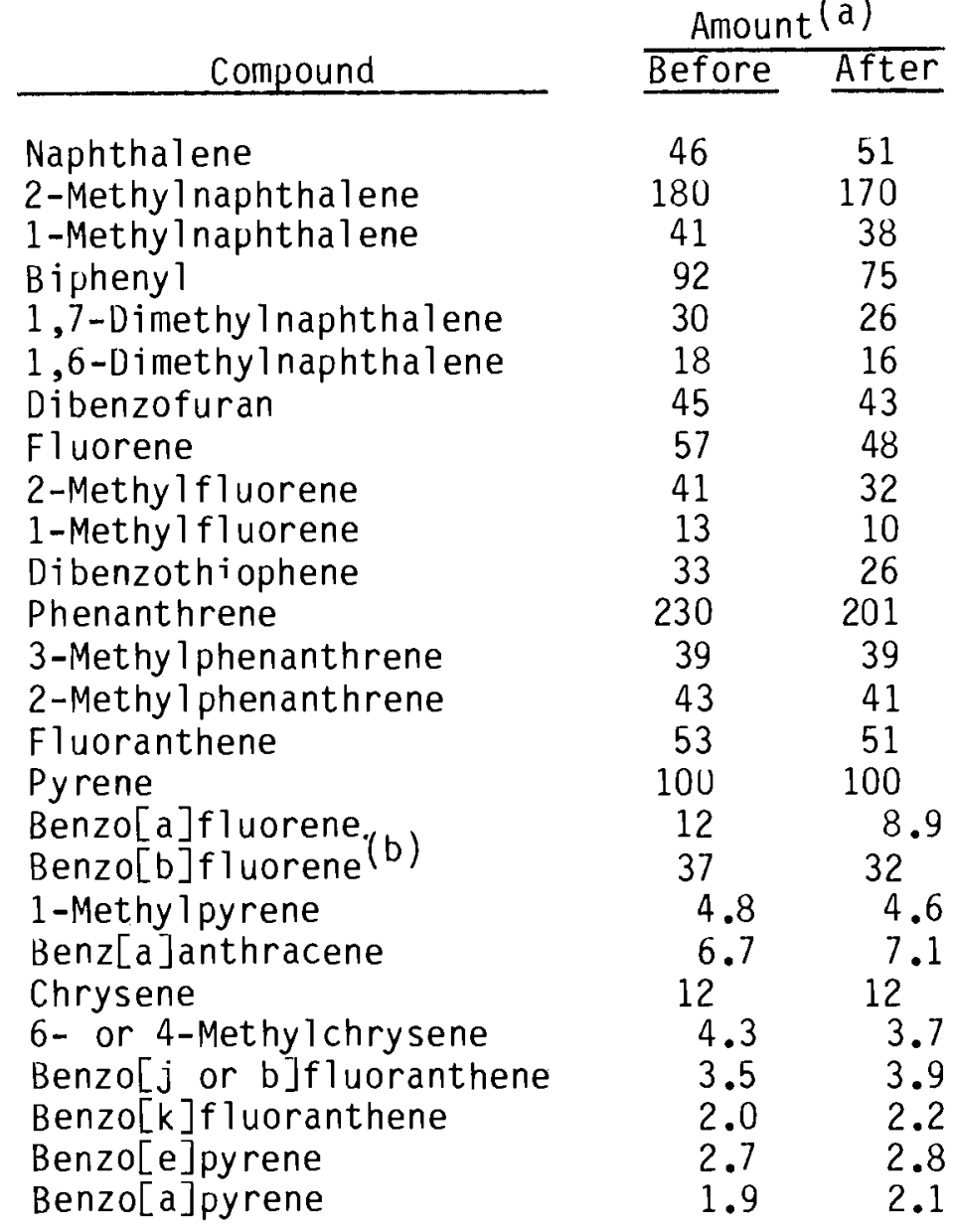

(a) Normalized to pyrene

(b) Co-elutes with 2- or 4-methylpyrene

The components in the N-PAC fraction $(A-3)$ were also chromatographed and were normalized to carbazole to see if the peak profile of any components changed after storage at $100^{\circ} \mathrm{C}$. Table 3.10 presents the means of the normalized data for 12 of the nitrogen heterocycles in the fraction. The data were obtained and analyzed in the same fashion as the A-2 fraction. The aniline, 
TABLE 3.10 Mean of Nitrogen Heterocycle Compound Concentration in the in the N-PAC Fraction of an SRC-II Fuel 0il Blend Before and After Storage at $100^{\circ} \mathrm{C}$, in the Dark, Under an Air Atmosphere for 16 Weeks

\begin{tabular}{|c|c|c|}
\hline \multirow[b]{2}{*}{ Compound } & \multicolumn{2}{|c|}{ Amount (a) } \\
\hline & Before & After \\
\hline Aniline & 13 & $--(c)$ \\
\hline$C_{1}$-Aniline & 62 & 0.83 \\
\hline Quinoline & 74 & 94 \\
\hline Indole & 120 & 13 \\
\hline 7-Methylquinoline & 74 & 62 \\
\hline 3-Methylquinol ine & 54 & 62 \\
\hline Benzo[f]quinoline & 20 & 23 \\
\hline Carbazole & 100 & 100 \\
\hline 1-Methylcarbazole & 15 & 18 \\
\hline 3-Methylcarbazole & 29 & 23 \\
\hline 2-Methylcarbazole & 18 & 15 \\
\hline Benzo[a]carbazole & 13 & 16 \\
\hline
\end{tabular}

(a) Normalized to Carbazole

(b) Co-elutes with phenanthridine

(c) None detected

methylaniline, and indole showed significant decreases in concentration after storage at $100^{\circ} \mathrm{C}$, in the dark, under an air atmosphere.

When the N-PAC fraction was further fractionated on silicic acid obtaining the amino-PAH fraction, the total area which was chromatographable in this fraction decreased in comparison to the control. The amino-PAH fraction was derivatized with pentafluoropropionic anhydride and chromatographed using an electron capture detector for primary aromatic amine-specific detection. The sample fractionated before storage at $100^{\circ} \mathrm{C}$ had over two times the total primary aromatic amine content of that fractionated after exposure $(5.5 \pm 0.5 \mathrm{x}$ $10^{6}$ versus $2.4 \pm 0.7 \times 10^{6}$ area counts). Figure 3.15 shows the comparison of amines before (top) and after (bottom) storaye at $100^{\circ} \mathrm{C}$ under an air atmosphere. 


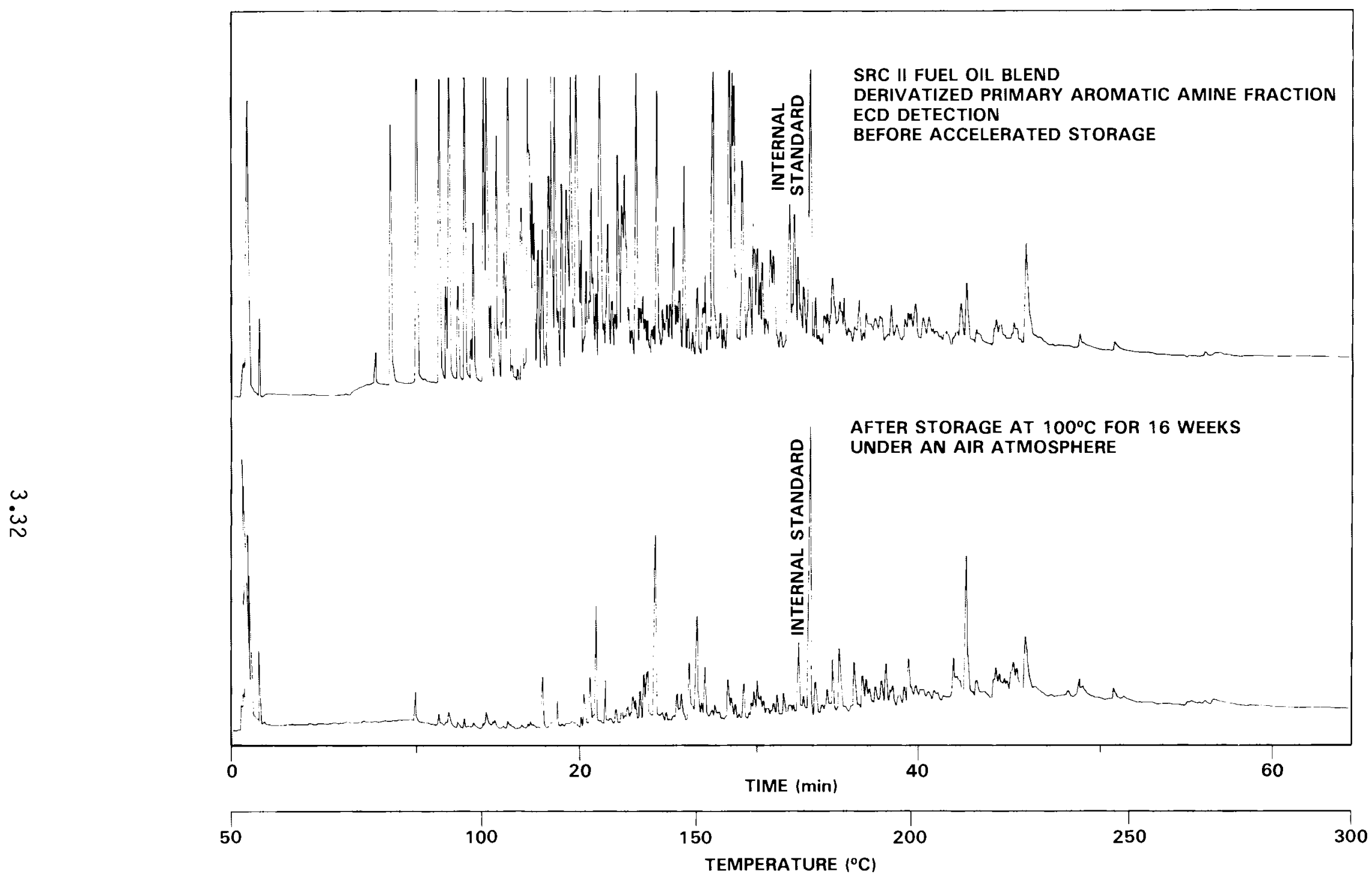

FIGURE 3.15. ECD Chromatograms of Derivatized Amino-PAH Fractions from an SRC-II FOB Before (Top) and After (Bottom) Storage at $100^{\circ} \mathrm{C}$ for 16 Weeks. Conditions: $50^{\circ} \mathrm{C}$ to $300^{\circ} \mathrm{C}$ at $3^{\circ} \mathrm{C} / \mathrm{min}, 15 \mathrm{M} \times 0.25 \mathrm{~mm}$ i.d. DB-5 Column, Helium Carrier at $50 \mathrm{~cm} / \mathrm{s}$ Linear Velocity. 


\section{2 .1 Sunmary}

The more-trace component analysis of the SRC-II FOB stored under harsh conditions showed that amino-PAH and indole degraded after 16 weeks at $100^{\circ} \mathrm{C}$, in the dark, under an air atmosphere. The overall material which was chromatoyraphable had decreased by $20 \%$, with decreases in the aliphatic, N-PAC, and HPAH fractions. The integrity of the PAH fraction (as monitored) was maintained.

\subsection{DIRECT PROBE MASS SPECTRUMETRY}

The top of Figure 3.16 shows the results of the probe analysis of the SRCII heavy distillate which had been mixed to homogeneity. The major components had masses of 178 (phenanthrene/anthracene), $192\left(C_{1}\right.$-phenanthrene/anthracenes), 202 (pyrene/fluoranthene), and 216 ( $C_{1}$-pyrene/fluoranthenes, benzofluorenes). The middle of Figure 3.16 shows the major components from the subsampling $2 \mathrm{~cm}$ from the top of the undisturbed container to be similar to the mixed sample. The sample taken $5 \mathrm{~cm}$ from the bottom of the undisturbed container (Figure 3.16, bottom), however, shows the lower molecular weight component of mass 178 to be significantly less than those of masses 192, 202, and 216. In this case, the components of mass $181\left(\mathrm{C}_{1}\right.$-carbazoles $)$ were in higher concentration than the phenanthrene/anthracene.

Figure 3.17 presents the direct probe results for the SRC-II HD taken from the bottom of the undisturbed container and the subsequent partitions into a light and heavy sludye. It appears that components of mass 167 (carbazole) settle to the bottom of the container or partition preferentially into the sludge-like bottom materials which form when stored undisturbed in the repository for long periods of time. (Probably a solubility effect.) These results highlight the need to mix synthetic fuel samples thoroughly prior to subsampling for any purpose. 


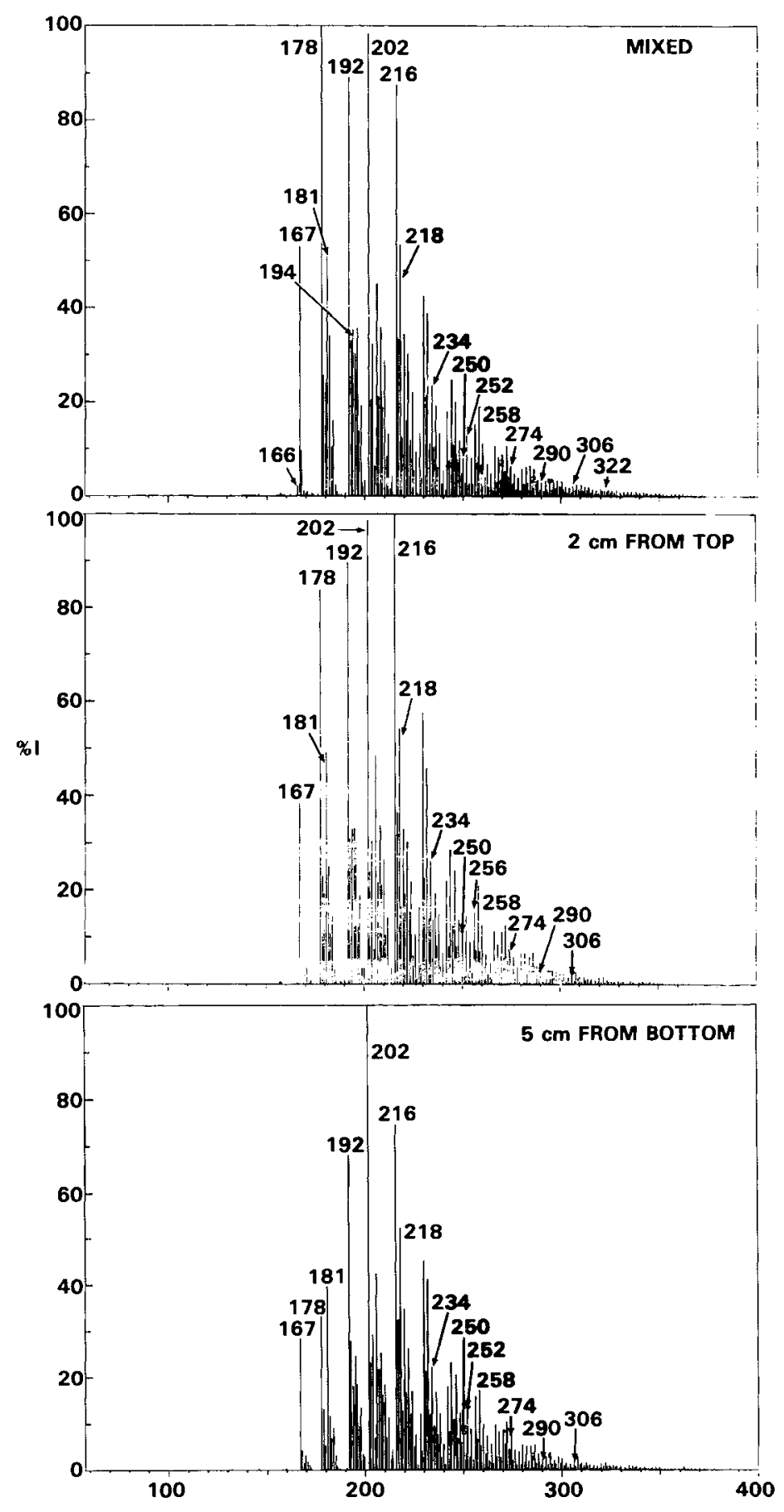

FIGURE 3.16. Direct Probe Results for SRC-II Heavy Distillate Sampled from a Mixed Container (top). Two $\mathrm{cm}$ from the Top of an Undisturbed Container (middle), and Five $\mathrm{cm}$ from the Bottom of an Undisturbed Container (bottom). 


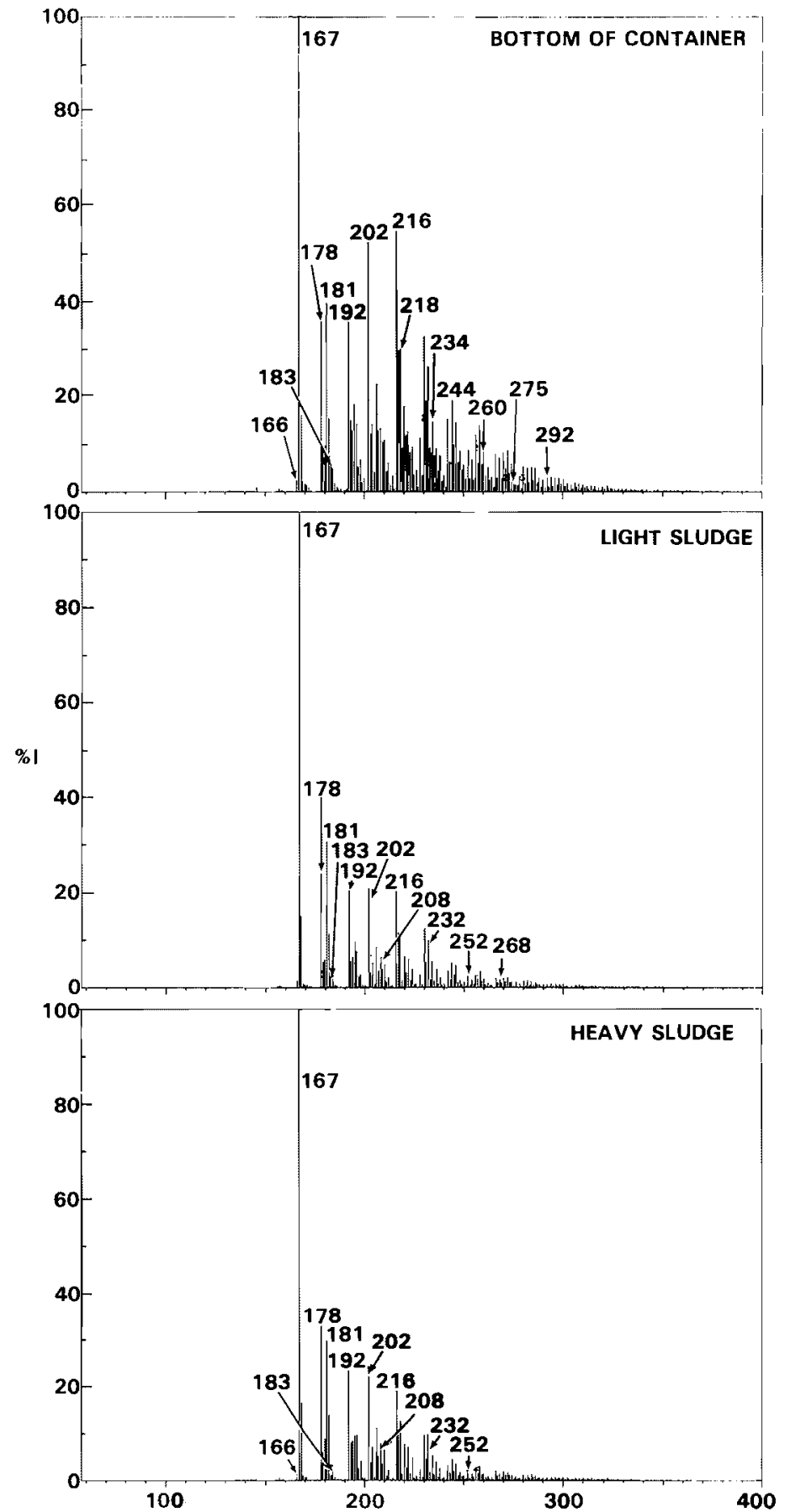

FIGURE 3.17. Direct Probe Results for SRC-II Heavy Distillate Sampled from the Bottom of an Undisturbed Container (top), and fron the Subsequently Partitioned Light (middle), and Heavy (bottom) Sludges. 


\subsection{MICROBIAL MUTAGENICITY}

\section{$3.4 .1 \quad \underline{4^{\circ} \mathrm{C}}$}

Results of the histidine reversion assay for mutagenicity at 12 doses ranging from $0.2 \mu \mathrm{g} / \mathrm{pl}$ ate to $50 \mu \mathrm{g} / \mathrm{plate}$ are given in Table 3.11 . Means and standard deviations of the means are yiven for the initial data collected in 1979 (23) and those in 1983. An initial (1979) value was not available for the SRC-II FOB; for comparative purposes the 1983 value of the SRC-II FOB that had been stored at $-20^{\circ} \mathrm{C}$, under a nitrogen atmosphere, in the dark was used. As can be seen in Table 3.11 and Figure 3.18, there was no significant change at the $95 \%$ confidence level in microbial mutagenicity after storage in the repository for four years. All samples had overlapping values when comparing the means and standard deviations of the mean from 1979 to 1983 determinations.

Table 3.12 presents mutagenicity data for the samples of SRC-II HD taken from varying depths of the undisturbed container (Teflon-lined stainless steel drum) stored at $4^{\circ} \mathrm{C}$. Results for the sample after mixing are also given. There were no significant differences at the $95 \%$ confidence limit. There was, however, a trend for the samples taken from the bottom of the container to have lower mutagenicity values than the samples taken nearer to the top of the container. Although the chemical data indicated the partitioning of carbazole into the sludge-like layers, there apparently is not a similar partitioning of the amino-PAH, the determinant mutagens in these samples. $(15,16)$

\section{$3.4 .2-20^{\circ}, 20^{\circ} \mathrm{C}$}

Results of the histidine reversion bioassay for the $-20^{\circ} \mathrm{C}$ and $20^{\circ} \mathrm{C}$ samples against TA98 at 12 doses ranging from $0.2 \mu \mathrm{g} / \mathrm{plate}$ to $50 \mu \mathrm{g} / \mathrm{plate}$ are given in Table 3.13 and shown in Figure 3.19. Comparisons of mutagenicity data under the various sample storage conditions are given in Table 3.14. This table contains a list of the samples which were compared, the storage parameters which were monitored, and the conclusions which were drawn from the mutagenicity data.

Overall results showed a slight (although not significant at the $95 \%$ level) decrease in mutagenicity for the samples stored at room temperature in the darkness (conditions 5 and 6 ) versus those stored at $-20^{\circ} \mathrm{C}$ (control, 
TABLE 3.11. Results of Microbial Mutagenicity Tests After Storage at $4^{\circ} \mathrm{C}$, in the Dark, Under a Nitrogen Atmosphere for Four Years

\begin{tabular}{|c|c|c|c|}
\hline & Sample & $1979(\mathrm{a})$ & 1983 \\
\hline SRC-I 1 & $\begin{array}{l}\text { Light } 0 i 1 \\
3317-073-16\end{array}$ & $<0.01$ & $0^{(b)}$ \\
\hline SRC-I & $\begin{array}{r}\text { Wash Solvent } \\
3317-075-19\end{array}$ & $<0.01$ & 0 \\
\hline SRC-I & $\begin{array}{l}\text { Process Solvent } \\
3317-066-26 \\
3317-066-27\end{array}$ & $12.3 \pm 1.9$ & $\begin{array}{l}11.6 \pm 4.5 \\
11.0 \pm 3.3\end{array}$ \\
\hline SRC-I I & $\begin{array}{l}\text { Naphtha } \\
3317-125-01 \mathrm{~B} \\
3317-055-04\end{array}$ & $<0.01$ & $\begin{array}{l}0 \\
0\end{array}$ \\
\hline SRC-I I & $\begin{array}{l}\text { Middle Distillate } \\
3317-058-02 \\
3317-129-02 \\
3317-130-02 \\
3317-131-02\end{array}$ & $<0.01$ & $\begin{array}{l}0 \\
0 \\
0 \\
0\end{array}$ \\
\hline SRC-I I & $\begin{array}{l}\text { Fuel 0il Blend } \\
3317-079-23 \\
3317-079-24 \\
3317-079-25 \\
3317-079-26\end{array}$ & $11.4 \pm 3.2^{(c)}$ & $\begin{array}{l}7.8 \pm 1.4 \\
6.8 \pm 1.7 \\
6.4 \pm 1.6 \\
8.5 \pm 0.6\end{array}$ \\
\hline SRC-I I & $\begin{array}{l}\text { Heavy Distillate } \\
3317-32-02 \\
3317-134-02 \\
3317-015-11\end{array}$ & $40 \pm 23$ & $\begin{array}{l}26.9 \pm 1.8 \\
34.7 \pm 8.5 \\
31.9 \pm 8.0\end{array}$ \\
\hline
\end{tabular}

(a) From reference 23 .

(b) No mutagenic activity detected.

(c) No data available from 1979, the value fror, the sample stored at $-20^{\circ} \mathrm{C}$, under nitrogen, in the dark was used for reference. 


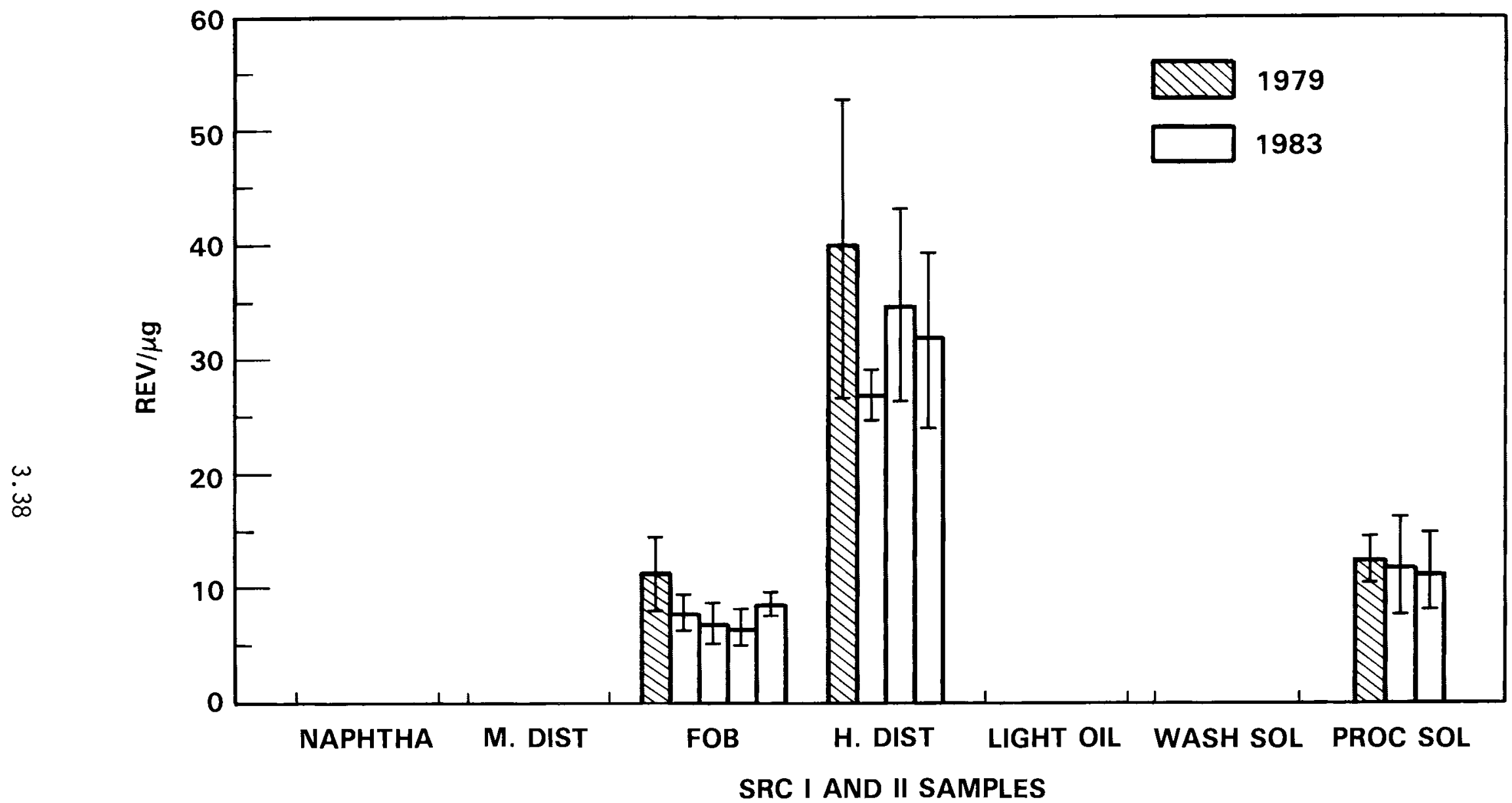

FIGURE 3.18. Comparison of Microbial Mutagenicity for SRC Materials in 1979 Versus Those Stored in the Repository at $4^{\circ} \mathrm{C}$, in the Dark, Under a Nitrogen Atmosphere in 1983. Replicates Refer to Those Identified in Table 3.11 . 
TABLE 3.12. Results of Microbial Mutagenicity Tests for Samples from Varying Depths of an Undisturbed Container of SRC-II Heavy Distillate Stored at $4^{\circ} \mathrm{C}$, in the Dark, Under a Nitrogen Atmosphere

$\begin{array}{lc}\text { Sample Location } & \text { Mutagenicity (rev/ug) } \\ \text { Mixed } & 21.8 \pm 9.0 \\ 2 \text { cm from the Top } & 27.6 \pm 10.1 \\ 5 \text { cm from the Bottom } & 21.4 \pm 6.3 \\ \text { Botton } & 15.0 \pm 6.1 \\ \text { Light Sludye }(a) & 17.9 \pm 4.5 \\ \text { Heavy Sludye }(a) & \end{array}$

(a) The two sludges were partitioned from the sample taken from the bottom of the storage container.

TABLE 3.13. Results of Microbial Mutagenicity Tests Against $S$. typhimurium $\mathrm{TA98},-20^{\circ} \mathrm{C}$ and $20^{\circ} \mathrm{C}$ Stability Study

Sample

3317-079-25 FOB, Control

3317-07y-25 FOB, Condition 1 (a)

3317-079-25 FOB, Condition 2

3317-079-25 FOB, Condition 3

3317-079-25 FOB, Condition 4

3317-079-25 FOB, Condition 5

3317-U79-2b FOB, Condition 6

$\mathrm{FOB}$ diluted in $\mathrm{MeC} \mathrm{l}_{2}$ at $-20^{\circ} \mathrm{C}$

for three years

$$
\begin{gathered}
\text { Rev/.19 } \\
11.4 \pm 3.2 \\
9.8 \pm 0.5 \\
7.0 \pm 1.4 \\
0 \text { (b) } \\
4.4 \pm 0.3 \\
6.9 \pm 0.6 \\
7.0 \pm 0.6 \\
3.1 \pm 1.6
\end{gathered}
$$

(a) Refers to conditions explained in Experimental Methods Section, Figure 2.1.

(b) No mutayenic activity detected. 

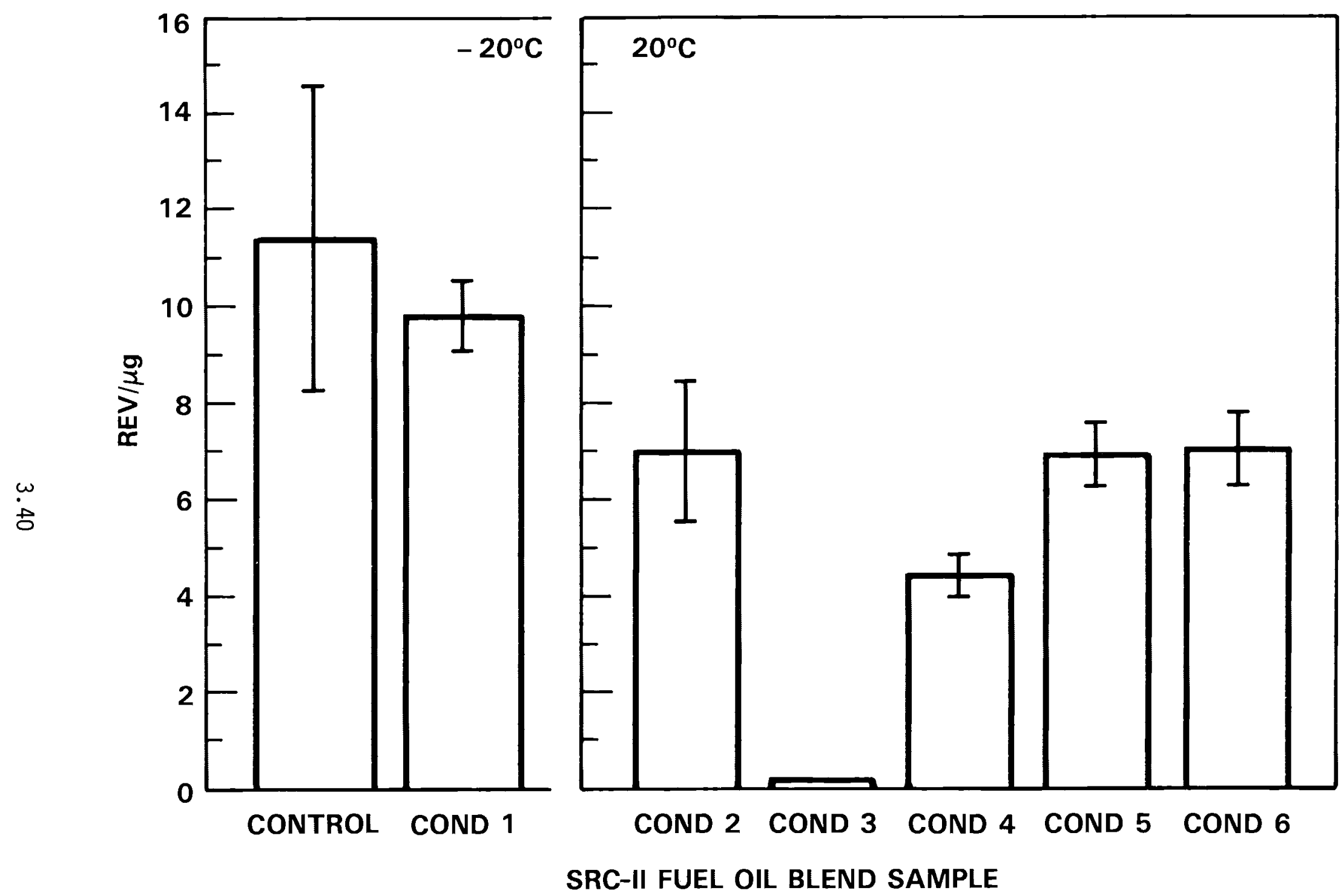

FIGURE 3.19. Comparison of Microbial Mutagenicity for an SRC-II Fuel $0 i 1$ Blend Stored Under Various Conditions at $-20^{\circ} \mathrm{C}$ and $20^{\circ} \mathrm{C}$. Conditions Refer to Those in Figure 2.1 of the Experimental Methods Section 2.0. 


\section{TABLE 3.14. Mutagenic Effects ${ }^{(a)}$ of Storage Under Various Conditions at $-20^{\circ} \mathrm{C}$ and $20^{\circ} \mathrm{C}$ for One Year}

\begin{tabular}{|c|c|}
\hline Sample Comparison(b) & $\operatorname{Parameter}(s)$ Monitored \\
\hline Condition 3 versus Condition 4 & Dilution in Methylene Chloride \\
\hline Control versus Condition 1 & Nitrogen versus Air Atmosphere \\
\hline Condition 2 versus Condtion 4 & Nitrogen versus Atr Atmosphere \\
\hline Condition 5 versus Condition 6 & Nitrogen versus Air Atmosphere \\
\hline $\begin{array}{l}\text { Control versus Condition } 5 \\
\text { Condition } 1 \text { versus Condtion } 6\end{array}$ & Temperatures of $-20^{\circ} \mathrm{C}$ versus $20^{\circ} \mathrm{C}$ \\
\hline Condition 2 versus Condition 5 & Light versus Dark \\
\hline Condition 4 versus Condition 6 & Light versus Dark \\
\hline $\begin{array}{l}\text { Control versus Condition } 2 \\
\text { Condition } 1 \text { versus Condition } 4\end{array}$ & Light plus Elevated Temperature \\
\hline Control versus Condition 6 & Air Atmosphere plus Elevated Temperature \\
\hline Control versus Condition 4 & Air Atmosphere, Elevated Temperature, Light \\
\hline Control versus Condition 3 & $\begin{array}{l}\text { Air Atmosphere, Elevated Temperature, Light, } \\
\text { Dilut fon }\end{array}$ \\
\hline
\end{tabular}

- Driution of a sample in Methylene chloride eliminated the mutagenic response with other conditions of light, alr atmosphere, and room temperature held constant (under these conditions the mutagenicity only decreased significantly)

- No change in mutagenicity between an air or nitrogen atmosphere at $-20^{\circ} \mathrm{C}$ in the tark

- Mutagenicity decreased under an air atmosphere versus a nitrogen at:nosphere in the light at room temperature

- No change in mutagenicity between an air or nitrogen atimosphere in the darix at room temperature

- Storage of a sample in the dark at an elevated temperature decreased the mutagenic response slightly but not significantly regardless of air or nitrogen cover atmospheres

- No change in mutagenic response between light or darkness under a nitrogen atmosphere at room temperature

- Light decreased the mutagenicity when stored under an air atmosphere at room temperature

- Mutagenicity only decreased significantly under conditfons of lighţ and room temperature under an air atmosphere. Under a nitrogen atmosinhere there was a slight but not significant decrease.

- Storage of a sample at room temperature under an air atmosphere decreased the mutagenicity slightly but not significantly

- Mutagenicity decreased significantly in the 1 ight inder an air atmosphere at roon temperature.

- Mutagenicity was eliminated by storage dfluted $1: 20$ or $1: 2700$ in methylene chloride in the light under an air atmosphere at room temperature

(a) As expressed in the histidine reversion test against TA98.

(b) Conditions correspond to those shown in Figure 2.1, Experimental Methods Section 2.0. 
condition 1). A significant change in mutagenicity was noted when the FOB sample was left stored at room temperature, in the light, under an air atmosphere (condition 4); the mutagenicity decreased by more than a factor of two from the control. However, the mutagenic response of the sample stored under the same conditions except under a nitrogen atomsphere (condition 2) did not show a similar mutagenicity decrease. Mutagenic response was completely eliminated when the sample was stored diluted in methylene chloride at room temperature, in the light, under an air atmosphere. Mutagenic response was also significantly decreased after storage at $-20^{\circ} \mathrm{C}$ diluted in methylene chloride under nitrogen for three years.

Dilution in methylene chloride proved to be the harshest storage condition with regard to maintenance of sample mutagenicity. The combination of air atmosphere, room temperature, and light was another storage condition which caused significant mutagenicity decrease. Since the chromatographic data showed no change in the chemical composition of this sample, trace component degradation is probably leading to the decreased mutagenicity. Amino-PAH are the likely candidates which are degrading. Mutagenicity of all other storage samples was not significantly changed from the control (Table 3.14).

\section{$3.4 .3 \quad 60^{\circ}, 100^{\circ} \mathrm{C}$}

Results of the microbial mutagenicity test at 12 doses with means and standard deviations calculated from a dose response two times that of background and a correlation coefficient greater the 0.8 are given in Figure 3.20. The data indicated an elimination of mutagenicity when the sample was stored at $60^{\circ} \mathrm{C}$ for 32 weeks and at $100^{\circ} \mathrm{C}$ for 26 weeks. (Mutagenicity may have been eliminated prior to these points, but mutagenicity tests were not performed on a weekly basis to monitor when mutagenicity was gone.) After storage at $100^{\circ} \mathrm{C}$ for 6 weeks, mutagenicity had decreased by more than a factor of three from the control.

\subsubsection{Summary}

Mutagenicity of samples stored for four years in the repository at $4^{\circ} \mathrm{C}$, in the dark, under a nitrogen atmosphere, was not significantly altered. Conditions which decreased or eliminated mutagenicity were storage at room temperature, in the light, under an air atmosphere either diluted in methylene F3.20 


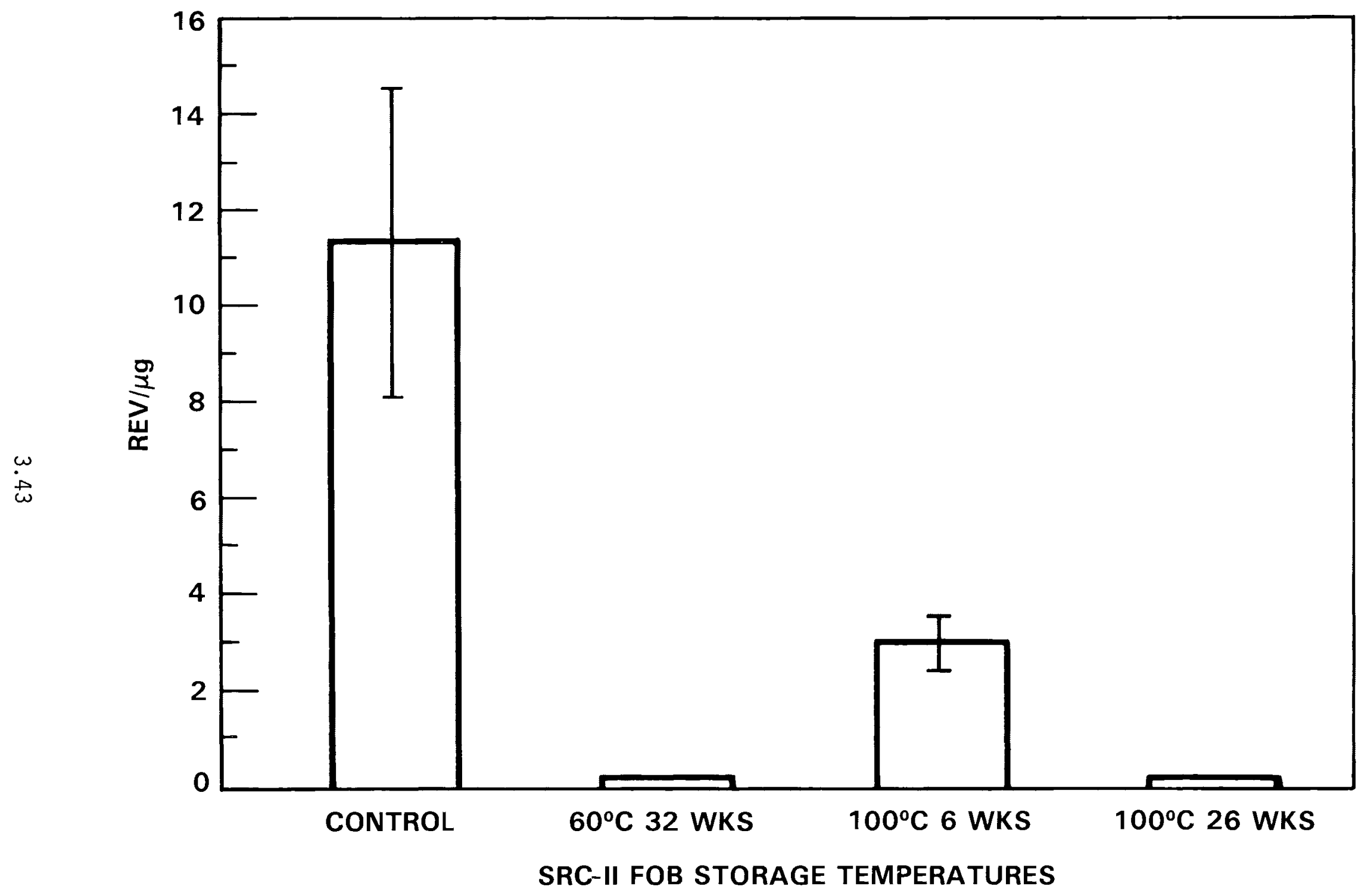

FIGURE 3.20. Comparison of Microbial Mutagenicity Data for SRC-II Fuel Oil Blend Under Accelerdated Conditions of Elevated Temperatures of $60^{\circ} \mathrm{C}$ and $100^{\circ} \mathrm{C}$. 
chloride or undiluted for one year, or storage at $60^{\circ} \mathrm{C}$ and $100^{\circ} \mathrm{C}$ in the dark under an air atmosphere for an extended period of time (32 weeks, 26 weeks, respectively). Mutagenicity was also significantly decreased when stored for three years at $-20^{\circ} \mathrm{C}$ after dilution with methylene chloride. There was no siynificant difference in mutagenicity from samples of SRC-II HD taken from varying depths of the unmixed container stored at $4^{\circ} \mathrm{C}$.

The histidine reversion assay is particularly sensitive to concentration changes in the trace constituent amino-PAH $(15,16)$. Because of this, it has been used in the past as a principal indicator of synfuel biological activity. The mutayenicity data for the repository samples, together with the chemical analysis data, indicated that the method used for sample storaye at PNL has maintained the inteyrity of the bioloyical activity of the samples stored in the repository. These samples can continue to be used in bioloyical testing proyrams with assurance that the data obtained today are comparable with data obtained as long as four years ago. 


\subsection{CONCLUSIONS}

The stability studies performed on seventeen SRC samples ranging in boiling point from ambient to $850^{\circ} \mathrm{F}$ showed that the major chemical composition of the materials as inonitored by high resolution gas chromatography did not change under the storage conditions of the repository, which were $4^{\circ} \mathrm{C}$, in inert containers, under a nitroyen atmosphere, in the dark. Samples were monitored after two years of storage. It was also found from microbial mutagenicity studies that after four years in the repository there was no significant change in the biological activity of any of the SRC materials. The materials which originally displayed mutagenicity maintained the same mutagenicity, and materials which originally were not mutagenic were still inactive. The SRC liquids have maintained their integrity upon storage in the repository. It was found from sampling varying depths of a storage container, however, that gross changes in the chemical composition occur due to the formation of a sludge-like material in the SRC-II heavy distillate. This sludge-like material contains elevated concentrations of carbazole. However, this sludge-like material can be completely eliminated by thorough mixing. Samples must be inixed to homogeneity after storage to ensure that the overall chemical composition remains unchanged.

Studies compariny the stability of an SRC-II FOB at room temperature versus storage in the freezer at $-20^{\circ} \mathrm{C}$ showed there was no change in the chemical composition as monitored by high resolution gas chromatography. Samples stored under various parameters of air versus nitrogen atmosphere and ambient light versus darkness at room temperature and $-20^{\circ} \mathrm{C}$ for one year showed there was no significant differences in the chemical composition of any of the samples. There was evidence, however, that trace components such as amino-PAH degraded at room temperature, in the light, under an air atmosphere since the microbial mutagenicity of samples stored under these conditions for one year decreased significantly.

Both the chemical composition and mutagenicity of FOB samples changed when stored diluted in methylene chloride, in the light, under an air atmosphere at room temperature. After one year of storage under these conditions, the 
microbial mutagenicity was eliminated. The major chemical constituents which degraded were hydroxylated $P A H$, such as the cresols, indanol, and more highly alkylated phenols, and partially hydrogenated $P A H$, such as alkylated indans, and tetralin (or any co-eluting species of the above). Similar results were noted for samples stored for three years at $-20^{\circ} \mathrm{C}$, diluted in methylene chloride, under a nitrogen atmosphere.

Storage of SRC-II FOB at increased temperatures of $60^{\circ} \mathrm{C}$ and $100^{\circ} \mathrm{C}$ showed significant changes in chemical composition due to volatility effects; early eluting peaks decreased in concentration while later eluting peaks increased in concentration. Components which showed consistent degradation (rather than volatility changes) over time were hydroxylated $P A H$, such as the cresols and indanol, and partially hydrogenated $P A H$, such as alkylated indans (or any coeluting species of the previously mentioned components). Further study into the more trace components in the sample showed the nitrogen heterocycles of indole almost completely degraded and the total amino-PAH content decreased by more than a factor of two after storage at $100^{\circ} \mathrm{C}$ for 16 weeks. The microbial mutagenicity of this sample had significantly decreased after 6 weeks of storage. The microbial mutagenicity of the FOB samples was completely eliminated after storage at $60^{\circ} \mathrm{C}$ for 32 weeks and $100^{\circ} \mathrm{C}$ for 26 weeks.

It appears that the amino-PAH and phenolic materials are the most susceptible components to degradation in the complex SRC materials. These components may be used as benchmark compounds to monitor the decomposition of SRC materials over long periods of time in the repository.

From a statistical standpoint, emphasis of replication should be placed on duplicating storage vials, since the differences in vial subsamples (after dilution) and chromatographic runs were not found to be significant. Samples should also be analyzed on a random rather than ordered basis. The order in which chromatographic runs were made showed a definite (although not significant) trend; the later chromatograms had lower relative concentrations than the earlier runs. 


\subsection{ABBREVIATIONS}

$\begin{array}{ll}\text { ANOVA } & \text { Analysis of Variance } \\ \text { Amino-PAH } & \text { Anino-Substituted Polycyclic Aronatic Hyrocarbons } \\ \text { FOB } & \text { Fuel Oil Blend } \\ \text { GC } & \text { Gas Chromatography } \\ \text { GC/MS } & \text { Gas Chromatography/Mass Spectrometry } \\ \text { HD } & \text { Heavy Distillate } \\ \text { HPAH } & \text { Hydroxylated PAH } \\ \text { HRMS } & \text { High Resolution Mass Spectronetry } \\ \text { ISTD } & \text { Internal Standard } \\ \text { LO } & \text { Light Oil } \\ \text { MD } & \text { Middle Distillate } \\ \text { N } & \text { Naphtha } \\ \text { N-PAC } & \text { Nitrogen-Containing PAC } \\ \text { PNL } & \text { Pacific Northwest Laboratory } \\ \text { PAC } & \text { Polycyclic Aromatic Compound } \\ \text { PAH } & \text { Polycyclic Aromatic Hydrocarbon } \\ \text { PFP } & \text { Pentafluoropropionic Anhydride } \\ \text { PS } & \text { Process Solvent } \\ \text { rev/ } / 4 & \text { Revertants Per Microgram } \\ \text { S. } & \text { Salmonella } \\ \text { SRC } & \text { Solvent Refined Coal } \\ \text { T } & \text { Time } \\ \text { WS } & \text { Wash Solvent }\end{array}$


$\bullet$ 


\subsection{REFERENCES}

1 Kershaw, J. R. and U. Gray. 1980. "Ayeiny Studies on Coal Hydropyrolysis Liquids. Fuel 59:436-438.

2 Karn, F. S., F. R. Brown and R. A. Friedel. 1976. Aging Studies of the SYNTH()IL Product, Part I: Viscosity Changes. ERDA 76/1. Energy Research and Development Administration, Pittsburgh, Pennsylvania.

3 Karn, F. S. and F. R. Brown. 1976. Aging Studies of the SYNTHOIL Product, Part II: Effect of Time, Temperature and Atmosphere. ERDA 76/2. Energy Research and Development Administration, Pittsburgh, Pennsylvania.

4 Karn, F. S., F. R. Brown, and A. G. Sharkey Jr. 1977. "Aging Characteristics of Coal Liquids." Am. Chem. Soc., Div Fuel Chem., Prepr. $22: 227-232$.

5 Frankenfeld, J. W., W. F. Taylor and D. W. Brinkman. 1983. "Storage Stability of Synfuels from 0il Shale. 1. General Features of Sediment Formation." Ind. Eng. Chem. Prod. Res. Dev. 22:608-614.

6 Frankenfeld, J. W., W. F. Taylor and D. W. Brinkman. 1983. "Storage Stability of Synfuels from $0 i l$ Shale. 2. Effects of Nitrogen Compound Type and the Influence of other Nonhydrocarbons on Sediment Formation in Model Fuel Systems." Ind. Eng. Chem. Prod. Res. Dev. 22:615-621.

7 Frankenfield, J. W., W. F. Taylor, and D. W. Brinkman. 1983. "Storage Stability of Synfuels from 0il Shale. 3. Studies with Actual ShaleDerived Middle Distillates." Ind. Eng. Chem. Prod. Res. Dev. 22:622-627.

8 Hara, T., L. Jones, N. C. Li, and K. C. Tewari. 1981. "Aging of SRC Liquids." Fuel 60:1143-1148.

9 Jones, L and N. C. Li. 1983. "Ageing of SRC-II Middle Distillate from Illinois No. 6 Coal. 1. In Presence of Copper and 0xygen." Fuel 62:11561160.

10 Hara, T., L. Jones, and N. C. Li. 1982. "Aging of Coal-Derived Liquids." Bull. Fac. Eng., Yokahama National University 31:205-215.

11 White, C. M., L. Jones, and N. C. Li. 1984. "Ageing of SRC-II Middle Distillate from Illinois No. 6 Coal." Fuel 63 (in press).

12 Later, D. W., M. L. Lee, K. D. Bartle, R. C. Kong, and D. L. Vassilaros. 1981. "Chemical Class Separation and Characterization of Organic Compounds in Synthetic Fuels." Anal. Chem. 53:1612-1620. 
13 Later, D. W., M. L. Lee, R. A. Pelroy, and B. W. Wilson. 1982. "Identification and Mutagenicity of Nitrogen-Containing Polycyclic Aromatic Compounds in Synthetic Fuels." In: Polynuclear Aromatic Hydrocarbons: Physical and Biological Chemistry (M. Cooke and A. J. Dennis, Eds.), Battelle Press, Columbus, Ohio, pp. 427-438.

14 Mahlum, D. D., M. E. Frazier, R. A. Pelroy, and R. E. Renne. 1983. Comparison of In Vitro and In Vivo Studies with Coal Liquids from the SRC-II Process. PNL-4836. Pacific Northwest Laboratory, Richland, Washington. NTIS, Springfield, Virginia.

15 Wilson, B. W., R. A. Pelroy, and J. T. Cresto. 1980. "Identification of Primary Aromatic Amines in Mutagenically Active Subfractions from Coal Liquefaction Materials." Mutat. Res. 79:193-202.

16 Guerin, M. R., C. -h. Ho, T. K. Rao, B. R. Clark, and J. L. Epler. 1980. "Polycyclic Aromatic Amines as Determinant Chemical Mutagens in Petroleum Substitutes." Environ. Res. 23:42-53.

17 Later, B. W., M. L. Lee, and B. W. Wilson. 1982. "Selected Detection of Amino Polycyclic Aromatic Compounds in Solvent Refined Coal Products." Anal. Chem. $54: 11 \%-123$.

18 Ames, B. N., J. McCann, and E. Yamasaki. 1975. "Methods for Detecting Carcinogens and Mutagens with Salmonella/Manmalian-Microsome Mutagenicity Test." Mutat. Res. 31:347-364.

19 ARTHUR statistical software package, Laboratory of Chemometrics, vepartment of Chemistry, University of Georgia, Athens, Georyia.

20 MINITAB statistical software packaye, Statistics Department, Pennsylvania State University, University Park, Pennsylvania.

21 RUMMAGE statistical software package, Applied Statistics Group, Brigham Young University, Provo, Utah.

22 Neter, J. and W. Wasserman. 1974. Applied Linear Statistical Models. Richard D. Irwin, Inc., Homewood, Illinois, $842 \mathrm{pp}$.

23 PNL-3189. 1979. Biomedical Studies on Solvent Refined Coal (SRC-II) Liquefaction Materials: A Status Report. Pacific Northwest Laboratory, Richland, Washington. NTIS, Springfield, Viryinia. 


\subsection{APPENDIX I}

MEANS AND STANDARD DEVIATIONS OF NORMALIZED AMOUNTS OF INDIVIOUAL COMPONENTS OF SRC MATERIALS

The tables on the following payes present the results of chromatoyraphic analyses of the stability samples under all storage conditions. Tables 7.1 to 7.17 contain the mean and standard deviation of the mean for each peak monitored in the 17 samples stored in the repository, at $4^{\circ} \mathrm{C}$, in the dark. The first two columns in each of these tables represent the normalized means correcting the time $=2$ years to the same dilution made at the beginning of the experiment (time $=0$ ). The data under the columns labeled "Raw Data" are the uncurrected means and standard deviations determined using different dilution factors at time $=2$ years. All dilutions are noted in the legends.

Tables 7.18 and 7.19 contain the means and standard deviations of the mean for the peaks monitored in the $-20^{\circ} \mathrm{C}$ and $20^{\circ} \mathrm{C}$ studies. Two sets are presented because the data were collected on two separate occasions using slightly different operating parameters and dilutions. Tables 7.20 and 7.21 contain the results of the $60^{\circ} \mathrm{C}$ and $100^{\circ} \mathrm{C}$ accelerated stability studies, respectively.

Table 7.22 contains the chromatographic results from the four SRC-II FOB samples after dilution in methylene chloride and storage at $-20^{\circ} \mathrm{C}$, under a nitroyen atmosphere, in the dark, for three years. This table should be compared to Tables 7.8-7.11 for time $=0$ data.

The numbers in the column labeled "Peak No." correspond to discrete chemical compounds which have been identified by GC/MS and their identifications are given. It should be noted that a compound with a specific number, e.y. 15, always refers to the same chemical component throuyhout Tables 7.1 to 7.22 . It should also be noted that trace component species could co-elute with the major component identifications given. 
TABLE 7.1. Chromatographic Results for SRC-II Naphtha Sample 3317-125-01B Stored at $4^{\circ} \mathrm{C}$, in the Dark, Under a Nitrogen Atmosphere

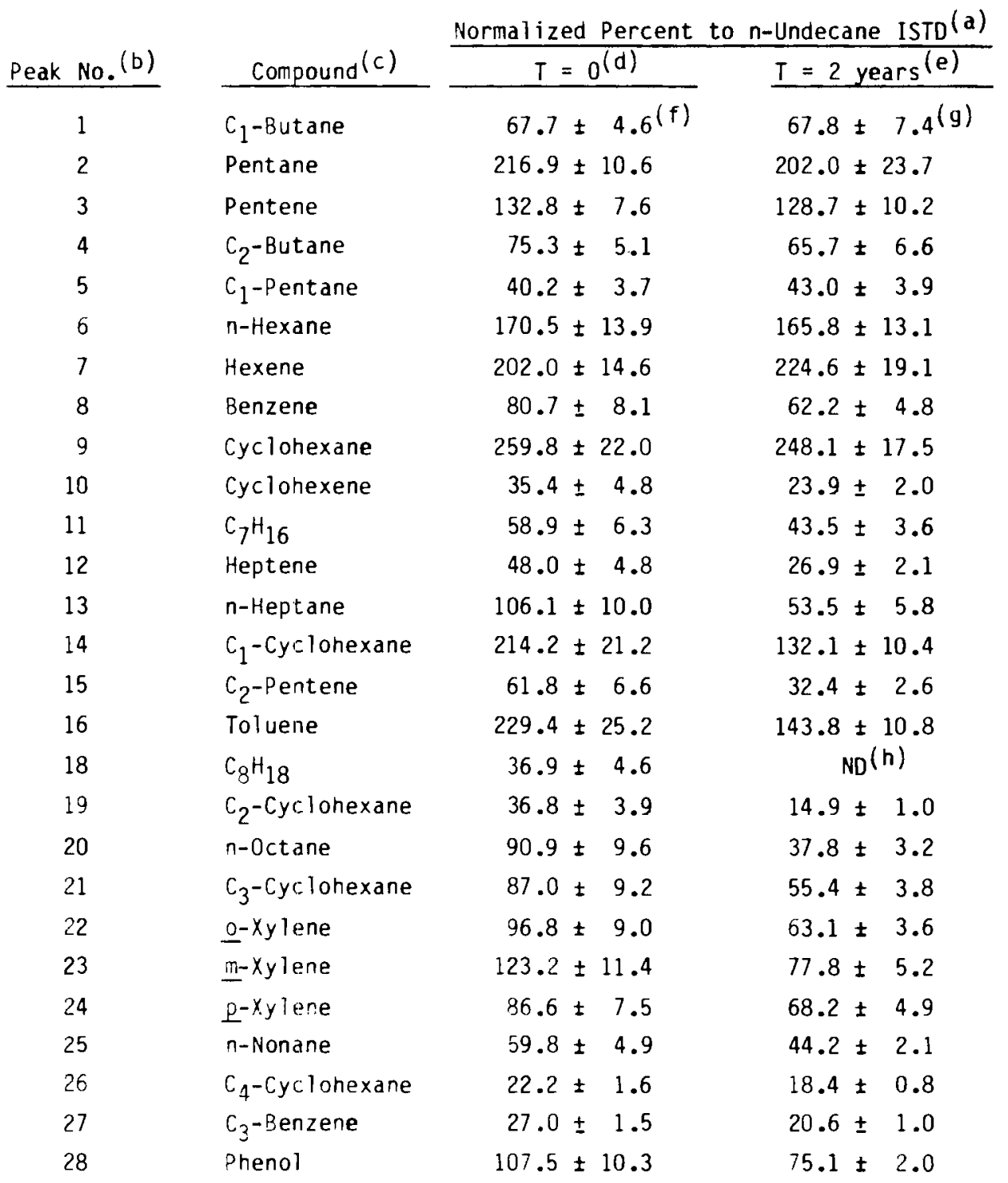

(a) Based on the inteyration of peak heights

(b) Numbers refer to $\delta$ zaxs in Figure 3.1 , Results and Discussion Section.

C'Ident ified by GC/MS

a) Based on approximately $26 \mathrm{mg} / \mathrm{mL} \mathrm{n}$-Undecane ISTD, neat, manual injections, 1980.

3) Based on an unk fown amount of n-Undecane ISTU, neat, manual in.e. : ns, 1982

i) Based on 5 runs.

j) Based on ? runs.

.) No data. 
TABLE 7.2. Chromatographic Results for SRC-II Naphtha Sample 3317-055-04 Stored at $4^{\circ} \mathrm{C}$, in the Dark, Under a Nitrogen Atmosphere

\begin{tabular}{|c|c|}
\hline Peak No. (b) & Compound $(c)$ \\
\hline 1 & $C_{1}$-Butane \\
\hline 2 & Pentane \\
\hline 3 & Pentene \\
\hline 4 & $C_{2}$-Butane \\
\hline 5 & $C_{1}$-Pentane \\
\hline 6 & n-Hexane \\
\hline 7 & Hexene \\
\hline 8 & Benzene \\
\hline 9 & Cyclohexane \\
\hline 10 & Cyclohexene \\
\hline 11 & $\mathrm{C}_{7} \mathrm{H}_{16}$ \\
\hline 12 & Heptene \\
\hline 13 & n-Heptane \\
\hline 14 & $C_{1}$-Cyclohexane \\
\hline 15 & $c_{2}$-Pentene \\
\hline 16 & Toluene \\
\hline 18 & $\mathrm{C}_{8} \mathrm{H}_{18}$ \\
\hline 19 & $C_{2}-C_{y c}$ lohexane \\
\hline 20 & n-0ctane \\
\hline 21 & $C_{3}$-Cyclohexane \\
\hline 22 & $\underline{0}-x y l e n e$ \\
\hline 23 & III-Xylene \\
\hline 24 & $p$-xylene \\
\hline 25 & $n$-Nonane \\
\hline 26 & $\mathrm{C}_{4}$-Cyclohexane \\
\hline 27 & $C_{3}$-Benzene \\
\hline 28 & Phenol \\
\hline
\end{tabular}

\begin{tabular}{|c|c|}
\hline$T=0^{(d)}$ & $T=2$ years $(e)$ \\
\hline $\mathrm{No}(f)$ & $20.8+3.2^{(9)}$ \\
\hline $130.5 \pm 18.1^{(f)}$ & $73.9 \pm 9.6$ \\
\hline $100.6 \pm 11.3$ & $65.9 \pm 9.0$ \\
\hline $56.5 \pm 5.0$ & $34.9 \pm 4.6$ \\
\hline $28.4 \pm 2.5$ & $20.8 \pm 2.9$ \\
\hline $123.2 \pm 9.3$ & $87.8 \pm 11.7$ \\
\hline $155.1 \pm 9.6$ & $121.1 \pm 15.1$ \\
\hline $52.9 \pm 2.6$ & $31.3 \pm 3.0$ \\
\hline $193.7 \pm 8.5$ & $131.4 \pm 16.9$ \\
\hline $27.7 \pm 1.6$ & $14.7 \pm 2.0$ \\
\hline $43.4 \pm 1.5$ & $24.3 \pm 2.8$ \\
\hline $35.9 \pm 3.8$ & $16.7 \pm 2.1$ \\
\hline $93.3 \pm 3.0$ & $35.9 \pm 4.5$ \\
\hline $174.5 \pm 4.9$ & $76.5 \pm 9.0$ \\
\hline $56.0 \pm 1.4$ & $21.7 \pm 2.9$ \\
\hline $154.7 \pm 3.4$ & $69.0 \pm 7.1$ \\
\hline $31.2 \pm 0.6$ & VD \\
\hline $31.8 \pm 0.6$ & $10.7 \pm 1.6$ \\
\hline $81.5 \pm 2.0$ & $26.8 \pm 3.3$ \\
\hline $82.1 \pm 1.0$ & $38.0 \pm 3.9$ \\
\hline $75.1 \pm 1.1$ & $36.3 \pm 3.9$ \\
\hline $103.2 \pm 1.2$ & $48.0 \pm 4.0$ \\
\hline $81.7 \pm 1.4$ & $49.5 \pm 4.0$ \\
\hline $56.0 \pm 0.8$ & $33.5 \pm 3.2$ \\
\hline $31.4 \pm 0.5$ & $19.8 \pm 1.3$ \\
\hline $68.6 \pm 1.7$ & $43.6 \pm 1.0$ \\
\hline $275.2 \pm 9.1$ & $132.7 \pm 31.0$ \\
\hline
\end{tabular}

(a) Based on the integration of peak heights.

(b) Numbers refer to peaks in Figure 3.1, Results and Discus ion Sertion.

(c) Identified by GC/MS.

(d) Based on approximately $23.2 \mathrm{mg} / \mathrm{mL} n$-Undecane ISTO, neat, Fidiual injections, 1980.

(e) Based on an unknown allount of II-Indecane ISTI), neat, manual injections, 1981 .

(f) No data.

(y) Based on 4 runs. 
TABLE 7.3. Chromatographic Results for SRC-I Light 0il Sample 3317-073-16 Stored at $4^{\circ} \mathrm{C}$, in the Dark, Under a Nitrogen Atmosphere

\begin{tabular}{|c|c|c|c|c|}
\hline Peak & No. $(b)$ & Compound $(c)$ & \multicolumn{2}{|c|}{$\begin{array}{cc}\text { Normalized Percent to n-Unuecand } 15 T)^{(a)} \\
T=0^{(d)} & T=2 \text { years }\end{array}$} \\
\hline & 1 & $C_{1}$-Butarie & $49.1 \pm 5.9^{(f)}$ & $56.2 \pm 7.96$ \\
\hline & 2 & Pent ane & $177.6 \pm 10.4$ & $211 . \pm \pm 33$. \\
\hline & 3 & Pentene & $119.8 \pm 5.0$ & $164.3 \pm 23 .:$ \\
\hline & 4 & $c_{2}$-Butane & $82.7 \pm 5.0$ & $107.0 \pm 13.6$ \\
\hline & 5 & $c_{1}$-Pentane & $36.7=2.4$ & $60.5 \pm 7.6$ \\
\hline & 6 & n-Hexane & $162.4 \pm 12.1$ & $232.6 \pm 32.7$ \\
\hline & 7 & Hexene & $172.0 \pm 14.7$ & $275.5 \pm 35.3$ \\
\hline & 8 & Benzene & $55.4 \pm 4.0$ & $48.4 \pm 6.1$ \\
\hline & 9 & Cyclohexane & $145.2 \pm 14.0$ & $193.1 \pm 23.6$ \\
\hline & 10 & Cyclohexene & $30.4 \pm 3.1$ & $27.6 \pm 3.5$ \\
\hline & 11 & $\mathrm{C}_{7} \mathrm{H}_{16}$ & $51.8 \pm 5.1$ & $53.5 \pm 6 .:$ \\
\hline & 12 & Heptene & $36.9 \pm 3.8$ & $30.5 \pm 3.6$ \\
\hline & 13 & $n$-Heptane & $103.3 \pm 11.1$ & $68.0 \pm 7.4$ \\
\hline & 14 & $c_{1}-c_{y c l o h e x a n e}$ & $102.2 \pm 11.2$ & $76.1 \pm 7.8$ \\
\hline & 15 & $c_{2}$-Pentene & $42.1 \pm 4.4$ & $28.5 \pm 3.2$ \\
\hline & 16 & Toluene & $76.7 \pm 7.8$ & $50.5 \pm 4.7$ \\
\hline & 17 & $\mathrm{C}_{8} \mathrm{H}_{18}$ & $21.7 \pm 2.9$ & ND $(h)$ \\
\hline & 18 & $\mathrm{C}_{8} \mathrm{H}_{18}$ & $16.6 \pm 2.3$ & ND \\
\hline & 19 & $\mathrm{C}_{2}$-Cyclohexane & $19.9 \pm 2.0$ & $9.4 \pm 0.8$ \\
\hline & 20 & n-Octanę & $56.1 \pm 5.4$ & $29.2 \pm 3.5$ \\
\hline & 21 & $C_{3}-C_{y c l}$ ohexane & $31.5 \pm 4.3$ & $22.1 \pm 2.1$ \\
\hline & 22 & $\underline{0}-x y l e n e$ & $28.0 \pm 3.2$ & $19.1 \pm 1.5$ \\
\hline & 23 & $m-x y l e n e$ & $37.1 \pm 3.3$ & $20.9 \pm 1.7$ \\
\hline & 24 & $p-x y l e n e$ & $20.8 \pm 2.0$ & $15.3 \pm 0.4$ \\
\hline & 25 & n-Nonane & $33.9 \pm 2.6$ & $25.4 \pm 2.0$ \\
\hline & 26 & $C_{4}$-Cyclohexane & $9.3 \pm 0.9$ & $7.4 \pm 0.5$ \\
\hline & 27 & $c_{3}$-Benzene & $19.0 \pm 1.6$ & $13.3 \pm 1.3$ \\
\hline & 28 & Phenol & $106.7 \pm 6.1$ & $82.4 \pm 4.2$ \\
\hline & 29 & $C_{3}$-Benzene & $16.0 \pm 1.6$ & $12.4 \pm 0.6$ \\
\hline & 30 & $C_{3}$-Benzene & $25.9 \pm 2.3$ & $20.2 \pm 1.0$ \\
\hline & 31 & n-Decane & $19.2 \pm 1.3$ & $15.9 \pm 0.4$ \\
\hline & 32 & Indan & $58.4 \pm 3.7$ & $23.1 \pm 1.2$ \\
\hline & 33 & o-Cresol & $24.1 \pm 1.1$ & ND \\
\hline
\end{tabular}

(a) Based on the integration of peak heights.

(b) Numbers refer to peaks in Figure 3.2, Results and Discussion Section.

(c) Identified by GC/MS.

(d) Based on approximately $22.4 \mathrm{mg} / \mathrm{mL} \mathrm{n}$-Undecane ISTO, neat, manua? injection, 1980.

(e) Based on an unknown amount of n-Undecane ISTD, neat, manual injection, 1982.

(f) Based on 4 runs.

(g) Based on 6 runs.

(h) No data. 
TABLE 7.4. Chromatoyraphic Results for SRC-II Middle Distillate Sample 3317-129-02 Stored at $4^{\circ} \mathrm{C}$, in the Dark, Under a Nitrogen Atmosphere

\begin{tabular}{|c|c|c|c|c|}
\hline \multirow{2}{*}{$\begin{array}{c}\text { Peak } \\
\text { No. (c) } \\
\end{array}$} & \multirow[b]{2}{*}{ Compound $(d)$} & \multicolumn{2}{|c|}{$\begin{array}{l}\text { Normalized Percent to } \\
\text { n-Nonadecane ISTD (a) }\end{array}$} & \multirow{2}{*}{$\begin{array}{l}\text { Raw Data }(b) \\
T=2 \text { years }\end{array}$} \\
\hline & & $T=0$ & $T=2$ years & \\
\hline 28 & Phenol & $136.2 \pm 14.6^{(e)}$ & $121.6 \pm 1.8^{(f)}$ & $38.7 \pm 0.6^{(f)}$ \\
\hline 30 & $C_{3}$-Benzene & $25.4 \pm 2.8$ & $24.2 \pm 0.4$ & $7.7 \pm 0.1$ \\
\hline 32 & Indan & $45.0 \pm 4.6$ & $39.9 \pm 1.4$ & $12.7 \pm 0.4$ \\
\hline 33 & o-Cresol & $86.9 \pm 5.3$ & $75.0 \pm 0.9$ & $23.9 \pm 0.3$ \\
\hline $35 \mathrm{a}$ & & $127.8 \pm 11.6$ & $N(g)$ & NO \\
\hline $35 b$ & m- \& $\mathrm{p}$-Cresol, $\mathrm{C}_{1}$-Indan & $132.0 \pm 11.1$ & $127.7 \pm 1.4$ & $40.7 \pm 0.5$ \\
\hline 38 & $c_{1}$-Indan & $29.0 \pm 1.5$ & $27.5 \pm 0.4$ & $8.8 \pm 0.1$ \\
\hline 39 & $c_{1}-$ Indan & $50.6 \pm 2.9$ & $43.4 \pm 0.5$ & $13.8 \pm 0.2$ \\
\hline 40 & $C_{2}$-Phenol & $36.6 \pm 1.9$ & $38.5 \pm 0.3$ & $12.3 \pm 0.1$ \\
\hline 41 & Tetralin & $82.0 \pm 4.6$ & $73.0 \pm 1.0$ & $23.3 \pm 0.3$ \\
\hline 42 & $c_{2}$-Phenol & $32.7 \pm 1.6$ & ND & No \\
\hline 43 & Naphthalene & $169.8 \pm 9.9$ & $165.1 \pm 2.0$ & $52.6 \pm 0.6$ \\
\hline 54 & $c_{2}$-Indan & $53.1 \pm 2.6$ & $52.5 \pm 0.9$ & $16.7 \pm 0.3$ \\
\hline 55 & $c_{2}$-Indan & $46.2 \pm 2.0$ & $49.9 \pm 0.4$ & $16.0 \pm 0.1$ \\
\hline 56 & 2-Methy Inaphthalene & $146.0 \pm 7.4$ & $148.5 \pm 2.5$ & $47.3 \pm 0.8$ \\
\hline 57 & 1-Methy inaphthalene & $33.3 \pm 1.3$ & $43.0 \pm 0.5$ & $13.7 \pm 0.2$ \\
\hline 59 & $c_{3}-$ Indan & $27.0 \pm 0.9$ & $30.0 \pm 0.3$ & $9.5 \pm 0.1$ \\
\hline 60 & Indanol & $25.9 \pm 2.6$ & $30.5 \pm 0.5$ & $9.7 \pm 0.2$ \\
\hline 61 & $\mathrm{C}_{2}$-Tetralin & $35.3 \pm 2.3$ & $35.3 \pm 0.6$ & $11.2 \pm 0.2$ \\
\hline 62 & $\mathrm{C}_{4}$-Phenol J & & & \\
\hline 65 & $\mathrm{C}_{2}$-Naphthalene & $50.3 \pm 1.6$ & $52.7 \pm 0.5$ & $16.8 \pm 0 . ?$ \\
\hline 66 & $C_{2}$-Naphthalene & $42.3 \pm 1.5$ & $48.3 \pm 0.6$ & $15.4 \pm 0.2$ \\
\hline 70 & $C_{3}$-Naphthalene & $29.9 \pm 0.9$ & $35.1 \pm 0.9$ & $11.2 \pm 0.3$ \\
\hline 71 & $\mathrm{C}_{3}$-Naphthalene & $29.9 \pm 0.9$ & $35.0 \pm 1.4$ & $11.2 \pm 0.4$ \\
\hline 77 & $\mathrm{C}_{4}$-Naphthalene & $43.6 \pm 1.3$ & $57.3 \pm 0.4$ & $18.2 \pm 0.1$ \\
\hline
\end{tabular}

(a) Based on $1.6 \mathrm{mg} / \mathrm{mL}$ n-Nonadecane ISTO, $1: 16$ dilution, based on the inteyration of peak heights, $T=0$ was $1980, T=2$ years was 1982 .

(b) Based on $0.40 \mathrm{mg} / \mathrm{mL}$ n-Nonadecane ISTD, l:201 dilution.

(c) Numbers refer to peaks in Figure 3.3. Results and Discussion soctinr.

(d) Ident ified by GC/MS.

(e) Based on $5 \mathrm{GC}$ runs.

(f) Based on 1 (iC runs.

(y) No data. 
TABLE 7.5. Chromatographic Results for SRC-I I Middle Distillate Sample 3317-130-02 Stored at $4^{\circ} \mathrm{C}$, in the Dark, Under a Nitrogen Atmosphere

\begin{tabular}{|c|c|c|c|c|}
\hline \multirow{2}{*}{$\begin{array}{l}\text { Peak } \\
\text { No. (c) } \\
\end{array}$} & \multirow[b]{2}{*}{ Compound $(d)$} & \multicolumn{2}{|c|}{$\begin{array}{l}\text { Workalit..ed Percent to } \\
\text { n-Nonadecane ISTD }(a)\end{array}$} & \multirow{2}{*}{$\begin{array}{l}\text { Raw Data }(0) \\
T=2 \text { years }\end{array}$} \\
\hline & & $T=0$ & $T=2$ years & \\
\hline 28 & Phenol & $72.8 \pm 3.9^{(e)}$ & $52.1 \pm 1.5^{(f)}$ & $37.2 \pm 1.1^{(f)}$ \\
\hline 30 & $C_{3}$-Benzene & $16.8 \pm 1.0$ & $11.7 \pm 0.4$ & $8.2 \pm 0.3$ \\
\hline 32 & Indan & $30.1 \pm 1.8$ & $20.6 \pm 0.8$ & $14.7 \pm 0.6$ \\
\hline 33 & o-Cresol & $50.5 \pm 2.5$ & $35.7 \pm 0.9$ & $25.5 \pm .7$ \\
\hline $35 \mathrm{a}$ & & $73.9 \pm 4.2$ & $N D^{(g)}$ & NO \\
\hline $35 \mathrm{~b}$ & $\underline{m}-\&$ p-Cresol, $C_{1}$-Indan & $74.4 \pm 4.1$ & $62.1 \pm 1.3$ & $44.3 \pm 0.9$ \\
\hline 38 & $c_{1}$-Indan & $18.6 \pm 1.3$ & $14.5 \pm 0.5$ & $10.3 \pm .4$ \\
\hline 39 & $c_{1}$-Indan & $31.2 \pm 1.9$ & $22.9 \pm 0.8$ & $16.1: 3.6$ \\
\hline 40 & $c_{2}$-Phenol & $21.8 \pm 1.3$ & $19.5 \pm 0.6$ & $13.2 \div 0.4$ \\
\hline 41 & Tetralin & $56.1 \pm 4.7$ & $40.8 \pm 1.3$ & $29.1 \pm 0.9$ \\
\hline 42 & $\mathrm{C}_{2}$-Phenol & $19.1 \pm 1.7$ & ND & ND \\
\hline 43 & Naphthalene & $102.4 \pm 6.4$ & $82.6 \pm 2.0$ & $59.0 \pm 1.5$ \\
\hline 54 & $\mathrm{C}_{2}$-Indan & $36.2 \pm 2.1$ & $30.8 \pm 0.8$ & $22.0 \pm 0.5$ \\
\hline 55 & $\mathrm{C}_{2}$-Indan & $27.1 \pm 1.1$ & $26.4 \pm 0.6$ & $18.8 \pm 0.4$ \\
\hline 56 & 2-Methyl naphtha lene & $87.9 \pm 3.8$ & $78.2 \pm 1.6$ & $55.8 \pm 1.2$ \\
\hline 57 & 1-Methylnaphthal ene & $20.0 \pm 1.2$ & $22.4 \pm 0.5$ & $16.0 \pm 0.4$ \\
\hline 59 & $C_{3}$-Indan & $16.7 \pm 0.6$ & $16.3 \pm 0.3$ & $11.7 \pm 0.2$ \\
\hline 60 & Indanol & $15.4 \pm 1.1$ & $16.8 \pm 0.3$ & $12.0 \pm 0.2$ \\
\hline 61 & $\mathrm{C}_{2}$-Tetralin & & & \\
\hline 62 & $\mathrm{C}_{4}$-Phenol & $22.4 \pm 1.0$ & $20.9 \pm 0.4$ & $14.9 \pm 0.3$ \\
\hline 65 & $C_{2}$-Naphthalene & $30.9 \pm 1.1$ & $29.5 \pm 0.5$ & $21.1 \pm 0.4$ \\
\hline 66 & $C_{2}$-Naphthalene & $26.8 \pm 0.7$ & $27.6 \pm 0.5$ & $19.7 \pm 0.3$ \\
\hline 70 & $C_{3}$-Naphthalene & $18.8 \pm 0.6$ & $19.8 \pm 0.8$ & $14.2 \pm 0.6$ \\
\hline 71 & $\mathrm{C}_{3}$-Naphthalene & $18.4 \pm 1.0$ & $19.0 \pm 1.0$ & $13.6 \pm 0.7$ \\
\hline 77 & $\mathrm{C}_{4}$-Naphthalene & $17.6 \pm 0.4$ & $21.3 \pm 0.6$ & $15.2 \pm 0.4$ \\
\hline
\end{tabular}

(a) Based on $3.6 \mathrm{mg} / \mathrm{mL}$ n-Nonadecane ISTD, 1:16 dilution, based on the integration of peak heights, $T=0$ was $1980, T=2$ years was 1982 .

(b) Based on $0.40 \mathrm{mg} / \mathrm{mL}$ n-Nonadecane ISTD, 1:201 dilution.

(c) Numbers refer to peaks in Figure 3.3, Results and Discussion section.

(d) Identified by GC/MS.

(e) Based on $6 \mathrm{GC}$ runs.

(f) Based on 4 GC runs.

(g) No data. 
TABLE 7.6. Chromatographic Results for SRC-II Middle Distillate Sample 3317-131-02 Stored at $4^{\circ} \mathrm{C}$, in the Dark, Under a Nitroyen Atmosphere

\begin{tabular}{|c|c|c|c|c|c|}
\hline \multirow{2}{*}{$\begin{array}{l}\text { Peak } \\
\text { No. (c) }\end{array}$} & \multirow[b]{2}{*}{ Compound $(d)$} & \multicolumn{3}{|c|}{$\begin{array}{l}\text { Normalized Percent to } \\
\text { n-Nonadecane ISTD }(a)\end{array}$} & \multirow{2}{*}{$\frac{\text { Raw Data }}{T=2 \text { years }}$} \\
\hline & & & $T=0$ & $T=2$ years & \\
\hline 28 & Phenol & 181.1 & $\pm 14.9(e)$ & $149.4 \pm 5.9^{(f)}$ & $41.5 \pm 1.6^{(f)}$ \\
\hline 30 & $C_{3}$-Benzene & 49.7 & \pm 2.8 & $36.7 \pm 1.4$ & $10.2 \pm 0.4$ \\
\hline 32 & Indan & 75.0 & \pm 5.5 & $53.6 \pm 2.3$ & $14.9 \pm 0.6$ \\
\hline 33 & o-Cresol & 105.4 & $\pm \quad 5.9$ & $84.7 \pm 4.3$ & $23.5 \pm 1.2$ \\
\hline $35 a$ & & 144.3 & \pm 17.2 & $148.7 \pm 4.3$ & $41.3 \pm 1.2$ \\
\hline $35 b$ & m- \& $\mathrm{p}$-Cresol, $\mathrm{C}_{1}$-Indan & 145.4 & \pm 16.2 & ${ }_{N D}(g)$ & ND \\
\hline 38 & $C_{1}$-Indan & 40.7 & \pm 2.6 & $33.2 \pm 1.4$ & $9.2 \pm 0.4$ \\
\hline 39 & $c_{1}$-Indan & 68.0 & \pm 3.5 & $51.7 \pm ? .2$ & $14.4 \pm 0.6$ \\
\hline 40 & $\mathrm{C}_{2}$-Phenol & 42.3 & $\pm \quad 3.4$ & $44.7 \pm 1.6$ & $12.4 \pm 0.4$ \\
\hline 41 & Tetral In & 114.2 & \pm 10.1 & $96.4 \pm 3.5$ & $26.8 \pm 1.0$ \\
\hline 42 & $C_{2}$-Phenol & 38.9 & \pm 3.2 & ND & ND) \\
\hline 43 & Naphthalene & 200.0 & \pm 16.5 & $197.3 \pm 5.1$ & $54.8 \pm 1.4$ \\
\hline 54 & $C_{2}$-Indan & 73.8 & \pm 4.2 & $74.4 \pm 1.8$ & $20.7 \pm 0.5$ \\
\hline 55 & $\mathrm{C}_{2^{-I n d a n}}$ & 52.6 & \pm 4.4 & $60.0 \pm 1.2$ & $16.7 \pm 0.3$ \\
\hline 56 & 2-Methyl naphthalene & 174.0 & \pm 14.0 & $187.2 \pm 5.6$ & $52.0 \pm 1.6$ \\
\hline 57 & 1-Methylnaphthalene & 41.4 & \pm 2.1 & $52.9 \pm 1.0$ & $14.1 \pm 0.3$ \\
\hline 59 & $C_{3}$-Indan & 32.4 & \pm 1.9 & $35.5 \pm 1.5$ & $9.9 \pm 0.4$ \\
\hline 60 & Indanol & 28.1 & \pm 4.4 & $38.5 \pm 0.5$ & $10.1 \pm 0.1$ \\
\hline 61 & $C_{2}$-Tetralin & & & & \\
\hline 62 & $c_{4}$-Phenol & 47.0 & \pm 2.1 & $49.2 \pm 0.6$ & $13.7 \pm 0.2$ \\
\hline 65 & $C_{2}$-Naphthalene & 63.0 & \pm 3.0 & $70.6 \pm 1.4$ & $19.6 \pm 0.4$ \\
\hline 66 & $C_{2}$-Naphthalene & 55.1 & \pm 2.5 & $66.7 \pm 1.3$ & $18.5 \pm 0.4$ \\
\hline 70 & $C_{3}$-Naphthalene & 39.0 & \pm 2.2 & $48.8 \pm 0.8$ & $13.6 \pm 0.2$ \\
\hline 71 & $C_{3}$-Naphthalene & 37.8 & \pm 2.5 & $46.1 \pm 1.7$ & $12.8 \pm 0.5$ \\
\hline 77 & $C_{4}$-Naphthalene & 35.3 & $\pm \quad 1.2$ & $50.7 \pm 0.5$ & $14.1 \pm 11.1$ \\
\hline
\end{tabular}

(a) Based on $1.4 \mathrm{my} / \mathrm{mL}$ n-Nonadecane ISTO, 1:16 dilution, based on the trint ition of peak heights, $T=0$ was $1980, T \div 2$ years was 1982.

(b) Based on $0.40 \mathrm{mg} / \mathrm{mL}$ n-Nonadecane ISTD, $1: 201$ dilution.

(c) Numbers refer to peaks in rigure 3.3, Results and Discussion.

(d) Identified by GC/MS.

(e) Based on $6 \mathrm{GC}$ runs.

(f) Based on $4 \mathrm{GC}$ rums.

(g) No data. 
TABLE 7.7. Chromatographic Results for SRC-II Middle Distillate Sample 3317-058-01 Stored at $4^{\circ} \mathrm{C}$, in the Dark, Under a Nitrogen Atmosphere

\begin{tabular}{|c|c|c|c|c|}
\hline \multirow{2}{*}{$\begin{array}{l}\text { Peak } \\
\text { No. (c) } \\
\end{array}$} & \multirow[b]{2}{*}{ Compound $(\mathrm{d})$} & \multicolumn{2}{|c|}{$\begin{array}{l}\text { Normalized Percent to } \\
\text { n-Undecane ISTD(a) }\end{array}$} & \multirow{2}{*}{$\begin{array}{l}\text { Raw Data }(b) \\
T=2 \text { years }\end{array}$} \\
\hline & & $T=0$ & $T=2$ years & \\
\hline 28 & Phenol & $76.2 \pm 4.7(\mathrm{e})$ & $60.5 \pm 3.5^{(f)}$ & $23.3 \pm 1.3^{(f)}$ \\
\hline 30 & $c_{3}$-Benzene & $12.1 \pm 1.2$ & $10.9 \pm 0.4$ & $4.2 \pm 0.2$ \\
\hline 32 & Indan & $20.2 \pm 1.8$ & $18.0 \pm 1.1$ & $6.9 \pm 0.4$ \\
\hline $\begin{array}{l}33 \\
35 a\end{array}$ & o-Cresol & $\begin{array}{c}40.4 \pm 2.2 \\
N D(g)\end{array}$ & $\begin{array}{c}34.4 \pm 2.1 \\
\text { ND }\end{array}$ & $\begin{array}{c}13.2 \pm 0.8 \\
\text { ND }\end{array}$ \\
\hline $35 b$ & m- \& $\mathrm{p}$-Cresol, $C_{1}$-Indan & $78.4 \pm 6.8$ & $74.5 \pm 2.4$ & $28.7 \pm 0.9$ \\
\hline 38 & $C_{1}$-Indan & $16.6 \pm 1.4$ & $15.8 \pm 0.7$ & $6.1 \pm 0.3$ \\
\hline 39 & $C_{1}$-Indan & $25.4 \pm 2.6$ & $22.1 \pm 1.0$ & $8.5 \pm 0.4$ \\
\hline 40 & $\mathrm{C}_{2}$-Phenol & $22.5 \pm 1.5$ & $23.0 \pm 0.9$ & $8.9 \pm 0.3$ \\
\hline 41 & Tetralin & $73.1 \pm 5.6$ & $65.9 \pm 2.5$ & $25.3 \pm 1.0$ \\
\hline 42 & $c_{2}$-Phenol & $16.1 \pm 1.1$ & $15.8 \pm 0.3$ & $6.1 \pm 0.1$ \\
\hline 43 & Naphthalene & $168.5 \pm 10.8$ & $173.6 \pm 4.5$ & $66.8 \pm 1.7$ \\
\hline 54 & $\mathrm{C}_{2^{-I n d a n}}$ & $56.5 \pm 4.7$ & $58.2 \pm 1.5$ & $22.4 \pm 0.6$ \\
\hline 55 & $\mathrm{C}_{2}$-Indan & $37.2 \pm 2.6$ & $42.2 \pm 0.7$ & $16.2 \pm 0.3$ \\
\hline 56 & 2-Methylnaphthalene & $171.7 \pm 11.1$ & $177.1 \pm 4.1$ & $68.1 \pm 1.6$ \\
\hline 57 & 1-Methylnaphthal ene & $32.3 \pm 3.2$ & $46.5 \pm 0.8$ & $17.9 \pm 0.3$ \\
\hline 59 & $\mathrm{C}_{3}$-Indan & $20.9 \pm 2.0$ & $26.1 \pm 0.5$ & $10.0 \pm 0.2$ \\
\hline 50 & Indanol & $22.2 \pm 2.1$ & $27.3 \pm 0.6$ & $10.5 \pm 0.2$ \\
\hline $\begin{array}{l}61 \\
52\end{array}$ & $\left.\begin{array}{l}C_{2} \text {-Tetralin } \\
c_{4} \text {-Pheno }\end{array}\right\}$ & $37.7 \pm 3.1$ & $41.7 \pm 0.7$ & $16.0 \pm 0.3$ \\
\hline 65 & $\mathrm{C}_{2}$-Naphthalene & $62.8 \pm 4.3$ & $70.5 \pm 1.5$ & $27.1 \pm 0.6$ \\
\hline 66 & $\mathrm{C}_{2}$-Naphthalene & $60.3 \pm 4.3$ & $74.5 \pm 1.6$ & $28.7 \pm 0.6$ \\
\hline 79 & $C_{3}$-Naphthalene & $47.8 \pm 2.8$ & $57.9 \pm 1.7$ & $22.3 \pm 0.7$ \\
\hline$\therefore$ & $\mathrm{C}_{3}-\mathrm{Naphthalene}$ & $30.7 \pm 1.9$ & $38.8 \pm 1.5$ & $14.9 \pm 0.6$ \\
\hline 77 & $\mathrm{O}_{\mathrm{d}}$-Naphtina? ene & $26.4 \pm 1.9$ & $39.0 \pm 0.8$ & $15.0 \pm 0.3$ \\
\hline $\begin{array}{ll} & \text { in } \\
\text { i) } \mathrm{Ba} \\
\therefore, \mathrm{Nu} \\
\text { a) } \mathrm{iO} \\
\text { a) } \mathrm{Ba} \\
\text { f) } \mathrm{Ba} \\
\text { (y) } \mathrm{NO}\end{array}$ & $\begin{array}{l}\text { d on } 1.95 \mathrm{mg} / \mathrm{mL} \text { n-Nonade } \\
\text { eyr..ion of peak heights, } \\
\text { ed on } u .40 \mathrm{mg} / \mathrm{mL} \text { n-Nonade } \\
\text { bers refer to peaks in } \mathrm{Fi} \\
\mathrm{nc} \text { if ied by } \mathrm{GC} / \text { Ms. } \\
\text { ed on } 4 \mathrm{CC} \text { runs. } \\
\text { ed on } 8 \mathrm{GC} \text { runs. } \\
\text { data }\end{array}$ & $\begin{array}{r}\text { cane ISTD, } 1: 16 \\
T=0 \text { was } 1980, T= \\
\text { cane ISTD, } 1: 201 \\
\text { gure } 3.3 \text {, Results }\end{array}$ & $\begin{array}{l}\text { dilution, based } \\
=2 \text { years was } 198 \\
\text { dilution. } \\
\leq \text { and Liscussion }\end{array}$ & $\begin{array}{l}\text { on the } \\
2 .\end{array}$ \\
\hline
\end{tabular}


Table 7.8. Chromatographic Results for SRC-II Fuel $0 i 1$ Blend Sample 3317-079-23 Stored at $4{ }^{\circ} \mathrm{C}$, in the Dark, Under a Nitrogen Atmosphere

\begin{tabular}{|c|c|c|c|c|}
\hline \multirow{3}{*}{$\frac{\text { Peak No, }(c)}{28}$} & \multirow[b]{2}{*}{ Compound $(d)$} & \multicolumn{2}{|c|}{ Normalized Percent to $n$-Nonadecane ISTD(a) } & \multirow{2}{*}{$\operatorname{Raw}_{T=2}$ years $(\mathrm{D})$} \\
\hline & & $T=0$ & $T=2$ years & \\
\hline & Phenol & $80.5 \pm 6.9(e)$ & $81.0 \pm 0.6^{(f)}$ & $40.5 \pm 0.3^{(f)}$ \\
\hline 30 & $C_{3}$ Benzene & $18.2 \pm 2.3$ & $15.7 \pm 0.1$ & $7.8 \pm 0.1$ \\
\hline 32 & Indan & $30.6 \pm 3.5$ & $23.9 \pm 0.5$ & $11.9 \pm 0.2$ \\
\hline 33 & $\underline{0}$-Cresol & $55.5 \pm 4.7$ & $51.9 \pm 0.6$ & $25.9 \pm 0.3$ \\
\hline $35 a$ & & $67.8 \pm 6.4$ & ND & ND \\
\hline $35 b$ & $\underline{m}-\mathrm{p}-\mathrm{C}$ resol, $\mathrm{C}_{1}$-Indan & $77.3 \pm 6.2$ & $91.6 \pm 0.4$ & $45.8 \pm 0.2$ \\
\hline 38 & $c_{1}$-Indan & $23.8 \pm 2.4$ & $20.3 \pm 0.3$ & $10.2 \pm 0.1$ \\
\hline 39 & $c_{1}$-Indan & $41.1 \pm 3.5$ & $31.6 \pm 0.3$ & $15.8 \pm 0.1$ \\
\hline 40 & $C_{2}$-Phenol & $28.1 \pm 2.8$ & $30.4 \pm 0.2$ & $15.2 \pm 0.1$ \\
\hline 41 & Tetralin & $74.6 \pm 5.5$ & $64.2 \pm 0.3$ & $32.1 \pm 0.2$ \\
\hline 42 & $C_{2}$-Phenol & $N D(g)$ & $23.7 \pm 0.1$ & $11.9 \pm 0.1$ \\
\hline 43 & Naphthalene & $144.1 \pm 7.7$ & $157.4 \pm 1.4$ & $78.7 \pm 0.7$ \\
\hline 48 & $c_{1}$-Tetralin & $21.6 \pm 1.5$ & $19.6 \pm 0.1$ & $9.8 \pm 0.1$ \\
\hline 54 & $C_{2}$-Indan & $52.3 \pm 2.6$ & $52.1 \pm 0.5$ & $26.0 \pm 0.2$ \\
\hline 55 & $c_{2}$-Indan & $38.6 \pm 2.0$ & $45.4 \pm 0.7$ & $22.7 \pm 0.4$ \\
\hline 56 & 2-Methy Inaphthalene & $123.8 \pm 5.5$ & $140.0 \pm 2.2$ & $70.0 \pm 1.1$ \\
\hline 57 & 1-Methy Inaphthalene & $34.4 \pm 1.8$ & $40.9 \pm 0.6$ & $20.4 \pm 0.3$ \\
\hline 59 & $\mathrm{C}_{3}$-Indan & $23.8 \pm 1.8$ & $28.5 \pm 0.3$ & $14.3 \pm 0.2$ \\
\hline so & Indanol & $24.1 \pm 1.5$ & $29.3 \pm 0.4$ & $14.6 \pm 0.2$ \\
\hline 51 & $c_{2^{-T} \text { tetralin }}$ & & & \\
\hline 52 & $c_{4}$-Phenol & $34.2 \pm 2.1$ & $36.5 \pm 0.8$ & $18.3 \pm 0.4$ \\
\hline 63 & $C_{4}$-Phenol, $C_{3}$-Indan & $25.6 \pm 2.7$ & ND & $N D$ \\
\hline 64 & 3 iphenyl & $45.4 \pm 2.0$ & $48.2 \pm 1.0$ & $24.1 \pm 0.5$ \\
\hline 55 & $2_{2}$-Naphthalene & $50.0 \pm 2.3$ & $51.1 \pm 0.6$ & $25.6 \pm 0.3$ \\
\hline 56 & -Naphthalene & $42.8 \pm 2.0$ & $46.3 \pm 0.2$ & $23.2 \pm 0.1$ \\
\hline$\therefore 3$ & -Naphthalene, Dipianylether & $73.0 \pm 2.9$ & $85.8 \pm 1.2$ & $42.9 \pm 0.5$ \\
\hline 9 & $\therefore$ enaphthene & $24.2 \pm 1.5$ & $26.7 \pm 0.5$ & $13.3 \pm 0.2$ \\
\hline$\because:$ & C:-Naphthalene & $23.5 \pm 1.3$ & $25.4 \pm 0.5$ & $12.7 \pm 0.3$ \\
\hline 71 & $\because$ Naphthalene & $19.9 \pm 1.4$ & $21.7 \pm 0.3$ & $10.8 \pm 0.1$ \\
\hline 74 & Tyorene & $18.8 \div 1.3$ & NO & ND \\
\hline$\because$ & $C_{1}$-Arenaptithene $\quad-B i p h e n y:$ & $14.5 \pm \quad .1$ & $18.7 \pm 0.3$ & $9.3 \pm 0.2$ \\
\hline$?$ & ${ }_{4}$-Naphthrilent & $14.9 \pm 0.8$ & $1.4 \pm 0.2$ & $5.7 \pm 0.1$ \\
\hline 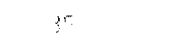 & Phenanthrene & $42.4 \pm 1.8$ & $62.9 \pm 0.5$ & $31.5 \pm 0.2$ \\
\hline y; & Pyrene & $1 E .1 \pm 1.6$ & NU & 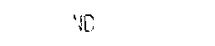 \\
\hline
\end{tabular}

\footnotetext{
(a) Basec on $4.0 \mathrm{mg} / \mathrm{mL}$ n-Nonadecane ISTr, l: l: jilution, based or the intetition of peak neights, $=0$ was $1980, T=2$ years was 1982.

(.) Basod on $0.40 \mathrm{mg} / \mathrm{mL}$ n-Nonadecane STU ::20l dilution.

(c) iumers rofer to peaks in figure 3.4. ?es 1 ts and Discussion setiti.

(- ident: ied by GC/MS.

e) Baser. on 5 GC runs.

$t$ iseu: 4 GC runs.

.y) 10 cata.
} 
TABLE 7.9. Chromatographic Results for SRC-II Fuel 0il Blend Sample 3317-079-24 Stored at $4^{\circ} \mathrm{C}$, in the Dark, Under a Nitrogen Atmosphere

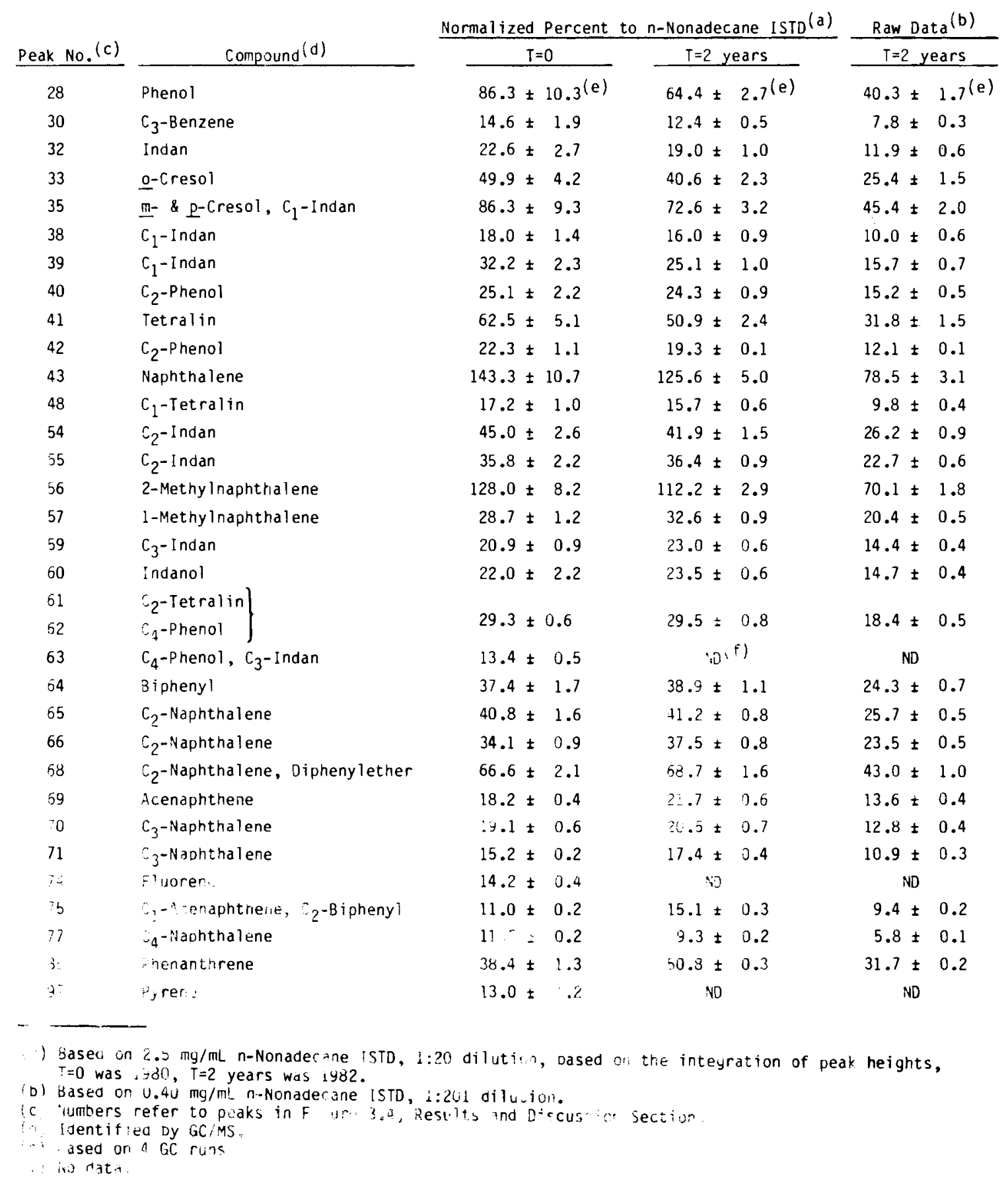


TABLE 7.10. Chromatographic Results for SRC-II Fuel 0il Blend Sample 3317-079-25 Stored at $4^{\circ} \mathrm{C}$, in the Dark, Under a Nitrogen Atmosphere

\begin{tabular}{|c|c|c|c|c|}
\hline \multirow{3}{*}{$\frac{\text { Peak No. (C) }}{28}$} & \multirow[b]{2}{*}{ Compound $(d)$} & \multicolumn{2}{|c|}{ Normalized Percent to n-Nonadecane ISTD (a) } & \\
\hline & & $\mathrm{T}=0$. & $T=2$ years & $\mathrm{T}=2$ years \\
\hline & Phenol & $77.1 \pm 6.1^{(e)}$ & $62.7 \pm 1.2^{(f)}$ & $39.2 \pm 0.7^{(f)}$ \\
\hline 30 & $C_{3}$-Benzene & $13.0 \pm 1.1$ & $12.0 \pm 0.2$ & $7.5 \pm 0.1$ \\
\hline 32 & Indan & $20.9 \pm 2.0$ & $18.4 \pm 0.4$ & $11.5 \pm 0.3$ \\
\hline 33 & $\underline{0}$-Cresol & $46.4 \pm 3.5$ & $39.2 \pm 1.0$ & $24.5 \pm 0.6$ \\
\hline 35 & If- \& $\mathrm{p}$-Cresol, $\mathrm{C}_{1}$-Indan & $78.2 \pm 8.1$ & $71.5 \pm 1.1$ & $44.7 \pm 0.7$ \\
\hline 38 & $c_{1}$-Indan & $17.0 \pm 1.3$ & $15.5 \pm 0.3$ & $9.7 \pm 0.2$ \\
\hline 39 & $c_{1}$-Indan & $30.2 \pm 2.1$ & $24.0 \pm 0.4$ & $15.0 \pm 0.3$ \\
\hline 40 & $\mathrm{C}_{2}$-Phenol & $23.4 \pm 1.4$ & $23.6 \pm 0.5$ & $14.7 \pm 0.3$ \\
\hline 41 & Tetralin & $58.0 \pm 4.6$ & $49.1 \pm 1.1$ & $30.7 \pm 0.7$ \\
\hline 42 & $C_{2}$-Phenol & $21.5 \pm 0.7$ & $18.4 \pm 0.3$ & $11.5 \pm 0.2$ \\
\hline 43 & Naphthalene & $132.8 \pm 8.5$ & $123.2 \pm 2.5$ & $77.0 \pm 1.6$ \\
\hline 48 & $C_{1}$-Tetralin & $16.4 \pm 1.0$ & $15.2 \pm 0.3$ & $9.5 \pm 0.2$ \\
\hline 54 & $\mathrm{C}_{2}$-Indan & $42.6 \pm 2.2$ & $40.5 \pm 0.9$ & $25.3 \pm 0.5$ \\
\hline 55 & $c_{2}$-Indan & $35.4 \pm 1.4$ & $35.8 \pm 0.6$ & $22.4 \pm 0.4$ \\
\hline 56 & 2-Methy Inaphthal ene & $117.0 \pm 4.9$ & $110.0 \pm 2.5$ & $68.7 \pm 1.6$ \\
\hline 57 & 1-Methylnaphthalene & $27.9 \pm 1.0$ & $32.5 \pm 0.4$ & $20.3 \pm 0.3$ \\
\hline 59 & $C_{3}$-Indan & $20.7 \pm 0.8$ & $22.4 \pm 0.3$ & $14.0 \pm 0.2$ \\
\hline 60 & Indanol & $19.8 \pm 1.6$ & $23.1 \pm 0.4$ & $14.4 \pm 0.3$ \\
\hline 61 & $c_{2}$-Tetralin & & & \\
\hline 62 & $\mathrm{C}_{4}$-Phenol & $31.0 \pm 1.2$ & $28.7 \pm 0.3$ & $17.9 \pm 0.2$ \\
\hline 63 & $C_{4}$-Phenol, $C_{3}$-Indan & $15.0 \pm 1.5$ & $N D^{(g)}$ & ND \\
\hline 64 & Biphenyl & $37.5 \pm 1.2$ & $38.1 \pm 0.3$ & $23.8 \pm 0.2$ \\
\hline 65 & $C_{2}$-Naphthalene & $40.3 \pm 1.1$ & $40.0 \pm 0.4$ & $25.0 \pm 0.3$ \\
\hline 66 & $C_{2}$-Naphthalene & $34.0 \pm 1.2$ & $36.2 \pm 0.6$ & $22.6 \pm 0.4$ \\
\hline 68 & $C_{2}$-Naphthalene, Diphenylether & $64.7 \pm 1.0$ & $67.3 \pm 0.7$ & $42.0 \pm 0.4$ \\
\hline 59 & Acenaphthene & $18.4 \pm 0.8$ & $21.0 \pm 0.4$ & $13.1 \pm 0.2$ \\
\hline 70 & $C_{3}$-Naphthalene & $19.0 \pm 0.4$ & $20.2 \pm 0.6$ & $12.6 \pm 0.4$ \\
\hline 71 & $C_{3}$-Naphthalene & $15.5 \pm 0.5$ & $17.1 \pm 0.3$ & $10.7 \pm 0.2$ \\
\hline$a$ & Fluorene & $14.0 \pm 1.0$ & ND & ND \\
\hline & $c_{1}$-Acenapl chene, $\tau^{2}$-Bipheny 1 & $10.8 \pm 0.9$ & $14.6 \pm 0.2$ & $9.1 \pm 0.1$ \\
\hline & $v_{4}$-Napt t. alene & $11.6 \pm 0.6$ & $9.1 \pm 0.1$ & $5.7 \pm 0.1$ \\
\hline & Phenantiorene & $36.7 \pm 1.5$ & $49.9 \pm 0.7$ & $31.2 \pm 0.4$ \\
\hline & $y$ ne & $11.8 \pm 0.9$ & ND & ND \\
\hline
\end{tabular}

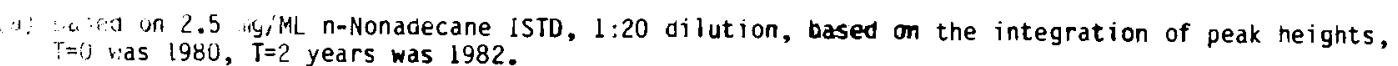

$\because$ Bas on $0.40 \mathrm{mg} / \mathrm{mL} n$-Nonadecane ISTD, $1: 201$ dilution.

$=$ : iumbers refer to peaks in Figure 3.4, Results and Discussion section.

ieritified by GC/MS.

(e) ised on 5 GC runs.

Dased on 4 GC runs.

()) : sata. 
TABLE 7.11. Chromatographic Results for SRC-II Fuel 0il Blend Sample 3317-079-26 Stored at $4^{\circ} \mathrm{C}$, in the Dark, Under a Nitrogen Atmosphere

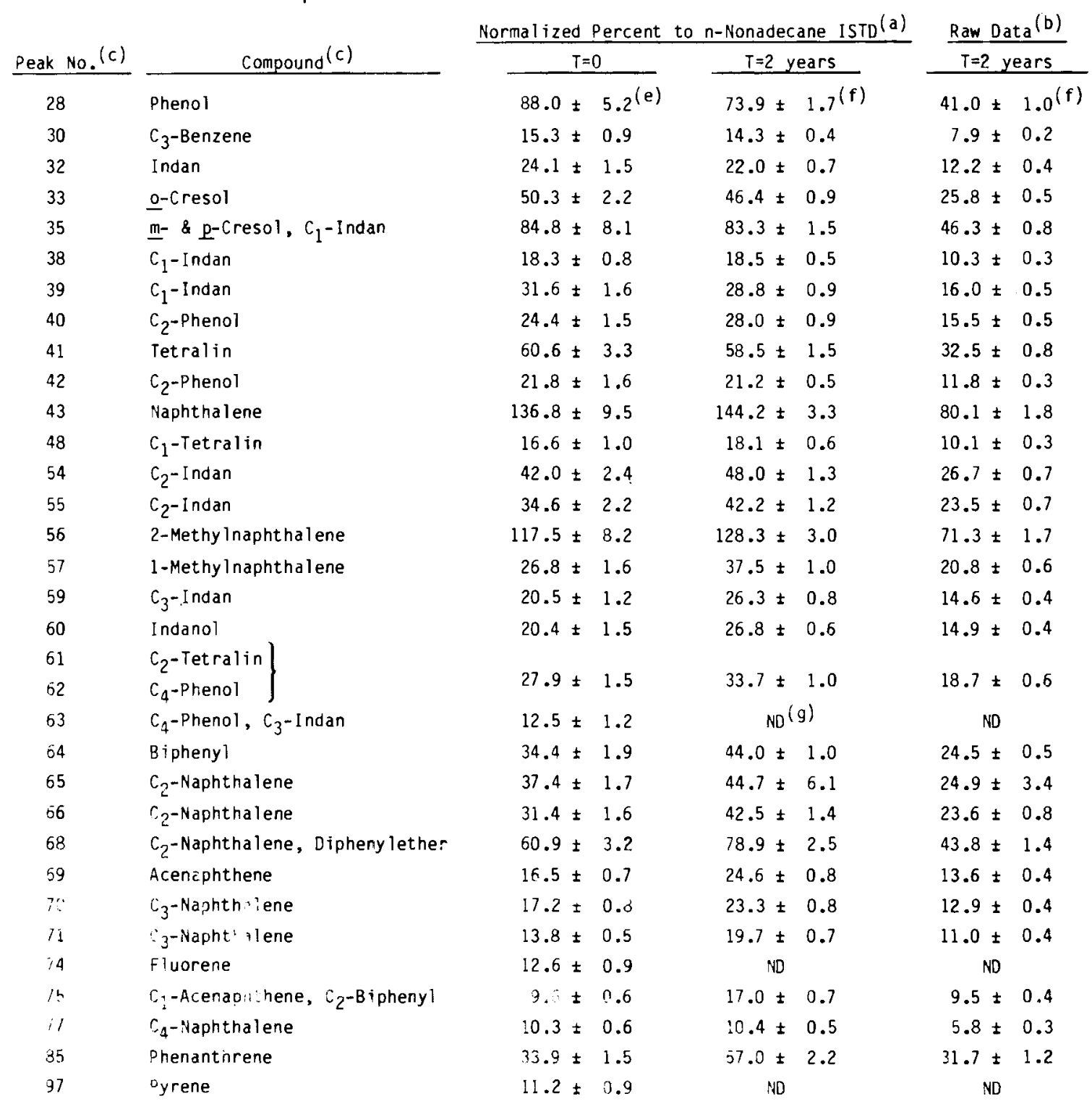

(2) Based on $2.2 \mathrm{mg} / \mathrm{ML}$-Nonadecane ISTD, 1:20 dilution, based on the integration of peak heights, $T=0$ was $1980, T=2$ years was 1982

o) Based or $0.40 \mathrm{mg} / \mathrm{mL}$ n-Nonadecane iSTD, $1: 201$ dilution.

(c) Numbers refer to peaks in Figure 3.4, Results and Discujsion Section.

(c) Identified by GC/MS.

(e) Baseo on 5 GC runs.

(f) Based on 8 Gr runs.

(y) No data. 
Table 7.12. Chromatographic Results for SRC-I Wash Solvent Sample 3317-075-19 Stored at $4^{\circ} \mathrm{C}$, in the Dark, Under a Nitrogen Atmosphere

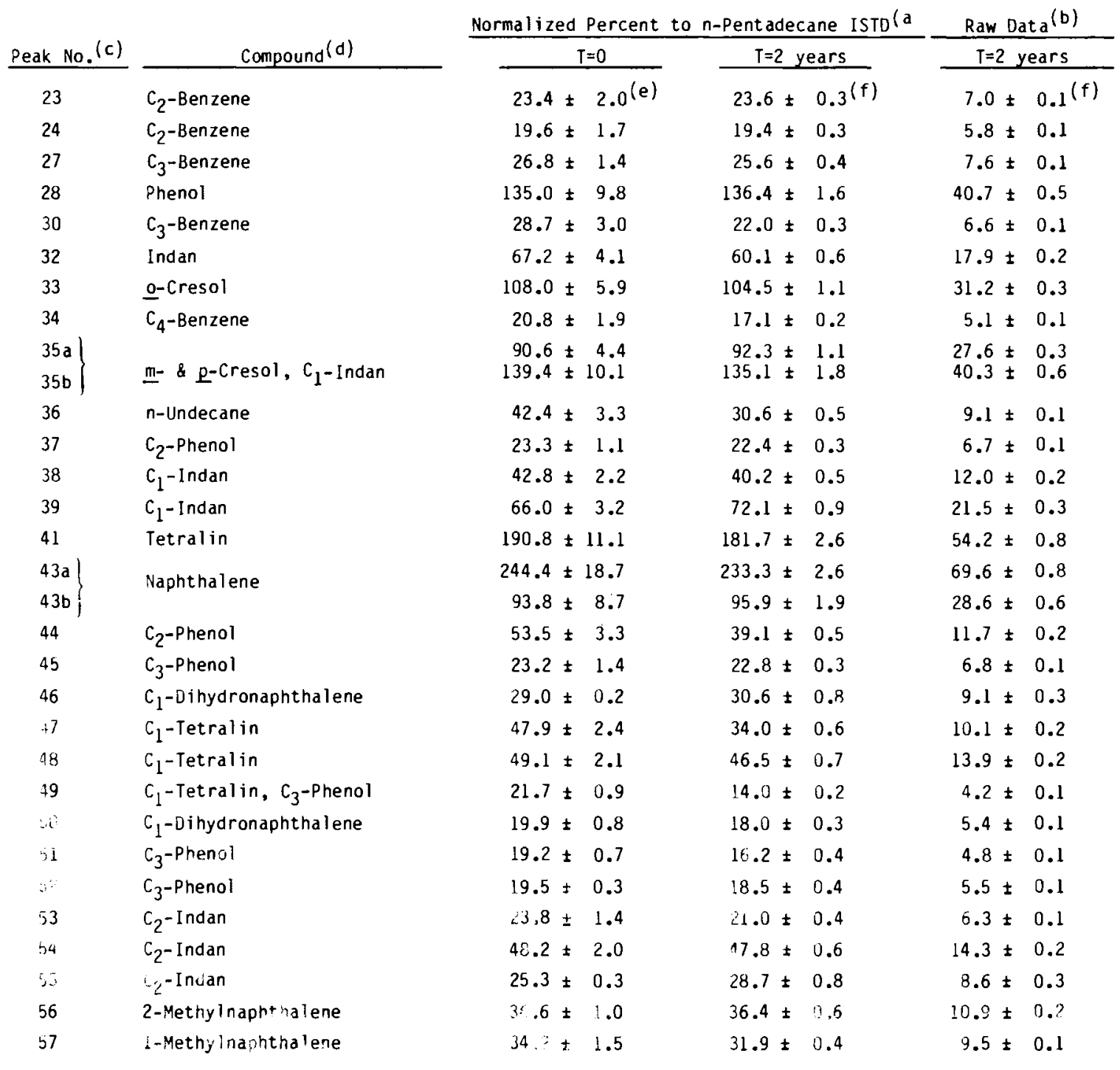

(a) liased on $2.0 \mathrm{mg} / \mathrm{ML}$ n-Pentadecane ISTD, 1:12 filution, Dasec on the integration of peak heights, $T=0$ :as $1980, T=2$ years was 1982 .

(D. Lid: in $0.40 \mathrm{my} / \mathrm{mL}$ n-Pentadecane ISTD, 1:201 ailuition.

c) imber's refer to peaks in Figure 3.5, Results and Discussion Section.

(a) Identified by GC/MS.

(c) Based on 4 GC runs.

(f) Based on $8 \mathrm{GC}$ runs. 
Table 7.13. Chromatoyraphic Results for SRC-II Heavy Distillate Sample 3317-132-02 Stored at $4^{\circ} \mathrm{C}$, in the Dark, Under a Nitrogen Atmosphere

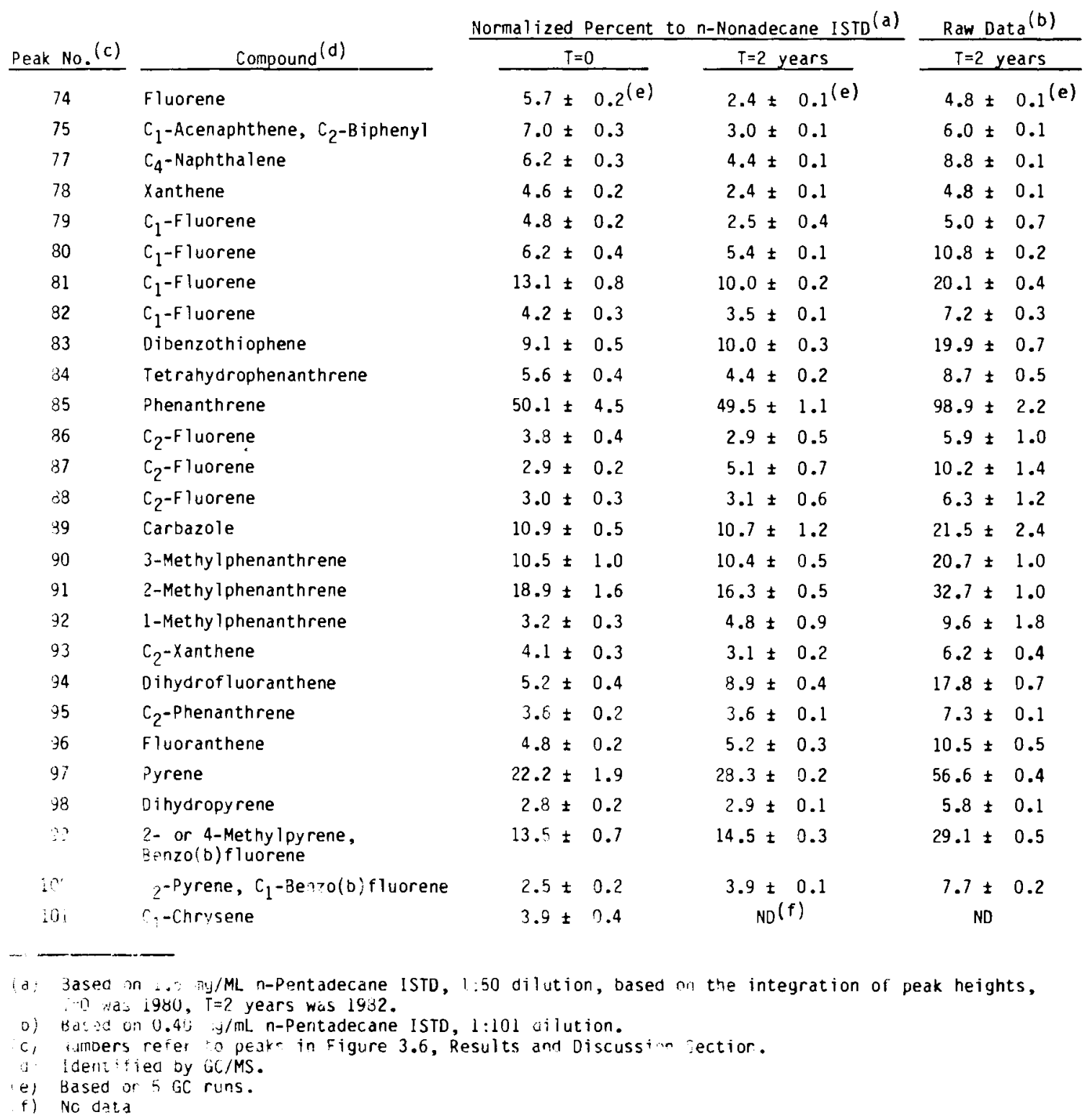


TABLE 7.14. Chromatographic Results for SRC-II Heavy Distillate Sample 3317-134-02 Stored at $4^{\circ} \mathrm{C}$, in the Dark, Under a Nitrogen Atmosphere

\begin{tabular}{|c|c|c|c|c|}
\hline \multirow[b]{2}{*}{ Peak No. (c) } & \multirow[b]{2}{*}{ Compound $(d)$} & \multicolumn{2}{|c|}{ Normal ized Percent to n-Nonadecane ISTD $(a)$} & Raw Data (b) \\
\hline & & $T=0$ & $T=2$ years & $T=2$ years \\
\hline 74 & Fluorene & $16.5 \pm 0.7^{(e)}$ & $7.9 \pm 0.1^{(f)}$ & $9.8 \pm 0.1^{(f)}$ \\
\hline 75 & $C_{1}$-Acenaphthene; $C_{2}$-Biphenyl & $18.6 \pm 0.9$ & $9.3 \pm 0.4$ & $11.6 \pm 0.5$ \\
\hline 77 & $C_{4}$-Naphthalene & $16.8 \pm 1.1$ & $14.3 \pm 0.4$ & $17.9 \pm 0.4$ \\
\hline 78 & Xanthene & $12.2 \pm 0.6$ & $7.7 \pm 0.6$ & $9.7 \pm 0.7$ \\
\hline 79 & $c_{1}$-Fluorene & $11.4 \pm 0.4$ & $8.7 \pm 1.4$ & $10.8 \pm 1.8$ \\
\hline 80 & $c_{1}$-Fluorene & $13.0 \pm 0.7$ & $13.0 \pm 0.9$ & $16.3 \pm 1.1$ \\
\hline 81 & $c_{1}$-Fluorene & $25.4 \pm 1.6$ & $22.2 \pm 1.0$ & $27.8 \pm 1.3$ \\
\hline 82 & $\mathrm{C}_{1}$-Fluorene & $9.0 \pm 1.0$ & $8.2 \pm 0.6$ & $10.3 \pm 0.8$ \\
\hline 83 & Dibenzothiophene & $15.8 \pm 0.9$ & $18.8 \pm 1.5$ & $23.5 \pm 1.9$ \\
\hline 84 & Tetrahydrophenanthrene & $8.3 \pm 0.5$ & $7.2 \pm 1.1$ & $9.0 \pm 1.3$ \\
\hline 85 & Phenanthrene & $81.9 \pm 8.8$ & $85.8 \pm 5.1$ & $107.3 \pm 6.4$ \\
\hline 86 & $\mathrm{C}_{2}-\mathrm{Fluorene}$ & $6.6 \pm 0.2$ & $5.4 \pm 1.0$ & $6.7 \pm 1.3$ \\
\hline 87 & $C_{2}$-Fluorene & $5.0 \pm 0.1$ & $9.2 \pm 1.3$ & $11.5 \pm 1.6$ \\
\hline 88 & $C_{2}$-Fluorene & $5.4 \pm 0.2$ & $5.8 \pm 1.1$ & $7.2 \pm 1.4$ \\
\hline 89 & Carbazole & $19.6 \pm 1.0$ & $20.6 \pm 1.8$ & $25.7 \pm 2.3$ \\
\hline 90 & 3-Methylphenanthrene & $16.5 \pm 1.3$ & $17.9 \pm 0.4$ & $22.3 \pm 0.5$ \\
\hline 91 & 2-Methyl phenanthrene & $29.6 \pm 1.6$ & $27.9 \pm 0.2$ & $34.8 \pm 0.3$ \\
\hline 92 & 1-Methylphenanthrene & $4.7 \pm 0.4$ & $9.0 \pm 0.3$ & $11.3 \pm 0.4$ \\
\hline 93 & $C_{2}-x$ anthene & $7.4 \pm 0.6$ & $5.4 \pm 0.1$ & $6.7 \pm 0.1$ \\
\hline 94 & Dihydrofluoranthene & $8.3 \pm 0.5$ & $15.4 \pm 0.1$ & $19.2 \pm 0.2$ \\
\hline 95 & $C_{2}$-Phenanthrene & $5.4 \pm 0.3$ & $6.1 \pm 0.1$ & $7.6 \pm 0.1$ \\
\hline 96 & Fluoranthene & $6.9 \pm 0.5$ & $8.1 \pm 0.6$ & $10.1 \pm 0.8$ \\
\hline 97 & Pyrene & $36.6 \pm 5.7$ & $49.6 \pm 1.5$ & $62.0 \pm 1.8$ \\
\hline 98 & Dihydropyrene & $4.2 \pm 0.4$ & $4.7 \pm 0.2$ & $5.8 \pm 0.2$ \\
\hline 99 & $\begin{array}{l}\text { 2- or 4-Methylpyrene, } \\
\text { Benzo(b) fluorene }\end{array}$ & $21.0 \pm 2.5$ & $24.9 \pm 0.7$ & $31.1 \pm 0.9$ \\
\hline 00 & $C_{2}$-Pyrene, $C_{1}$-Benzo(b)fluorene & $4.1 \pm 0.5$ & $6.6 \pm 0.5$ & $8.2 \pm 0.6$ \\
\hline .01 & $C_{j}$-Chrysene & $5.5 \pm 0.5$ & $\mathrm{ND}(\mathrm{g})$ & ND \\
\hline
\end{tabular}

(a) Based on $1.0 \mathrm{mg} / \mathrm{ML}$-Pentadecane ISTD, 1:50 dilution, based on the integration of peak heights, $T=0$ wis $1980, T=2$ years was 1982 .

(i) Based $\mathrm{C}_{i i} 0.4 \mathrm{mg} / \mathrm{mL}$ ri-Pent adecane ISTD, 1:101 dilution.

(c) ijumbers refer to peaks in Figure 3.6, Results and Discussion Section.

(a) Idet:tified by GC/MS.

(e) Based on 5 GC runs.

(f) Based on 4 GC runs.

(g) No: date 
TABLE 7.15. Chromatographic Results for SRC-II Heavy Distillate Sample 3317-015-11 Stored at $4^{\circ} \mathrm{C}$, in the Dark, Under a Nitrogen Atmosphere

\begin{tabular}{|c|c|c|c|c|c|}
\hline \multirow{3}{*}{$\frac{\text { Peak No. (C) }}{74}$} & \multirow[b]{2}{*}{ Compound $(d)$} & \multicolumn{2}{|c|}{ Normalized Percent to n-Pentadecane ISTD (a) } & \multicolumn{2}{|c|}{ Raw Data ${ }^{(b)}$} \\
\hline & & $\mathrm{T}=0$ & $\mathrm{~T}=2$ years & $\mathrm{T}=2$ & years \\
\hline & Fluorene & $34.0 \pm 1.6(\mathrm{e})$ & $14.5 \pm 0.8^{(f)}$ & $14.5 \pm$ & $0.8^{(\mathrm{f})}$ \\
\hline 75 & $C_{1}$-Acenaphthene, $C_{2}$-Biphenyl & $27.4 \pm 1.8$ & $11.6 \pm 0.4$ & $11.6 \pm$ & 0.4 \\
\hline 77 & $\mathrm{C}_{4}$-Naphthalene & $24.0 \pm 1.2$ & $16.7 \pm 0.7$ & $16.7+$ & 0.7 \\
\hline 78 & Xanthene & $16.4 \pm 1.4$ & $8.3 \pm 0.6$ & $8.3 \pm$ & 0.6 \\
\hline 79 & $C_{1}$-Fluorene & $14.6 \pm 1.2$ & $7.4 \pm 0.9$ & $7.4 \pm$ & 0.9 \\
\hline 80 & $c_{1}$-Fluorene & $20.2 \pm 1.1$ & $16.8 \pm 0.7$ & 16.8 & 0.7 \\
\hline 81 & $C_{1}$-Fluorene & $42.2 \pm 2.6$ & $27.4 \pm 1.1$ & 27.4 & 1.1 \\
\hline 82 & $c_{1}$-Fluorene & $11.0 \pm 0.9$ & $6.9 \pm 0.3$ & $6.9 \pm$ & 0.3 \\
\hline 83 & Dibenzothiophene & $21.9 \pm 1.8$ & $19.7 \pm 1.0$ & $19.7 \pm$ & 1.0 \\
\hline 84 & Tetrahydrophenanthrene & $12.7 \pm 1.2$ & $8.0 \pm 0.5$ & $8.0 \pm$ & 0.5 \\
\hline 85 & Phenanthrene & $100.4 \pm 6.7$ & $107.6 \pm 5.2$ & $107.6 \pm$ & 5.2 \\
\hline 86 & $C_{2}$-Fluorene & $11.9 \pm 0.7$ & $7.6 \pm 1.1$ & $7.6 \pm$ & 1.1 \\
\hline 87 & $\mathrm{C}_{2}$-Fluorene & $8.7 \pm 0.7$ & $9.4 \pm 1.6$ & 9.4 & 1.6 \\
\hline 88 & $C_{2}$ Fluorene & $9.4 \pm 0.7$ & $6.1 \pm 1.4$ & $6.1 \pm$ & 1.4 \\
\hline 89 & Carbazole & $35.3 \pm 2.2$ & $34.5 \pm 4.3$ & $34.5 \pm$ & 4.3 \\
\hline 90 & 3-Methyl phenanthrene & $22.6 \pm 1.0$ & $21.2 \pm 1.4$ & 21.2 & 1.4 \\
\hline 91 & 2-Methylphenanthrene & $43.3 \pm 2.4$ & $32.9 \pm 2.1$ & $32.9 \pm$ & 2.1 \\
\hline 32 & 1-Methyl phenanthrene & $8.9 \pm 0.9$ & $10.3 \pm 1.4$ & $10.3+$ & 1.4 \\
\hline 93 & $c_{2}-x$ anthene & $10.0 \pm 0.8$ & $7.1 \pm 0.7$ & $7.1 \pm$ & 0.7 \\
\hline 94 & Dihydrof luoranthene & $14.3 \pm 0.9$ & $17.6 \pm 1.4$ & $17.6 \pm$ & 1.4 \\
\hline 95 & $C_{2}$-Phenanthrene & $8.8 \pm 1.0$ & $6.8 \pm 0.5$ & $6.8 \pm$ & 0.5 \\
\hline 96 & Fluoranthene & $13.4 \pm 0.8$ & $11.1 \pm 1.5$ & $11.1 \pm$ & 1.5 \\
\hline 97 & Pyrene & $42.8 \pm 3.8$ & $56.0 \pm 2.3$ & $56.0 \pm$ & 2.3 \\
\hline 98 & Dihydropyrene & $7.9 \pm 0.5$ & $6.8 \pm 0.5$ & $6.8 \pm$ & 0.5 \\
\hline 99 & $\begin{array}{l}\text { 2- or 1-Methylpyrene, } \\
\text { 3enzo(b)fluorene }\end{array}$ & $30.1 \pm 4.2$ & $29.1 \pm 0.9$ & $29.1 \pm$ & 0.9 \\
\hline 100 & $C_{2}$-Pyrene, $c_{1}$-Benzo(b)fluorene & $\dot{0.1} \pm 0.9$ & $7.5 \pm 0.7$ & $7.5 \pm$ & 0.7 \\
\hline 101 & $\mathrm{C}_{1}$-Chrysene & $3.0 \pm 0.4$ & $N D(g)$ & ND & \\
\hline
\end{tabular}

(a) Based in $0.30 \mathrm{mg} / \mathrm{ML}$ ti-Pentadecane ISTD, 1:50 dilution, based on the integration of peak heights, $T=0$ was $1980, T=2$ years was 1982 .

b) Based on $0.40 \mathrm{~ms} / \mathrm{mL}$ il-Pentadecane ISTD, 1:101 cilution.

: N Numbers refer to peaks in 5 igure 3.6 , Resilts aisd Discussion section.

a) Ident ified iC/MS.

e) Based on 5 uí rins.

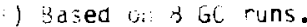

'ji ió data. 
TABLE 7.16. Chromatographic Results for SRC-I Process Solvent Sample 3317-066-26 Stored at $4^{\circ} \mathrm{C}$, in the Dark, Under a Nitrogen Atmosphere

\begin{tabular}{|c|c|c|c|c|}
\hline \multirow[b]{2}{*}{ Peak No. (a) } & \multirow[b]{2}{*}{ Compound $(0)$} & \multicolumn{2}{|c|}{ Nu iized iercent lo ISTD $(c, g)$} & \multirow{2}{*}{$\begin{array}{l}\text { Raw Data }(\mathrm{D} ; \\
\mathrm{T}=2 \text { years }\end{array}$} \\
\hline & & $\therefore=0$ & $T=2$ years & \\
\hline 43 & Naphthalene & $11.9=1.3(r, d)$ & $16.4 \pm 0.1^{(e)}$ & $11.7 \pm 0.1(e, f)$ \\
\hline 54 & $C_{2}$-Indan & $17.4 \pm 0.6(c)$ & $13.4 \pm 0.1$ & $9.6 \pm 0.1^{(f)}$ \\
\hline 55 & $\mathrm{C}_{2}$-Indan & $24.9 \pm 1.9^{(c)}$ & $26.2 \pm 0.1$ & $18.7 \pm 0.1^{(f)}$ \\
\hline 56 & 2-Methylnaphthalene & $96.1 \pm 12.2^{(c)}$ & $81.1 \pm 0.2$ & $57.9 \pm 0.2^{(f)}$ \\
\hline 57 & 1-Methylnaphthalene & $20.4 \pm 1.0^{(c)}$ & $16.5 \pm 0.1$ & $11.8 \pm 0.1^{(f)}$ \\
\hline 60 & lndanol & $12.6 \pm 0.8(c)$ & $9.7 \pm 0.1$ & $0.3 \pm 0.3^{(f)}$ \\
\hline 61 & $\mathrm{C}_{2}$-Tetralin & 3016 & & $103+$ \\
\hline 62 & $C_{4}$-Phenol & $13.3 \pm 3.00$ & $\therefore \rightarrow \pm 0.1$ & $10.3 \pm$ \\
\hline 63 & $\mathrm{C}_{4}$-Phenol, $\mathrm{C}_{3}$-Indan & $11.6 \pm 2.3^{(c)}$ & $? 2.0 \pm 0.1$ & $8.6+\because f$ \\
\hline 64 & Biphenyl & $26.4 \pm 2.7(c)$ & $27.0 \pm 0.1$ & $19.3 \pm 1: 4$ \\
\hline 65 & $\mathrm{C}_{2}$-Naphthalene & $23.0 \pm 2.3^{(c)}$ & $23.2 \pm 0.1$ & $16.6 \pm 0.1(f$ \\
\hline 66 & $\mathrm{C}_{2}$-Naphthalene & $20.8 \pm 1.8^{(c)}$ & $24.2 \pm 0.1$ & $17.3 \pm 2.1^{1+}$ \\
\hline 67 & $C_{2}$-Naphthalene & $10.3 \pm 1.0(\mathrm{c})$ & $6.6 \pm 0.1$ & $4.7 \pm 0.1^{f f}$ \\
\hline 68 & $C_{2}$-Naphthalene, Diphenylether & $27.2 \pm 2.6(c)$ & $27.6 \pm 0.2$ & $19.7 \pm 0.1^{6 f}$ \\
\hline 69 & Acenaphthene & $15.2 \pm 1.6^{(c)}$ & $18.7 \pm 0.2$ & $13.4 \pm 0.16$ \\
\hline 70 & $C_{3}$-Naphthalene & $10.6 \pm 1.3^{(c)}$ & $15.6 \pm 0.1$ & $11.1 \pm 0 . I^{(f)}$ \\
\hline 71 & $C_{3}$-Naphthalene & $7.2 \pm 1.0^{(c)}$ & $10.2 \pm 0.2$ & $7.3 \pm 0.2^{(f)}$ \\
\hline 72 & Dibenzofuran & $21.3 \pm 2.9^{(c)}$ & $27.0 \pm 0.1$ & $19.3 \pm 0.1^{(f)}$ \\
\hline 74 & Fluorene & $35.2 \pm 3.2(9)$ & $25.0 \pm 0.3$ & $15.6 \pm 0.2^{\left(r_{t}\right.}$ \\
\hline 75 & $C_{1}$-Acenaphthene, $C_{2}$-Biphenyl & $17.3 \pm 1.8(9)$ & $14.0 \pm 0.3$ & $8.7 \pm 0.2^{(n}$ \\
\hline 76 & $\mathrm{C}_{4}$-Naphthalene & $15.2 \pm 1.7(9)$ & $10.7 \pm 0.3$ & $6.7 \pm 0.2^{(h)}$ \\
\hline 77 & $\mathrm{C}_{4}$-Naphthalene & $27.6 \pm 3.1(9)$ & $31.5 \pm 1.0$ & $19.7 \pm 0.6(\mathrm{~h})$ \\
\hline 78 & Xanthene & $12.8 \pm 1.3(g)$ & $10.9 \pm 0.2$ & $6.8 \pm 0.1(h)$ \\
\hline 79 & $c_{1}$-Fluorene & $12.6 \pm 1.2^{(g)}$ & $10.4 \pm 0.6$ & $6.5 \pm 0.4(h)$ \\
\hline 81 & $c_{1}$-Fluorene & $12.6 \pm 1.1(9)$ & $10.6 \pm 0.2$ & $6.7 \pm 0.1^{(h)}$ \\
\hline 85 & Phenanthrene & $92.4 \pm 6.2^{(g)}$ & $111.7 \pm 2.1$ & $69.8 \pm 1.3^{(h)}$ \\
\hline 90 & 3-Methylphenanthrene & $9.4 \pm 0.6(g)$ & $11.0 \pm 0.3$ & $6.8 \pm 0.2^{(h)}$ \\
\hline 91 & 2-Methylphenanthrene & $12.4 \pm 0.8^{(g)}$ & $13.5 \pm 0.3$ & $8.5 \pm 0.2^{(h)}$ \\
\hline 96 & Fluoranthene & $9.5 \pm 1.3^{(g)}$ & $14.5 \pm 0.4$ & $9.1 \pm 0.2^{(h)}$ \\
\hline 97 & Pyrene & $11.1 \pm 1.6^{(g)}$ & $16.9 \pm 0.5$ & $10.5 \pm 0.3^{(h)}$ \\
\hline 99 & $\begin{array}{l}\text { 2- or 4-Methylpyrene, } \\
\text { Benzo(b) fluorene }\end{array}$ & $13.1 \pm 2.1(9)$ & $N D^{(1)}$ & ND \\
\hline
\end{tabular}

\footnotetext{
(a) Numbers refer to peaks in Figure 3.7, Results and Discussion Section.

(b) Identified by GC/ms.

(c) Based on 1.0 mg/mL n-Dodecane ISTO, 1:50 dilution, based on the integration of peak heights, $T=0$ was $1980, T=2$ years was 1982 .

(d) based on $5 \mathrm{GC}$ runs.

(e) Based on 4 GC runs.

(f) Based on $0.35 \mathrm{mg} / \mathrm{mL}$ n-Dodecane 1STD, 1:201 dilution.

(g) Based on $1.0 \mathrm{mg} / \mathrm{mL}$ n-Nonadecane ISTD, $1: 50$ dilution.

(h) Based on $0.40 \mathrm{mg} / \mathrm{mL}$ n-Nonadecane ISTD, $1: 201 \mathrm{dilution.}$

(i) No data.
} 
TABLE 7.17. Chromatographic Results for SRC-I Process Solvent Sample 3317-066-27 Stored at $4^{\circ} \mathrm{C}$, in the Dark, Under a Nitrogen Atmosphere

\begin{tabular}{|c|c|c|c|c|}
\hline \multirow{2}{*}{$\begin{array}{l}\text { Peak } \\
\text { No. (a) } \\
\end{array}$} & \multirow[b]{2}{*}{ Compound (b) } & \multicolumn{2}{|c|}{ Normalized Percent to ISTD } & \multirow{2}{*}{$\begin{array}{l}\text { Raw Data } \\
T=2 \text { years }\end{array}$} \\
\hline & & $T=0$ & $T=2$ years & \\
\hline 43 & Naphthalene & $22.6 \pm 1.7^{(c, d)}$ & $13.8 \pm 0.4^{(e)}$ & $11.5 \pm 0.3^{(e, f)}$ \\
\hline 54 & $C_{2}$-Indan & $9.6 \pm 1.3^{(c)}$ & $11.2 \pm 0.3$ & $9.3 \pm 0.2^{(f)}$ \\
\hline 55 & $c_{2}$-Indan & $16.5 \pm 1.8^{(c)}$ & $21.7 \pm 0.6$ & $18.1 \pm 0.5(f)$ \\
\hline 56 & 2-Methyl naphthalene & $65.1 \pm 6.4(c)$ & $67.5 \pm 1.8$ & $56.2 \pm 1.5^{(f)}$ \\
\hline 57 & 1-Methylnaphthalene & $12.8 \pm 1.6^{(c)}$ & $13.7 \pm 0.4$ & $11.4 \pm 0.3^{(f)}$ \\
\hline 60 & Indanol & $8.3 \pm 0.9^{(c)}$ & $8.1 \pm 0.2$ & $6.7 \pm 0.2^{(f)}$ \\
\hline 61 & $c_{2}$-Tetralin & & & \\
\hline 62 & $c_{4}$-Phenol & $9.7 \pm 1.7(c)$ & $12.0 \pm 0.4$ & $10.0 \pm 0.3^{(f)}$ \\
\hline 63 & $C_{4}$-Phenol, $C_{3}$-Indan & $8.2 \pm 1.4(c)$ & $10.0 \pm 0.4$ & $8.3 \pm 0.3^{(f)}$ \\
\hline 64 & Biphenyl & $18.3 \pm 2.5^{(c)}$ & $22.5 \pm 0.8$ & $18.7 \pm 0.6^{(f)}$ \\
\hline 65 & $C_{2}$-Naphthalene & $16.7 \pm 1.7^{(c)}$ & $19.4 \pm 0.7$ & $16.2 \pm 0.5^{(f)}$ \\
\hline 66 & $C_{2}$-Naphthalene & $15.3 \pm 1.8^{(c)}$ & $20.1 \pm 0.6$ & $16.8 \pm 0.5^{(f)}$ \\
\hline 67 & $c_{2}$-Naphthalene & $7.6 \pm 1.0(c)$ & $5.5 \pm 0.2$ & $4.6 \pm 0.2^{(f)}$ \\
\hline 68 & $C_{2}$-Naphthalene, Diphenylether & $20.0 \pm 2.2^{(c)}$ & $23.0 \pm 0.8$ & $19.2 \pm 0.6^{(f)}$ \\
\hline 69 & Acenaphthene & $12.2 \pm 1.7^{(c)}$ & $15.3 \pm 1.8$ & $12.8 \pm 1.5^{(f)}$ \\
\hline 70 & $C_{3}$-Naphthalene & $8.1 \pm 1.0(\mathrm{c})$ & $13.0 \pm 0.6$ & $10.8 \pm 0.5^{(f)}$ \\
\hline 71 & $C_{3}$-Naphthalene & $6.0 \pm 1.2^{(c)}$ & $8.4 \pm 0.4$ & $7.0 \pm 0.3^{(f)}$ \\
\hline 72 & Dibenzofuran & $17.7 \pm 2.9(c)$ & $22.6 \pm 0.8$ & $18.8 \pm 0.7^{(f)}$ \\
\hline 74 & Fluorene & $21.7 \pm 2.7(\mathrm{~g})$ & $15.4 \pm 0.6$ & $15.4 \pm 0.6^{(h)}$ \\
\hline 75 & $C_{1}$-Acenaphthene, $C_{2}$-Biphenyl & $10.6 \pm 1.5(\mathrm{~g})$ & $8.5 \pm 0.3$ & $8.5 \pm 0.3^{(h)}$ \\
\hline 76 & $C_{4}$-Naphthalene & $9.3 \pm 1.4(9)$ & $6.6 \pm 0.2$ & $6.6 \pm 0.2^{(h)}$ \\
\hline 77 & $C_{4}$-Naphthalene & $17.1 \pm 2.5(\mathrm{~g})$ & $19.3 \pm 0.6$ & $19.3 \pm 0.6(h)$ \\
\hline 78 & $x$ anthene & $8.1 \pm 1.1(g)$ & $6.7 \pm 0.3$ & $6.7 \pm 0.3^{(h)}$ \\
\hline 79 & $c_{1}$-fluorene & $7.8 \pm 0.8(\mathrm{~g})$ & $6.5 \pm 0.6$ & $6.5 \pm 0.6^{(h)}$ \\
\hline 81 & -Fluorene & $8.3 \pm 1.1^{(g)}$ & $6.6 \pm 0.2$ & $5.6 \pm 0.2^{(h)}$ \\
\hline 35 & Phenanthrene & $63.2+0.7(9)$ & $68.7 \pm 2.8$ & $68.7 \pm 2.8(h)$ \\
\hline$x$ & 3-Methylphenanth: ene & $6.6 \pm 0.4^{(g)}$ & $6.6 \pm 0.3$ & $6.6 \pm 0.3^{(h)}$ \\
\hline 91 & ¿-Methylphenanthrent & $9.0 \pm 0.9(9)$ & $8.1 \pm 0.3$ & $8.1 \pm 0.3^{(h)}$ \\
\hline$\because$ & Eluo anthene & $7.1 \pm 0.7^{(g)}$ & $8.8 \pm 0.4$ & $8.8 \pm 0.4^{(h)}$ \\
\hline 97 & 'yrine & $8.1 \pm 0.8 \cdot 3$ & $9.8 \pm 0.5$ & $9.8 \pm 0.5^{(\mathrm{h})}$ \\
\hline 99 & 2- or 4-Methylpyrene: Benzo(b, fluorene & $12.3 \pm 3.3(9)$ & $N D^{(i)}$ & \\
\hline
\end{tabular}

\footnotetext{
a: Vurner, refer to peaks in Figure 3,7 , Results and uiscussion Section.

(D) Ident ified by GC/MS.

c) Based on $1.15 \mathrm{mg} / \mathrm{mL} \mathrm{n}$-Dodecane ISTD, 1:50 dilution, based on tive ificegration of :y rati: .

(d) an $6 \mathrm{GC}$ runs, $T=0$ was 1980.

e) based on $8 \mathrm{GC}$ runs, $T=2$ years was 1982 .

(f) Based on $0.35 \mathrm{mg} / \mathrm{ML}$-Dodecane ISTD, $1: 201$ dilution.

i) Based on $1.7 \mathrm{mg} / \mathrm{mL}$ n-Nonadecane ISTD, 1:50 dilution

(in) Based on $0.4 \mathrm{~cm} / \mathrm{mL}$ n-Nonadecane ISTD; i:201 dilution.

i) No data.
} 
TABLE 7.18. Chromatographic Results for SRC-II Fuel 0il Blend Sample 3317-079-25 Stored at $-20^{\circ} \mathrm{C}$ and $20^{\circ} \mathrm{C}$ Under Various Conditions for One Year - Set 1

\begin{tabular}{|c|c|c|c|c|c|c|c|c|c|c|}
\hline \multirow[b]{2}{*}{ Peak No. (D) } & \multirow[b]{2}{*}{ Compound $(c)$} & \multicolumn{9}{|c|}{ nalized Percent to n-Nonadecane Internal Standaraia) } \\
\hline & & Contr & $\mathrm{rol}(\mathrm{d})$ & Condit & tion $1(e)$ & Condition $2^{(f)}$ & Condition $3(9)$ & Condition $4^{(h)}$ & Condition $5(i)$ & Condition $6(\mathrm{j})$ \\
\hline 28 & Phenol & $19.3=$ & $\pm 2.2^{(k)}$ & $22.4 \pm$ & $\pm 2.7^{(1)}$ & $23.7 \pm 1.2^{(\mathrm{m})}$ & $N D(n)$ & $20.1 \pm 3.8(0)$ & $25.3 \pm 1.0(p)$ & $24.1 \pm 2.2^{(q)}$ \\
\hline 32 & Indan & $5.0 \pm$ & \pm 0.5 & $6.5 \pm$ & \pm 1.0 & $6.0 \pm 0.3$ & No & $5.1 \pm 1.0$ & $6.5 \pm 0.8$ & $6.1 \pm 0.9$ \\
\hline 33 & Q-Cresol & $12.1=$ & \pm 1.4 & $14.0 \pm$ & $\pm \quad 1.6$ & $15.1 \pm 0.7$ & ND & $12.8 \pm 2.4$ & $15.8 \pm 0.9$ & $15.3 \pm 1.4$ \\
\hline 35 & II- $\mathrm{p}_{\text {-Cresol, }} C_{1}$-Indan & $49.0=$ & \pm 3.2 & $55.0 \pm$ & \pm 5.1 & $57.6 \pm 2.1$ & ND & $51.7 \pm 5.3$ & $60.2 \pm 2.4$ & $60.2 \pm 5.2$ \\
\hline 38 & $C_{1}$-Indan & $19.3=$ & \pm 2.0 & $22.1 \pm$ & $\pm \quad 2.3$ & $23.9 \pm 0.8$ & ND & $20.8 \pm 3.2$ & $24.5 \pm 1.0$ & $24.3 \pm 1.9$ \\
\hline 39 & $c_{1}-1$ ndan & $20.3 \pm$ & \pm 2.1 & $22.9 \pm$ & \pm 2.3 & $24.7 \pm 1.0$ & No & $21.7 \pm 3.0$ & $25.2 \pm 1.1$ & $24.9 \pm 1.7$ \\
\hline 41 & Tetralin & $39.5 \pm$ & $\pm \quad 3.9$ & $45.3 \pm$ & \pm 4.2 & $49.1 \pm 1.5$ & ND & $43.1 \pm 6.1$ & $50.3 \pm 1.9$ & $50.1 \pm 3.8$ \\
\hline 43 & Naphthai ene & $37.9 \pm$ & \pm 3.6 & $42.7 \pm$ & $\pm \quad 4.0$ & $46.2 \pm 1.5$ & vo & $40.7 \pm 5.5$ & $47.3 \pm 1.8$ & $46.7 \pm 3.2$ \\
\hline 48 & $C_{1}$-Tetralin & 5.7 & \pm 0.5 & $6.9 \pm$ & \pm 0.6 & $7.2 \pm 0.5$ & ND & $6.4 \pm 1.2$ & $7.4 \pm 0.4$ & $7.4 \pm 0.6$ \\
\hline 54 & $c_{2}$-Indan & $41.8+$ & \pm 4.7 & $50.2 \pm$ & $\pm \quad 3.8$ & $53.8 \pm 1.3$ & No & $47.5 \pm 5.9$ & $56.6 \pm 2.5$ & $54.7 \pm 4.1$ \\
\hline 56 & 2-Methylnaphthalene & $69.3 \pm$ & \pm 10.5 & $90.3 \pm$ & \pm 12.9 & $82.5 \pm 2.1$ & ND & $72.8 \pm 8.7$ & $103.6 \pm 14.9$ & $83.7 \pm 6.2$ \\
\hline 57 & 1-Methyinaphthalene & $13.7 \pm$ & \pm 1.0 & $14.7 \pm$ & \pm 3.1 & $16.8 \pm 0.4$ & NO & $14.9 \pm 1.6$ & $17.3 \pm 0.4$ & $16.9 \pm 1.2$ \\
\hline 59 & $c_{3}$-indan & $11.0 \pm$ & \pm 0.7 & $12.2 \pm$ & \pm 0.8 & $13.3 \pm 0.6$ & ND & $11.9 \pm 0.3$ & $13.2 \pm 0.5$ & $13.0 \pm 0.8$ \\
\hline 30 & Indanol & $13.3 \pm$ & \pm 1.0 & $15.6 \pm$ & \pm 1.0 & $16.6 \pm 0.3$ & NO & $14.9 \pm 1.4$ & $17.0 \pm 0.4$ & $16.8 \pm 1.3$ \\
\hline 62 & $c_{4}$-Phenol & $10.0 \pm$ & \pm 1.7 & $10.1 \pm$ & \pm 1.5 & $11.9 \pm 2.1$ & ND & $12.3 \pm 1.2$ & $11.2 \pm 2.1$ & $12.6 \pm 1.6$ \\
\hline b3 & $c_{4}+$ Phenol, $c_{3}$-Indan & $6.0 \pm$ & $\pm \quad 0.5$ & $6.9 \pm$ & \pm 0.6 & $7.3 \pm 0.1$ & ND & $6.6 \pm 0.6$ & $7.6 \pm 0.7$ & $7.5 \pm 0.5$ \\
\hline 34 & Biphenyl & $19.1 \pm$ & \pm 1.3 & $21.6 \pm$ & \pm 1.5 & $23.2 \pm 0.5$ & NO & $20.8 \pm 1.8$ & $24.0 \pm 1.6$ & $23.5 \pm 1.6$ \\
\hline 65 & $\mathrm{C}_{2}$-Naphthalene & $27.3 \pm$ & \pm 1.6 & $30.2 \pm$ & \pm 2.2 & $33.0 \pm 0.6$ & ND & $29.6 \pm 2.6$ & $33.9 \pm 2.0$ & $33.2 \pm 2.4$ \\
\hline 68 & $\begin{array}{l}\text { C-Naphthalene, } \\
\text { Diphenylether }\end{array}$ & $59.4 \pm$ & \pm 4.1 & $69.0 \pm$ & \pm 4.1 & $21.7 \pm 1.3$ & No & $64.8 \pm 5.0$ & $79.1 \pm 3.7$ & $72.6 \pm 4.7$ \\
\hline 59 & Acenaphthene & $10.1+$ & \pm 0.7 & $11.7 \pm$ & \pm 0.6 & $11.7 \pm 0.9$ & No & $10.8 \pm 1.0$ & $12.9 \pm 0.3$ & $11.8 \pm 1.1$ \\
\hline 70 & $\mathrm{C}_{3}$-Napinthalene & $17.5 \pm$ & $\pm \quad 3.7$ & $20.2 \pm$ & $\pm \quad 3.6$ & $19.3 \pm 3.0$ & ND & $17.5 \pm 0.9$ & $21.8 \pm 3.3$ & $20.5 \pm 2.5$ \\
\hline 71 & $\hat{C}_{3}$-Naphthalene & $14.3=$ & $\pm \quad 1.8$ & $17.9 \pm$ & \pm 1.0 & $18.0 \pm 1.5$ & NO & $16.1 \pm 2.2$ & $19.2 \pm 3.7$ & $18.2 \pm 1.6$ \\
\hline 74 & Fivorene & $9.6 \pm$ & $\pm \quad 0.4$ & $11.6 \pm$ & \pm 1.1 & $12.0 \pm 1.0$ & ND & $10.9 \pm 1.3$ & $13.0 \pm 1.2$ & $11.5 \pm 0.9$ \\
\hline 75 & $\begin{array}{l}\tau_{1} \text {-Acenaphthene, } \\
{ }_{2} \text {-Biphenyl }\end{array}$ & $7.2 \pm$ & \pm 0.3 & $7.8 \pm$ & $+\quad 2.9$ & $3.8 \pm 0.3$ & ND & $8.0 \pm 0.3$ & $9.6 \pm 0.9$ & $8.5 \pm 0.6$ \\
\hline 77 & $\breve{C}_{4}$-Vaphthalene & $14.6 \pm$ & \pm 0.7 & $17.1+$ & $+\quad: .2$ & $17.7 \pm 0.6$ & WD & $15.9 \pm 0.6$ & $19.2 \pm 1.6$ & $16.8 \pm 0.8$ \\
\hline 85 & The anthrene & $32.4=$ & \pm 1.4 & $34.5 \pm$ & $\pm \quad 0.6$ & $38.7 \pm 0.7$ & ND & $36.1 \pm 0.2$ & $38.9 \pm 0.2$ & $37.1 \pm 1.7$ \\
\hline 37 & Pyrene & $: 0.6$ & \pm 0.5 & $12.5 \pm$ & +1.2 & $12.2 \pm 0.4$ & 40 & $11.6 \pm 0.7$ & $12.0 \pm 1.2$ & $11.5 \pm 0.6$ \\
\hline
\end{tabular}

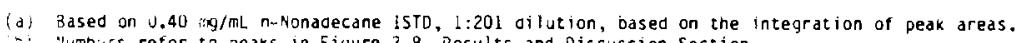
"lumbers refer to peaks in Figure 3.8 , Results and Discussion Section. icentified by $\mathrm{GC} / \mathrm{M}$

stored at $-20^{\circ} \mathrm{C}$, in the sark, unoer a nitroyen atmospnere.

Stored at $-20^{\circ} \mathrm{C}$, in the dark, under an air atmosphere.

9 ) stored at $20^{\circ} \mathrm{C}$, in the iight, under an dir atmosphere, ailuted in methylene chloride.

stored at $0^{\circ} \mathrm{C}$, in the ingt, under an dir atmosphere,

stored at $20^{\circ} \mathrm{C}$, in the dark, under a nicrogen atmosphere.

storea at $20^{\circ} \mathrm{C}$, in the dark, under an a $r$ atump a

based on $b$ ir ric runs.

based on 11 GC runs.

yased on $4 \mathrm{GC}$ runs.

No data cui icted.

based on 2 GC runs.

zased on 9 lic runs. 
TABLE 7.19. Chromatographic Results for SRC-II Fuel 0iT Blend Sample 3317-079-25 Stored at $-20^{\circ} \mathrm{C}$ and $20^{\circ} \mathrm{C}$ Under Various Conditions - Set $2(\mathrm{a})$

\begin{tabular}{|c|c|c|c|c|c|c|c|c|c|c|}
\hline \multirow[b]{2}{*}{ Pedk Nu. (c) } & \multirow{3}{*}{$-e_{\text {Phenol }}^{\text {compound }}$} & \multicolumn{8}{|c|}{ ane Internal Standard $(b)$} & \multirow{3}{*}{$\frac{\text { Condition } 6(k)}{9.6 \pm 0.4(1)}$} \\
\hline & & Control $(e)$ & Condition $1(f)$ & Condition $2^{(g)}$ & Condit & ion $3^{(h)}$ & & Condition $4^{(i)}$ & Condition $5^{(j)}$ & \\
\hline 30 & & $9.8 \pm 0.4(1)$ & $\mathrm{NO}_{\mathrm{O}}(\mathrm{m})$ & $12.1 \pm 0.1(n)$ & $12.4 \pm 0.1^{(0)}$ & $11.1 \mathrm{t}$ & $0.3(0)$ & $10.8 \pm 0.3(p)$ & $8.6 \pm 0.2^{(n)}$ & \\
\hline 32 & Indan & $4.5 \pm 1.4$ & ND & $5.0 \pm 0.9$ & $1.4 \pm 0.5$ & $6.4 \pm$ & 0.1 & $4.3 \pm 0.6$ & $3.2 \pm 0.1$ & $3.5 \pm 0.1$ \\
\hline 33 & $\underline{\underline{p}-C \text { resol }}$ & $8.6 \pm 1.1$ & ND & $11.5 \pm 0.2$ & $1.5 \pm 0.5$ & $2.8 \pm$ & 1.0 & $10.5 \pm 0.3$ & $8.4 \pm 0.2$ & $9.5 \pm 0.6$ \\
\hline 35 & m- $\Delta$-Cresol, $C_{1}$-Indar & $39.8 \pm 2.0$ & NO & $50.3 \pm 0.9$ & $8.6 \pm 2.0$ & $12.2 \pm$ & 0.4 & $45.4 \pm 1.5$ & $35.9 \pm 0.7$ & $40.5 \pm 2.8$ \\
\hline 38 & $\mathrm{C}_{1}-\ln \mathrm{n} d a n$ & $0.2 \pm \ldots(4)$ & NO & $7.7 \pm 0.2$ & $2.2 \pm 0.4$ & $4.1 \pm$ & 0.2 & $6.9 \pm 0.1$ & $5.4 \pm 0.3$ & $6.0 \pm 0.2$ \\
\hline 39 & $c_{l}$ - indan & $10.1 \pm 0.3$ & ND & $13.0 \pm 0.2$ & $7.9 \pm 1.8$ & $13.0 \pm$ & 0.9 & $11.5 \pm 0.3$ & $9.2 \pm 0.3$ & $10.6 \pm 0.6$ \\
\hline 41 & Tetralin & $15.9 \pm 0.7$ & ND & $22.1 \pm 0.4$ & $7.4 \pm 1.3$ & $10.4 \mathrm{t}$ & 0.1 & $19.1 \pm 0.9$ & $14.6 \pm 0.1$ & $16.5 \pm 0.9$ \\
\hline 43 & Maphthalene & $16.6 \pm 0.5$ & no & $21.4 \pm 0.3$ & $13.8 \pm 3.5$ & $21.4 \pm$ & 0.9 & $19.0 \pm 0.5$ & $15.1 \pm 0.4$ & $16.9 \pm 1.0$ \\
\hline 48 & $c_{1}$-letrahn & $0.6 \pm 0.6$ & No & $9.0 \pm 0.6$ & $1.6 \pm 0.2$ & $13.9 \pm$ & 1.4 & $8.0 \pm 0.3$ & $6.2 \pm 0.2$ & $7.0 \pm 0.5$ \\
\hline 54 & $c_{z^{-} \text {-Indan }}$ & $19.1 \pm 1.0$ & ND & $25.3 \pm 0.6$ & $13.4 \pm 2.5$ & $26.0 \pm$ & 1.0 & $22.8 \pm 0.8$ & $17.7 \pm 0.3$ & $19.3 \div 0.6$ \\
\hline 56 & 2-Methy Inaphtha lene & $29.5 \pm 1.9$ & ND & $38.6 \pm 1.3$ & $38.7 \pm 6.9$ & $39.3 \pm$ & -. & $35.2 \pm 1.6$ & $27.1 \pm 0.3$ & $28.9 \pm--$ \\
\hline 57 & 1-Methy I naphthalene & $5.9 \pm 1.1$ & ND & $8.2 \pm 0.4$ & $5.3 \pm 1.9$ & $7.8 \pm$ & 1.3 & $7.5 \pm 0.5$ & $6.1 \pm 1.1$ & $5.2 \pm 0.8$ \\
\hline 59 & $c_{3}$-indan & $4.3 \pm 0.3$ & ND & $3.6 \pm 0.2$ & $1.6 \pm 0.7$ & $2.2 \pm$ & 0.9 & $5.1 \pm 0.2$ & $4.1 \pm 0.1$ & $3.7 \pm 0.5$ \\
\hline 60 & Indanol & $6.5 \pm 0.5$ & No & $7.9 \pm 0.2$ & $1.3 \pm=-$ & $2.2 \pm$ & -- & $5.8 \pm 3.2$ & $6.3 \pm 0.1$ & $5.0 \pm 1.0$ \\
\hline 62 & $C_{4}$-Phenol & $4.8 \pm 0.4$ & No & $6.8 \pm 0.4$ & $3.5 \pm 1.5$ & $5.2 \pm$ & 1.4 & $5.8 \pm 0.5$ & $4.6 \pm 0.1$ & $3.8 \pm 0.7$ \\
\hline 63 & $c_{4}$-Phenol, $c_{3^{-}}$- Indan & $3.7 \pm 0.3$ & No & $5.1 \pm 0.2$ & $2.7 \pm 1.2$ & $4.1 \pm$ & 0.9 & $4.4 \pm 0.4$ & $3.4 \pm 0.1$ & $2.9 \pm 0.5$ \\
\hline 64 & Biphenyl & $8.6 \pm 0.5$ & No & $13.7 \pm 1.8$ & $7.7 \pm 2.5$ & $11.3 \pm$ & 1.1 & $10.8 \pm 1.8$ & $8.1 \pm 0.1$ & $1.4 \pm 0.7$ \\
\hline $6 b$ & $c_{2}$-Maphthal ene & $16.8 \pm 1.1$ & No & $15.3 \pm 0.4$ & $8.7 \pm 2.7$ & $12.7 \pm$ & 0.9 & $13.5 \pm 1.1$ & $11.1 \neq 0.1$ & $10.7 \pm 2.3$ \\
\hline 68 & $\begin{array}{l}C_{C_{2}} \text {-Naphthalene, } \\
\text { Diphenylether }\end{array}$ & $24.1 \pm 1.2$ & ND & $34.2 \pm 3.1$ & $24.3 \pm 5.2$ & $34.5 \pm$ & 1.2 & $29.5 \pm 1.2$ & $22.7 \pm 0.2$ & $25.0 \pm 1.7$ \\
\hline 64 & Acenaphthene & $5.3 \pm 1.2$ & No & $6.7 \pm 0.2$ & $3.0 \pm 0.3$ & $4.3 \pm$ & 0.5 & $6.7 \pm 0.9$ & $5.2 \pm 0.7$ & $5.1 \pm 0.3$ \\
\hline 70 & $C_{3}$-Maphthalene & $6.5 \pm 0.6$ & ND & $9.0 \pm 0.3$ & $7.5 \pm 2.7$ & $9.0 \pm$ & 0.6 & $8.1 \pm 0.3$ & $6.4 \pm 0.1$ & $6.9+0.4$ \\
\hline 71 & $c_{3}$-Naphthalene & $6.6 \pm 0.6$ & no & $9.0 \pm 0.3$ & $5.9 \pm 0.8$ & $8.4 \pm$ & 0.6 & $8.3 \pm 0.2$ & $6.6 \pm 0.1$ & $1.2 \pm 0.4$ \\
\hline 74 & Fluorene & $4.6 \pm 0.7$ & No & $6.7 \pm 0.3$ & $5.1 \pm 1.1$ & $6.3 \pm$ & 1.2 & $6.2 \pm 0.2$ & $4.9 \pm 0.1$ & $5.2 \div 0.3$ \\
\hline 75 & $\begin{array}{l}c_{1}-\text { Acenaphthene, } \\
c_{2}-8 \text { - } i \text { phenyl }\end{array}$ & $3.3 \pm 0.4$ & ND & $4.8 \pm 0.2$ & $3.0 \pm 0.3$ & $4.2 \pm$ & 1.7 & $4.4 \pm 0.1$ & $3.5 \pm 0.1$ & $3.7 \pm 0.2$ \\
\hline$n$ & $\mathrm{C}_{4}$-Naphthalene & $7.0 \pm 0.4$ & No & $9.4 \pm 0.3$ & $5.6 \pm 0.7$ & $7.5 \pm$ & 0.7 & $8.6 \pm 0.3$ & $6.7 \pm 0.1$ & $7.2 \pm 0.5$ \\
\hline 85 & Phenanthrene & $40.7 \pm 5.2$ & No & $47.8 \pm 2.0$ & $36.6 \pm 3.6$ & $42.7 \pm$ & & $48.4 \pm 3.6$ & $42.6 \div 2.3$ & $44.7 \pm 0.8$ \\
\hline 97 & Pyrene & $4.9 \pm 1.3$ & No & $5.2 \pm 0.1$ & $3.3 \pm 0.5$ & $6.2 \pm$ & 3.7 & $5.2 \pm 0.7$ & $4.1 \div 0.4$ & $4.0 \pm 0.4$ \\
\hline
\end{tabular}

(a) Set 1 and Set 2 were acyuired usiny difterent chromatographic paralieters. based on the integration of peaks oreas.

(i) Numbers refer to to peaks it Figure 3.8 . Results and Discussion Section.

(a) Identif fed by bic/MS.

(f) Stored at $-20^{\circ} \mathrm{C}$, in the durk, under an air atmosphere.

(y) Stored at $20^{\circ} \mathrm{C}$, in the light, under a nitrogen atmosphere.

(j) Stored at $20^{\circ} \mathrm{C}$. in the dark. Under a nitroyen atmosphere.

(k) St.ured at $20^{\circ} \mathrm{c}$. in the tark, under an air at fnosphere.

(ini) No dat d collected.

(u) based on - Gic runs.

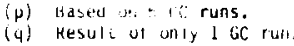


TABLE 7.20. Chromatographic Results for SRC-II Fuel 0il Blend Sample 3317-079-25 Stored at $60^{\circ} \mathrm{C}$, in the Dark, Under an Air Atmosphere

\begin{tabular}{|c|c|c|c|c|c|c|}
\hline \multirow[b]{2}{*}{ 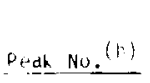 } & \multirow[b]{2}{*}{ Con wan! ! } & \multicolumn{5}{|c|}{ Normal leed Percent to n-Nonadecane Internal Standard (a) } \\
\hline & & $T=0$ & $T=1$ week & $T=2$ weeks & $I=16$ weeks & $\mathrm{T}=32$ weeks \\
\hline 28 & Phenul & $38.7 \pm 4.1^{(d)}$ & $55.6 \pm 1.9^{(e)}$ & $51.2 \pm 3.0(f)$ & $38.4 \pm 9.3^{(g)}$ & $17.0 \pm 6.3(9)$ \\
\hline$\because$ & Indan & $13.9 \pm 1.3$ & $12.8 \pm 0.9$ & $11.9 \pm 1.1$ & $7.2 \pm 2.1$ & $7.0 \pm 1.2$ \\
\hline 33 & $\underline{a}$-Cresol & $4.2 \pm 4.0$ & $37.6 \pm 2.7$ & $34.8 \pm 3.6$ & $23.5 \pm 3.8$ & $10.7 \pm 1.9$ \\
\hline 35 & il- $\&$ p-resesal, $c_{1}$-Indidn & $99.7 \neq 7.9$ & $97.1 \neq 3.4$ & $90.2 \pm 7.6$ & $62.5 \pm 9.5$ & $43.6 \pm 10.4$ \\
\hline 38 & $c_{1}$-Indan & $47.4 \pm 6.8$ & $47.6 \pm 1.6$ & $44.9 \pm 2.6$ & $18.0 \pm 3.5$ & $18.9 \pm 2.7$ \\
\hline 34 & $\therefore,-$ Indan & $44.4 \pm 3.4$ & $42.0 \pm 2.2$ & $40.9 \pm 2.6$ & $34.7 \pm 5.4$ & $21.5 \pm 6.1$ \\
\hline 41 & letralif: & $7 b .0 \pm 5.2$ & $74.8 \pm 2.2$ & $69.9 \pm 5.0$ & $50.2 \pm 6.5$ & $34.7 \pm 5.2$ \\
\hline 43 & vaphthiline & $70.5 \pm 10.6$ & $71.6 \pm 2.3$ & $67.8 \pm 3.5$ & $60.2 \pm 8.0$ & $41.8 \pm 8.7$ \\
\hline 48 & $C_{1}$-letralin & $13.3 \pm 0.8$ & $12.9 \pm 0.4$ & $12.4 \pm 1.0$ & $13.5 \pm 2.8$ & $7.6 \pm 1.7$ \\
\hline 54 & $C_{\ell}-\operatorname{lndan}$ & $86.5 \neq 5.8$ & $87.5 \pm 3.3$ & $83.3 \pm 5.6$ & $40.9 \pm 5.9$ & $47.9 \neq 4.8$ \\
\hline 50: & a-Methylnawthalene & $148.4 \pm 16.3$ & $143.8 \pm 13.6$ & $137.9 \pm 14.2$ & $157.3 \pm 26.5$ & $106.3 \neq 19.2$ \\
\hline 47 & 1-MethyInaphthalene & $26.7 \pm 1.5$ & $26.4 \pm 0.8$ & $25.4 \pm 1.9$ & $18.5 \pm 3.0$ & $16.1 \pm 2.9$ \\
\hline 38 & C. - - ndan & $34.5 \neq 2.0$ & $33.9 \pm 1.0$ & $32.3 \pm 2.3$ & $12.4 \pm 5.6$ & $9.5 \pm 1.2$ \\
\hline bij & indanol & $24.8 \pm 1.5$ & $24.2 \pm 0.7$ & $22.5 \pm 3.4$ & $9.8 \pm 3.6$ & $10.4 \pm 2.2$ \\
\hline 61 & $C_{2}$-Tetralin & $22.0 \pm 1.4$ & $21.9 \pm 1.0$ & $20.7 \pm 1.6$ & $N^{(h)}$ & No \\
\hline 62 & $\mathrm{C}_{4}$-Phenol & $14.6 \pm 1.2$ & $14.5 \pm 2.0$ & $13.4 \pm 1.5$ & ND & $9.8 \pm 1.4$ \\
\hline 64 & Bi pheny 1 & $31.9 \pm 2.1$ & $32.4 \pm 3.6$ & $31.0 \pm 3.4$ & $28.5 \pm 3.8$ & $23.7 \pm 4.2$ \\
\hline 65 & $\ddots_{2}$-Naphthalene & $53.4 \neq 3.9$ & $53.5 \neq 3.2$ & $49.8 \pm 4.2$ & $31.8 \pm 4.0$ & $27.9 \pm 2.7$ \\
\hline 68 & $\begin{array}{l}\text { Naphthalene, } \\
\text { niphenylether }\end{array}$ & $124.2 \pm 12.5$ & $121.9 \pm 12.1$ & $109.6 \pm 10.7$ & $94.5 \pm 12.3$ & $78.4 \pm 9.1$ \\
\hline 69 & Aciaphthene & $17.7 \neq 3.4$ & $17.9 \pm 0.6$ & $17.4 \pm 1.1$ & $14.5 \neq 1.9$ & $13.5 \pm 2.2$ \\
\hline 70 & $C_{3}$-Napht hatene & $27.6 \pm 1.5$ & $27.2 \pm 0.6$ & $26.3 \pm 1.3$ & $20.2 \pm 2.6$ & $22.6 \pm 4.8$ \\
\hline 1 & $C_{3}$-Naphthalene & $19.8 \pm 1.1$ & $19.4 \pm 0.5$ & $19.1 \pm 1.0$ & $18.9 \pm 2.5$ & $19.2 \pm 3.0$ \\
\hline 74 & Fluorene & $14.5 \pm 0.8$ & $14.3 \pm 0.3$ & $13.8 \pm 0.7$ & $13.4 \pm 2.1$ & $12.7 \pm 1.9$ \\
\hline 10 & $\begin{array}{l}C_{1} \text {-Acenaphtirene, } \\
C_{2}-B i \text { iphenyl }\end{array}$ & $14.1 \neq 0.9$ & $13.7 \pm 0.9$ & $13.7 \pm 0.7$ & No & $10.2 \pm 1.4$ \\
\hline "1 & $\check{L}_{4}$-Naphthalene & $21.5 \pm 1.1$ & $21.2 \pm 0.3$ & $21.2 \pm 1.2$ & $20.4 \pm 4.5$ & $23.6 \pm 3.0$ \\
\hline 85 & Phenanthrene & $39.7 \pm 1.4$ & $40.1 \pm 1.0$ & $39.8 \pm 1.2$ & $51.5 \pm 12.0$ & $40.9 \pm 5.0$ \\
\hline 97 & Pyrene & $10.7 \pm 1.7$ & $11.6 \pm 1.5$ & $12.1 \pm 0.8$ & $32.1 \pm 12.0$ & $11.4 \neq 3.9$ \\
\hline
\end{tabular}

(a) Based un U.4U my/mL n-Nunadecane 15TD, 1:10i dilution, based on the integration of peak areas.

(ic) Numbers reter to peaks in figure 3.9 , Kesults and viscusston Section.

(ic) Identified by GC/MS.

((d) Based on $2 b$ GC runs.

(it) Based an 48 GC runs.

(iy) Based un 72 lic runs.

(h) No data collected. 
TABLE 7.21. Chromatographic Results for SRC-II Fuel $0 i 1$ Blend Sample 3317-079-25 Stored at $100^{\circ} \mathrm{C}$, in the Dark, Under an Air Atmosphere

\begin{tabular}{|c|c|c|c|c|c|c|}
\hline$=0$ & $I=1$ week & $I=2$ meeks & $I=4$ weeks & $r=8$ weeks & $T=16$ meeks & $I=32$ weeks \\
\hline$\cdot \pm U . i^{(d)}$ & $2.1 \pm 0.4^{(0)}$ & $1.6 \pm 0.6^{(d)}$ & $1.010 .9^{(0)}$ & $0.0 \pm \ldots(0)$ & $0.2 \pm 1.0^{(e)}$ & $0.0 \pm--$ \\
\hline $1+0.4$ & $4.2 \pm 0.7$ & $3.8 \pm 0.8$ & $2.5 \pm 1.3$ & $1.5 \pm 1.6$ & $1.8 \pm 1.8$ & $0.0 \pm \ldots$ \\
\hline $40.2 \pm 0.8$ & $40.4 \pm 3.2$ & $38.7 \pm 3.2$ & $28.7 \pm 6.7$ & $21.0 \pm 8.4$ & $20.1 \pm 10.8$ & $1.6 \pm 0.2$ \\
\hline $9.6 \pm 2.1$ & $8.7 \pm 1.0$ & $8.6 \pm 0.9$ & $6.3 \pm 1.8$ & $4.3 \pm 2.3$ & $4.8 \pm 3.3$ & $0.2 \pm 0.1$ \\
\hline $22.6 \pm 1.3$ & $21.0 \pm 1.5$ & $20.0 \pm 2.1$ & $15.7 \pm 2.9$ & $11.7 \pm 3.3$ & $12.8 \pm 5.6$ & $1.6 \pm 0.1$ \\
\hline $77.3 \pm 3.7$ & $76.7 \pm 4.6$ & $75.5 \pm 7.7$ & $70.8 \pm 10.9$ & $50.7 \pm 9.2$ & $46.9 \pm 13.3$ & $5.4 \pm 3.9$ \\
\hline 10.00 .6 & $10.3 \pm 0.6$ & $10.3 \pm 0.5$ & $8.5 \pm 1.2$ & $6.6 \pm 1.3$ & $7.7 \pm 2.3$ & $1.1 \pm 0.1$ \\
\hline $11.2 \pm 0.5$ & $15.1 \pm 2.8$ & $11.6 \pm 0.5$ & $8.9 \pm 1.1$ & $7.0 \pm 1.3$ & $8.3 \pm 2.1$ & $0.7 \pm 0.5$ \\
\hline $53.0 \pm 3.2$ & $3 b .9 \pm 3.0$ & $54.5 \pm 5.8$ & $38.4 \pm 4.8$ & $36.1 \pm 6.0$ & $32.6 \pm 8.2$ & $3.0 \pm 2.9$ \\
\hline $80.0 \pm 3.3$ & $78.3 \pm 3.7$ & $77.7 \pm 2.8$ & $60.0 \pm 5.0$ & $52.0 \pm 3.7$ & $52.5 \pm 7.3$ & $4.6 \pm 5.5$ \\
\hline $39.9 \pm 2.3$ & $34 . y \pm 3.4$ & $38.4 \pm 2.0$ & $36.0 \pm 4.5$ & $27.8 \div 2.9$ & $39.2 \pm 10.0$ & $4.3 \pm 1.7$ \\
\hline $9.9 \neq 0.6$ & $10.1 \pm 0.6$ & $10.4 \pm 0.4$ & $8.9 \pm 0.8$ & $1.5 \pm 0.4$ & $11.2 \pm 1.9$ & $1.2 \pm 0.9$ \\
\hline $11.1 \pm 0.8$ & $11.5 \div 1.5$ & $11.7 \pm 0.6$ & $10.3 \pm 1.2$ & $10.6 \pm 0.4$ & $7.7 \pm 2.7$ & $1.7 \pm 0.9$ \\
\hline $11.4 \pm 1.1$ & $10.8 \pm 0.7$ & $10.9 \pm 1.4$ & $8.9 \pm 0.8$ & $7.1 \pm 0.8$ & No $(t)$ & $0.6 \pm 0.3$ \\
\hline $31.1 \pm 1.7$ & $30.9 \neq 1.8$ & $31.9 \pm 1.4$ & $27.6 \pm 2.2$ & $23.3 \pm 1.2$ & $27.6 \pm 4.0$ & $3.7 \pm 5.3$ \\
\hline $37.8 \pm 5.0$ & $37.6 \pm 2.5$ & $38.9 \pm 1.3$ & $33.1 \pm 2.7$ & $22.6 \pm 2.3$ & $31.7 \pm 6.9$ & $4.6 \pm 2.8$ \\
\hline $97.9+5.8$ & $98.0 \pm 4.6$ & $104.5 \pm 4.2$ & $91.4 \pm 6.2$ & $80.7 \pm 2.1$ & $96.0 \pm 8.7$ & $14.0 \pm 10.3$ \\
\hline $21.0 \pm 1.3$ & $19.2 \pm 1.4$ & $20.0 \pm 1.0$ & $18.3+1.4$ & $17.5 \pm 1.4$ & $19.3 \pm 1.7$ & $3.4 \pm 1.9$ \\
\hline $19.0 \pm 1.1$ & $19.4 \div 1.1$ & $19.8 \pm 2.3$ & $14.4 \pm 1.8$ & $10.3 \pm 1.0$ & $12.5 \pm 4.2$ & $2.2 \pm 0.9$ \\
\hline $20.9 \pm 1.4$ & $14.9 \pm 2.1$ & $17.1 \pm 2.2$ & $14.4 \pm 1.7$ & $10.6 \pm 1.5$ & $8.3 \pm 3.0$ & $1.2 \pm 0.7$ \\
\hline $13.8 \pm 0.8$ & $18.1 \pm 3.7$ & $14.4 \pm 0.7$ & $11.6 \pm 1.0$ & $9.4 \pm 0.7$ & $10.7 \pm 1.4$ & $1.4 \pm 0.9$ \\
\hline $11.6 \pm 0.4$ & $14.4 \pm 2.3$ & $10.5 \pm 0.7$ & $8.5 \pm 0.7$ & $7.7 \pm 0.8$ & $7.3 \pm 2.0$ & $0.9 \pm 0.7$ \\
\hline $28.4 \pm 1.6$ & $29.3 \pm 2.7$ & $29.8 \pm 1.1$ & $26.4 \pm 1.8$ & $24.7 \pm 1.4$ & $35.0 \pm 3.8$ & $8.3 \pm 2.9$ \\
\hline $40.6 \pm 4.4$ & $41.8 \pm 3.5$ & $43.6 \pm 2.3$ & $31.2 \pm 3.4$ & $28.5 \pm 1.0$ & $32.8 \pm 3.1$ & $5.5 \pm 4.1$ \\
\hline $37.8 \pm 3.5$ & $42.6 \pm 3.1$ & $44.4 \pm 2.3$ & $39.2 \pm 3.2$ & $33.2 \pm 1.4$ & $44.8 \pm 4.0$ & $7.6 \pm 5.1$ \\
\hline $43.6 \pm 2.2$ & $44.1 \pm 2.0$ & $45.8 \pm 1.8$ & $43.1 \pm 2.7$ & $41.3 \neq 1.9$ & $44.9 \pm 3.5$ & $9.4 \pm 6.5$ \\
\hline $13.4 \pm 1.9$ & $16.5 \pm 2.9$ & $13.9 \pm 3.2$ & $15.4 \pm 0.9$ & $11.1 \pm 1.0$ & $14.4 \pm 2.0$ & $2.9 \pm 1.7$ \\
\hline $17.1 \pm 1.4$ & $18.8 \pm 2.2$ & $18.3 \neq 0.8$ & $16.8 \pm 0.9$ & $16.1 \pm 0.8$ & $17.0 \pm 1.2$ & $4.2 \div 2.5$ \\
\hline $13.3 \pm 1.0$ & $14.1 \pm 1.0$ & $14.1 \neq 0.9$ & $12.6 \pm 0.7$ & $12.1 \pm 0.8$ & $12.0 \pm 1.5$ & $3.3 \pm 1.7$ \\
\hline $16.4 \neq 1.5$ & $16.4 \pm 3.7$ & $17.5 \pm 2.1$ & $16.4 \pm 1.4$ & $15.4 \pm 2.0$ & $12.2 \pm 2.0$ & $4.0 \pm 1.9$ \\
\hline $10.0 \pm 0.8$ & $10.3 \pm 1.5$ & $10.2 \pm 0.9$ & $9.5 \pm 0.6$ & $8.7 \pm 0.7$ & $9.1 \pm 0.9$ & $1.7 \pm 1.0$ \\
\hline $11.8 \neq 0.6$ & $12.0 \pm 1.5$ & $11.8 \pm 0.7$ & $10.0 \pm 1.0$ & $9.9 \pm 0.6$ & $9.8 \pm 1.0$ & $2.4 \pm 0.8$ \\
\hline $8.8 \pm 1.0$ & $9.2 \pm 0.9$ & $8.9 \pm 1.0$ & $7.9 \pm 1.1$ & $8.2 \pm 0.7$ & $9.6 \pm 0.9$ & $3.1 \pm 1.1$ \\
\hline $9.9 \pm 1.9$ & $11.2 \pm 0.5$ & 0.5 & $11.3 \pm 0.7$ & $10.0 \pm 0.2$ & $11.8 \pm 0.7$ & $6.4 \pm 2.7$ \\
\hline $7.7 \pm 0.5$ & $7.8 \pm 0.7$ & $8.2 \pm 0.3$ & $7.0 \pm 0.3$ & $7.7 \pm 0.3$ & $7.2 \pm 0.6$ & $2.7 \pm 0.5$ \\
\hline $35.9 \pm 2.0$ & $37.2 \pm 1.3$ & $37.8 \pm 1.5$ & $34.1 \pm 2.0$ & $39.5 \pm 2.3$ & $39.0 \pm 3.1$ & $23.1 \pm 5.3$ \\
\hline $7.8 \pm 0.5$ & $8.0 \pm 0.9$ & $8.9 \pm 0.4$ & $7.5 \pm 0.4$ & $9.7 \pm 0.8$ & $8.8 \pm 0.8$ & $5.9 \pm 2.3$ \\
\hline $15.0 \pm 0.5$ & $15.0 \pm 1.3$ & $15.4 \pm 2.1$ & $13.3 \pm 0.8$ & $17.8 \pm 1.3$ & $16.1 \pm 1.8$ & $10.9 \pm 4.0$ \\
\hline
\end{tabular}

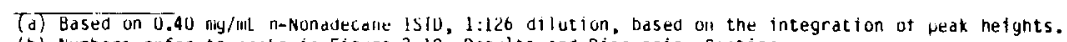

(b) Numbers refer to peaks in Figure 3.10, Results and Discussion Section.

(c) Ident if ied by to ge/ms.

(d) Based on 24 GC runs.

(y) Volatihity effects mere too larye to use 32 week data for chemical compositional changes. 


\section{TABLE 7.22. Chromatographic Results for SRC-II Fuel 0il Blend Samples Stored at $-20^{\circ} \mathrm{C}$, in the Dark, Under a Nitrogen Atmosphere for Three Years Diluted in Methylene Chloride}

\begin{tabular}{|c|c|}
\hline Peak No. (a) & Compound $(b)$ \\
\hline 28 & Phenol \\
\hline 34 & $i_{3}$-Benzene \\
\hline 32 & Indar \\
\hline 33 & o-Cresol \\
\hline 35 & $m \& \mathrm{p}$-Cresol, $\mathrm{C}_{1}$-lndan \\
\hline 38 & $c_{1}$-lnaar \\
\hline 39 & $c_{1}$-Inaan \\
\hline 40 & $\mathrm{C}_{2}$-Phenol \\
\hline 41 & Tetralin \\
\hline 42 & $C_{2}$-Phenol \\
\hline 43 & Naphthalene \\
\hline 48 & $c_{1}$-Tetralin \\
\hline 54 & $\mathrm{C}_{2^{-I n a a n}}$ \\
\hline 55 & $\mathrm{C}_{2}-$ Indan \\
\hline 56 & 2-Methylnaphthalene \\
\hline 57 & l-Methylnaphthalene \\
\hline 59 & $\mathrm{C}_{3}-$ Indan \\
\hline 60 & Indanol \\
\hline 61 & $c_{2}$-Tetralin \\
\hline 62 & $C_{4}$-Phenol \\
\hline 63 & $C_{4}$-Pnenol, $C_{3}$-Indan \\
\hline 64 & Biphenyl \\
\hline 65 & $\mathrm{C}_{2}$-Napnthalene \\
\hline 66 & $C_{2^{-N a p h t h a l e n e}}$ \\
\hline 68 & $C_{2}$-Naphthalene, Diphenyletner \\
\hline 69 & Acenaphthene \\
\hline 70 & $C_{3}$-Naphthalene \\
\hline 71 & $\mathrm{C}_{3}$-Naphthalene \\
\hline 74 & Fluorene \\
\hline 75 & $C_{1}$-Acenaphthene, $C_{2}$-Biphenyl \\
\hline 77 & $C_{4}$-Naphthalene \\
\hline 85 & Phenanthrene \\
\hline 97 & Pyrene \\
\hline
\end{tabular}

\begin{tabular}{|c|c|c|c|}
\hline FOB $3317-79-23(c)$ & FOB $3317-79-24$ ! & $50 \mathrm{~B} 3317-79-25$ (e) & FOB $3317-79-2$ \\
\hline $28.6 \pm 0.6$ & $31.1=0 . y$ & $+0.4 \pm 3.2$ & $28.8+\therefore$ \\
\hline $13.3 \pm 0.2$ & $11.2 \pm 0.1$ & $n 0^{(f)}$ & $9.7 \pm 0.1$ \\
\hline $11.4 \pm 0.3$ & $8.3 \pm 0.1$ & $11.0 \pm 0.8$ & $8.2 \pm 6 .$. \\
\hline $22.3 \pm 0.5$ & $23.0 \pm 0.2$ & $25.8 \pm 1.1$ & 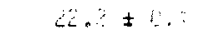 \\
\hline $50.0 \pm 0.4$ & $49.2 \pm 0.5$ & $44.8 \pm 1.9$ & $45.4 \pm 6$. \\
\hline $11.7 \pm 0.3$ & $20.0 \pm 0.1$ & $13.1 \pm 0.5$ & $10 .: \ldots$ \\
\hline $19.5 \pm 0.2$ & $17.7 \pm 0.3$ & $21.5 \pm 0.6$ & $18.0 \pm$ \\
\hline $13.7 \pm 0.2$ & $12.3 \pm 0.2$ & $19.3 \pm \ldots(h)$ & $+4.4 \pm 0$ \\
\hline $48.8 \pm 0.3$ & $39.5 \pm 0.5$ & $44.6 \pm 4.3$ & $35.2 \pm \ldots$ \\
\hline $13.7 \pm 0.1$ & $12.5 \pm 0.2$ & $N C$ & $1+.2=\ldots$ \\
\hline $100.2 \pm 0.7$ & $93.9 \pm 1.1$ & $87.6 \div 2.6$ & $.8 .4 \pm r . h$ \\
\hline $12.2 \pm 0.2$ & $11.3 \pm 0.1$ & $13.3 \pm 0.2$ & $11.3 \pm 0.2$ \\
\hline $32.4 \pm 0.3$ & $30.4 \pm 0.5$ & $33.8 \pm 0.9$ & $30 .+0.2$ \\
\hline $26.2 \pm 0.3$ & $25.5 \pm 0.2$ & $25.7 \pm 0.6$ & $26.8 \div u$ \\
\hline $95.7 \pm 0.7$ & $91.5 \pm 0.9$ & $80.2 \pm 1.3$ & $86.4 \approx$ \\
\hline $20.6 \pm 0.2$ & $20.2 \pm 0.3$ & $27.7 \pm 2.6$ & $20.9 \pm 0.1$ \\
\hline $13.2 \pm 0.2$ & $12.4 \pm 0.5$ & $16.4 \pm 1.6$ & $13.9 \pm 0.1$ \\
\hline $14.6 \pm 0.1$ & $13.7 \pm 0.2$ & $13.6 \pm--$ & $14.9 \pm 0.1$ \\
\hline $21.9 \pm 0.3$ & $22.2 \pm 0.3$ & $2 \ldots \pm 0.5$ & $24.4 \pm .2$ \\
\hline $11.4 \pm 0.1$ & $11.3 \pm 0.1$ & $16.6 \pm 3.4$ & $13.3 \pm 0.2$ \\
\hline $29.8 \pm 0.3$ & $29.1 \pm 0.3$ & $32.5 \pm 2.3$ & $30.4 \pm 0.1$ \\
\hline $34.0 \pm 0.2$ & $33.0 \pm 0.3$ & $38.6 \pm 2.3$ & $34.6 \pm 0.3$ \\
\hline $28.3 \pm 0.2$ & $27.5 \pm 0.3$ & $34.4 \pm 1.1$ & $29.0 \pm 0.4$ \\
\hline $53.6 \pm 0.1$ & $52.0 \pm 0.7$ & $54.6 \pm 2.1$ & $52.6 \pm 0.2$ \\
\hline $15.0 \pm 0.1$ & $14.8 \pm 0.1$ & $18.4 \pm 1.9$ & $15.4 \pm 0.1$ \\
\hline $16.1 \pm 0.1$ & $16.0 \pm 0.2$ & $20.2 \pm 1.8$ & $16.8 \pm 0.1$ \\
\hline $14.8 \pm 0.1$ & $14.6 \pm 0.1$ & $18.6 \pm 1.8$ & $15.4 \pm 0.2$ \\
\hline $11.9 \pm 0.1$ & $11.8 \pm 0.1$ & $18.1 \pm 2.3$ & $13.4 \pm 0.3$ \\
\hline $10.4 \pm 0.1$ & $10.4 \pm 0.1$ & $14.5 \pm 2.0$ & $11.2 \pm 0.1$ \\
\hline $11.9 \pm 0.1$ & $11.8 \pm 0.1$ & $15.7 \pm 1.3$ & $12.9 \pm 0.1$ \\
\hline $30.1 \pm 0.2$ & $31.4 \pm 0.3$ & $40.0 \pm 0.8$ & $35.0 \pm 0.4$ \\
\hline $13.6 \pm 0.4$ & $14.0 \pm 0.2$ & $18.7 \pm 2.7$ & $16.1 \pm 0.1$ \\
\hline
\end{tabular}

(a) Numbers refer to peaks in Figure 3.4 , Results and Discussion section.

(b) Identified by GC/MS.

(c) Based on $4.0 \mathrm{mg} / \mathrm{mL}$ iSTD, $1: 10$ dilution in methylene chloride, 3 determinations, compare to Table 7.8 for time $=0$ results.

(a) Based on $2.5 \mathrm{mg} / \mathrm{mL}$ ISTD, 1:20 dilution in methylene chloride, 3 determinations, compared to Table 7.9 for time $=0$ results.

(e) Based on $2.5 \mathrm{mg} / \mathrm{mL}$ ISTD, 1:20 dilution in methylene chloride, 3 determinations, compare to Table 7.10 for time $=0$ results.

(f) No data received.

(g) Based on $2.2 \mathrm{mg} / \mathrm{mL}$ ISTD, $1: 20$ dilution in methylene chloride, 3 determinations, compare to Table 7.11 for time $=0$ results.

(n) Value from one determination only. 

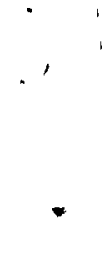


\subsection{APPENDIX II}

\section{PLOTS AND F VALUES FROM STATISTICAL ANALYSIS OF CHROMATOGRAPHIC DATA}

The plots and tables on the following pages present results of ANOVA techniques applied to the chromatographic data. Figure 8.1 and Table 8.1 present the $\log$ transformed results and $F$ values from the SRC-II naphtha samples stored in the repository. Figure 8.2 and Table 8.2 present the results from the SRC-I light oil samples stored in the repository. Figures 8.3 and 8.4 and Tables 8.3 and 8.4 present the results from the SRC-II middle and heavy distillates, respectively. Figures 8.5 and 8.6 and Tables 8.5 and 8.6 present the results from the SRC-I wash solvent and process solvents stored in the repository, respectively. The data for the SRC-II FOB is in the text of the status report.

The data from the studies at $-20^{\circ} \mathrm{C}$ and $20^{\circ} \mathrm{C}$ under various parameters of light versus darkness, air versus nitrogen atmosphere, and diluted in methylene chloride versus undiluted are given in the text of the status report.

Figure 8.7 and Table 8.7 present the $\log$ transformed results and $F$ values from the chromatographic data acquired from the accelerated study of an SRC-II FOB stored at $100^{\circ} \mathrm{C}$ under an air atmosphere. The results from the $60^{\circ} \mathrm{C}$ study are in the text. 


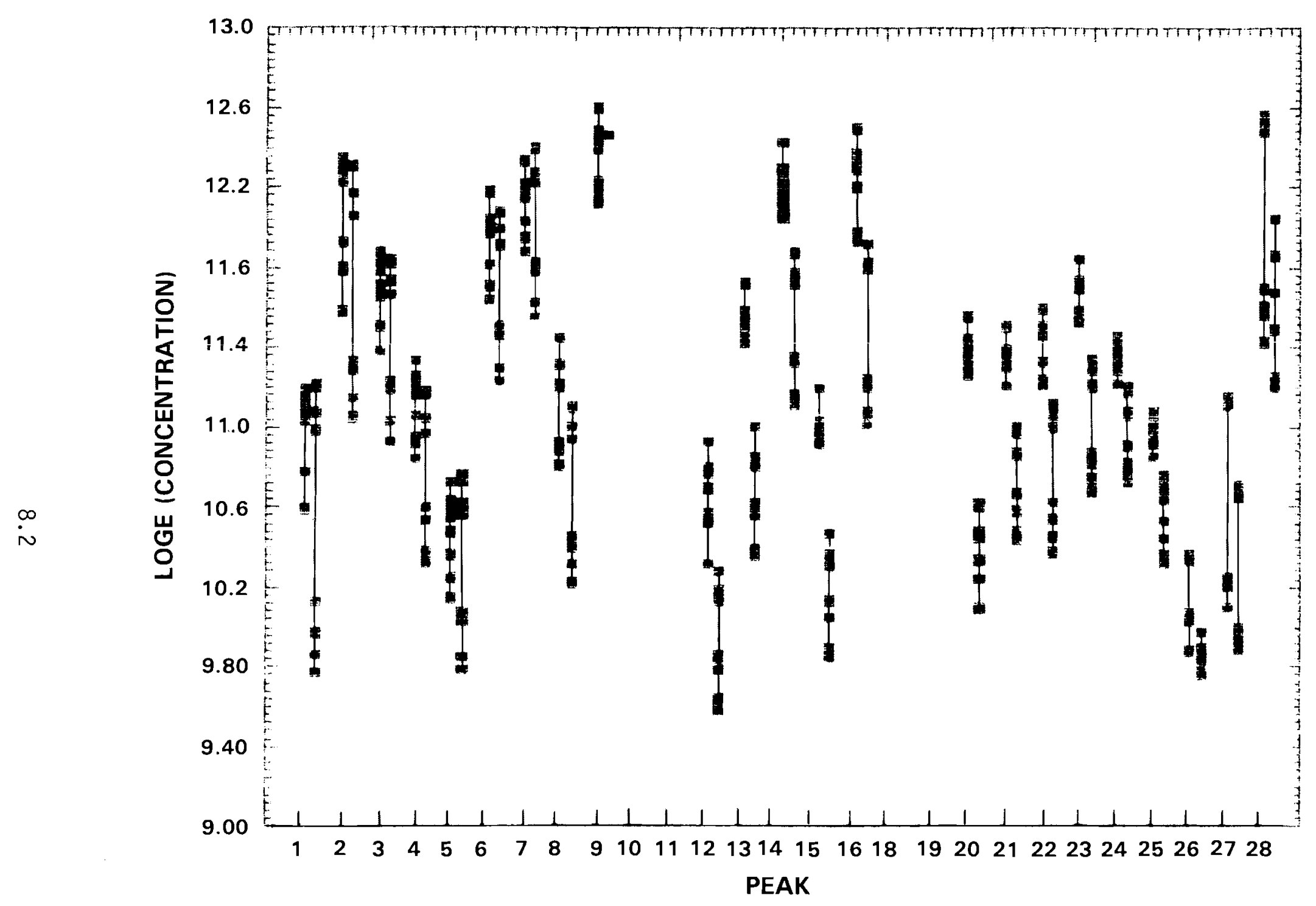

FIGURE 8.1. Log Transformed Data from Chromatographic Results for SRC-I I Naphtha Samples Stored in the Repository. Data points after two years are offset by 0.3 peak units 
TABLE 8.1. F Values from the ANOVA Techniques Applied to the SRC-II Naphtha Chromatographic Data After Storage in the Repository for Two Years

\begin{tabular}{|c|c|c|}
\hline Peak $(a)$ & $\begin{array}{l}\text { Calculated } \\
\text { F Value }\end{array}$ & $\begin{array}{l}\text { Critical F Value } \\
(5 \% \alpha \text { Level }) \\
\end{array}$ \\
\hline 1 & 3.30 & $4.54^{(d)}$ \\
\hline 2 & 2.81 & 4.54 \\
\hline 3 & 3.13 & 4.54 \\
\hline 4 & 11.72 & 18.51 (e) \\
\hline 5 & 2.21 & 18.51 \\
\hline 6 & 4.40 & 18.51 \\
\hline 7 & 0.82 & 18.51 \\
\hline 8 & 18.50 & 18.51 \\
\hline 9 & 0,36 & 18.51 \\
\hline 10 & $N D(c)$ & \\
\hline 11 & ND & \\
\hline 12 & 40.27 & 18.51 \\
\hline 13 & 72.52 & 18.51 \\
\hline 14 & 49.08 & 18.51 \\
\hline 15 & 68.14 & 18.51 \\
\hline 16 & 46.80 & 18.51 \\
\hline 18 & ND & \\
\hline 19 & ND & \\
\hline 20 & 106.1 & 18.51 \\
\hline 21 & 39.96 & 18.51 \\
\hline 22 & 37.01 & 18.51 \\
\hline 23 & 41.09 & 18.51 \\
\hline 24 & 14.77 & 18.51 \\
\hline 25 & 17.80 & 18.51 \\
\hline 26 & 4.42 & 4.54 \\
\hline 27 & 1.96 & 4.54 \\
\hline 28 & 5.81 & 4.54 \\
\hline
\end{tabular}

(a) Peaks refer to compounds identified by GC/MS contained in Table 3.1 and shown in Figure 3.1.

(b) Values greater than the 5\% a level were considered chromatographic differences caused by the split injection. Therefore, no conclusions were made regarding decomposition of these compounds.

(c) No data.

(d) Based on calculated statistical error.

(e) Based on $20 \%$ error. 


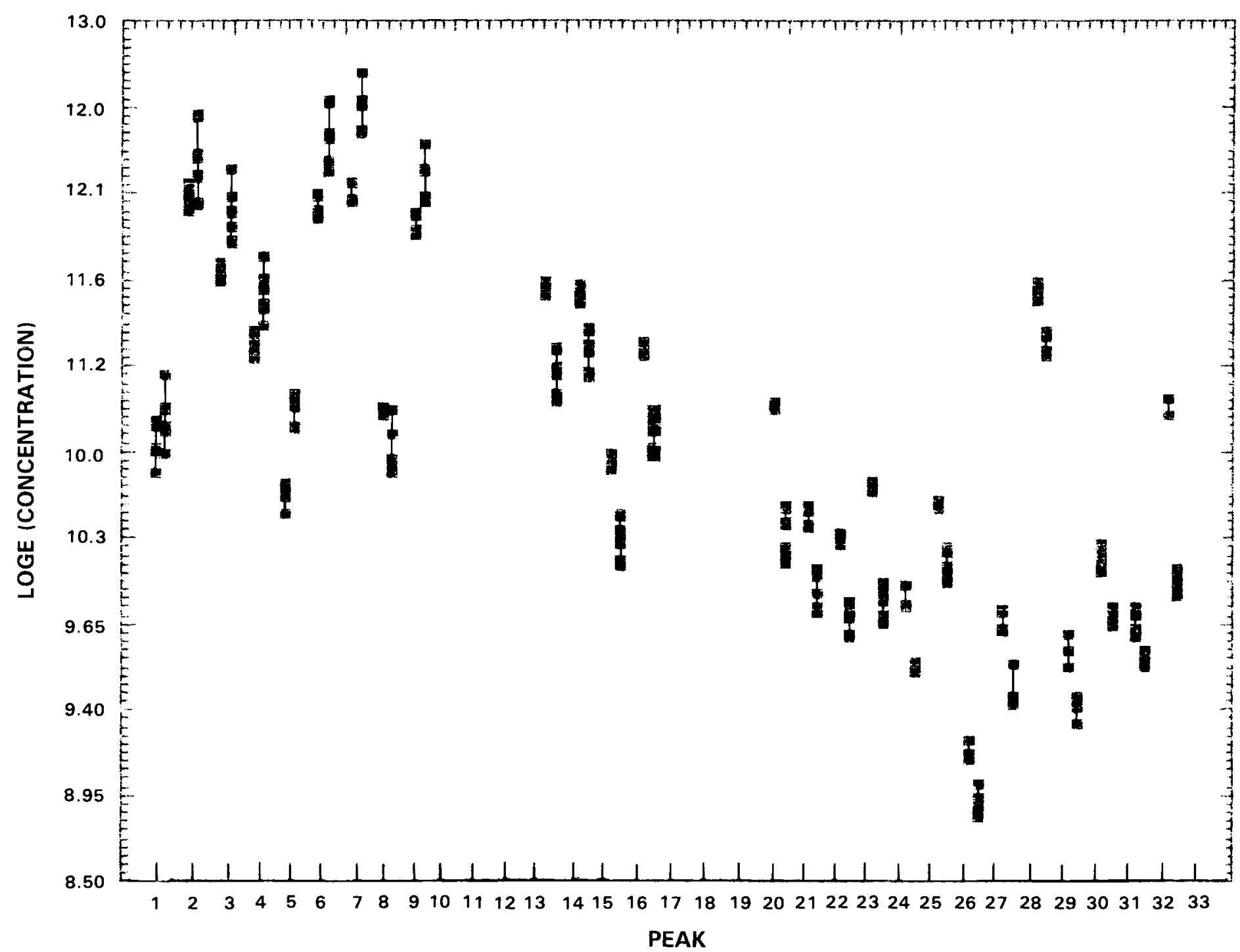

FIGURE 8.2. Log Transformed Data from Chromatographic Results for SRC-I Light 0il Samples Stored in the Repository. Data points after two years are offset by 0.3 peak units 
TABLE 8.2. F Values from the ANOVA Techniques Applied to the SRC-I Light $0 i 1$ Chromatographic Data After Storage in the Repository for Two Years

\begin{tabular}{|c|c|c|}
\hline Peak (a) & $\begin{array}{l}\text { Calculated } \\
\text { F value } \\
\end{array}$ & $\begin{array}{c}\text { Critical F Value } \\
(5 \% \alpha \text { Level }) \\
\end{array}$ \\
\hline 1 & 1.06 & $18.51^{(d)}$ \\
\hline 2 & 1.64 & 18.51 \\
\hline 3 & 5.72 & 18.51 \\
\hline 4 & 3.84 & 18.51 \\
\hline 5 & 12.48 & 18.51 \\
\hline 6 & 5.75 & 18.51 \\
\hline 7 & 10.33 & 18.51 \\
\hline 8 & 1.95 & 18.51 \\
\hline 9 & 3,00 & 18.51 \\
\hline 10 & $N D(C)$ & \\
\hline 11 & ND & \\
\hline 12 & ND & \\
\hline 13 & 13.93 & 18.51 \\
\hline 14 & 7.68 & 18.51 \\
\hline 15 & 12.32 & 18.51 \\
\hline 16 & 13.24 & 18.51 \\
\hline 17 & ND & \\
\hline 18 & ND & \\
\hline 19 & ND & \\
\hline 20 & 29.69 & 18.51 \\
\hline 21 & 9.79 & 18.51 \\
\hline 22 & 11.28 & 18.51 \\
\hline 23 & 22.43 & 18.51 \\
\hline 24 & 4.83 & 18.51 \\
\hline 25 & 6.25 & 18.51 \\
\hline 26 & 4.30 & 18.51 \\
\hline 27 & 6.95 & 18.51 \\
\hline 28 & 4.20 & 18.51 \\
\hline 29 & 4.23 & 18.51 \\
\hline 30 & 4.56 & 18.51 \\
\hline 31 & 2.02 & 18.51 \\
\hline 32 & 45.28 & 18.51 \\
\hline 33 & ND & \\
\hline
\end{tabular}

(a) Peaks refer to compounds identified by GC/MS contained in Table 3.1 and shown in Figure 3.2 .

(b) Values greater than the $5 \%$ a level were considered chromatographic differences caused by the split injection. No value was greater than the $1 \% \alpha$ value of 98.49 .

(c) No data.

(d) Based on 20\% error. 


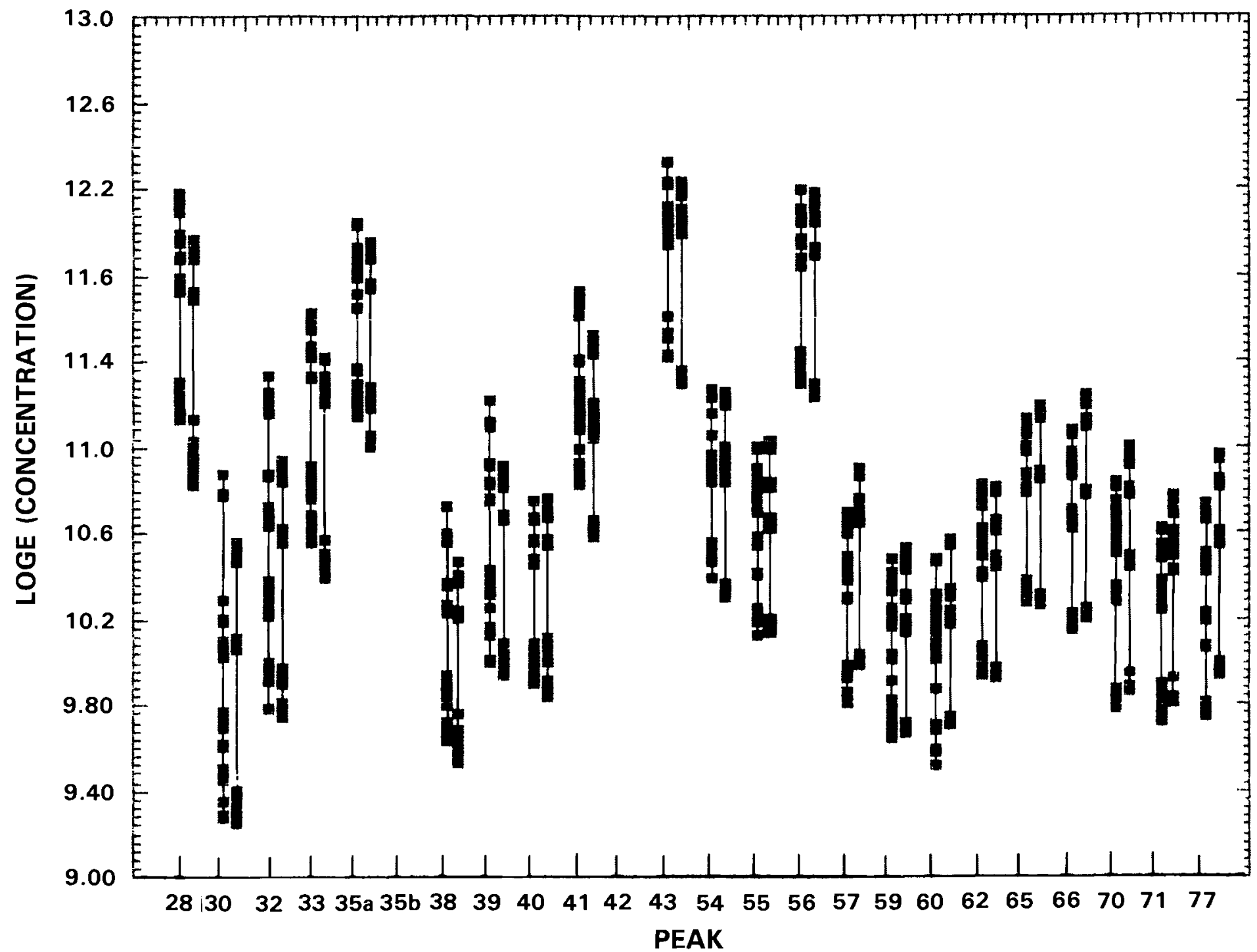

FIGURE 8.3. Log Transformed Data from Chromatographic Results for SRC-II Middle Disti11ate Samples Stored in the Repository. Data points after two years are offset by 0.3 peak units 
TABLE 8.3. F Values from the ANOVA Techniques Applied to the SRC-I I Middle Distillate Chromatographic Data After Storage in the Repository for Two Years

c.

\begin{tabular}{|c|c|c|}
\hline $\operatorname{Peak}^{(a)}$ & $\begin{array}{c}\text { Calculated } \\
\text { F Value } \\
\end{array}$ & $\begin{array}{c}\text { Critical F Value } \\
(5 \% \text { a Level })\end{array}$ \\
\hline 28 & 4.11 & $4.11^{(b)}$ \\
\hline 30 & 2.10 & 4.11 \\
\hline 32 & $5.60(\mathrm{c})$ & 4.11 \\
\hline 33 & $6.03^{(c)}$ & 4.11 \\
\hline 35 & 1.70 & 4.11 \\
\hline 38 & 3.31 & 4.11 \\
\hline 39 & $6.22^{(c)}$ & 4.11 \\
\hline 40 & 0.00 & 4.11 \\
\hline 41 & 2.83 & 4.11 \\
\hline 42 & $N D(d)$ & \\
\hline 43 & 0.03 & 4.11 \\
\hline 54 & 0.09 & 4.11 \\
\hline 55 & 1.48 & 4.11 \\
\hline 56 & 1.04 & 4.11 \\
\hline 57 & $11.07^{(\mathrm{e})}$ & 4.11 \\
\hline 59 & 2.16 & 4.11 \\
\hline 60 & $7.14^{(\mathrm{e})}$ & 4.11 \\
\hline 61,62 & 1.04 & 4.11 \\
\hline 65 & 2.65 & 4.11 \\
\hline 66 & $5.98^{(\mathrm{e})}$ & 4.11 \\
\hline 70 & $6.44^{(\mathrm{e})}$ & 4.11 \\
\hline 71 & 13.67 & 18.51 (f) \\
\hline 77 & $9.31(\mathrm{e})$ & 4.11 \\
\hline
\end{tabular}

(a) Peaks refer to compounds identified by GC/MS contained in Table 3.1 and shown in Figure 3.3 .

(b) Based on calculated statistical error.

(c) Data among 4 replicates did not show consistent degradation, see Tables 7.4 - 7.7 in Appendix I.

(d) No data.

(e) Peaks showed increase in concentration, not degradation.

(f) Based on 20\% error. 


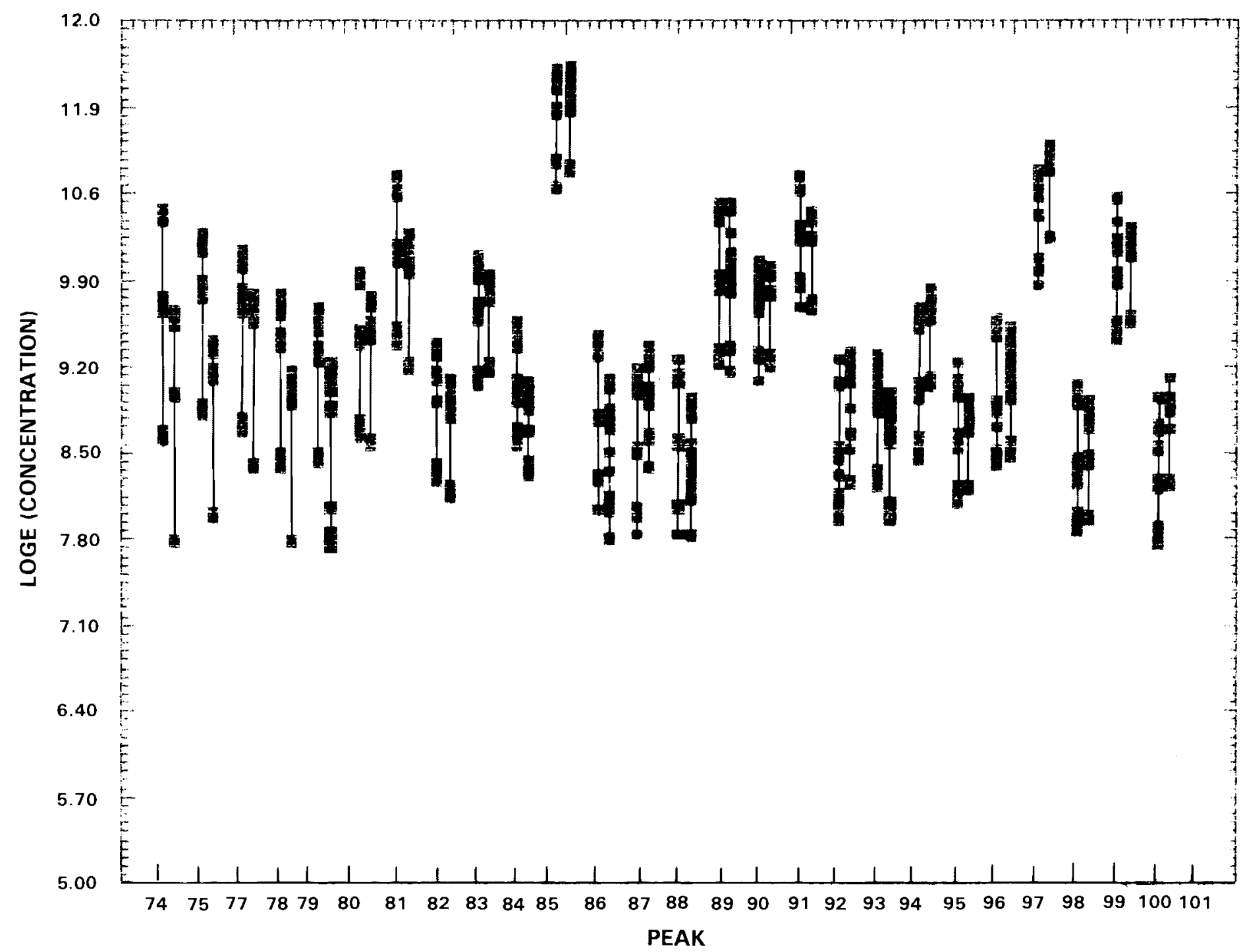

FIGURE 8.4. Log Transformed Data from Chromatographic Results for SRC-II Heavy Distillate Samples Stored in the Repository. Data points after two years are offset by 0.3 peak units 
TABLE 8.4. F Values from the ANOVA Techniques Applied to the SRC-II Heavy Distillate Chromatographic Data After Storage in the Repository for Two Years

6.

\begin{tabular}{|c|c|c|}
\hline Peak ${ }^{(a)}$ & $\begin{array}{l}\text { Calculated } \\
\text { F Value } \\
\end{array}$ & $\begin{array}{c}\text { Critical F Value } \\
(5 \% \alpha \text { Level }) \\
\end{array}$ \\
\hline 74 & $6.27^{(b)}$ & 4.22 (e) \\
\hline 75 & $11.66^{(b)}$ & 4.22 \\
\hline 77 & 1.09 & 4.22 \\
\hline 78 & $5.84(b)$ & 4.22 \\
\hline 79 & $5.68^{(b)}$ & 4.22 \\
\hline 80 & 0.04 & 4.22 \\
\hline 81 & 1.69 & 4.22 \\
\hline 82 & 2.69 & 4.22 \\
\hline 83 & 0.47 & 4.22 \\
\hline 84 & 12.33 & 18.51 (f) \\
\hline 85 & 0.58 & 4.22 \\
\hline 86 & 2.10 & 4.22 \\
\hline 87 & $9.76^{(\mathrm{C})}$ & 4.22 \\
\hline 88 & 0.47 & 4.22 \\
\hline 89 & 0.00 & 4.22 \\
\hline 90 & 0.17 & 4.22 \\
\hline 91 & 0.94 , & 4.22 \\
\hline 92 & $7.75^{(c)}$ & 4.22 \\
\hline 93 & 3.42 & 4.22 \\
\hline 94 & $13.92^{(c)}$ & 4.22 \\
\hline 95 & 0.00 & 4.22 \\
\hline 96 & 0.36 & 4.22 \\
\hline 97 & 19.81 & 18.51 \\
\hline 98 & 0.21 & 4.22 \\
\hline 99 & 0.94 & 4.22 \\
\hline 100 & 11.61 (c) & 4.22 \\
\hline 101 & ND $(\mathrm{d})$ & 4.22 \\
\hline
\end{tabular}

(a) Peaks refer to compounds identified by GC/MS contained in Table 3.1 and shown in Figure 3.6 .

(b) Due to sample handling and volatility effects.

(c) Peaks showed increase in concentration, not degradation.

(d) No data.

(e) Based on calculated statistical error.

(f) Based on 20\% error. 


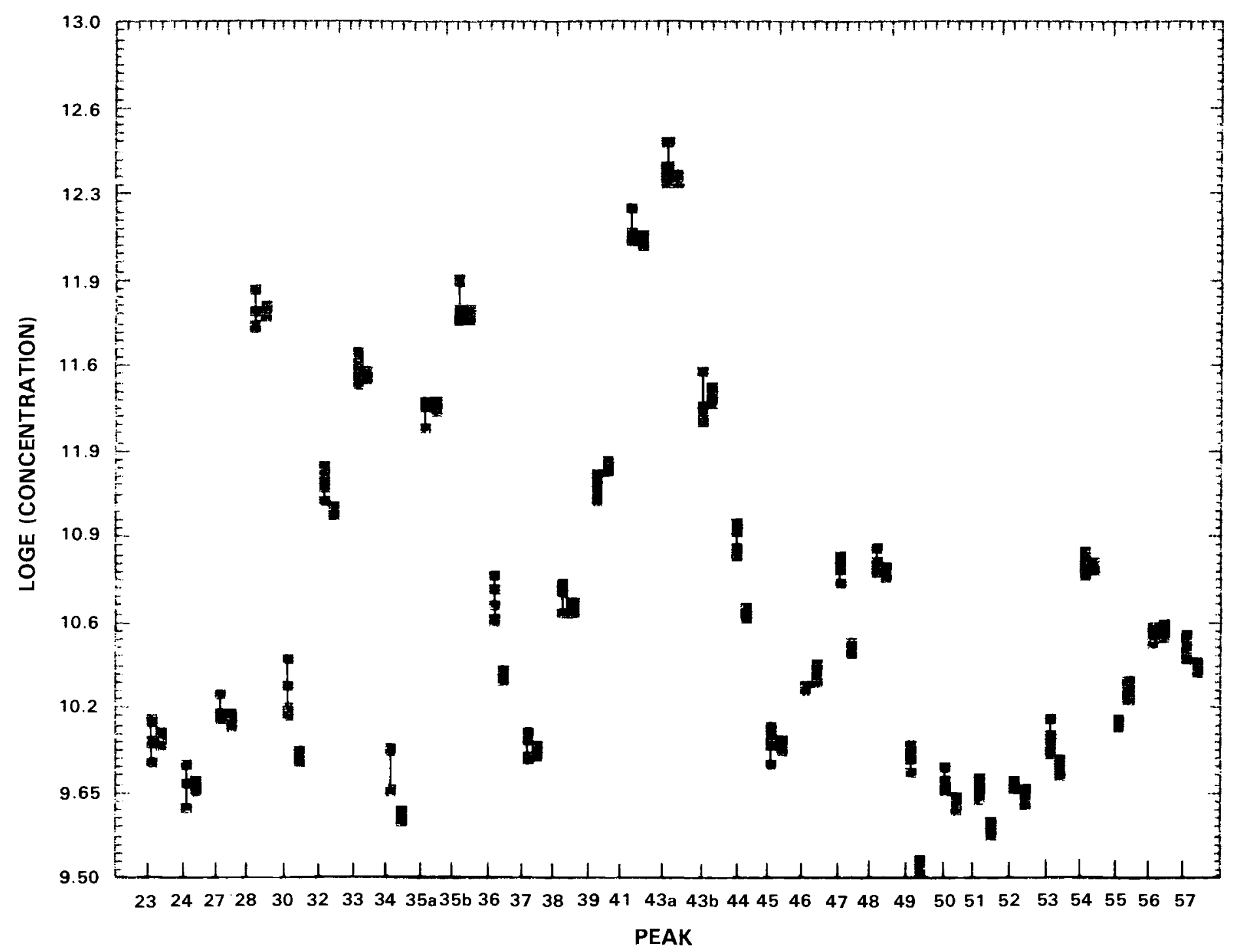

FIGURE 8.5. Log Transformed Data from Chromatographic Results for SRC-I Wash Solvent Sample Stored in the Repository. Data points after two years are offset by 0.3 peak units 
TABLE 8.5. F Values from the ANOVA Techniques Applied to the SRC-I Wash Solvent Chromatographic Data After Storage in the Repository for Two Years

\begin{tabular}{|c|c|c|}
\hline Peak (a) & $\begin{array}{c}\text { Calculated } \\
\text { F Value } \\
\end{array}$ & $\begin{array}{c}\text { Critical F Value } \\
(5 \% \alpha \text { Level }) \\
\end{array}$ \\
\hline 23 & 0.004 & $18.51^{(b)}$ \\
\hline 24 & 0.006 & 18.51 \\
\hline 27 & 0.104 & 18.51 \\
\hline 28 & 0.011 & 18.51 \\
\hline 30 & 4.53 & 18.51 \\
\hline 32 & 0.822 & 18.51 \\
\hline 33 & 0.068 & 18.51 \\
\hline 34 & 2.42 & 18.51 \\
\hline $35 a$ & 0.026 & 18.51 \\
\hline $35 b$ & 0.059 & 18.51 \\
\hline 36 & 7.03 & 18.51 \\
\hline 37 & 0.085 & 18.51 \\
\hline 38 & 0.255 & 18.51 \\
\hline 39 & 0.54 & 18.51 \\
\hline 41 & 0.15 & 18.51 \\
\hline $43 a$ & 0.13 & 18.51 \\
\hline $43 \mathrm{~b}$ & 0.042 & 18.51 \\
\hline 44 & 6.48 & 18.51 \\
\hline 45 & 0.018 & 18.51 \\
\hline 46 & 0.19 & 18.51 \\
\hline 47 & 6.25 & 18.51 \\
\hline 48 & 0.21 & 18.51 \\
\hline 49 & 12.71 & 18.51 \\
\hline 50 & 0.66 & 18.51 \\
\hline 51 & 1.83 & 18.51 \\
\hline 52 & 0.18 & 18.51 \\
\hline 53 & 1.06 & 18.51 \\
\hline 54 & 5.23 & 18.51 \\
\hline 55 & 1.08 & 18.51 \\
\hline 56 & 0.001 & 18.51 \\
\hline 57 & 0.54 & 18.51 \\
\hline
\end{tabular}

(a) Peaks refer to compounds identified by GC/MS contained in Table 3.1 and shown in Figure 3.5 .

(b) Based on $20 \%$ error. 


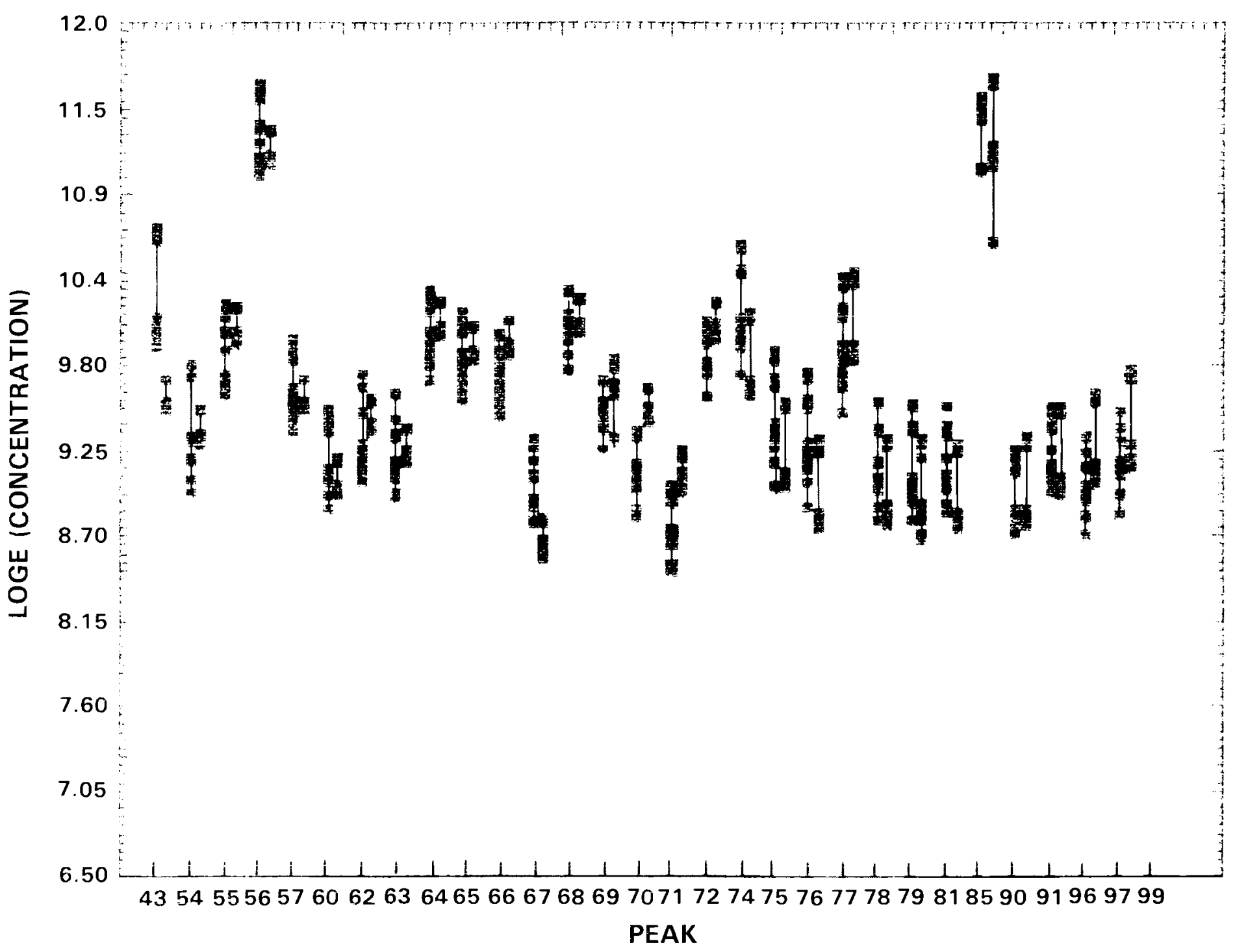

FIGURE 8.6. Log iransformed Data from Chromatographic Results for SRC-I Process Solvent Samples Stored in the Repository. Data points after two years are offset by 0.3 peak units 
TABLE 8.6. F Values from the ANOVA Techniques Applied to the SRC-I Process Solvent Chromatographic Data After Storage in the Repository for Two Years

\begin{tabular}{|c|c|c|}
\hline Peak (a) & $\begin{array}{c}\text { Calculated } \\
\text { F Value } \\
\end{array}$ & $\begin{array}{c}\text { Critical F Value } \\
(5 \% \alpha \text { Level }) \\
\end{array}$ \\
\hline 43 & $73.75^{(b)}$ & $18.51(\mathrm{e})$ \\
\hline 54 & 0.59 & 18.51 \\
\hline 55 & 3.65 & 18.51 \\
\hline 56 & 1.17 & 18.51 \\
\hline 57 & 1.27 & 18.51 \\
\hline 60 & 4.10 & 18.51 \\
\hline 61,62 & 2.77 & 18.51 \\
\hline 63 & 1.16 & 18.51 \\
\hline 64 & 0.995 & 18.51 \\
\hline 65 & 0.69 & 18.51 \\
\hline 66 & 5.85 & 18.51 \\
\hline 67 & $22.17(c)$ & 18.51 \\
\hline 68 & 0.618 & 18.51 \\
\hline 69 & 5.45 & 18.51 \\
\hline 70 & $24.67^{(d)}$ & 18.51 \\
\hline 71 & 15.44 & 18.51 \\
\hline 72 & 7.50 & 18.51 \\
\hline 74 & $22.72(c)$ & 18.51 \\
\hline 75 & 10.52 & 18.51 \\
\hline 76 & $23.62^{(c)}$ & 18.51 \\
\hline 77 & 0.725 & 18.51 \\
\hline 78 & 7.44 & 18.51 \\
\hline 79 & 9.74 & 18.51 \\
\hline 81 & 9.45 & 18.51 \\
\hline 85 & 0.095 & 18.51 \\
\hline 90 & 0.008 & 18.51 \\
\hline 91 & 0.795 & 18.51 \\
\hline 96 & 8.99 & 18.51 \\
\hline 97 & 7.46 & 18.51 \\
\hline 99 & ND & \\
\hline
\end{tabular}

(a) Peaks refer to compounds identified by GC/MS contained in Table 3.1 and shown in Figure 3.7 .

(b) Due to sample handling and volatility effects.

(c) Data among 2 replicates did not show consistent degradation, see Tables 7.16 and 7.17 in Appendix 1 .

(d) Peak showed an increase in concentration, not degradation.

(e) Based on $20 \%$ error. 


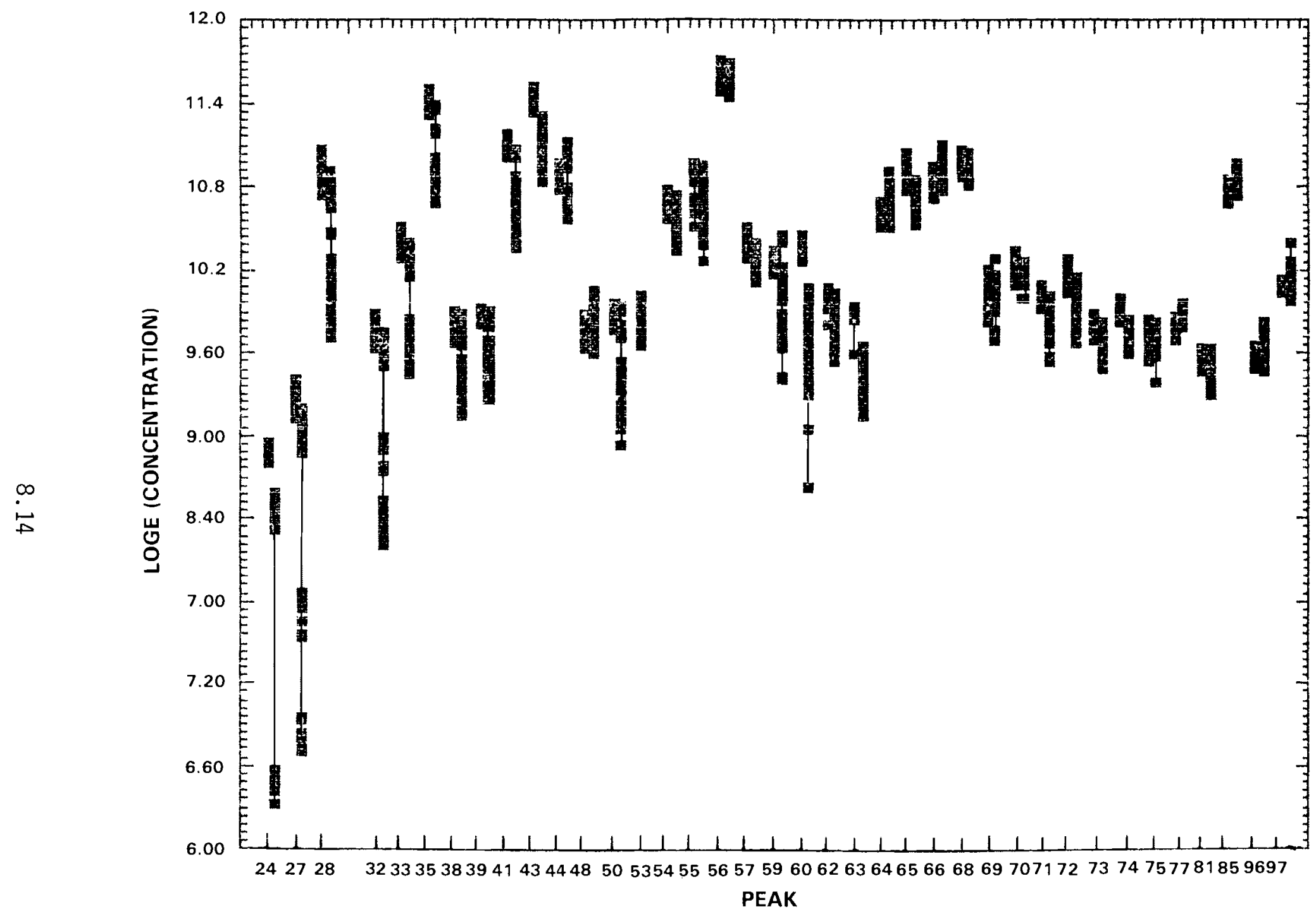

FIGURE 8.7. Log Transformed Data from Chromatographic Results for SRC-II FOB Stored at $100^{\circ} \mathrm{C}$, Under an Air Atmosphere, in the Dark. Data points for Time $=0$ are offset by 0.0 peak units, 16 weeks by 0.3 peak units 
TABLE 8.7. F Values from the ANOVA Techniques Applied to the SRC-II Fuel 0il Blend Chromatographic Data After Storage at $100 \mathrm{C}$ for 16 Weeks

\begin{tabular}{|c|c|c|}
\hline Peak (a) & $\begin{array}{l}\text { Calculated } \\
\text { FValue } \\
\end{array}$ & $\begin{array}{c}\text { Critical F Value } \\
(5 \% a \text { Level }) \\
\end{array}$ \\
\hline 24 & 25.5 & $4.0^{(d)}$ \\
\hline 27 & 46.1 & 4.0 \\
\hline 28 & 76.6 & 4.0 \\
\hline 32 & 49.4 & 4.0 \\
\hline 33 & 59.3 & 4.0 \\
\hline 35 & 80.2 & 4.0 \\
\hline 38 & 37.8 & 4.0 \\
\hline 39 & 20.6 & 4.0 \\
\hline 41 & 117.3 & 4.0 \\
\hline 43 & 66.75 & $18.51(\mathrm{e})$ \\
\hline 44 & 0.90 & 18.51 \\
\hline 48 & 2.80 & 18.51 \\
\hline 50 & 64,50 & 18.51 \\
\hline 53 & ND $(\mathrm{C})$ & \\
\hline 54 & 10.83 & 18.51 \\
\hline 55 & 18.58 & 18.51 \\
\hline 56 & 0.82 & 18.51 \\
\hline 57 & 4.60 & 18.51 \\
\hline 59 & 81.5 & 18.51 \\
\hline 60 & 328.3 & 18.51 \\
\hline 62 & 14.28 & 18.51 \\
\hline 63 & 67.5 & 18.51 \\
\hline 64 & 11.58 & 18.51 \\
\hline 65 & 21.6 & 18.51 \\
\hline 66 & 7.38 & 18.51 \\
\hline 68 & 0.00 & 18.51 \\
\hline 69 & 0.30 & 18.51 \\
\hline 70 & 0.49 & 18.51 \\
\hline 71 & 6.08 & 18.51 \\
\hline 72 & 38.8 & 18.51 \\
\hline 73 & 6.6 & 18.51 \\
\hline 74 & 17.5 & 18.51 \\
\hline 75 & 0.48 & 18.51 \\
\hline 77 & 1.78 & 18.51 \\
\hline 81 & 3.25 & 18.51 \\
\hline 85 & 1.00 & 18.51 \\
\hline 96 & 2.58 & 18.51 \\
\hline 97 & 0.55 & 18.51 \\
\hline
\end{tabular}

(a) Peaks refer to compounds identified by GC/MS contained in Table 3.1 and shown in Figure 3.10.

(b) Peaks, 28 (phenol), 35 (m \& p-cresol), 41 (tetralin), $59\left(C_{3}-i n d a n\right)$, and 60 (indanol) showed the greatest degradation over time.

(c) No data.

(d) Based on calculated statistical error.

(e) Based on $20 \%$ error. 


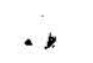

$\checkmark$ 
No. of

Copies

OFFSITE

27 DOE Technical Information Center

E. L. Alpen

Lawrence Berkeley Laboratory

University of California

Building 90, Room 2056

No. 1 Cyclotron Road

Berkeley, CA 94720

L. D. Attaway

1005 A Street

Suite 405

San Rafael, CA 94901

N. F. Barr

ER-73, GTN

U.S. Department of Energy

Washington, DC 20545

J. Batchelor

FE-43, GTN

U.S. Department of Energy

Washington, DC 20545

D. L. Bauer

Acting Assistant Secretary

for Fossil Energy

FE-1, FORSTL

U.S. Department of Energy

Washington, DC 20585

H. L. Bergman

University of Wyoming

Laramie, WY 82071

R. W. Biles

Exxon Corporation

Research and Environmental

Health Division

Medical Department

P.0. Box 235

East Millstone, NJ 08873
No. of

Copies

\author{
J. R. Blair \\ ER-73, GTN \\ U.S. Department of Energy \\ Wasington, DC 20545 \\ V. P. Bond \\ Brookhaven National Laboratory \\ Upton, Long Island, NY 11973 \\ R. G. Boykin \\ Catalytic, Inc. \\ P.0. Drawer 239 \\ Wilsonville, AL 35186 \\ J. E. Bratina, Jr. \\ Environmental Research and \\ Technology, Inc. \\ 601 Grant Street \\ Porter Building, 10th Floor \\ Pittsburgh, PA 15219
}

A. Brink

SASOL Technology (Proprietary), Ltd.

57 Commissioner Street P.0. Box 5486

Johannesburg 2000

REPUBLIC OF SOUTH AFRICA

P. E. Brubaker

Exxon Corporation

Research and Environmental

Health Division

Medical Department

P.0. Box 235

East Millstone, $\mathrm{NJ} 08873$

P. Buhl

FE-43, GTN

U.S.Department of Energy

Washington, DC 20545 
No. of

Copies

H. H. Bulkowski

Catalytic, Inc.

Centre Square West

1500 Market Street

Philadelphia, PA 19102

F. P. Burke

Conoco Coal Development Co. 4000 Brownsville Road

Library, PA 15129

J. A. Carrol, Capt., USA

Medical Bioengineering R\&D Laboratory

Ft. Detrich, MD 21701

C. E. Carter

Scientific Director

National Institute of

Environmental Health Sciences

P.0. Box 12233

Research Triangle Park, NC 27709

M. Chartock

Science \& Public

Policy Program

Norman, OK 73019

C. T. Chen

OSHA

U.S. Department of Labor

200 Constitution Avenue, NW

Washington, DC 20210

P. Cho

ER-73, GTN

U.S. Department of Energy

Washington, DC 20545

A. V. Colucci

A. V. Colucci \& Associates, Inc.

15305 Calle Enrique, Suite D

Morgan Hill, CA 95037

4 K. E. Cowser

Oak Ridge National Laboratory

P.0. Box $X$

Oak Ridge, TN 37830
No. of

Copies

G. Day

Kentucky Division of Air Pollution Control

18 Riley Rd.

Frankfort, KY 40601

2 Department of Library and Archives

James Nelson, Librarian

Box 537, Berry Hill

Frankfort, KY 40602

2 DOE Public Document Room

Attn: Mr. R. A. Evans

Room G-298, Federal Building

P.0. Box E

Oak Ridge, TN 37830

2 DOE Public Reading Room, FOI

Room IE-180, Forrestal Building

1000 Independence Avenue, SW

Washington, DC 20585

2 DOE Technical Information Center

Customer Services Branch

P.0. Box 62

Oak Ridge, TN 37830

2 DOE Public Document Room

Room G-208

Oak Ridge Federal Building

Oak Ridge, TN 37830

2 DOE Public Reading Room

Room GA-142

Forrestal Building

1000 Independence Avenue, SW

Washington, DC 20585

B. Z. Drozdowicz

International Coal Refining

Co.

P.0. Box 2752

Allentown, PA 18001 
No. of

Copies

1.

\author{
H. Drucker \\ Argonne National Laboratory \\ 9700 South Cass Avenue \\ Argonne, IL 60439 \\ C. Drummond \\ Pittsburgh Energy \\ Technology Center \\ P.0. Box 10940 \\ Pittsburgh, PA 15236
}

25 A. P. Duhame 1

ER-74, GTN

U.S. Department of Energy

Washington, DC 20545

H. E. Dunn

Indiana State University, Evansville

8600 University Boulevard

Evansville, IN 47702

M. J. Eaman

Concord Scientific Corporation

3101-B Hawthorn Road

Ottawa, Ontario, K1G-3H9

CANADA

\section{W. Edington,} Associate Di rector

Office of Health and

Environmental Research

ER-70, GTN

U.S. Department of Energy

Washington, DC 20545

H. Enoch

Kentucky Department of Energy

P.0. Box 11888

Lexington, KY 40578

J. L. Epler

Oak Ridge National Laboratory

P.0. Box $X$

Oak Ridge, TN 37830
No. of

Copies

2 Evansville \& Vanderburgh

County Public Library

Attn: Ann Pearson

22 Southeast 5th Street

Evansvilie, IN 47708

J. P. Fillo

Environmental Research and

Technology, Inc.

601 Grant Street

Porter Building, 10th Floor

Pittsburgh, PA 15219

S. Foster

Energy and Environmental Analysis, Inc.

1111 North 19th Street

Arlington, VA 22209

L. Fradkin

Argonne National Laboratory

Building 12

Argonne, IL 60439

R. E. Franklin

ER-75, GTN

U.S. Department of Energy

Washington, DC 20545

R. J. Fry

Oak Ridge National Laboratory

P.0. Box $X$

Oak Ridge, TN 37830

K. Frye

FE-40, GTN

U.S. Department of Energy

Washington, DC 20545

A. A. Galli

U.S. Environmental Protection Agency

401 M Street, SW

Washington, DC 20460 
No. of

Copies

C. W. Gehrs

Oak Ridge National Laboratory

P.0. Box X

Oak Ridge, TN 37830

H. Gerstenkorn

Ruhrkohle 0el und Gas GMBH

Gleiwitzer Platz 3

4250 Bottropp

FEUERAL REPUBLIC OF GERMANY

J. M. Giddings

Oak Ridge National Laboratory

P.0. Box $X$

Oak Ridge, TN 37830

G. F. Goethel

VEBA OEL AG

Postfach 45

4660 Gel senkirchen-Buer

FEDERAL REPUBLIC OF GERMANY

L. Goldberg

Chemical Industrial

Institute of Toxicology

2109 Nancy Ann Drive

Raleigh, NC 27607

G. Goldstein

ER-74, GTN

U.S. Department of Energy

Washington, DC 20545

J. R. Gough

Catalytic, Inc.

P.0. Box 239

Wilsonville, AL 35186

J. Gray

Ashland Synthetic Fuels, Inc.

P.0. Box 391

Ashland, KY 41101

M. D. Gray

NCB (Coal Products) Ltd.

Coal House, Lyon Rd.

Harrow, HA1 2 EX

ENGLAND
No. of

Copies

R. A. Griesemer

Oak Ridge National Laboratory

P.0. Box $X$

Oak Ridge, TN 37830

M. Guerin

Oak Ridge National Laboratory

P.0. Box X

Oak Ridge, TN 37830

R. M. Hamilton

FE-43, GTN

U.S. Department of Energy

Washington, DC 20545

A. Hartstein

FE-43, GTN

U.S. Department of Energy

Washington, DC 20545

L. Headley

Morgantown Energy

Technology Center

Morgantown, WV 26505

G. E. Hedstrom

FE-44, GTN

U.S. Department of Energy

Washington, DC 20545

M. G. Henry

Columbia National Fisheries Research Laboratory

Route 1

Columbia, MO 65201

2 B. Henschel

Industrial Environmental Research Laboratory

MD-61, U.S. EPA

Research Triangle Park, NC 27711

J. Hill

Ashland Synthetic Fuels, Inc. P.0. Box 391

Ashland, KY 41101 
No of
Copies

R. $\mathrm{Hill}$

Ashland Synthetic Fuels, Inc.

P.0. Box 391

Ashland, KY 41101

C. H. Hobbs

Lovelace Inhalation Toxicology Research Institute

P.0. Box 5890

Albuquerque, NM 87115

J. M. Holl and

Chevron Environmental

Health Center

P.0. Box 4054

Richmond, CA 94804

H. L. Hollister, Assistant Secretary

Environmental Protection, Safety and Emergency Preparedness

EP-1, FORSTL

U.S. Department of Energy

Washington, DC 20585

G. R. Holt

ARCO Coal Company

1860 North Lincoln St.

P.0. Box 5300

Denver, C0 80217

H. Hosang

VEBA OEL AG

Postfach 45

4660 Gelsenkirchen-Buer

FEDERAL REPUBLIC OF GERMANY

$P$. House

EP-33, FORSTL

U.S. Department of Energy

Washington, DC 20585

W. Hubis

4031 South Magnolia Way

Denver, C0 80237
No. of

Copies

E. L. Huffman

Southern Company Services, Inc.

P.0. Box 2625

Birmingham, AL 35202

S. Ikeda

Japan Coal Liquefaction

Development Co., Ltd.

Rm 1115, Shuwa Kioi-Cho

TBR Bldg.

No. 7, Kōjimachi 5-chome,

Chiyoda-Ku, Tokyo 102

JAPAN

H. Inhaber

Oak Ridge National Laboratory

P.0. Box $X$

Oak Ridge, TN 37830

J. C. Johnson

FE-13, GTN

U.S. Department of Energy

Washington, DC 20545

T. W. Johnson

Southern Company Services, Inc.

c/o Catalytic, Inc.

P.0. Drawer 239

Wilsonville, AL 35186

W. S. Jones

FE-43, GTN

U.S. Department of Energy

Washington, DC 20545

L. Joseph

Hydrocarbon Research, Inc. 1313 Dolly Madison Blvd.

McLean, VA 22101

J. S. Kane, Deputy Director

Office of Energy Research

ER-2, FORSTL

U.S. Department of Energy

Washington, DC 20585 
No. of

Copies

C. M. Kelly

Air Products \& Chemicals, Inc. Corporate Research \& Development P.0. Box 538

Allentown, PA 18001

S. C. Lewis

Exxon Corporation

Research and Environmental

Health Division

Medical Department

P.0. Box 235

East Millstone, NJ 08873

R. R. Maddocks

Catalytic, Inc.

Centre Square West

1500 Market Street

Philadelphia, PA 19102

A. W. Maki

Exxon Corp.

Research and Environmental

Health Division

P.0. Box 235

East Millstone, NJ 08873

2 M. J. Massey

Environmental Research and Technology, Inc.

601 Grant Street

Porter Building, 10th Floor

Pittsburgh, PA 15219

H. McCammon

ER-75, GTN

U.S Department of Energy

Washington, DC 20545

R. 0. McClellan

Lovelace Inhalation Toxicology

Research Institute

P.0. Box 5890

Albuquerque, NM 87115
No. of

Copies

G. V. McGurl

Pittsburgh Energy

Technology Center

P.0. Box 10940

Pittsburgh, PA 15236

R. E. Mckee

Exxon Corp.

Research and Environmental Health Division

P.0. Box 235

East Millstone, NJ 08873

P. M. Mehrle

Columbia National Fisheries

Research Laboratory

Route 1

Columbia, MO 65201

M. L. Mendelsohn

Lawrence Livermore Laboratory

University of California

P.0. Box 808

Livermore, CA 94550

L. Miller

FE-42, GTN

U.S. Department of Energy

Washington, DC 20545

M. Minthorn

ER-72, GTN

U.S. Department of Energy Washington, DC 20545

A. Moghissi

U.S. Environmental

Protection Agency

401 M Street, SW

Washington, DC 20460

2 Morgantown Public Library

373 Spruce Street

Morgantown, WV 26505 
No. of

Copies

E. C. Moroni

FE-43, GTN

U.S. Department of Energy

Washington, DC 20545

S. C. Morris

Brookhaven National Laboratory

Building 475

Upton, NY 11973

N. B. Munro

Fossil Energy Information Center

Building 9207

Oak Ridge National Laboratory

P.0. Box Y

Oak Ridge, TN 37830

P. J. Musser

FE-44, GTN

U.S. Department of Energy

Washington, DC 20545

M. B. Neuworth

The Mitre Corp.

1820 Dolly Madison Blvd.

McLean, VA 22102

J. Norwood

International Coal Refining Co.

P.0. Box 2752

Allentown, PA 18001

2 Owensboro-Davies

County Public Library

Attn: Alice G. Lewis

450 Griffith Avenue

Owensboro, KY 42301

\footnotetext{
B. Pallay

National Institute for

0ccupational Safety \& Health

5600 Fishers Lane

Rockville, MD 20852
}

M. Parmenter

Kerr-McGee Corporation

Kerr-McGee Center

Packaging \& Labeling Dept.

Oklahoma City, OK 73125
No. of

Copies

R. M. Perhac

Electric Power Research Institute

P.0. Box 10412

Palo Alto, CA 93404

W. Piver

National Institute of Environmental Health Sciences

P.0. Box 12233

Research Triangle Park, NC 27709

J. D. Potts

Cities Service Research

\& Development Co.

Box 3908

Tulsa, OK 74102

2 J. Reafsnyder

Oak Ridge Operations

U.S. Department of Energy

P.0. Box E

Oak Ridge, TN 37830

C. Reaux

National Institute for Occupational

Safety and Health

Room 117

944 Chestnut Ridge Road

Morgantown, WV 26504

C. A. Reilly

Argonne National Laboratory

9700 South Cass Avenue

Argonne, IL 60439

H. Retcofsky

Pittsburgh Energy Technology

Center

P.0. Box 10940

Pittsburgh, PA 15236

D. E. Rhodes

Kerr-McGee Corporation

P.0. Box 035

Crescent, OK 73028 
No. of

Copies

W. J. Rhodes

Industrial Environmental

Research Laboratory

MD-61, US EPA

Research Triangle Park, NC 27711

C. R. Richmond

Oak Ridge National Laboratory

P.0. Box X

Oak Ridge, TN 37830

T. C. Ruppel

Pittsburgh Energy Technology Center

P.0. Box 10940

Pittsburgh, PA 15236

H. D. Schindler

The Lummus Company

1515 Broad Street

Bloomfield, NJ 07003

D. K. Schmalzer

The Pittsburg \& Midway

Coal Mining Co.

1720 South Bellaire Street

Denver, C0 80222

M. Schulman

ER-70, GTN

U.S. Department of Energy

Washington, DC 20545

0. J. Schwarz

Botany Department

University of Tennessee

Knoxville, TN 37916

J. W. Scott

Chevron Research Company

P.0. Box 1627

Richland, CA 94802

R. Scripsick

P.0. Box 1663, MS-986

Los Alamos, NM 87545
No. of

Copies
A. G. Sharkey

Pittsburgh Energy Technology Center

P.0. Box 10940

Pittsburgh, PA 15236

A. Shepard

American Petroleum Institute 2101 L Street, NW

Washington, DC 20037

C. Shih

TRW

1 Space Park

R42142

Redondo Beach, CA 90278

D. A. Smith

ER-72, GTN

U.S. Department of Energy

Washington, DC 20545

V. G. Stamoudis

Argonne National Laboratory

9700 South Cass Avenue

Argonne, IL 60439

G. E. Stapleton

ER-72, GTN

U.S. Department of Energy

Washington, DC 20545

J. Stasior

Enviro Control

11300 Rockville Pike

Rockville, MD 20852

R. J. Stern

EP-33, FORSTL

U.S. Department of Energy

Washington, DC 20585

J. Stetter

Argonne National Laboratory

9700 South Cass Avenue

Argonne, IL 60439 
No. of

Copies

J. A. Strasser

Atlantic Coal Institute

P.0. Box 1133

Sydney, Nova Scotia, BIP 6J7

CANADA

R. F. Sullivan

Chevron Research Company

P.0. Box 1627

Richmond, CA 94802

J. Talty

National Institute for

Occupational Safety \& Health

5600 Fishers Lane

Rockville, MD 20852

J. W. Thiessen

Deputy Associate Director

Office of Health and

Environmental Research

ER-71, GTN

U.S. Department of Energy

Washington, DC 20545

G. G. Thurlow

National Coal Board

Coal Research Establishment

Stoke Orchard

Cheltenham, Glos. GL52 4RZ

ENGLAND

R. V. Trense

Exxon Corporation

Environmental Affairs Programs

Exxon Research \& Engineering $\mathrm{Co}$.

P.0. Box 101

Florham Park, NJ 07932

3 A. W. Trivelpiece, Director

Office of Energy Research

ER-1, FORSTL

U.S. Department of Energy

Washington, DC 20585
No. of

Copies

2 University of Kentucky

Attn: J. Pivarnik

Government Publications

Department

M. L. King Library

Lexington, KY 40506

2 G. K. Vick

Exxon Research \& Engineering Co.

Clinton Township

Route 22 East

Annandale, NJ 08801

G. L. Voelz

University of California

Los Alamos Scientific Laboratory

P.0. Box 1663

Los Alamos, NM 97545

W. H. Weber

EPRI

c/o Catalytic, Inc.

.P.0. Drawer 239

Wilsonville, AL 35186

2 Library

West Virginia University

Downtown Campus

Attn: C. Hamerick

Morgantown, WV 26506

4 K. Wilzbach

Argonne National Laboratory

9800 South Cass Avenue

Argonne, IL 60439

F. E. Witmer

EP-33, GTN

U.S. Department of Energy

Washington, DC 20545

F. J. Wobber

ER-75, GTN

U.S. Department of Energy

Washington, DC 20545 
No. of

Copies

R. W. Wood

ER-74, GTN

U.S. Department of Energy

Washington, DC 20545

A. F. Yen

International Coal Refining Co. P.0. Box 2752

Allentown, PA 18001 .

\section{ONSITE}

1 DOE Richland Operations Office

H. E. Ransom

101 Pacific Northwest Laboratory

R. L. Aabery

L. E. Anderson

W. J. Bair

R. M. Bean

C. D. Becker

F. G. Burton

W. C. Cannon

D. A. Cataldo

E. K. Chess

J. F. Cline

D. D. Dauble

W. E. Fallon

L. J. Felice

W. D. Felix

D. H. Fickeisen

M. E. Frazier

R. H. Gray (30)

P. L. Hackett

D. R. Kalkwarf

M. T. Karagianes

B. J. Kelman

J. C. Kutt

D. W. Later
No. of

Copies
R. H. Lovely
D. D. Mahlum
S. Marks
R. P. Marshall
$P$. J. Mellinger
J. E. Morris
0 . R. Moss
T. Nelson
J. M. Nielsen
D. E. Olesen
T. L. Page
J. F. Park (5)
R. A. Pelroy
R. W. Perkins
R. D. Phillips
H. A. Ragan
R. A. Renne
R. E. Schirmer
R. P. Schneider
D. M. Schoengold
M. R. Sikov
S. D. Sklarew
L. G. Smith
D. L. Springer
J. A. Strand
D. L. Stewart
W. L. Templeton
T. A. Toste
D. Tolley
B. E. Vaughan
M. L. Warner
W. C. Weimer
R. E. Wildung
W. R. Wiley
D. H. Willard
B. W. Wilson
C. W. Wright
Biology Publications Office Technical Information (5)
Publishing Coordination (2) 